UNIVERSIDADE DE SÃO PAULO

FACULDADE DE FILOSOFIA, LETRAS E CIÊNCIAS HUMANAS

DEPARTAMENTO DE LINGÜÍSTICA

PROGRAMA DE PÓS-GRADUAÇÃO EM SEMIÓTICA E LINGÜÍSTICA GERAL

\title{
PERFIL FUNCIONAL DA COMUNICAÇÃO E A ADAPTAÇÃO SÓCIO- COMUNICATIVA NO ESPECTRO AUTÍSTICO
}

\author{
Priscilla Faria Sousa Morato
}

Tese apresentada à Faculdade de Filosofia, Letras e Ciências Humanas da Universidade de São Paulo para a obtenção do título de Doutor em Lingüística

Área de concentração: Semiótica e Lingüística Geral Orientadora: Profa Dra Fernanda Dreux Miranda Fernandes

v.1

São Paulo 
Serviço de Biblioteca e Documentação da Faculdade de Filosofia, Letras e Ciências Humanas da Universidade de São Paulo

Sousa-Morato, Priscilla Faria.

S725 Perfil funcional da comunicação e a adaptação sócio-comunicativa no espectro autístico / Priscilla Faria Sousa Morato ; orientadora Fernanda Dreux Miranda Fernandes. -- São Paulo, 2007. 229 f. : il.

Tese (Doutorado - Programa de Pós-Graduação em Semiótica e Lingüística Geral. Área de concentração: Semiótica e Lingüística Geral) - Departamento de Lingüística da Faculdade de Filosofia, Letras e Ciências Humanas da Universidade de São Paulo.

1. Autismo infantil (Aspectos pragmáticos; Aspectos cognitivos). 2. Fonoaudiologia. 3. Avaliação da linguagem. I. Título. 
Esta tese está de acordo com as seguintes normas, em vigor no momento desta publicação:

Diretrizes para apresentação de dissertações e teses da USP: documento eletrônico e impresso. Universidade de São Paulo, Sistema Integrado de Bibliotecas (Sibi), São Paulo, 2004. Elaborado por Vânia M.B. de Oliveira Funaro, Maria Aparecida B Ayello, Cristiane de A C Carvalho, Eliana Maria Garcia, Katia M de A Ferraz, Maria Claudia Pestana, Maria José de J Carvalho, Mariza L. de M. do Couto, Rosana A Paschoalino, Suely campos Cardoso, Telma de Carvalho, Valéria de Vilhena Lombardi.

Referências: adaptado de International Committee of Medical Jounals Editors (Vancouver).

Abreviaturas dos títulos dos periódicos de acordo com List of Journals Indexed in Index Medicus.

Esta pesquisa foi financiada pelo CAPES (Coordenação de Aperfeiçoamento de Nível Superior). 


\section{Folha de Aprovação}

\section{Priscilla Faria Sousa Morato}

PERFIL FUNCIONAL DA COMUNICAÇÃO E A ADAPTAÇÃO SÓCIO-COMUNICATIVA

NO ESPECTRO AUTÍSTICO
Tese apresentada à Faculdade de Filosofia, Letras e

Ciências Humanas da Universidade de São Paulo para a obtenção do título de Doutor em Lingüística

Área de concentração: Semiótica e Lingüística Geral Orientadora: Profa Dra Fernanda Dreux Miranda Fernandes

APROVADA EM :-

BANCA EXAMINADORA

Prof (a) $\operatorname{Dr}(a)$

Instituição

Assinatura

Prof (a) $\operatorname{Dr}(a)$

Instituição-

Assinatura-

Prof (a) $\operatorname{Dr}(a)$

Instituição

Assinatura

Prof (a) $\operatorname{Dr}(a)$

Instituição

Assinatura-

Prof (a) Dr (a)

Instituição 


\title{
Dedicatóría
}

\author{
Aos meus pais e irmãos, \\ por serem o meu porto seguro.
}

Ao Daniel, portrazer novas cores à minha vida. 


\section{Agradecimentos}

Agradecer; após anos na realização deste trabalho é grande o número de pessoas que também fizeram parte, direta ou indiretamente, da confecção deste. Pessoas que influenciaram a minha vida, minhas idéias e pensamentos, fazendo com que eu refletisse e amadurecesse, não só pessoalmente, mas academicamente.

Agradeço aos meus pais, Ezio e Maria José, e aos meus irmãos, Frederico e Eduardo, por sempre estarem comigo e por me permitirem viver meu sonho, demonstrando por mim um imenso carinho, respeito e confiança.

Aos meus familiares, Daniela, Mateus, Lucas, Ana Gabriela, Isabela, Fernanda, por me mostrarem o real sentido da felicidade e da importância de se ter uma família.

Ao Daniel por todo amor, incentivo, por me dar força nos momentos mais difíceis e compreender a importância do estudo acadêmico em minha vida.

Devo toda minha gratidão à minha orientadora, Profa Dra Fernanda Dreux Miranda Fernandes, por me deixar estar ao seu lado, aprendendo diariamente o real sentido da docência, com sua enorme paciência, entusiasmo, incentivo, apoio e confiança. Por me fazer entender que muitas vezes só aprendemos se tentarmos e que o erro, faz parte deste aprendizado.

Às fonoaudiólogas e amigas, Carla Cardoso, Daniela Molini-Avejonas e Cibelle Albuquerque De La Higuera Amato, que me foram grandes exemplos de fibra, força e empenho; sempre prontas a me ajudar em qualquer situação, e sempre tão seguras quanto ao meu futuro na Fonoaudiologia. 
Um agradecimento especialmente às minhas grandes amigas, também fonoaudiólogas, Sílvia Letícia Ribeiro Rodrigues, Fabíola Juste e Melissa Alves, por estarem sempre ao meu lado, não só na vida profissional, fazendo parte de importantes momentos da minha vida.

Agradeço às companheiras do Laboratório de Investigação Fonoaudiológica nos Distúrbios do Espectro Autístico-FMUSP, em especial, Kenya Ayo-Kianga S. Faustino, Camila Ramos Moreira, Aline Elise Gerbelli Bellini, Liliane Perroud Milher, Milene Rossi Barbosa e Fernanda Chiarion Sassi, pela convivência diária, pelas idéias, pela paciência, e por me mostrarem as diferentes formas de viver.

Agradeço ainda, às Professoras Dra Débora Maria Béfi-Lopes, Dra Suelly Olivan Limongi e Dra Claudia Regina Furquim de Andrade, pelo exemplo de profissionalismo e por acompanharem de perto meu processo de crescimento acadêmico.

Agradeço à Professora Dra Ana Luiza Gomes Pinto Navas pelas informações e sugestões dadas na qualificação deste trabalho.

Aos pacientes e suas famílias, pela participação e confiança.

À equipe do Programa de Pós-Graduação em Semiótica e Lingüística Geral da faculdade de Filosofia, letras e Ciências Humanas da Universidade de São Paulo, em especial, Érica Flávia Lima. 
Os limites da minha linguagem são também os limites do meu pensamento.

Ludwig Wittgenstein 


\section{Resumo}

Sousa-Morato, PF. Perfil Funcional da Comunicação e a Adaptação SócioComunicativa no Espectro Autístico; São Paulo: Faculdade de Filosofia, Letras e Ciências Humanas da Universidade de São Paulo, 2007.229f.

O trabalho fonoaudiológico com crianças do espectro autístico está profundamente relacionado às perspectivas lingüísticas, em especial às teorias pragmáticas, uma vez que as características observadas no comportamento destas crianças são justamente deficitárias nos aspectos propostos por estas teorias, ou seja, as relações entre o uso da linguagem e os aspectos sociais e cognitivos do desenvolvimento. Deste modo, a observação individualizada, detalhada, buscando diferentes análises sobre processos individuais, é fundamental. O objetivo geral deste trabalho foi verificar a existência de correlações significativas entre os dados da adaptação sócio-comunicativa obtidos por meio de entrevistas com os pais e terapeutas, registrados no protocolo de adaptação sócio-comunicativa (Sousa, 2004), e os dados referentes ao perfil funcional da comunicação (Fernandes, 2004), bem como suas possíveis alterações, após um período de aproximadamente 12 meses de terapia fonoaudiológica com crianças e adolescentes com Distúrbios do Espectro Autístico. O método estabeleceu dois estudos: Estudo I: -48 sujeitos, com os quais foram aplicados os protocolos acima citados, e Estudo II -37 sujeitos, sorteados, aleatoriamente, entre aqueles que tinham feito parte do Estudo I e que tiveram atendimento fonoaudiológico no Laboratório de Investigação Fonoaudiológica nos Distúrbios do Espectro Autístico- FMUSP, por aproximadamente 12 meses, sem interrupções maiores do que 4 semanas, e que tinham freqüentado pelo menos 45 sessões, com os quais foram reaplicados os protocolos da pesquisa. No que se refere aos resultados referentes ao acompanhamento longitudinal, por tratar-se de um transtorno em que as grandes diferenças individuais são uma característica marcante, a abordagem considerou cada sujeito como seu próprio controle, visando 
o melhor aproveitamento dos dados obtidos, sendo assim, possível observar as relações existentes entre a adaptação sócio-comunicativa e o perfil funcional da comunicação. Os resultados obtidos no Estudo I permitem dizer que se observou um número maior de correlações entre a adaptação sócio-comunicativa e o perfil funcional da comunicação quando as terapeutas foram as informantes e não os pais. Em relação ao Estudo II, os resultados demonstraram que ao final de um período de aproximadamente um ano de atendimento fonoaudiológico houve maior convergência entre os dados obtidos com os pais e aqueles obtidos com as terapeutas, no que diz respeito à adaptação sócio-comunicativa, bem como uma maior convergência entre os resultados do perfil funcional da comunicação e da adaptação sócio-comunicativa. Conclui-se que este trabalho contribuiu no sentido de fornecer uma forma de analisar e acompanhar o desenvolvimento de habilidades sociais necessárias para as crianças se adaptarem e funcionarem como parceiros comunicativos. A utilização dos pais e também das terapeutas na coleta dos dados de adaptação sócio-comunicativa mostrou-se de grande valia, possibilitando uma produtiva troca de informações e a formação de parcerias que agem na detecção de possíveis falhas no processo de reabilitação. E, apesar das crianças do espectro autístico apresentarem um desenvolvimento deficitário das habilidades de linguagem, cognição e socialização, ainda sim elas foram capazes de extrair pistas lingüísticas e não-lingüísticas do meio comunicativo, e utilizá-las de forma contextual em sua vida social, associando-as com os ganhos na linguagem e no desempenho sóciocognitivo.

PALAVRAS-CHAVE:

LINGUAGEM, PRAGMÁTICA, COMUNICAÇÃO, SOCIALIZAÇÃO, AUTISMO. 


\section{Abstract}

Sousa-Morato, PF. Functional communicative profile and social communicative adaptation in the autistic spectrum; São Paulo: Faculdade de Filosofia, Letras e Ciências Humanas da Universidade de São Paulo, 2007.229f.

The speech and language therapist's role with children of the autistic spectrum is deeply linked to the linguistic perspectives. Specially to the pragmatic theories, since the behavioral characteristics observed in autistic children behavior involve the same deficits approached by these theories, that is, the relation between language and the social and cognitive aspects of development. This way, the individualized and detailed observation, seeking different analysis about individual processes is essential. The general purpose of this study was to verify significant correlations between data about social communicative adaptation and the functional communicative profile and their possible variations after a period of 12 months of language therapy. The social communicative adaptation data was obtained in interviews with parents and therapists and registered in specific protocols (Sousa, 2004). The functional communicative profile was determined by the analysis of a filmed sample of 30 minutes of play session (Fernandes, 2004). The method determined two studies the first with 48 subjects and the second with 37 subjects (randomly chosen from the participants of the first study that attended to language therapy for a period of 12 months without interruptions longer than 4 weeks). The follow-up study considered each subject as his/her own control, due to the large individual variations characteristic of the autistic spectrum. It allowed the observation of the relation between social communicative adaptation and the functional communicative profile. Results of Study 1 showed that there were more correlations when the information was provided by the therapists. In the Study 2 results show that after a period of 12 months of language therapy there was more association of the 
data provided by parents and therapists. It can be concluded that this research determined a way to analyze and follow-up the development of social abilities that are fundamental to the child's adaptation and participation on the communicative process. The use of parents and therapists as informants about social communicative adaptation was shown to be useful in providing a productive information exchange and the determination of cooperative teams for the detections and prevention of failures of rehabilitation processes. Despite children of the autistic spectrum present deficits on the development of language, cognitive and social abilities, they were able to derive linguistic and non-linguistic clues from the communicative environment and to use them according to the social context, thus leading to language and socialcognitive progress.

Key -Words:

Language, Pragmatics, Communication, Socialization, Autism. 


\section{Lista de Tabelas}

\section{Estudo I}

TABELA I.1- VALORES DE MÉDIA E DESVIO-PADRÃO DA IDADE E TEMPO DE INTERVENÇÃO

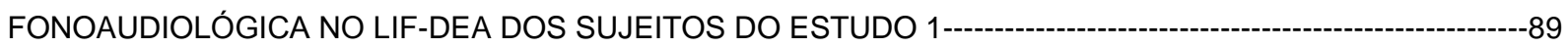

TABELA I.2- VALORES DE SIGNIFICÂNCIA NA COMPARAÇÃO DOS DADOS DE ADAPTAÇÃO SÓCIOCOMUNICATIVA OBTIDOS COM PAIS E TERAPEUTAS--

TABELA I.3- VALORES DE SIGNIFICÂNCIA OBTIDOS NA COMPARAÇÃO DE RESPOSTAS DADAS POR PAIS E TERAPEUTAS, A CADA ESTÁGIO E NÍVEL DA ESCALA DE ADAPTAÇÃO SÓCIO-COMUNICATIVA-------100

TABELA 1.4- VALORES OBTIDOS NA COMPARAÇÃO DAS REPOSTAS SIM OU NÃO DADAS POR DIFERENTES INFORMANTES PARA OS NÍVEIS E ESTÁGIOS DA ESCALA DE ADAPTAÇÃO SÓCIOCOMUNICATIVA QUE APRESENTARAM DIFERENÇA ESTATISTICAMENTE SIGNIFICATIVA----------------102

TABELA I.5- VALORES DE SIGNIFICÂNCIA ENCONTRADOS NA CORRELAÇÃO ENTRE PERFIL FUNCIONAL DA COMUNICAÇÃO E OS DADOS DE ADAPTAÇÃO SÓCIO-COMUNICATIVA OBTIDOS COM OS PAIS-----104

TABELA I.6- VALORES DE SIGNIFICÂNCIA ENCONTRADOS NA CORRELAÇÃO ENTRE O PERFIL FUNCIONAL DA COMUNICAÇÃO E OS DADOS DE ADAPTAÇÃO SÓCIO-COMUNICATIVA OBTIDOS COM AS TERAPEUTAS-

TABELA I.7 - CORRELAÇÕES SIGNIFICATIVAS DO COMPORTAMENTO DA IDADE FRENTE AOS DADOS DE ADAPTAÇÃO SÓCIO-COMUNICATIVA OBTIDOS COM OS PAIS E TERAPEUTAS-

TABELA 1.8 - CORRELAÇÕES SIGNIFICATIVAS DO COMPORTAMENTO DO TEMPO DE TERAPIA (EM ANOS) FONOAUDIOLÓGICA NO LIF-DEA FRENTE AOS DADOS DE ADAPTAÇÃO SÓCIO-COMUNICATIVA OBTIDOS COM OS PAIS COMO INFORMANTES

TABELA I.9- VALORES DE SIGNIFICÂNCIA OBTIDOS NA COMPARAÇÃO DO PERCENTUAL DE USO DO MEIO VERBAL ENTRE OS NÍVEIS CLASSIFICADOS PELOS PAIS DA ESCALA DE ADAPTAÇÃO SÓCIO-

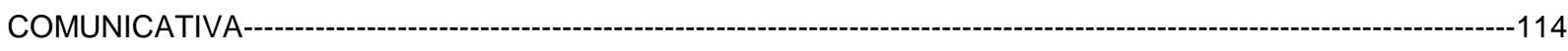

TABELA I.10- VALORES DE SIGNIFICÂNCIA OBTIDOS NA COMPARAÇÃO DAS ÁREAS DO PERFIL FUNCIONAL DA COMUNICAÇÃO ENTRE OS NIVEIS DA ESCALA DE ADAPTAÇÃO SÓCIO-COMUNICATIVA ATRIBUÍDOS PELAS TERAPEUTAS-

TABELA I.11 - VALORES DE SIGNIFICÂNCIA NA COMPARAÇÃO DE ÁREAS DO PERFIL COMUNICATIVO QUE SE DIFERENCIAM ENTRE OS NÍVEIS SÓCIO-COMUNICATIVOS ATRIBUÍDOS PELAS TERAPEUTAS---- 


\section{Estudo II}

TABELA II.1- VALORES DE MÉdIA E DESVIO-PADRÃO DA IDADE E TEMPO DE INTERVENÇÃO FONOAUDIOLÓGICA EM ANOS DOS SUJEITOS NOS DIFERENTES MOMENTOS DE COLETA-------------133

TABELA II.2- VALORES DE SIGNIFICÂNCIA NA COMPARAÇÃO ENTRE OS DADOS DE ADAPTAÇÃO SÓCIOCOMUNICATIVA OBTIDOS COM AS TERAPEUTAS NOS DOIS DIFERENTES MOMENTOS DE COLETA---146

TABELA II.3- VALORES DE SIGNIFICÂNCIA NA COMPARAÇÃO ENTRE OS DADOS DE ADAPTAÇÃO SÓCIOCOMUNICATIVA OBTIDOS COM PAIS E TERAPEUTAS NO SEGUNDO MOMENTO DE COLETA------------149

TABELA II.4- VALORES DE SIGNIFICÂNCIA OBTIDOS NA COMPARAÇÃO DE RESPOSTAS DADAS POR PAIS E TERAPEUTAS A CADA ESTÁGIO E NÍVEL DA ESCALA DE ADAPTAÇÃO SÓCIO-COMUNICATIVA, NO PRIMEIRO MOMENTO DE COLETA-

TABELA II.5- VALORES OBTIDOS NA COMPARAÇÃO DAS REPOSTAS SIM OU NÃO DADAS POR DIFERENTES INFORMANTES PARA O NÍVEL E ESTÁGIO DA ESCALA DE ADAPTAÇÃO SÓCIOCOMUNICATIVA QUE APRESENTOU DIFERENÇA ESTATISTICAMENTE SIGNIFICATIVA, NO PRIMEIRO MOMENTO DE COLETA

TABELA II.6- VALORES DE SIGNIFICÂNCIA OBTIDOS NA COMPARAÇÃO DE RESPOSTAS DADAS POR PAIS E TERAPEUTAS A CADA ESTÁGIO E NÍVEL DA ESCALA DE ADAPTAÇÃO SÓCIO-COMUNICATIVA, NO SEGUNDO MOMENTO DE COLETA-

TABELA II.7- VALORES OBTIDOS NA COMPARAÇÃO DAS REPOSTAS SIM OU NÃO DADAS POR DIFERENTES INFORMANTES PARA OS NÍVEIS E ESTÁGIOS DA ESCALA DE ADAPTAÇÃO SÓCIOCOMUNICATIVA QUE APRESENTARAM DIFERENÇA ESTATISTICAMENTE SIGNIFICATIVA, NO SEGUNDO MOMENTO DE COLETA-

TABELA II.8- CORRELAÇÕES SIGNIFICATIVAS ENTRE OS DADOS DA ADAPTAÇÃO SÓCIOCOMUNICATIVA OBTIDOS COM OS PAIS E O PERFIL FUNCIONAL DA COMUNICAÇÃO NO PRIMEIRO MOMENTO DE COLETA 155

TABELA II.9- CORRELAÇÕES SIGNIFICATIVAS ENTRE OS DADOS DA ADAPTAÇÃO SÓCIOCOMUNICATIVA OBTIDOS COM OS PAIS E O PERFIL FUNCIONAL DA COMUNICAÇÃO NO SEGUNDO MOMENTO DE COLETA-

TABELA II.10- CORRELAÇÕES SIGNIFICATIVAS ENTRE A ADAPTAÇÃO SÓCIO-COMUNICATIVA OBTIDA PELAS TERAPEUTAS E O PERFIL FUNCIONAL DA COMUNICAÇÃO NO PRIMEIRO MOMENTO DE COLETA- 
TABELA II.11- CORRELAÇÕES SIGNIFICATIVAS ENTRE A ADAPTAÇÃO SÓCIO-COMUNICATIVA OBTIDA COM AS TERAPEUTAS E O PERFIL FUNCIONAL DA COMUNICAÇÃO NO SEGUNDO MOMENTO DE

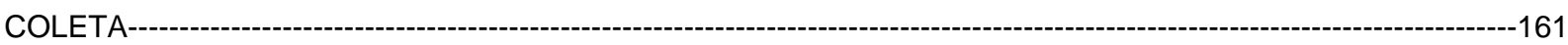

TABELA II.12 - VALORES DE SIGNIFICÂNCIA ENCONTRADOS NA IDENTIFICAÇÃO DE DIFERENÇAS DO PERFIL FUNCIONAL DA COMUNICAÇÃO ENTRE OS NÍVEIS SÓCIO-COMUNICATIVOS, TENDO OS PAIS COMO INFORMANTES NO PRIMEIRO MOMENTO DE COLETA, INCLUINDO O GRUPO INSTÁVEL $-164$

TABELA II.13 - VALORES DE SIGNIFICÂNCIA ENCONTRADOS NA IDENTIFICAÇÃO DE DIFERENÇAS DO PERFIL FUNCIONAL DA COMUNICAÇÃO ENTRE OS NÍVEIS SÓCIO-COMUNICATIVOS, INCLUINDO O GRUPO INSTÁVEL, ATRIBUÍDOS PELAS TERAPEUTAS NO PRIMEIRO MOMENTO DE COLETA------------166

TABELA II.14 - VALORES DE SIGNIFICÂNCIA ENCONTRADOS NA IDENTIFICAÇÃO DE DIFERENÇAS DO PERFIL FUNCIONAL DA COMUNICAÇÃO ENTRE OS NÍVEIS SÓCIO-COMUNICATIVO, EXCLUINDO O GRUPO INSTÁVEL, ATRIBUÍDOS PELAS TERAPEUTAS NO PRIMEIRO MOMENTO DE COLETA------------166

TABELA II.15 - VALORES DE SIGNIFICÂNCIA ENCONTRADOS NA IDENTIFICAÇÃO DE DIFERENÇAS DO PERFIL FUNCIONAL DA COMUNICAÇÃO ENTRE OS NIVVEIS SÓCIO-COMUNICATIVOS CLASSIFICADOS PELOS PAIS NO SEGUNDO MOMENTO DE COLETA INCLUINDO O GRUPO INSTÁVEL $-168$

TABELA II.16 - VALORES DE SIGNIFICÂNCIA ENCONTRADOS NA IDENTIFICAÇÃO DE DIFERENÇAS DO PERFIL FUNCIONAL DA COMUNICAÇÃO ENTRE OS NÍVEIS SÓCIO-COMUNICATIVOS, EXCLUINDO O GRUPO INSTÁVEL, ATRIBUÍDOS PELOS PAIS NO SEGUNDO MOMENTO DE COLETA 169

TABELA II.17 - VALORES DE SIGNIFICÂNCIA ENCONTRADOS NA IDENTIFICAÇÃO DE DIFERENÇAS DO PERFIL FUNCIONAL DA COMUNICAÇÃO ENTRE OS NÍVEIS SÓCIO-COMUNICATIVOS, INCLUINDO O GRUPO INSTÁVEL, ATRIBUÍDOS PELAS TERAPEUTAS NO SEGUNDO MOMENTO DE COLETA-----------171

TABELA II.18 - VALORES DE SIGNIFICÂNCIA ENCONTRADOS NA IDENTIFICAÇÃO DE DIFERENÇAS DO PERFIL FUNCIONAL DA COMUNICAÇÃO ENTRE OS NÍVEIS SÓCIO-COMUNICATIVOS, EXCLUINDO O GRUPO INSTÁVEL, ATRIBUÍDOS PELAS TERAPEUTAS NO SEGUNDO MOMENTO DE COLETA------------172 


\section{Lista de Figuras}

\section{Estudo I}

FIGURA I.1- NÚMERO DE SUJEITOS COM RESPOSTAS POSITIVAS EM CADA NÍVEL/ESTÁGIO DA ESCALA DE ADAPTAÇÃO SÓCIO-COMUNICATIVA, OBTIDAS EM ENTREVISTAS COM OS PAIS E COM AS TERAPEUTAS98

FIGURA I.2- MÉDIAS DOS PERCENTUAIS DE USO DO MEIO VERBAL E GESTUAL PARA CADA NÍVEL DA ESCALA DE ADAPTAÇÃO SÓCIO-COMUNICATIVA-

\section{Estudo II}

FIGURA II.1- COMPARAÇÃO DO NÚMERO DE RESPOSTAS POSITIVAS NA ESCALA DE ADAPTAÇÃO SÓCIO-COMUNICATIVA, OBTIDAS COM OS PAIS NOS DOIS DIFERENTES MOMENTOS DE COLETA-----144

FIGURA II.2- COMPARAÇÃO DO NÚMERO DE RESPOSTAS POSITIVAS NA ESCALA DE ADAPTAÇÃO SÓCIO-COMUNICATIVA, OBTIDAS COM AS TERAPEUTAS NOS DOIS DIFERENTES MOMENTOS DE COLETA-

FIGURA II. 3- NÚMERO DE RESPOSTAS POSITIVAS NA ESCALA DE ADAPTAÇÃO SÓCIO-COMUNICATIVA, OBTIDAS PELOS PAIS E TERAPEUTAS NO PRIMEIRO MOMENTO DE COLETA-

FIGURA II.4- COMPARAÇÃO DO NÚMERO DE RESPOSTAS POSITIVAS NA ESCALA DE ADAPTAÇÃO SÓCIO-COMUNICATIVA, OBTIDAS COM PAIS E TERAPEUTAS NO SEGUNDO MOMENTO DE COLETA---150

FIGURA II.5- MÉDIAS DO PERFIL FUNCIONAL DA COMUNICAÇÃO ENTRE OS NÍVEIS DA ESCALA DE ADAPTAÇÃO SÓCIO-COMUNICATIVA, COM OS PAIS COMO INFORMANTES NO PRIMEIRO MOMENTO DE COLETA-

FIGURA II.6- MÉDIAS DO PERFIL FUNCIONAL DA COMUNICAÇÃO ENTRE OS NÍVEIS DA ESCALA DE ADAPTAÇÃO SÓCIO-COMUNICATIVA, TENDO AS TERAPEUTAS COMO INFORMANTES NO PRIMEIRO MOMENTO DE COLETA-

FIGURA II.7- MÉDIAS DAS ÁREAS DO PERFIL FUNCIONAL DA COMUNICAÇÃO ENTRE OS NÍVEIS DA ESCALA DE ADAPTAÇÃO SÓCIO-COMUNICATIVA, TENDO OS PAIS COMO INFORMANTES NO SEGUNDO MOMENTO DE COLETA-

FIGURA II.8- MÉDIAS DO PERFIL FUNCIONAL DA COMUNICAÇÃO ENTRE OS 4 NÍVEIS DA ESCALA DE ADAPTAÇÃO SÓCIO-COMUNICATIVA, TENDO AS TERAPEUTAS COMO INFORMANTES NO SEGUNDO MOMENTO DE COLETA- 


\section{Lista de Dendogramas}

\section{Estudo I}

DENDOGRAMAS I.1 E I.2- AGLOMERADOS DETERMINADOS PELAS VARIÁVEIS DO PERFIL FUNCIONAL DA COMUNICAÇÃO DOS SUJEITOS DO NÍVEL 1DA ESCALA DE ADAPTAÇÃO SÓCIO-COMUNICATIVA CLASSIFICADOS PELOS PAIS E TERAPEUTAS118

DENDOGRAMAS I.3 E I.4- AGLOMERADOS DETERMINADOS PELAS VARIÁVEIS DO PERFIL FUNCIONAL DA COMUNICAÇÃO DOS SUJEITOS DO NÍVEL 2 DA ESCALA DE ADAPTAÇÃO SÓCIO-COMUNICATIVA CLASSIFICADOS PELOS PAIS E TERAPEUTAS-

DENDOGRAMAS I.5 E I.6- AGLOMERADOS DETERMINADOS PELAS VARIÁVEIS DO PERFIL FUNCIONAL DA COMUNICAÇÃO DOS SUJEITOS DO NÍVEL 3 DA ESCALA DE ADAPTAÇÃO SÓCIO-COMUNICATIVA CLASSIFICADOS PELOS PAIS E TERAPEUTAS$-120$

DENDOGRAMAS 1.7 e I.8- AGLOMERADOS DETERMINADOS PELAS VARIÁVEIS DO PERFIL FUNCIONAL DA COMUNICAÇÃO DOS SUJEITOS DO NÍVEL 4 DA ESCALA DE ADAPTAÇÃO SÓCIO-COMUNICATIVA CLASSIFICADOS PELOS PAIS E TERAPEUTAS $-121$

\section{Estudo II}

DENDOGRAMAS II.1 E II.2- AGLOMERADOS DETERMINADOS PELAS VARIÁVEIS DO PERFIL FUNCIONAL DA COMUNICAÇÃO DOS SUJEITOS DO NIVEL 1 DA ESCALA DE ADAPTAÇÃO SÓCIO-COMUNICATIVA CLASSIFICADOS PELOS PAIS E TERAPEUTAS NO PRIMEIRO MOMENTO DE COLETA $-174$

DENDOGRAMAS II.3 E II.4- AGLOMERADOS DETERMINADOS PELAS VARIÁVEIS DO PERFIL FUNCIONAL DA COMUNICAÇÃO DOS SUJEITOS DO NÍVEL 1 DA ESCALA DE ADAPTAÇÃO SÓCIO-COMUNICATIVA CLASSIFICADOS PELOS PAIS E TERAPEUTAS NO SEGUNDO MOMENTO DE COLETA-

DENDOGRAMAS II.5 E II.6- AGLOMERADOS DETERMINADOS PELAS VARIÁVEIS DO PERFIL FUNCIONAL DA COMUNICAÇÃO DOS SUJEITOS DO NÍVEL 2 DA ESCALA DE ADAPTAÇÃO SÓCIO-COMUNICATIVA CLASSIFICADOS PELOS PAIS E TERAPEUTAS NO PRIMEIRO MOMENTO DE COLETA $-176$

DENDOGRAMAS II.7 e II.8- AGLOMERADOS DETERMINADOS PELAS VARIÁVEIS DO PERFIL FUNCIONAL DA COMUNICAÇÃO DOS SUJEITOS DO NÍVEL 2 DA ESCALA DE ADAPTAÇÃO SÓCIO-COMUNICATIVA CLASSIFICADOS PELOS PAIS E TERAPEUTAS NO SEGUNDO MOMENTO DE COLETA

DENDOGRAMAS II.9 E II.10 AGLOMERADOS DETERMINADOS PELAS VARIÁVEIS DO PERFIL FUNCIONAL DA COMUNICAÇÃO DOS SUJEITOS DO NÍVEL 3 DA ESCALA DE ADAPTAÇÃO SÓCIO-COMUNICATIVA CLASSIFICADOS PELOS PAIS E TERAPEUTAS NO PRIMEIRO MOMENTO DE COLETA

DENDOGRAMAS II.11 E II.12- AGLOMERADOS DETERMINADOS PELAS VARIÁVEIS DO PERFIL FUNCIONAL DA COMUNICAÇÃO DOS SUJEITOS DO NÍVEL 3 DA ESCALA DE ADAPTAÇÃO SÓCIOCOMUNICATIVA CLASSIFICADOS PELOS PAIS E TERAPEUTAS NO SEGUNDO MOMENTO DE COLETA-179

DENDOGRAMAS II.13 E II.14- AGLOMERADOS DETERMINADOS PELAS VARIÁVEIS DO PERFIL FUNCIONAL DA COMUNICAÇÃO DOS SUJEITOS DO NÍVEL 4 DA ESCALA DE ADAPTAÇÃO SÓCIOCOMUNICATIVA CLASSIFICADOS PELOS PAIS E TERAPEUTAS NO PRIMEIRO MOMENTO DE COLET--180

DENDOGRAMAS $\| .15$ e $\| .16$ - AGLOMERADOS DETERMINADOS PELAS VARIÁVEIS DO PERFIL FUNCIONAL DA COMUNICAÇÃO DOS SUJEITOS DO NÍVEL 4 DA ESCALA DE ADAPTAÇÃO SÓCIOCOMUNICATIVA CLASSIFICADOS PELOS PAIS E TERAPEUTAS NO SEGUNDO MOMENTO DE COLETA----- 


\section{Lista de Quadros}

\section{Estudo I}

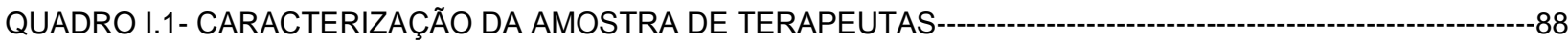

QUADRO I.2- CARACTERIZAÇÃO DA AMOSTRA DAS 48 CRIANÇAS PERTENCENTES AO ESPECTRO AUTÍSTICO-

QUADRO I.3- DIVISÃO DOS SUJEITOS EM FUNÇÃO DO NÍVEL DE ADAPTAÇÃO SÓCIO-COMUNICATIVA

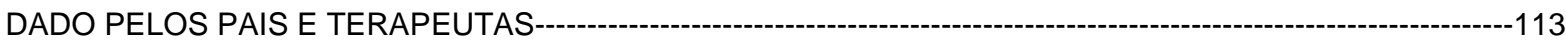

\section{Estudo II}

QUADRO II.1- CARACTERIZAÇÃO DA AMOSTRA-

QUADRO II.3- DIVISÃO DOS SUJEITOS EM FUNÇÃO DO NÍVEL DE ADAPTAÇÃO SÓCIO-COMUNICATIVA CLASSIFICADOS POR PAIS E TERAPEUTAS NOS DOIS DIFERENTES MOMENTOS DE COLETA---:--------- 


\section{Lista de Esquemas}

ESQUEMA 1- DIVISÃO METODOLÓGICA DO ESTUDO I-

ESQUEMA 2- DIVISÃO METODOLÓGICA DO ESTUDO ॥

ESQUEMA I.1- DIVISÃO METODOLÓGICA DOS SUJEITOS DO ESTUDO I$-89$ 


\section{Sumário}

Apresentação------------------------------------------------------------------------------------------------21

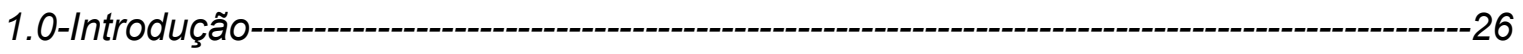

2.0- Revisão da Literatura----------------------------------------------------------------------------------34

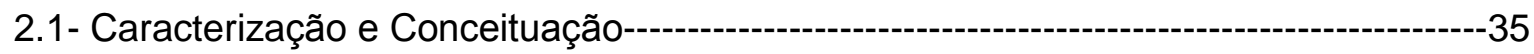

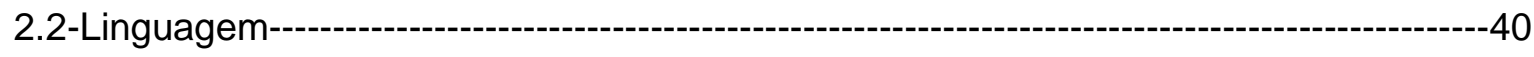

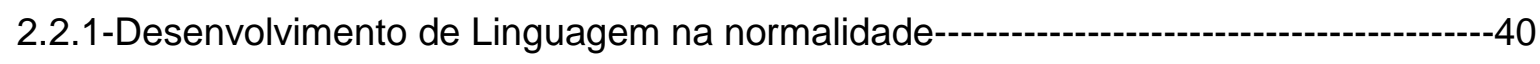

2.2.2- Pragmática: interface entre o desenvolvimento cognitivo, social e lingüístico-------44

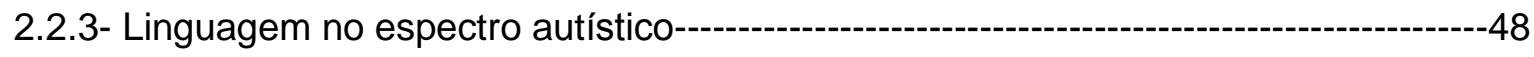

2.3- Cognição, desempenho sócio-cognitivo e o espectro autístico----------------------------59

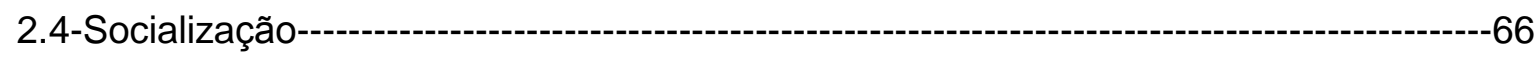

2.4.1-Desenvolvimento social: relações entre a normalidade e o espectro autístico------66

2.4.2-Desenvolvimento social no espectro autístico e suas relações com a linguagem e

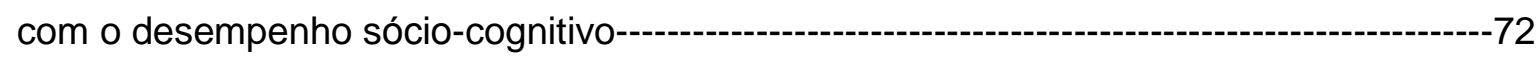

2.5- Identificação, intervenção e instrumentos investigativos nos distúrbios do espectro

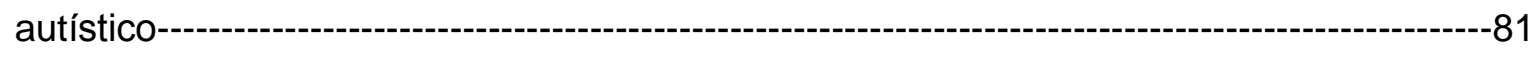

3.0- Estudo 1- Perfil Funcional da Comunicação e Adaptação sócio-comunicativa de crianças do espectro autístico: dados obtidos com pais e terapeutas-------------------------86

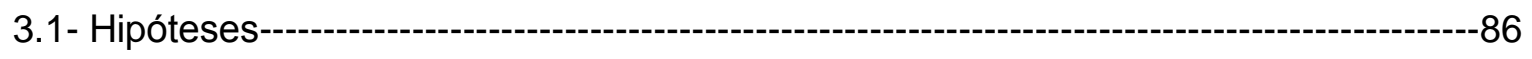

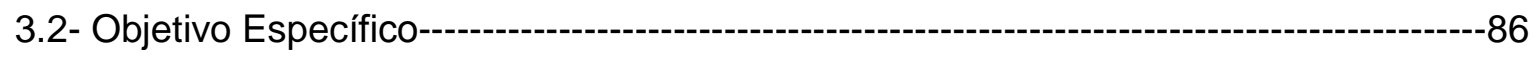

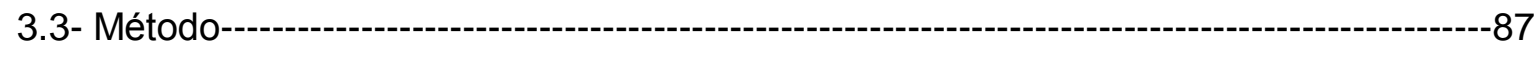

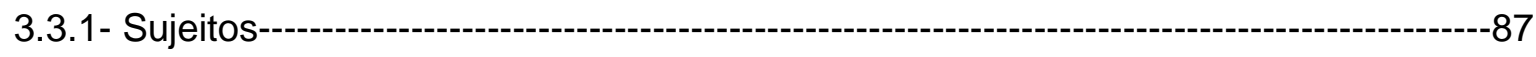




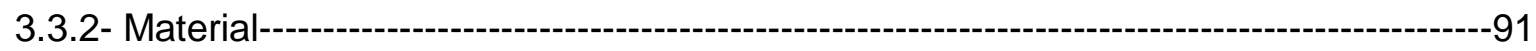

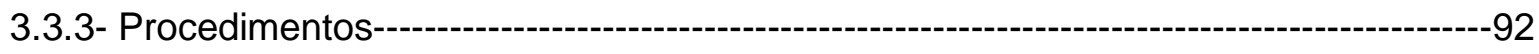

3.3.4- Análise Estatística----o-

3.4- Resultados----o-

3.5- Discussão---o-122

3.6- Conclusão-----

4.0- Estudo 2- Adaptação sócio-comunicativa e Perfil Funcional da Comunicação no espectro autístico: estudo longitudinal---_-

4.1- Hipóteses---

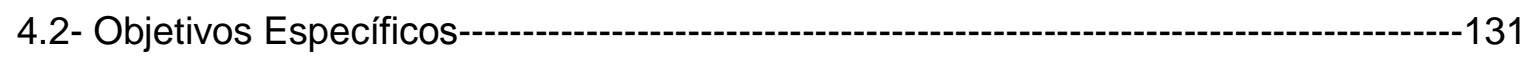

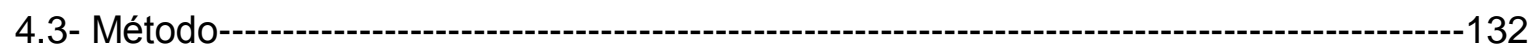

4.3.1- Sujeitos-----on

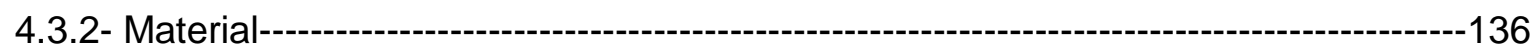

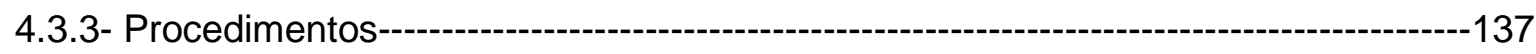

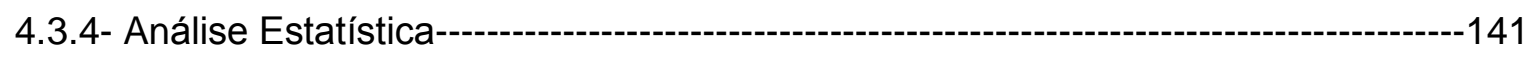

4.4- Resultados-----on

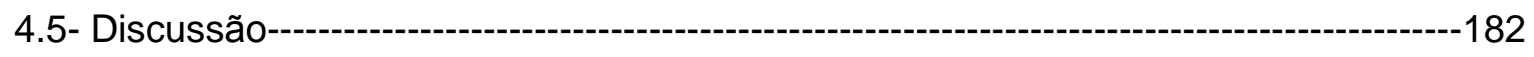

4.6- Conclusão----

5.0- Conclusão Geral---_-_-195

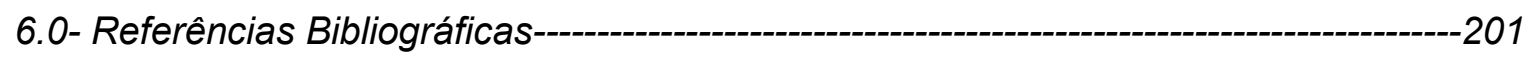

Anexos-- 


\section{Apresentação}

O estudo do autismo infantil vem se desenvolvendo ao longo de décadas, sendo que em um primeiro momento focou-se mais a parte semiológica do distúrbio. Entretanto, atualmente existem inúmeras pesquisas que demonstram a importância da linguagem e da comunicação, bem como a sua inter-relação com a cognição e a socialização na caracterização deste distúrbio do desenvolvimento.

Durante a prática fonoaudiológica, embora quase sempre estivessem presentes nas crianças em atendimento no Laboratório de Investigação Fonoaudiológica nos Distúrbios do Espectro Autístico da Faculdade de Medicina da Universidade de São Paulo, características como diminuição no contato ocular, dificuldade em desenvolver relações de companheirismo apropriadas para o nível de comportamento, falta de procura espontânea em dividir satisfações, bem como a ausência de reciprocidade social ou emocional; e esses fossem aspectos diagnósticos para o autismo infantil, segundo o DSM-IV-TR (2000); muitas vezes essas crianças eram capazes de se comunicar e realizar trocas sociais, expressando-as de forma contextual. 
$\mathrm{Na}$ literatura nacional quase não existem trabalhos que tratem desta relação tão estreita entre a linguagem e a socialização em crianças do espectro autístico. Se considerarmos que a linguagem e a socialização são mutuamente interferentes, e que caminham juntas, permitindo ao indivíduo participar de relações sociais que expressam trocas comunicativas equilibradas, é de extrema importância que compreendamos a relação entre essas áreas do desenvolvimento nos distúrbios do espectro autístico.

Em estudo anterior (Sousa, 2004), foram relacionados os aspectos de linguagem, desempenho sócio-cognitivo e relacionamento social de crianças do espectro autístico, sendo proposta uma forma de análise do relacionamento social de crianças do espectro autístico. Concluiu-se que o material elaborado pela pesquisadora foi capaz de estabelecer o desempenho sócio-comunicativo, segundo a análise dos pais em relação à adaptação social de seus filhos. Entretanto, fazia-se necessária uma análise e uma comparação dos mesmos aspectos, obtidos a partir da perspectiva de indivíduos que enxergam esse mesmo alvo, mas com outro foco, como as terapeutas.

Por essa motivação, foi proposta a análise dos dados de adaptação sóciocomunicativa de crianças do espectro autístico, considerando também as terapeutas como informantes do questionário e protocolo referentes ao relacionamento social dessas crianças, em atendimento fonoaudiológico semanal no Laboratório de Investigação Fonoaudiológica nos Distúrbios do Espectro Autístico da Faculdade de Medicina da Universidade de São Paulo. 
Neste estudo realizou-se mais uma forma de análise desta população, buscando observar, em um grupo de crianças do espectro autístico, qual a correlação entre as áreas de linguagem e a socialização, e como esta correlação pode influenciar o desempenho comunicativo deste grupo, além de quais variáveis podem interferir neste processo, analisando conjuntamente os aspectos de linguagem e socialização.

Os objetivos gerais e específicos deste trabalho, que foi dividido em dois estudos, bem como as hipóteses norteadoras, às quais serão buscadas respostas, considerando uma base teórica multidisciplinar, estão apresentados no primeiro capítulo.

No segundo capítulo, uma síntese da literatura a respeito do conceito de distúrbios do espectro autístico está apresentada, buscando correlacioná-lo de maneira clara e objetiva como os conceitos de aquisição e desenvolvimento da linguagem, da cognição e da socialização, abordando especificamente os temas determinados e embasando a discussão dos resultados obtidos.

A seguir serão apresentados os dois estudos realizados no Laboratório de Investigação Fonoaudiológica nos Distúrbios do Espectro Autístico do Curso de Fonoaudiologia da Faculdade de Medicina da Universidade de São Paulo. 
Nos terceiro e quarto capítulos, estão apresentados o primeiro e o segundo estudo, respectivamente, sendo que o primeiro estudo trata-se de uma análise transversal que investiga a relação entre o perfil funcional da comunicação e os dados de adaptação sócio-comunicativa colhidos a partir de diferentes fontes de informação. O segundo estudo apresenta uma análise longitudinal dos dados do perfil funcional da comunicação e da adaptação sócio-comunicativa, sendo esta variável também obtida por meio de diferentes fontes, considerando que ambas as variáveis foram obtidas em dois momentos de coleta, estando apresentada, em cada estudo, a discussão dos resultados obtidos.

E finalmente, no quinto capítulo, as conclusões gerais. 


\section{0 /ntrodução}

Atualmente, principalmente nas ciências da área da saúde, tem-se considerado a necessidade de fazer clínica baseada em evidências. Especialmente na Fonoaudiologia, observa-se que a necessidade de se basear a conduta clínica em provas científicas visa assegurar que ela seja sempre fruto de uma busca conscienciosa e criteriosa de evidências científicas confiáveis.

Em relação à clínica fonoaudiológica, embora haja espaço para a análise subjetiva, e nem todas as intervenções possam ser analisadas segundo o mesmo prisma, a busca de uma análise, em primeiro plano, de procedimentos clínicos baseados em evidências, torna-se cada vez mais necessária no sentido de padronizar e avaliar procedimentos válidos, no que diz respeito à detecção precoce, ao diagnóstico e às intervenções terapêuticas.

A detecção precoce da patologia condiciona em grande parte a qualidade do prognóstico; e esta detecção levanta inúmeras questões clínicas, teóricas e éticas. Para cada resposta às questões acima levantadas, deve-se assegurar que a decisão clínica destinada a cada paciente seja cientificamente orientada, buscando sempre o melhor tratamento, neste caso, para crianças com distúrbios do espectro autístico. 
Faz-se necessário considerar todos estes aspectos no sentido de que a Fonoaudiologia, sendo uma ciência relativamente nova, consolide suas bases considerando a importância e a influência das demais ciências; como a Psicologia, Pedagogia, Medicina e principalmente a Lingüística, uma vez que esta é a grande responsável pelo estudo das línguas e da linguagem humanas. Sendo assim, a correlação entre as ciências torna-se fator primordial na estruturação de correntes teóricas que fundamentam a prática clínica, bem como a base deste estudo.

O trabalho fonoaudiológico na área dos distúrbios psiquiátricos da infância, mais especificamente com crianças pertencentes ao espectro autístico, busca, em fundamentos lingüísticos, idéias e formas de análise das alterações de linguagem apresentadas por esta população.

Desde que o estudo dos aspectos funcionais da linguagem em crianças do espectro autístico tornou-se mais evidenciado, em detrimento do estudo focado nos aspectos formais da língua, a partir das décadas de 70 e 80, a linguagem desses indivíduos passou a ser analisada de uma forma mais contextual, considerando sua relação com agentes sócio-comunicativos de integração, colaboração e co-criação. 
Com o aumento do interesse no estudo sobre o autismo tornou-se evidente a impossibilidade de definir ou descrever as alterações de linguagem, cognição e socialização por apenas uma ótica. Não que os aspectos diagnósticos do espectro autístico ainda estejam em discussão, uma vez que, é fato que o diagnóstico está baseado na tríade linguagem, cognição e socialização. Entretanto, ainda é variante a forma como estas áreas fundamentais são abordadas, desde as primeiras referências, sendo cada uma delas mais focada em cada estudo.

A perspectiva pragmática na Lingüística passou a ser uma parceira neste processo de evolução da clínica em Fonoaudiologia com crianças do espectro autístico, possibilitando ao terapeuta perceber e incluir elementos como o uso da intenção comunicativa, a influência do contexto, a importância dos diferentes papéis comunicativos, bem como o desempenho social e cognitivo.

Pode-se considerar como um elemento a mais na consolidação da ciência fonoaudiológica nos distúrbios do espectro autístico, a existência e a determinação de procedimentos avaliativos já validados quanto à possibilidade de retratar o perfil dos pacientes inseridos neste espectro em diferentes aspectos, sejam eles comunicativos, sócio-cognitivos ou sócio-comunicativos. Tudo isso contribui para que objetivos clínicos mais claros sejam traçados, bem como para fornecer material para a análise objetiva da evolução clínica e terapêutica. 
A valorização da perspectiva familiar é outro fator que vem sendo ressaltado na clínica fonoaudiológica, buscando assim, considerar a percepção dos pais quanto ao desempenho e desenvolvimento de seus filhos, contribuindo para a determinação de objetivos clínicos mais específicos.

Em estudo anterior (Sousa, 2004), foi considerada a perspectiva dos pais quanto à adaptação sócio-comunicativa de um grande número de crianças do espectro autístico, por meio da aplicação de um protocolo específico desenvolvido pela pesquisadora. Os resultados demonstraram que este instrumento foi útil e sensível para verificar variações individuais das habilidades sociais dessa população, sendo necessário relatar que os dados obtidos pelas respostas dos pais retratam a forma como estes consideram seus filhos como agentes de ação e participação no meio comunicativo e social.

Neste mesmo estudo (Sousa op. cit.), a autora buscou ressaltar que a relação entre os aspectos de linguagem, cognição e socialização é estreita nos quadros clínicos que abrangem o espectro autístico; entretanto, deve-se considerar a existência de percursos individuais estabelecidos em cada criança.

Na medida em que a relação entre a Lingüística e a Fonoaudiologia tornase mais estreita, a identificação de problemas e soluções passa a ser mais objetiva e efetiva, uma vez que a investigação científica conjunta nos remete a grandes variáveis e a considerações importantes para o desenvolvimento da própria ciência, proporcionando novas formas de atuação, capazes de inserir o indivíduo autista em um mundo lingüístico completo. 


\section{1- Objetivo Geral:}

Verificar as relações entre a adaptação sócio-comunicativa e o perfil funcional da comunicação em crianças com distúrbios do espectro autístico em atendimento fonoaudiológica especializado em um período de aproximadamente um ano.

\section{2- Objetivos específicos:}

- Verificar a efetividade da aplicação do protocolo de adaptação sóciocomunicativa a diferentes fontes de informação; neste caso, pais e terapeutas, na identificação de diferenças individuais em crianças com Distúrbios do Espectro Autístico.

- Verificar se há correlações significativas entre os dados referentes ao perfil funcional da comunicação e os dados da adaptação sócio-comunicativa obtidos por meio de entrevistas individuais com os pais e com as terapeutas de crianças com Distúrbios do Espectro Autístico (DEA).

- Verificar se existem correlações significativas entre os dados de adaptação sócio-comunicativa, obtidos com os pais e com as terapeutas, após um período de aproximadamente 12 meses de terapia fonoaudiológica com crianças com Distúrbios do Espectro Autístico (DEA).

- Verificar se há aumento nas relações entre os níveis de adaptação sóciocomunicativa e o perfil funcional da comunicação observado após um período de aproximadamente 12 meses de terapia fonoaudiológica com crianças com Distúrbios do Espectro Autístico (DEA). 
As hipóteses que norteiam este trabalho estão apresentadas em relação a cada estudo proposto:

\section{3-Estudo I:}

\section{Adaptação sócio-comunicativa e Perfil Funcional da Comunicação de} crianças do espectro autístico: dados obtidos com pais e terapeutas:

Hipótese - Os resultados referentes à adaptação sócio-comunicativa obtidos a partir das entrevistas com as terapeutas apresentarão maiores correlações com o perfil funcional da comunicação do que aqueles obtidos a partir de entrevistas com os familiares.

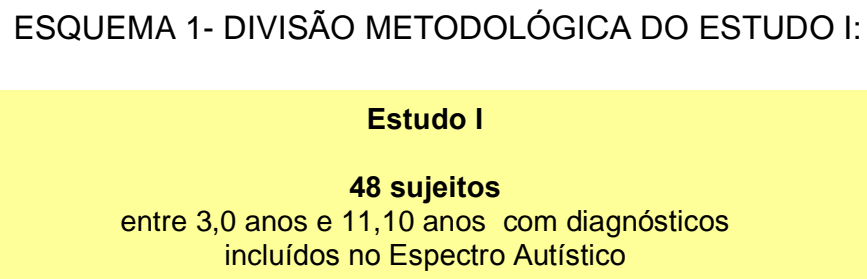

Estudo I

48 sujeitos

entre 3,0 anos e 11,10 anos com diagnósticos incluídos no Espectro Autístico

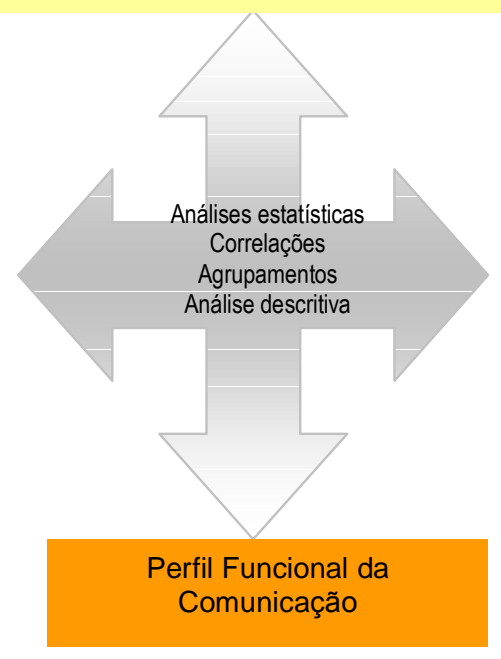




\section{4- Estudo II:}

\section{Adaptação sócio-comunicativa e Perfil Funcional da Comunicação no espectro autístico: estudo longitudinal}

Hipótese 1- Ao final de um período de aproximadamente um ano de atendimento fonoaudiológico haverá maior convergência entre os dados obtidos com os pais e aqueles obtidos com as terapeutas, no que diz respeito à adaptação sócio-comunicativa.

Hipótese 2- Ao final de um período de aproximadamente um ano de atendimento fonoaudiológico haverá maior convergência entre os resultados do perfil funcional da comunicação e da adaptação sócio-comunicativa. 


\section{ESQUEMA 2- DIVISÃO METODOLÓGICA DO ESTUDO II:}

\section{Estudo II}

\section{7 sujeitos}

entre 3,0 anos e 12,11 anos com diagnósticos

incluídos no Espectro Autístico

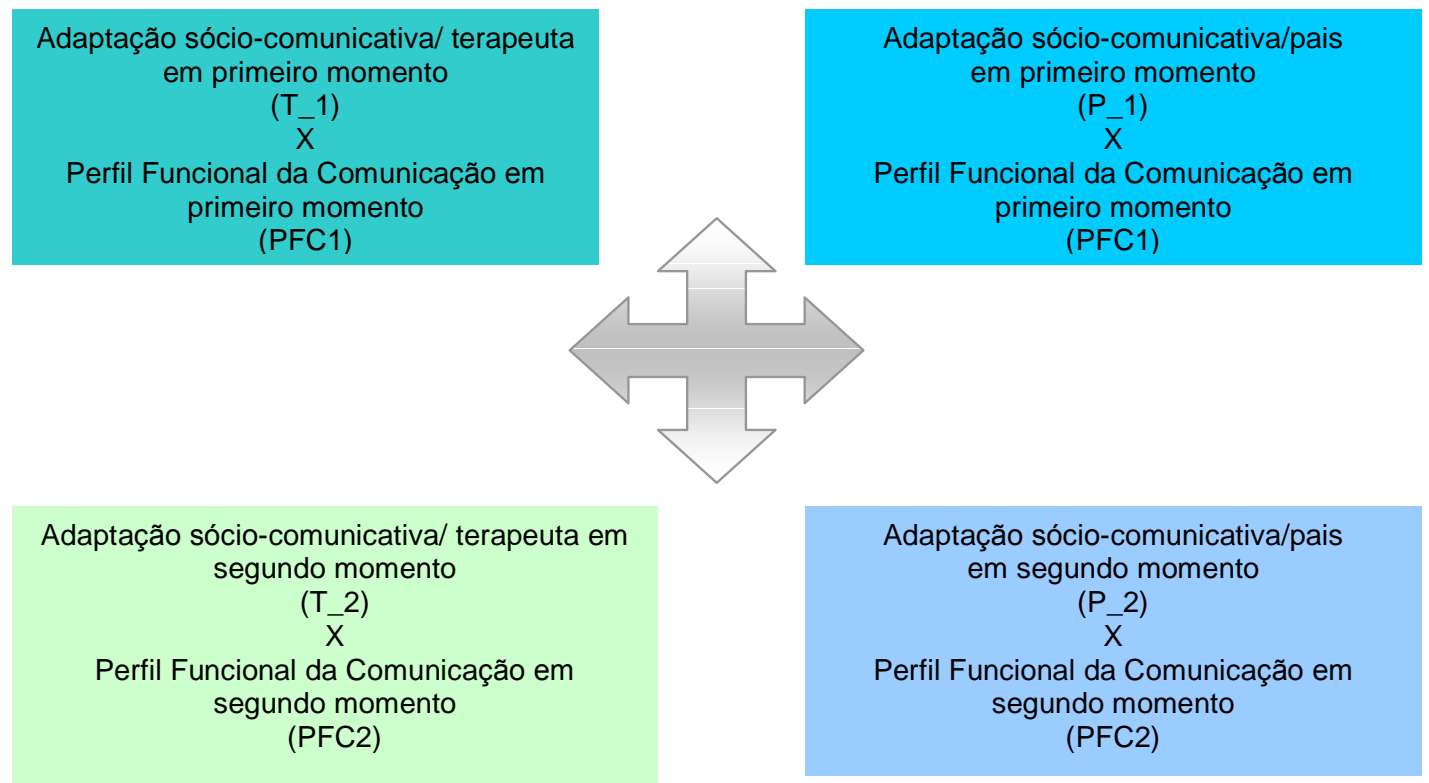

Adaptação sócio-comunicativa

Terapeuta (T_1) X Pais (P_1)

$x$

Adaptação sócio-comunicativa

Terapeuta (T_2) X Pais (P_2) 


\section{0-Revisão da Literatura:}

Este capítulo faz uma síntese dos estudos que fornecem fundamentação teórica para este trabalho, iniciando-se pela conceituação e caracterização dos Distúrbios do Espectro Autístico.

Serão abordadas, a seguir, as três áreas mais importantes para a Fonoaudiologia na questão diagnóstica deste quadro clínico, ou seja, a linguagem, analisada sob uma perspectiva pragmática enfocando de modo mais específico o perfil funcional da comunicação, o desempenho sócio-cognitivo e a investigação da adaptação sócio-comunicativa, bem como o processo de intervenção nestes quadros clínicos, considerando os pais como elementos na pesquisa científica dos distúrbios do espectro autístico.

Este estudo não foi organizado pela cronologia das publicações, privilegiando o encadeamento de idéias, sendo os assuntos apresentados divididos de uma maneira didática. 


\section{1- Caracterização e Conceituação:}

A proposta do conceito de espectro autístico como uma alternativa ao diagnóstico de transtorno invasivo do desenvolvimento tornou-se uma necessidade, uma vez que este diagnóstico abrange uma grande variedade de distúrbios neurodesenvolvimentais centrados em alterações na interação social, desvios na comunicação verbal e não-verbal, comportamentos repetitivos e interesses restritos. Desta forma, a classificação em termos de categorias diagnósticas rígidas torna-se extremamente difícil, considerando que nem todos esses distúrbios prejudicam as áreas centrais no diagnóstico destes quadros na mesma intensidade em todos os seus níveis (Wing, 1988; Bishop, 1989; Tanguay et al., 1998; Lord e Risi, 2001).

Cada vez mais se faz necessário considerar a idéia de um continuum autístico, pois o conceito de espectro autístico baseia-se não só na severidade, mas também, nas características lingüísticas, cognitivas e sociais, essenciais para o diagnóstico desses quadros clínicos. Neste espectro, o autismo estaria em posição central e quanto mais os outros quadros clínicos se afastam do mesmo, menor a severidade e o número de áreas afetadas (Lord e Risi, 2001). 
O caráter abrangente dos distúrbios que compõem o espectro autístico leva à formação da noção de um continuum, variando no nível de severidade dos déficits na interação social, comunicação, rigidez de interesses, comportamentos repetitivos, sendo possível diferenciá-los baseando-se no início e/ou curso dos sintomas; na presença ou não de retardos desenvolvimentais, bem como na severidade dos sintomas e áreas mais afetadas. Desta maneira, o autismo seria caracterizado pelo início dos sintomas antes dos três anos de idade, podendo estar ou não associado a retardos mentais, excedendo os limites típicos de números de sintomas determinados pela CID-10 (1993) e pelo DSM-IV (1995), apresentando alterações nas áreas de socialização, comunicação, comportamentos repetitivos e interesses restritos (Lord e Risi, 2001).

O distúrbio desintegrativo da infância seria um dos quadros que compõem o espectro autístico e difere principalmente do autismo pelo fato de ocorrer um desenvolvimento normal até o segundo ano de vida, com perda progressiva da fala e de, no mínimo, mais uma habilidade. Na síndrome de Asperger, outro quadro do referido espectro, ocorre a ausência de retardo global em cognição e linguagem, sendo a socialização e os interesses restritos, os aspectos mais afetados (Lord e Risi, 2001). 
As autoras (Lord e Risi, op.cit.) descrevem ainda o quadro de autismo atípico ou transtorno invasivo do desenvolvimento não-especificado como parte do espectro autístico, caracterizando-o como tendo início do surgimento dos sintomas não necessariamente correspondente ao critério para o autismo. Este quadro pode ou não estar associado a retardos de desenvolvimento, ou ainda estar abaixo dos limites típicos de números de sintomas em uma ou mais áreas centrais, sendo que a socialização e a comunicação ou comportamentos repetitivos, ou até ambos, podem estar seriamente afetadas.

Definir exatamente o conceito de espectro autístico, bem como quais os quadros clínicos que deveriam ser incluídos nele envolve muitas discussões que estão relacionadas às diferentes formas de análise. Entretanto, é de fundamental importância notar que o critério utilizado na questão diagnóstica destas crianças converge sempre para déficits na linguagem, cognição e socialização (Tanguay et al., 1998; Fernandes, 2002).

Baird et al. (2005) afirmam que os manuais diagnósticos de saúde mental têm sido diversas vezes revisados, alterando os critérios para o diagnóstico de autismo e suas subcategorias. Apesar do termo "distúrbios do espectro autístico" não aparecer nos manuais diagnósticos, observa-se que sua utilização é mais facilmente compreendida que 0 uso do termo transtorno invasivo do desenvolvimento, terminologia esta descrita nos manuais. Sendo assim, atualmente os dois termos passaram a ser usados como uma alternativa ou até mesmo, como sinônimos. 
Fernandes (2002) relata que o termo transtorno invasivo do desenvolvimento foi estabelecido a fim de poder diagnosticar casos clínicos semelhantes ao autismo, mas que não incluíam todos os critérios necessários para esse diagnóstico específico, buscando com este fato diferenciar os subtipos do distúrbio autístico de outros tipos de desordens, como a deficiência mental.

A validade da distinção entre os vários subtipos de desordens do espectro autístico tem sido freqüentemente questionada, sendo que na quarta edição do Manual de Diagnóstico e Estatística de Distúrbios Mentais - DSM-IV-TR (APA, 2000) já estão incluídos vários subtipos dos Distúrbios do Espectro Autístico. A edição do Manual de Diagnóstico e Estatística de Distúrbios Mentais - DSM-IV-TR (APA, 2000) apresenta informações sobre o autismo e seus subtipos, entretanto os critérios diagnósticos continuam os mesmos da edição anterior (Verté et al. 2006; Klin, 2006).

No DSM-IV-TR (APA, 2000) o diagnóstico é baseado tanto na consideração de déficits qualitativos em relação ao nível geral do desenvolvimento quanto no número de sintomas manifestados. Desta maneira, o diagnóstico de autismo pode implicar diferentes grupos de sintomas e ainda assim, por outro lado ser consistente com o desenvolvimento, demonstrando a necessidade de uma caracterização dos sintomas mais precisa ao longo do desenvolvimento, ressaltando a importância da documentação das mudanças sintomatológicas apresentadas por essa população. 
Existem diversas hipóteses etiológicas de que o autismo seria uma desordem cerebral que se desenvolveria no período pré ou neonatal (Bauman e Kemper, 1994; Bailey et al., 1998; Tager-Flusberg,1999; Chugani, 2002; Volkmar e Pauls, 2003; Landa e Garrett-Mayer, 2006), ou então, que seria um distúrbio em que fortes componentes genéticos estariam envolvidos (Folstein e RosenSheidley, 2001; Mundy e Stella, 2001), resultando na interrupção do desenvolvimento social e comunicativo, com a presença de comportamentos e interesses característicos e estereotipados. Por outro lado, Golsen (2005) afirma que o autismo infantil não poderia ser reduzido meramente a um déficit do desenvolvimento neurológico, devendo este ser considerado uma desordem de múltiplos fatores.

Outras hipóteses baseiam-se em perspectivas psicodinâmicas que vão de encontro ao pensamento de que a natureza do autismo seria fundamentada em alterações sócio-emocionais relacionadas às alterações no vínculo primário, mãebebê (Rutter, 1978; Fernandes, 1996a, 2003; Klin, 2006).

Muitas discussões quanto à etiologia do autismo ainda existem, e seu diagnóstico envolve a observação comportamental das alterações presentes na linguagem, na cognição e na socialização. A importância dessa tríade na caracterização dos quadros clínicos pertencentes ao espectro autístico tem sido utilizada na maioria dos estudos a respeito do tema, permitindo a compreensão das dificuldades de comunicação e linguagem que são de extrema importância para as questões de diagnóstico e intervenção (Fernandes, 2003). 


\section{2-Linguagem:}

\subsection{1-Desenvolvimento de Linguagem e pragmática:}

Desde o nascimento, a criança é capaz de utilizar a comunicação nãoverbal e funções sociais como reconhecimento de emoções, de atitudes interpessoais, além de executar a regulação da interação social, iniciando assim o processo de socialização. Estes comportamentos não-verbais, principalmente 0 olhar e ações face a face, têm papel fundamental nas interações comunicativas primitivas (Prinz, 1982).

O uso do olhar em relação à fala para a criança é ressaltado por Schieffelin (1983) uma vez que, o olhar exerce a função de monitorar e regular o ritmo das seqüências conversacionais, de sinalizar a prontidão e a intenção de interagir, tendo este um papel fundamental na constituição dos primeiros vínculos mãebebê.

De acordo com Prinz (1982), com o desenvolvimento da criança, logo no segundo mês de vida esta se torna capaz de adquirir rapidamente as regras sintáticas e semânticas da linguagem, começando a orientar-se para o ponto de vista do ouvinte na conversação. Existe então, uma necessidade de aprender níveis básicos de competência sócio-lingüística, usar e compreender comportamentos não-verbais apropriados, respeitar regras conversacionais, seqüenciar e integrar as informações baseadas em experiências passadas, adaptando-se ao contexto social. 
Alguns autores (Ochs Keenan, 1983; Wetherby et al, 1998) afirmam que antes mesmo da linguagem oral, a criança responde às iniciativas sociais de outros, ou seja, ocorre a emergência de habilidades que subjazem às trocas conversacionais. Com a maturação, começam a surgir jogos recíprocos, funções comunicativas como, pedidos de ação, de objeto e questionamentos, sendo que uma das maiores conquistas do estágio pré-lingüístico é a emergência da comunicação intencional. Considerando a regulação comportamental, a interação social e a atenção compartilhada, como intenções comunicativas inatas, pode-se dizer que, segundo as autoras, o comportamento comunicativo de uma criança, mesmo antes da emergência da fala, pode ser um indicador sensível da probabilidade de dificuldades subseqüentes no desenvolvimento de linguagem.

De acordo com Tager-Flusberg (1999), com o desenvolvimento da linguagem a interação da criança com o outro centra-se em características de comunicação, que incluem o direcionamento da atenção para ela mesma, para os outros ou para um objeto do ambiente, usando meios vocais e gestuais.

Kecskés (2000) afirma que muito da linguagem natural é composta por elementos repetidos, ensaiados, não-criativos e proposicionais, sendo que a freqüência de ocorrência tem impacto crucial na significância dos elementos lingüísticos, e que esse significado combinado das emissões freqüentemente passa a adquirir importância secundária, e o aspecto funcional passa a dominar, considerando a subjetividade e o contexto. 
Yont et al. (2003) propõem que a linguagem apresenta-se enquanto fenômeno social sensível a dimensões como formalidade da situação, objetivos de interação e relação entre os interlocutores. Ou seja, é sensível ao contexto, considerando este como o caminho que possibilita a distinção entre os efeitos da estrutura lingüística e os efeitos da situação e que é, em parte, determinado pela cultura, o que gera diferenças nos detalhes do contexto interativo. Os autores analisaram a função do contexto na interação mãe-bebê, e observaram que determinados contextos promovem estilos particulares de interação e influenciam as intenções pragmáticas da díade.

Bara et al. (1997) discutem a relação entre as habilidades de linguagem e a competência comunicativa, uma vez que a habilidade de linguagem refere-se à competência da criança em compreender e formular os sistemas simbólicos, falados ou escritos, enquanto a competência comunicativa refere-se à habilidade em fazer uso da linguagem como um instrumento efetivamente interativo com outros contextos sociais, envolvendo a intenção comunicativa independentemente dos meios utilizados para a comunicação.

Wollner e Geller (1982), pensando sob uma perspectiva pragmática, ressaltam que, gradualmente, começaram a surgir questões de como determinar o perfil funcional da comunicação, considerando as idéias de funcionalidade da linguagem, traçando os pontos mais marcantes nas habilidades de expressar atos comunicativos; iniciar e estender seqüências conversacionais, responder a quebras comunicativas, bem como quais os meios comunicativos mais utilizados, observando a habilidade da criança em funcionar tanto como falante quanto como ouvinte. 
Não se pode negar que o período entre 1,6 e 2,0 anos de vida é de extrema importância para o desenvolvimento lingüístico da criança. Entretanto, este desenvolvimento não é igual para todos os indivíduos, ou seja, para se afirmar que determinados comportamentos são adequados, faz-se necessário considerar as diferenças individuas (Rice, 1997).

Cervone e Fernandes (2005), analisando o perfil comunicativo de 40 crianças de 4 a 5 anos sem queixa de alteração no desenvolvimento da linguagem, encontraram diferença significante entre 0 número de atos comunicativos expressados por minuto pelas crianças e pelo adulto, bem como na ocorrência das funções mais interpessoais de pedido de ação, de informação e de reconhecimento do outro. As autoras observaram ainda que os meios comunicativos preferenciais foram o verbal, gestual e vocal. Sendo assim, estes resultados poderiam constituir um parâmetro inicial para nortear a clínica fonoaudiológica, fornecendo subsídios para a intervenção nos distúrbios do espectro autístico, baseados na perspectiva pragmática. 


\subsection{2- Pragmática: interface entre o desenvolvimento cognitivo, social e lingüístico}

Bates (1976) definiu pragmática como o estudo dos índices lingüísticos, sendo que estes só podem ser interpretados quando utilizados. Não se pode descrever o significado dos índices, sendo somente possível descrever as regras que os relacionam ao contexto, no qual o significado pode ser encontrado. Para que a comunicação ocorra efetivamente é necessária a presença de alguns aspectos lingüísticos como as estruturas performativas, que buscam considerar a intenção do outro e o uso do sentença como um comando, além da proposição, que é o conteúdo a ser comunicado, e a pressuposição, que se mostra como o emprego deste conteúdo em um dado contexto.

A definição de pragmática adotada inclui as distinções originais, propostas por Pierce e os estudos das regras indexicais para relacionar uma forma lingüística a um dado contexto, sendo esta extremamente importante no estudo do desenvolvimento da linguagem (Bates, 1976).

Segundo Bates (op. cit), durante o desenvolvimento normal das habilidades pragmáticas, estas se encontram intimamente ligadas às habilidades cognitivas.

Mcduffie et al. (2006) sugerem que a pragmática aproxima a aquisição de linguagem, demonstrando claramente a possibilidade de correlações entre as habilidades lingüísticas, sócio-cognitivas e sócio-comunicativas. 
Fernandes (1996b) afirma que a pragmática é um ponto de partida para o estudo de linguagem, incluindo os elementos contextuais, lingüísticos ou extra-lingüísticos, que podem estabelecer as funções comunicativas. Segundo a autora, a questão interacional é que determina o uso da linguagem, associado ao desenvolvimento cognitivo e à adaptação social, sendo possível, assim, um desenvolvimento lingüístico paralelo ao desenvolvimento da competência pragmática.

Carter (1979) e Yont et al. (2003) ressaltam a importância do contexto, com seus diversos fatores, como a situação interativa proposta, o tipo de linguagem, e as diferenças na complexidade da fala utilizada para a interação, para o desenvolvimento da linguagem, podendo refletir no tipo e no estilo conversacional das proposições realizadas pela criança e na que determina a produção do significado.

Segundo Bates (1976) e Adams (2002), os trabalhos que formaram a base do desenvolvimento da teoria dos atos de fala e análise conversacional foram as grandes influências para se analisar como os falantes transmitiam os significados por meio de sentenças e contextos, possibilitando que a pragmática fosse considerada como uma interface entre o desenvolvimento cognitivo, social e lingüístico. 
Kent (2004) afirma que a pragmática pode ser definida como o estudo das regras que governam o uso da linguagem em contextos sociais, incorporando comportamentos como a intenção comunicativa (atos de fala), gerenciamento conversacional (turno de fala, tópicos de manipulação, conhecimentos pressupostos, e regras lingüísticas culturalmente determinadas). Segundo o autor, atualmente, tem-se considerado progressivamente as contribuições da pragmática nas intervenções da linguagem, com proposições situacionais mais naturalísticas e contextuais, a fim de possibilitar a comunicação motivada e reforçada por acontecimentos naturais.

A pragmática expressa na linguagem falada é o aspecto central da avaliação de crianças com déficits de comunicação e desordens relacionadas, propondo ainda uma aproximação do desenvolvimento para avaliá-las, abrangendo a problemática do complexo interação social, lingüística, cognição, influências culturais (Adams, 2002).

Segundo Creghead (1982), o interesse em pragmática levou à identificação de déficits comunicativos em crianças, que antes eram ignorados. A variedade de possíveis transtornos pragmáticos mostrou-se enorme, sendo que crianças com distúrbios pragmáticos apresentam alterações funcionais na comunicação, podendo interferir no desenvolvimento futuro da linguagem. 
Gilmour et al. (2004) afirmam algumas crianças com déficits severos nas habilidades pragmáticas também apresentam características autísticas, sendo que estes déficits parecem se tornar cada vez menos distinto nos limites entre as habilidades pragmáticas, propriamente ditas, em déficits na comunicação social, e as desordens do espectro autístico.

Considerando a pragmática como o uso apropriado e a interpretação da linguagem verbal e não-verbal em relação às situações sociais, alguns autores (Prizant, 1983 e Verté et al., 2006) afirmam que crianças com desordens do espectro autístico apresentam alterações nos aspectos semântico e pragmático da comunicação como dificuldades na linguagem receptiva, habilidades de conversação inadequadas e uso de linguagem estereotipada, embora muitas vezes a fluência, a fonologia e a sintaxe encontrem-se intactas. 


\subsection{3- Linguagem no espectro autístico}

Alterações na linguagem e na comunicação são fatores primordiais na avaliação diagnóstica do autismo. Desde as décadas de 70 e 80 , a visão da linguagem no autismo, restrita às características de fala, como ecolalias, uso ou não da comunicação verbal, vem se modificando, uma vez que se passou a considerar não só os aspectos formais da linguagem, mas também seus aspectos funcionais (Tager-Flusberg, 1996, 2000; Fernandes, 2002).

Hale e Tager-Flusberg (2005a) afirmam que déficits na linguagem são as principais características dos distúrbios do espectro autístico, e que pesquisas têm demonstrado que alterações pragmáticas da linguagem, no uso da linguagem em contextos sociais, estão sempre presentes nas crianças com estes distúrbios, considerando os aspectos funcionais da comunicação e suas relações, o que vem sendo relatado por diversos autores (Prutting, 1982; Stone e Caro-Martinez, 1990; Pastorello, 1996, Fernandes, 1996, 2002, 2003).

Kjelgaard e Tager-Flusberg (2001) afirmam que ainda recentemente estes déficits do autismo na linguagem e na comunicação, são o foco de pesquisas que definem essa população. Entretanto, as autoras relatam que entre essa população existe uma heterogeneidade nas habilidades de linguagem. 
Existe uma relação íntima entre a interação social e a comunicação, sendo esta relação crucial, especialmente durante os estágios de desenvolvimento que marcam o ponto em que o autismo torna-se evidente (Tager-Flusberg, 1999).

Tager-Flusberg (1999), Hale e Tager-Flusberg (2005a) e Rubin e Laurent (2002) afirmam que crianças com distúrbios do espectro autístico são deficientes no uso do discurso, e que os déficits de linguagem e comunicação, também podem ser interpretados pelas dificuldades de meta-representação, uma vez que esta população apresenta dificuldades em comunicar-se considerando a perspectiva do outro, o que afeta a habilidade de manter a coerência contextual na troca comunicativa e gera as falhas nas relações dos significados entre gesto e fala.

Pry et al. (2005) afirmam que o grau de severidade do autismo está associado a diferentes formas sensoriais de análise de informações, do comportamento e das emoções, ou seja, estas relações sugerem que as alterações de linguagem afetam a totalidade dos distúrbios do autismo, como a atividade comunicativa, a interação social e os comportamentos repetitivos.

De acordo com Rollins e Snow (1998), as crianças começam a adquirir linguagem expressando suas intenções interpessoais. Entretanto, crianças com autismo são capazes de desenvolver o uso instrumental da linguagem, sem nenhuma habilidade na participação social ou na regulação da atenção. 
Hale e Tager-Flusberg (2005a), estudando um grupo de crianças do espectro autístico, verbais ou não, observaram um volume pequeno de comunicações proto-declarativas gestuais (p.ex: apontar para um objeto a fim de direcionar a atenção de outra pessoa) por parte dessas crianças. Entretanto, resultado diferente foi encontrado com o uso dos gestos proto-imperativos (que envolvem uma expressão do desejo ou necessidade da criança), pois os atos proto-declarativos envolvem a atenção conjunta e requerem a compressão da intencionalidade, estando ambas as habilidades profundamente deficitárias em crianças do espectro autístico.

Joseph et al. (2005) examinaram a função executiva e sua relação com a habilidade verbal de 37 autistas em idade escolar, que foram comparados com 31 crianças sem autismo, pareadas pela idade e pelo QI verbal e não-verbal. Os resultados demonstraram que crianças com autismo apresentaram a linguagem menos desenvolvida que seus pares, entretanto, análises de correlações não revelaram associações específicas entre as habilidades de linguagem e o desempenho executivo no grupo de autistas. Em contraste, este desempenho foi positivamente correlacionado com as habilidades lingüísticas no grupo de comparação. Estes achados sugerem que a função executiva no autismo não está diretamente relacionada a déficits de linguagem, mas envolve falhas no uso da linguagem para auto-regulação. 
Joseph et al. (2002) relatam, ao comparar dois grupos de crianças autistas (um grupo com média de 5.5 anos e outro com média de 8.11 anos), que em ambos os grupos, a competência comunicativa estava especificamente relacionada à habilidade verbal, indicando que a severidade dos déficits de linguagem são um importante fator na expressão dos déficits comunicativos do autismo, sendo esta relação particularmente forte no grupo mais velho.

Turner et al. (2006) afirmam que, assim como na normalidade, as habilidades de linguagem de crianças com autismo em idade pré-escolar vão aumentando progressivamente, mas de forma atípica. Entretanto, algumas crianças continuam a demonstrar déficits significantes na linguagem, sendo que estes ganhos só podem ser observados até determinado nível.

Os autores (Turner et al., op.cit.), afirmam ainda que em crianças autistas também ocorre um desenvolvimento significativo das habilidades lingüísticas durante o período típico de aquisição da linguagem, em diferentes formas e ritmos, considerando sempre as variações individuais que são aparentes, além da presença de fatores que relacionam melhoras significativas nas habilidades cognitivas e sócio-comunicativas com o aumento nas habilidades de linguagem. 
Bernard-Optiz (1982) afirma que a ausência de alguns comportamentos sociais dificulta as habilidades comunicativas de crianças autistas, como as habilidades de intenção comunicativa, manutenção do discurso e do tópico e respeito às trocas comunicativas, demonstrando que a competência comunicativa não depende somente da integridade das habilidades formais da língua como a morfologia, sintaxe e semântica.

A fim de estabelecer o perfil funcional da comunicação de crianças do espectro autístico, Fernandes (1996) analisou o número de atos comunicativos, bem como quais os meios e funções comunicativas mais utilizadas, e qual 0 espaço comunicativo utilizado pela criança. Foram estabelecidas 20 categorias funcionais: pedido de objeto, pedido de ação, pedido de rotina social, pedido de consentimento, pedido de informação, protesto, reconhecimento do outro, exibição, comentário, auto-regulatória, nomeação, performativa, exclamativa, reativos, não-focalizados, jogo, exploratório, narrativa, expressão de protesto, jogo compartilhado.

Fernandes e Galinari (1999) propõem uma divisão dessas 20 categorias propostas por Fernandes (1996), em mais e menos interpessoais sendo elas: 
Funções mais interpessoais:

- Pedido de objeto (PO): atos ou emissões usados para solicitar um objeto concreto desejável.

- Pedido de ação (PA): atos ou emissões para solicitar ao outro que execute uma ação, incluindo pedidos de ajuda e ações que envolvem outra pessoa ou outra pessoa e um objeto.

- Pedido de rotina (PS): atos ou emissões usados para solicitar ao outro que inicie ou continue um jogo de interação social. É um tipo específico de pedido de ação que envolve uma interação.

- Pedido de consentimento (PC): atos ou emissões usadas para pedir o consentimento do outro para a realização de uma ação.

- Pedido de informação (PI): atos ou emissões usados para solicitar informações sobre um objeto ou evento. Inclui questões "wh" e outras emissões com contorno entoacional de interrogação.

- Protesto (PR): atos ou emissões usados para interromper uma ação indesejada. Inclui oposição de resistência à ação do outro e rejeição de objeto oferecido.

- Reconhecimento do outro (RO): atos ou emissões usados para obter a atenção do outro e para indicar o reconhecimento de sua presença. Incluem cumprimentos, chamados, marcadores de polidez e de tema. 
- Exibição (E): atos usados para atrair a atenção para si. A performance inicial pode ser acidental e a criança pode repeti-la quando percebe que isso atrai a atenção do outro.

- Comentário (C): atos ou emissões usados para dirigir a atenção do outro ou evento. Inclui apontar, descrever, informar e nomear de forma interativa.

- Nomeação (N): atos ou emissões usados para focalizar sua própria atenção em um objeto ou evento por meio da identificação do referente.

- Exclamativo (EX): atos ou emissões que expressem reação emocional a um evento ou situação. Inclui expressões de surpresa, prazer, frustração e descontentamento, sendo imediatamente posteriores a um evento significativo.

- Narrativa (NA): emissões destinadas a relatar fatos reais ou imaginários, e pode haver ou não atenção por parte do ouvinte.

- Jogo compartilhado (JC): atividade organizada e compartilhada entre adulto e criança. 
Funções menos interpessoais:

- Performativo (PE): atos ou emissões usados em esquemas de ação familiares aplicados a objetos. Inclui efeitos sonoros e vocalizações ritualizadas produzidas em sincronia com o comportamento motor da criança.

- Auto-regulatório (AR): emissões usadas para controlar verbalmente sua própria ação. As emissões precedem ou ocorrem ao mesmo tempo em que o comportamento motor.

- Reativos (RE): emissões produzidas enquanto a pessoa examina ou interage com um objeto ou com parte do corpo. Não há evidência de intenção comunicativa, mas o sujeito está focalizando sua atenção em um objeto/ parte do corpo e parece estar reagindo a isso.Pode servir a funções de treino ou auto-estimulação.

- Não-focalizada (NF): emissões produzidas, embora o sujeito não esteja focalizando sua atenção em nenhum objeto ou pessoa, Não há evidência de intenção comunicativa, mas pode servir a funções de treino ou auto-estimulação.

- Jogo (J): atos envolvendo atividade organizada, mas autocentrada. Inclui reações circulares primárias, podendo servir a funções de treino ou auto-estimulação. 
- Exploratória (XP): atos envolvendo atividades de investigação de um objeto particular ou de uma parte de corpo ou da vestimenta do outro.

- Expressão de protesto (EP): choro, manha, birra ou outra manifestação de protesto não necessariamente dirigida a objeto, evento ou pessoa.

Diversos estudos (Molini-Avejonas, 2004; Fernandes et al., 2006; Cardoso, 2006; Sousa-Morato e Fernandes, 2006a; Sousa-Morato e Fernandes, 2006b) foram realizados utilizando as idéias propostas por Fernandes (1996) e Fernandes e Galinari (1999) demonstrando ser este um instrumento útil e sensível para a obtenção de dados do perfil funcional da comunicação.

Fernandes e Teles (2005) relataram, ao verificar a contribuição da avaliação do perfil funcional da comunicação para a determinação de características de comunicação específicas de 58 crianças do espectro autístico e de 60 crianças com outros distúrbios psiquiátricos, que as variáveis estudadas, quando utilizadas para analisar grupos de sujeitos, não indicam a ocorrência de agrupamentos significativos associados aos diferentes diagnósticos. 
Cardoso (2001) afirma que o desenvolvimento do perfil comunicativo de crianças do espectro autístico pode acontecer de diferentes maneiras, considerando os meios comunicativos utilizados e as diferenças contextuais que podem influenciar diretamente na efetividade da comunicação.

Cardoso e Fernandes (2003) relatam, em um de seus estudos, que crianças do espectro autístico, comparadas em três diferentes situações contextuais, durante 12 meses, apresentaram, ao final deste período, acréscimo nas funções interpessoais e decréscimo nas funções não-interpessoais, em todas as situações, demonstrando que essas crianças são capazes de adquirir e desenvolver habilidades comunicativas.

Cardoso (2006) conclui que existem diferenças na ocupação do espaço comunicativo, em função de diferentes contextos e interlocutores, sendo os interlocutores capazes de utilizar, de diferentes modos, os meios comunicativos e de considerar e estabelecer um padrão comunicativo de acordo com o contexto.

Fernandes (2003) afirma que é difícil obter uma linearidade dos progressos obtidos nas áreas do perfil funcional da comunicação e do desempenho sóciocognitivo, sendo necessária a busca de estudos individualizados, que poderiam trazer dados importantes para a reavaliação dos critérios terapêuticos utilizados. 
Fernandes et al. (2006), avaliando 58 crianças do espectro autístico quanto ao perfil funcional da comunicação, não encontraram diferenças estatisticamente significantes em relação às áreas de espaço comunicativo ocupado, meio comunicativo preferencial, número de atos comunicativos por minuto, nem quanto à interatividade da comunicação, reiterando a necessidade de estudos individualizados nesta população.

Amato (2006) traçou correlações entre o perfil funcional da comunicação e o desempenho sócio-cognitivo de crianças normais de zero a seis meses e de autistas, concluindo que existem diferenças entre os grupos quanto às formas de correlacionar a linguagem com as habilidades cognitivas e sociais. Neste estudo, a autora demonstrou claramente a inter-relação entre as áreas de linguagem e desempenho sócio-cognitivo, que são tão importantes para a caracterização dos distúrbios do espectro autístico. 


\section{3- Cognição, desempenho sócio-cognitivo e o espectro autístico}

Bates (1979), em seus estudos, relata a existência de uma capacidade humana simbólica que evolui com a construção de novas habilidades, em função da emergência e do grau de desenvolvimento de habilidades co-existentes, resultando no processo de heterocronia. Por meio deste processo, áreas específicas e independentes como a cognição e a socialização desenvolvem-se em função de habilidades não-lingüísticas, gerando diferentes e novas interações entre os elementos destas áreas, criando uma nova capacidade simbólica. Entretanto, podem ocorrer alterações de desenvolvimento nas habilidades especificamente destinadas para a capacidade simbólica, resultando em déficits ou dificuldades na aquisição e desenvolvimento da linguagem.

Sinclair (1975), com base em teorias piagetianas, considerando a linguagem uma criação especificamente humana possibilitada pela capacidade cognitiva, ressalta a importância das estruturas cognitivas, a fim de organizar a experiência de modo que permita ao homem produzir novidades.

Wetherby e Prutting (1984) afirmam que o desenvolvimento sensório-motor específico pode ser pré-requisito para a comunicação intencional e que a compreensão de causalidade seria importante para o desenvolvimento da comunicação. 
Segundo Wetherby e Gaines (1982), no desenvolvimento de crianças típicas, as habilidades cognitivas e lingüísticas surgem em uma seqüência ordenada, considerando os níveis sensório-motores como indispensáveis para a ativação da linguagem, sugerindo assim uma complexa correlação entre cognição e linguagem. Entretanto em crianças autistas, as autoras sugerem que a interdependência entre linguagem e cognição é variável durante o processo de desenvolvimento, sendo necessário um determinado nível de desenvolvimento sensório-motor para o estabelecimento de uma comunicação intencional.

No desenvolvimento normal as interações iniciais com seus pares focam-se no jogo, começando com simples imitações das ações direcionando-se a incorporar o jogo simbólico e atividades representativas. (Tager-Flusberg, 1999).

Rutter $(1981,1983,1987)$ afirma que são vários os conceitos de cognição; entretanto a idéia de que crianças autistas apresentam um déficit cognitivo básico envolve muito mais do que assumir a correlação entre cognição e socialização. No autismo existe uma gama de alterações comportamentais em que a linguagem está intimamente relacionada às habilidades sociais e aos comportamentos repetitivos que refletem em alterações cognitivas. Ao comparar autistas verbais com não-verbais, o autor observou que os sujeitos não-verbais apresentaram maior prejuízo que os verbais no uso funcional dos objetos e do próprio corpo e nas habilidades sociais; em suma, em comportamentos que envolvem a cognição. 
Tager-Flusberg (1999) afirma que, de acordo com teóricos cognitivistas, um déficit que explicaria uma gama de desordens nos domínios sociais, do brincar (considerado uma terceira dimensão, separado da interação social e da comunicação) e da comunicação, seria na habilidade de meta-representação.

As questões de meta-representação referem-se à habilidade de atribuir estados mentais, como desejos, conhecimento, crenças, como um meio de explicar comportamentos. Esta habilidade surge por volta do fim do primeiro ano, quando a criança percebe as pessoas de forma intencional, ou direciona objetivos em seu comportamento. Com três anos a criança compreende desejos e simples emoções em si mesma e nos outros, e pode falar sobre as ações da pessoa em relação aos estados mentais que as causaram. Por volta dos quatro anos, a criança compreende estados mentais mais complexos especificamente crenças, incluindo a noção que as pessoas podem apresentar crenças que conflitam com a realidade. Toda esta noção permite à criança compreender que a realidade pode ser representada de forma abstrata (Tager-Flusber, 1999).

Tager-Flusberg (2000) afirma que se podem fazer correlações entre as alterações comunicativas de crianças do espectro autístico e as questões de meta-representação, uma vez que as habilidades de engajamento social, solicitação de objetos e ações e o compartilhamento de experiências são o resultado da relação íntima entre as habilidades de comunicação e as de cognição social. 
Joseph et al. (2002) relatam, quanto ao desempenho sócio-cognitivo, em uma comparação de dois grupos de crianças autistas (um grupo com média de 5,5 anos e outro com média de 8,11 anos) que autistas do grupo de média de idade mais nova apresentaram piores resultados em habilidades verbais que autistas do grupo mais velho; mas em situação não-verbal os dois grupos apresentaram semelhanças, corroborando a idéia de que as discrepâncias entre as habilidades não-verbais e verbais vão diminuindo com a idade.

Blanc et al. (2005) estudaram a relação entre o jogo simbólico e o desenvolvimento da comunicação em crianças com autismo, considerando que estas crianças apresentam pobres habilidades de representação mental, as quais são a base do jogo simbólico e do desenvolvimento da comunicação. Comparando 21 crianças com autismo com 14 crianças com déficits intelectuais globais e 15 crianças típicas, observou-se que a regulação do jogo foi desordenada para crianças com autismo, com quebras comunicativas, dissociação e instabilidade das ações. Entretanto, no jogo dirigido suas ações foram mais estruturadas e corresponderam a uma melhora no nível de desenvolvimento.Os autores ressaltam neste estudo a importância do papel do jogo simbólico em diagnósticos diferenciais e em atividades terapêuticas baseadas na regulação de processos e no jogo simbólico. 
Wetherby e Prutting (1984) investigando o perfil das habilidades comunicativas e sócio-cognitivas, compararam um pequeno grupo de crianças autistas em estágios pré-lingüísticos da linguagem, com crianças normais em estágios semelhantes de desenvolvimento da linguagem. Os resultados demonstraram que o grupo autista apresentou um desenvolvimento diferente nas áreas sócio-cognitivas de intenção comunicativa, imitação, jogo e compreensão da linguagem.

Em um estudo com 60 crianças do espectro autístico, Molini (1997) observou que o desempenho sócio-cognitivo abaixo do esperado, apresentado por alguns sujeitos, era conseqüência da interferência do contexto, neste caso, da espontaneidade da situação terapêutica, demonstrando a necessidade de procedimentos mais específicos para a investigação de alguns aspectos como a imitação vocal e gestual. Neste mesmo estudo (Molini, op.cit.) a autora relata que esta população apresenta intenção comunicativa, ressaltando a necessidade da inclusão deste dado na prática fonoaudiológica.

Segundo as idéias de Wetherby e Prutting (1984) quanto à intenção comunicativa gestual e vocal, ao uso do objeto mediador, à imitação vocal e gestual, ao jogo combinatório e ao jogo simbólico, Molini (2001) propõe um estudo e um modelo de investigação destas habilidades sócio-cognitivas, relacionando a cognição e os aspectos sociais. A autora conclui em seus estudos que a criança autista pode apresentar habilidades sócio-cognitivas quando está sendo testada, mas muitas vezes não as utiliza em situação espontânea, demonstrando uma inabilidade em aplicar seus conhecimentos no seu cotidiano. Observou, ainda, 
que existem diferenças de desempenho sócio-cognitivo entre os subtipos do espectro autístico, sendo necessário considerar as variações.

Em outro estudo, Molini e Fernandes (2003), afirmam que existe um ponto de inabilidade sócio-cognitiva por parte das crianças do espectro autístico, sendo que estas crianças muitas vezes são capazes de compreender como o mundo funciona, mas falham em compartilhar com os outros seus conhecimentos.

Molini-Avejonas (2004) estabelece a relação do perfil comunicativo de crianças normais, com síndrome de Down e autismo, em função do desempenho sócio-cognitivo, e observou que as crianças com autismo apresentam um desempenho muito inferior em relação aos outros grupos correlacionados, comprovando mais uma vez que essas crianças apresentam inabilidades, ou seja, muitas vezes elas possuem as habilidades, mas não sabem quando e como utilizá-las funcionalmente.

Bieberich e Morgan (2004) afirmam que uma das disfunções básicas que podem distinguir crianças com autismo de crianças com outras desordens do desenvolvimento envolvem os domínios cognitivos. Um grande número de hipóteses tem sido direcionado para a questão de quais déficits cognitivos seriam específicos do autismo, sendo propostas alterações na auto-regulação, especialmente na modulação de atenção ou funções executivas, as quais seriam necessárias para apreender e participar de situações cotidianas sociais e nãosociais. 
Algumas pesquisas encontraram que a falha em realizar contato com os outros, por parte de indivíduos com autismo é devido à falha em compreender esses eventos e não a uma insensibilidade ou aversão ao outro. Outros estudos demonstram que crianças autistas não são necessariamente deficientes em perceber as expressões faciais, mas demonstram déficits em habilidades sóciocognitivas que as ajudariam a determinar a sincronia e o uso adequado de cada expressão (Bieberich e Morgan, 2004).

Hale e Tager-Flusberg (2005a) e Meyer et al. (2006) afirmam que déficits sócio-cognitivos têm sido teoricamente ligados a déficits nas habilidades sóciocomunicativas, uma vez que estas crianças apresentam dificuldades em compreender que a linguagem pode ser um meio para se comunicar e interagir com os outros, e em entender que a comunicação faz-se por meio da expressão e da interpretação de significado intencional. 


\section{4-Socialização:}

\subsection{1-Desenvolvimento social: relações entre a normalidade e o espectro autístico}

Gutstein (2000) propõe uma escala de adaptação sócio-comunicativa buscando analisar o processo de desenvolvimento social de crianças autistas, sendo esta escala dividida em quatro níveis. O primeiro nível desta escala foi denominado de "principiante" em que se observa a habilidade da criança em compartilhar experiências com ações face a face com seus pais, em especial a mãe, passando pelas etapas de referência social, a utilização de expressões nãoverbais do parceiro como referência crítica para suas ações; a capacidade de aprender ações através de imitações e modelos, coordenando com o parceiro, ações simples, das quais os dois possam desfrutar mutuamente.

No primeiro nível, de forma geral, busca-se observar as habilidades de orientação social e o aprendizado do uso de outras pessoas como o primeiro referencial da criança. Já no segundo nível, a criança é considerada um "aprendiz", sendo esta capaz de aprender a gostar de variações e novidades, conseguir se adaptar a mudanças, a utilizar a referência e a regulação para funcionar coordenadamente, preocupando-se com os outros, buscando identificar e realizar mudanças para um maior aproveitamento, ou seja, co-regular e coordenar ações como parceiro de ações (Gutstein, 2000).

No terceiro nível o autor (Gutstein, op.cit) considera a criança como um "desafiante", pois ela faz uso da colaboração, da co-criação, da improvisação e de 
percepções compartilhadas, sendo capaz de balancear a co-regulação com a covariação na cooperação em atividades de co-criação, descobrir sua criatividade e imaginação, aprendendo a desfrutar como um igual ao parceiro, praticar improvisos coordenados, bem como experenciar e dividir emoções e percepções com seus parceiros, em resumo, compartilhar experiências com seus pares, em que esta pode co-criar e improvisar pela criatividade usando diferentes estímulos como a música, movimentos corporais, elementos do jogo simbólico.

No quarto nível a criança é vista como um "desbravador", uma vez que é capaz de compreender diferentes perspectivas, compartilhar imaginações e idéias, sendo capaz de estabelecer relações de amizade, começando a valorizar o ponto de vista do outro, a compartilhar imaginações, a misturar e integrar idéias e ter amigos que dividem interesses e experiências em comum; em síntese, a criança compreende a importância do grupo e de ser parte do grupo (Gutstein, 2000).

Gutstein (2000) afirma que crianças que já passaram do nível de coordenação social, ou seja, capazes de sincronizar ações simples para aproveitamento mútuo, poderão apresentar desempenho social mais interativo, sendo possível explorar e participar de atividades que requerem variação, adaptação, sincronização e aceitação do outro como agente de participação, colaboração e co-criação. 
A escala de adaptação sócio-comunicativa proposta por Gutstein (2000) foi testada em um estudo-piloto realizado pela pesquisadora (Sousa et al., 2003) com 30 crianças normais, sendo possível observar que o processo de desenvolvimento e adaptação social na normalidade passa por diversas etapas, em que a criança deve adquirir habilidades para adaptar-se, apresentar imaginação e criatividade, desejos por novidades e experiências, bem como valorizar outras perspectivas e opiniões, além de construir uma consciência a respeito do outro e de si mesma.

Em outros estudos (Sousa, 2004; Sousa et al., 2005; Gerbelli et al., 2006) a pesquisadora aplicou o protocolo de avaliação da adaptação sócio-comunicativa, em crianças com desenvolvimento típico de zero a seis anos de idade, além de 65 crianças do espectro autístico, sendo que em todas as situações este protocolo mostrou-se um instrumento sensível e útil na identificação de variações individuais das habilidades sociais, possibilitando a caracterização do desenvolvimento social dessas crianças, bem como a adequação de procedimentos clínicos e de orientação aos pais.

Bono et al. (2004) relatam que algumas teorias sugerem que as habilidades de orientação social são pré-requisito para o desenvolvimento da linguagem, e este desenvolvimento depende da qualidade da estrutura do mundo social e da capacidade da criança em se ajustar a ele e participar proximamente do meio. As habilidades de orientação social ajudam a criança a organizar a informação perceptual e a desenvolver habilidades de linguagem como um produto direto de uma compreensão de pistas referenciais por meio de tentativas de iniciar, manter, 
ou aumentar a participação em interações espontâneas diárias que fornecem uma vasta disposição de aprender oportunidades sociais.

Segundo Leekam e Ramsden (2006) um dos mais perceptíveis indicadores precoces para o diagnóstico de autismo é a falha na habilidade de orientação social, como as alterações nas habilidades de atenção compartilhada. Os autores observaram que crianças com autismo apresentaram dificuldades especificamente em relação à orientação para o estímulo social, comparado com estímulos não-sociais, sugerindo que alguns aspectos da interação social (p.ex: chamar pelo nome) estão especificamente alterados nestas crianças, sendo estes achados também comprovados por outros autores (Dawson et al., 2004; Klin, 2006).

Entretanto, Sousa et al. (2006), ao verificar a presença e a especificidade dos déficits de orientação social para estímulos auditivos no espectro autístico, por meio de estímulos sociais e não-sociais, observaram que, embora os resultados não evidenciassem diferenças estatisticamente significativas, foram observadas respostas com uma freqüência ligeiramente maior aos estímulos sociais em relação aos não-sociais, o que poderia ser explicado por uma possível interferência da descontextualização dos estímulos durante a situação de pesquisa, ou até mesmo pela familiaridade do avaliador. 
Baron-Cohen et al. (2000) afirmam que pais de crianças com autismo freqüentemente relatam que a primeira suspeita que a sua criança não está se desenvolvendo normalmente acontece por volta dos dezoito meses de idade, uma vez que certos comportamentos presentes no desenvolvimento normal estão ausentes ou limitados na criança com autismo. Dois destes comportamentos são, a atenção compartilhada, que se refere à habilidade de estabelecer e compartilhar um foco de atenção com outra pessoa por meio do apontar, mostrar ou monitoramento do olhar, habilidade esta que permite a criança aprender pelos outros (referência social), e o jogo simbólico, que envolve a atribuição de estratégias imaginárias, pessoas, objetos, eventos.

Indivíduos com autismo freqüentemente exibem déficits na iniciativa e na interação social, bem como na responsividade social - estímulo discriminativo do comportamento social -, e na verbalização espontânea; conseqüentemente eles não recebem a quantidade ou a qualidade da atenção dos outros indivíduos sem o distúrbio (McDonald e Hemmes, 2003).

Tager-Flusberg (1999) afirma que crianças autistas não evitam completamente as pessoas, elas falham em demonstrar interesse social ou afeição, especialmente, em relação a familiares próximos. Comportamentos sociais e de interação não estão ausentes no autismo, mas eles podem ser impressionantemente desviantes. Um dos fatores importantes na interpretação do comportamento social é o papel da familiaridade, rotinas e estruturação da participação desta criança em atividades sociais. Rotinas e atividades estruturadas reduzem a complexidade e a imprevisibilidade do mundo social, o 
que pode ser de extrema importância para crianças que não compreendem as razões mentais para as ações das pessoas.

A autora afirma (Tager-Flusberg, op. cit.) que, em contextos familiares e estruturados, crianças autistas são mais interessadas e responsivas à aproximação das pessoas, apresentando iniciativas comunicativas e ações de cooperação. Algumas habilidades sociais, como a troca de turno, tornam-se presentes no contexto de jogos ou outras atividades estruturadas, uma vez que esta habilidade não depende, de forma direta, das habilidades de metarepresentação.

Com o desenvolvimento das habilidades de meta-representação, a criança troca experiências com os outros, experimentando vários papéis. Esta habilidade de compreender as emoções e ações dos outros começa desde o primeiro olhar. Entretanto, esta habilidade muitas vezes não se desenvolve em todas as crianças, como acontece nas crianças autistas, sendo este um dos fatores cruciais para o comprometimento social no autismo (Bosa, 2002).

Dificuldades de meta-representação podem ser um dos pontos centrais na forma como os déficits sociais são interpretados no autismo, uma vez que o desenvolvimento social humano depende da compreensão intencional das pessoas com as quais interagimos. Sendo assim, para crianças autistas, o mundo social torna-se complexo devido à dificuldade de entender as razões das ações das pessoas, as quais podem ser altamente previsíveis, ou não (Tager-Flusberg, 1999). 


\subsection{2-Desenvolvimento social no espectro autístico e suas relações} com a linguagem e com o desempenho sócio-cognitivo:

Buitelaar (1991), em um estudo comparativo entre crianças autistas e crianças com deficiência mental, observou que as crianças autistas apresentaram comportamentos caracterizados por déficits comunicativos, sociais e pragmáticos, como alterações na reciprocidade visual, na atenção compartilhada, na coordenação funcional e na integração do olhar e dos mecanismos gestuais; conseqüentemente, estes dados refletem a influência de fatores sociais nos aspectos cognitivos e lingüísticos.

Palermo et al. (2006) afirmam que a socialização requer habilidades de comunicação efetivas, incluindo comunicação não-verbal e a compreensão das expressões faciais é um ingrediente fundamental no comportamento social. Alterações nestes aspectos têm conseqüências óbvias na arena social, o que ocorre com crianças com distúrbios do espectro autístico, as quais são inábeis em compreender e usar apropriadamente informações sociais relevantes, obtidas das faces dos outros. 
Crianças com autismo freqüentemente apresentam profundos déficits nas habilidades de troca social, como a atenção conjunta ou o jogo social imitativo, além de déficits na imitação simples de atos motores, sendo que estas falhas nas habilidades sociais não somente impedem uma interação recíproca, mas também podem retardar o desenvolvimento do comportamento sócio-comunicativo e ampliar o desnível entre estas crianças e seus pares (Hwang e Hughes, 2000).

Entretanto, são evidentes em crianças com autismo os déficits na imitação espontânea, que é uma das primeiras formas de interação, e é uma das rotas primárias para o desenvolvimento das habilidades de meta-representação, sugerindo-se então, uma conexão entre as alterações meta-representacionais e os déficits sociais no autismo (Tager-Flusberg,1999).

Segundo Carpenter e Tomasello (2001), seriam possíveis causas para o surgimento de dificuldades comunicativas e sociais das crianças com autismo, a ausência das primeiras habilidades lingüísticas e pré-lingüísticas, bem como das habilidades de orientação social, como a atenção compartilhada, de imitação de ações dos outros e até mesmo a dificuldade em se colocar no lugar do outro de forma abstrata, considerando suas intenção e desejos. 
Existem diferenças individuais no uso das habilidades de atenção compartilhada que são associadas com os resultados da linguagem. $O$ desenvolvimento das habilidades de atenção conjunta é associado a mudanças na linguagem receptiva e expressiva, bem como a apresentação de níveis de linguagem mais elaborados; ou seja, crianças que respondem com maior freqüência a oportunidades de atenção compartilhada apresentam maiores ganhos nas habilidades de linguagem (Bono et al., 2004).

De acordo com Konstantareas e Stewart (2006), considerando que, se a interação com os outros é um pré-requisito para desenvolver as habilidades de regulação do afeto, crianças com desordens do espectro autístico apresentariam, então, uma particular desvantagem devido às suas dificuldades de interação social.

Segundo Sperry e Mesibov (2005), assim como as outras áreas que estão alteradas nos distúrbios do espectro autístico, os déficits sociais são características bem marcadas, uma vez que estes déficits podem se tornar barreiras para relacionamentos interpessoais, levando a sentimentos de solidão e rejeição. Muitos indivíduos com distúrbios do espectro autístico apresentam o desejo de participar de trocas sociais, fazer amizades profundas, entretanto, a falta de fluência em participar deste mundo social pode dificultar a efetivação deste desejo, mas, mesmo assim, alguns são capazes de vencer estas barreiras. 
Macintosh e Dissanayake (2006) afirmam que, apesar de crianças com autismo de alto-funcionamento ou com síndrome de Asperger serem socialmente isoladas, freqüentemente, em relação a seus pares em desenvolvimento típico, elas são capazes de se entrosar socialmente de forma espontânea com outras crianças.

Muitos estudiosos (Beyer, Gammeltoft, 2000; Howlin, 1986; Lord, 1984; Lord, Magill, 1989; Wolfberg, 1999; Loveland et al., 2001), relatam que crianças e adolescentes com desordens do espectro autístico freqüentemente comportam-se inapropriadamente quando interagem e se comunicam com os outros, provavelmente devido a falhas de meta-representação e, em especial, a dificuldades e desvios no desenvolvimento do jogo social.

Jordan (2003) sugere a definição de jogo como a presença de prazer e diversão, atividades que buscam o contato social, ausência de objetivos impostos por fatores externos, presença de espontaneidade e motivação. Observa-se o envolvimento de parceiros em atividades e a existência de certas relações sistemáticas para o que é jogo, o que pode ser contrastado com o não-jogo. Há uma gama de comportamentos de jogo, sendo que estes não podem ser classificados sem considerar o contexto em que ocorrem. Entretanto, pouco se discute a importância vital do jogo social no desenvolvimento normal da criança. Ainda há muitas controvérsias sobre quais aspectos do jogo seriam vitais e que elementos deste poderiam ser caracterizados como tal. $\mathrm{O}$ jogo social tem um papel chave na identificação e no diagnóstico de desordens do espectro autístico (DEA), identificado também sozinho ou como confluência de jogos e déficits sociais identificados separadamente. 
São identificados três aspectos criticamente afetados no jogo social de crianças com distúrbios do espectro autístico, os quais seriam os processos sociais com as habilidades de compreender e compartilhar atenção, a regulação emocional e a competência social. Observa-se também a complexidade do jogo cognitivo, com a dificuldade de substituir interações mais longas e complexas, além de alterações no status social. Apesar de serem notadas dificuldades no jogo simbólico de crianças autistas, pode-se observar que crianças com autismo são capazes de participar de jogos simbólicos em situações estruturadas (White, 2002).

Van Berckelaer-Onnes (2003) afirma que as primeiras formas de jogo em crianças com autismo envolvem a exploração dos objetos com ações repetitivas e limitadas; entretanto é inquestionável a importância das primeiras manipulações e suas relações para o desenvolvimento das percepções representacionais significantes e para o desenvolvimento subseqüente do jogo simbólico e funcional.

Kok et al. (2002) compararam o efeito do jogo estruturado (caracterizado pelo uso massivo da prática frente à instrução de um guia) e do jogo facilitado (incorporação incidental por meio de múltiplos exemplos) na promoção da espontaneidade e da responsividade na comunicação e nos comportamentos de jogo em oito crianças com autismo. Ganhos na apropriação da comunicação e no jogo em ambas as formas de jogo foram observados pelos autores, entretanto respostas aos atos comunicativos foram observadas mais freqüentemente em todos os participantes durante a situação de jogo estruturado. 
Segundo Dominguez et al. (2006) a interação social, a comunicação e a imaginação são elementos chave no jogo das crianças, e são estes os déficits básicos do autismo. Sendo assim, o jogo poderia fornecer um poderoso meio potencial de avaliação e tratamento para crianças com distúrbios autísticos.

Considerando alguns aspectos do desenvolvimento social, propostos na escala sócio-comunicativa de Gutstein (2000) - como interação face a face, imitação colaboração e auto-regulação- estudos que tratam da relação entre o desenvolvimento social, a linguagem e o desempenho sócio-cognitivo estão apresentados a seguir.

Kylliäinen e Hietanen (2006) relatam que os efeitos da busca do contato visual foram investigados em 20 crianças com autismo e em 12 crianças típicas como grupo controle, sendo as respostas medidas pelos comportamentos faciais. Foram apresentados estímulos faciais com contato visual direto e desviado em um monitor de computador. Em crianças autistas as respostas para o contato visual direto foram mais fortes que as respostas para o contato visual desviado; entretanto em crianças com desenvolvimento típico não foram observadas diferenças significativas nas duas condições. Os resultados ressaltam que o despertar do contato visual pode contribuir para os comportamentos anormais de troca comunicativa face a face freqüentemente relatadas no contexto do autismo. 
Hale e Tager-Flusberg (2005b), analisando as habilidades de participação em atividades sócio-comunicativas de crianças do espectro autístico com seus pais em situações terapêuticas, observaram um ganho significante na habilidade de manter o tópico do discurso, demonstrando ainda que estas crianças apresentaram um aumento progressivo em aspectos críticos da adaptação sóciocomunicativa. Esta efetividade sócio-comunicativa pode ser explicada pelas diferenças individuais nas habilidades de discurso, e a sensibilidade do interlocutor em sincronizar seus comportamentos às atividades destas.

Receuveur et al. (2005) investigaram a influência do nível de desenvolvimento na interação e na imitação de dezoito crianças com autismo, divididas em dois grupos de acordo com o quociente de desenvolvimento (QD), com base em vídeos familiares e consultas filmadas, demonstrando que, em idades muito precoces, crianças diagnosticas tardiamente com distúrbio autístico demonstraram diferentes intensidades nos déficits de interação e imitação, de acordo com o nível de desenvolvimento.

Crianças com autismo exibem déficits significativos nas habilidades de imitação que podem impedir a aquisição de comportamentos mais complexos e as habilidades de socialização. Em um estudo com cinco crianças autistas, a fim de observar alterações na imitação em um processo de intervenção terapêutica, Ingersoll e Schreibman (2006) observaram que estas aumentaram as habilidades de imitação, sendo capazes de generalizá-las para novas situações, além de apresentarem ganhos em comportamentos sócio-comunicativos, incluindo linguagem, jogo simbólico e atenção compartilhada. 
Downs e Smith (2004) relatam que, em contraste com o desenvolvimento típico da criança, crianças com autismo raramente exibem comportamentos de cooperação social. Com o objetivo de examinar como esta alteração reflete no desenvolvimento global de dez crianças com autismo, comparadas com 16 crianças com déficit de atenção e hiperatividade (TDAH) e dez crianças típicas, foi observado, quanto ao comportamento cooperativo, nível de compreensão emocional e comportamento de afastamento, que as crianças autistas apresentaram uma performance além das crianças com TDAH, mas não diferiram de forma significante das crianças típicas. Entretanto, os autores (Downs e Smith, op cit.) observaram que o grupo com autismo apresentou resultados piores quanto ao reconhecimento emocional, bem como um número maior de comportamentos de afastamento que os demais grupos. Os resultados indicam que crianças com autismo de alto-funcionamento podem desenvolver comportamentos sociais de cooperação e habilidades avançadas de metarepresentação, mas continuam apresentando déficits na identificação de emoções e na apresentação apropriada dos comportamentos sociais.

Bieberich e Morgan (2004) examinaram a estabilidade da auto-regulação e expressão afetiva em crianças com autismo e crianças com síndrome de Down, por um período de dois anos. Os dados característicos de cada grupo foram semelhantes do primeiro momento para o segundo, sendo que o grupo dos autistas apresentou resultados mais desviantes quanto à auto-regulação e a troca de afeto. As autoras observaram ainda que, no mesmo intervalo de tempo, as crianças com autismo demonstraram um relativo aumento na estabilidade do fator 
auto-regulação, entretanto, este foi menor que o apresentado pelas crianças com Síndrome de Down para os fatores de auto-regulação, troca de afeto positiva e negativa.

Amato (2006) conclui em seu estudo que crianças normais e crianças autistas realizam formas diferentes de correlacionar linguagem, cognição e socialização, reforçando a importância do processo de heterocronia (Bates, 1979) ${ }^{1}$, o que poderia explicar a dificuldade do uso interativo da comunicação por parte das crianças autistas.

Sousa (2004) relata que a proposta de correlacionar a linguagem, a cognição e a socialização, três aspectos tão importantes no diagnóstico clínico dos distúrbios do espectro autístico, busca ressaltar a importância da hipótese de que a relação entre estes aspectos é estreita, mas envolve percursos individuais estabelecidos em cada criança. Ressalta a necessidade de estudos e da análise conjunta destes aspectos, pois isso possibilitaria enxergar o paciente como um todo, auxiliando na identificação e na intervenção dos distúrbios do espectro autístico.

\footnotetext{
1 Heterocronia: processo em que áreas específicas e independentes como a cognição e a socialização desenvolvem-se em função de habilidades não-lingüísticas, gerando diferentes e novas interações entre os elementos destas áreas, criando uma nova capacidade simbólica (Bates, 1979).
} 


\section{5- Identificação, intervenção e instrumentos investigativos nos distúrbios do espectro autístico:}

Embora haja inúmeras pesquisas quanto à identificação dos distúrbios do espectro autístico, apesar de possível, a detecção e a intervenção precoce ainda não são totalmente uma realidade, mesmo sabendo que o diagnóstico precoce interfere na possibilidade de intervenção e pode minimizar a intensidade dos déficits de interação e imitação de acordo com o nível de desenvolvimento sóciocomunicativo (Tafuri, 2002; Receuver et al., 2005; Golse, 2005).

Turner et al. (2006) afirmam que atualmente teorias sobre o desenvolvimento do autismo sugerem que a intervenção precoce pode atenuar as seqüelas negativas que resultam de déficits iniciais e que acabam interferindo tardiamente no funcionamento, considerando-a como um aspecto crítico no gerenciamento e no tratamento de crianças com autismo.

Apesar de existirem diferentes variáveis nestes processos de intervenção, como técnicas mais diretivas com a participação ou não dos pais em algumas estratégias, ou intervenções envolvendo o desenvolvimento das funções comunicativas e do jogo simbólico, deve-se primeiramente considerar a necessidade e a importância das áreas de linguagem, cognição e socialização na efetivação de um diagnóstico claro e objetivo (Bernard-Optiz et al., 2004). 
Os tratamentos de linguagem para crianças do espectro autístico podem cobrir uma gama de habilidades comunicativas, incluindo compreensão, produção, bem como a forma (fonologia, sintaxe, morfologia), o conteúdo (semântica), e o uso social da linguagem (pragmática). A comunicação apropriada depende do amplo uso das habilidades lingüísticas, sendo elas aplicadas coletivamente e adaptadas para interações com os outros (Goldstein, 2002).

Intervenções normalmente possibilitam à criança usar a comunicação para controlar, compreender, e participar no seu mundo social, sendo importante ter em mente que a maioria das crianças com autismo têm deficiências em uma variedade de domínios lingüísticos (Goldstein, 2002).

Verté et al. (2006), ao comparar o perfil pragmático de subtipos de distúrbios do espectro autístico, relatam que o mesmo tipo de tratamento pode ser utilizado para diferentes subtipos, como a síndrome de Asperger, o autismo de alto-funcionamento e os transtornos invasivos do desenvolvimento nãoespecificados.

Legoff e Sherman (2006) relatam que as intervenções para indivíduos com distúrbios do espectro autístico têm sido direcionadas principalmente aos déficits sociais, pois estudos comprovam que o aumento na competência social reflete no comportamento adaptativo. A competência social é claramente um importante aspecto no sentido de fornecer às crianças as habilidades necessárias para se adaptarem e funcionarem independentemente em suas comunidades. 
Alguns autores (p. ex: Bauminger, 2002; Gutstein, 2002; Gutstein e Whitney, 2002) sugerem programas de intervenção nas alterações das habilidades sócio-comunicativas de crianças do espectro autístico, a fim de que estas melhorem suas interações sociais com seus pares, desenvolvendo capacidades de se sentirem recompensados com as experiências e trocas sociais.

Analisando um grupo de 24 crianças com autismo durante um ano em um programa de intervenção por meio do jogo, Van Berckelaer-Onnes (2003) concluiu que a intervenção, de modo geral, apresentou resultado positivo, permitindo a essas crianças compreender melhor o mundo e os objetos, de forma geral, tornar a compreensão de informações incomuns mais coerentes e significativas, refletindo em melhora nos níveis cognitivos de representação simbólica. Entretanto, esses ganhos só eram mantidos se a criança continuasse a receber o suporte terapêutico.

Bernard-Optiz et al. (2004) relatam que há poucos estudos comparando as diferentes abordagens terapêuticas, além de existir relativamente pouca informação de efeitos a curto e a longo-prazo, ou a respeito de impactos diferenciais em crianças autistas com alto ou baixo-funcionamento. Entretanto, nestas comparações deve-se levar sempre em conta os diferentes níveis de linguagem e jogo, as experiências terapêuticas anteriores, planos terapêuticos específicos, bem como o grau de envolvimento dos pais neste processo. 
A consideração da perspectiva dos pais de crianças do espectro autístico quanto ao comportamento lingüístico, cognitivo e social de seus filhos vem sendo colocada em um lugar de destaque, uma vez que estes passam a ser parceiros dos profissionais envolvidos no processo de intervenção, ajudando no monitoramento do nível de desenvolvimento destas crianças (Luiselli et al., 2001; Charman et. al, 2004, Siperstein e Volkmark, 2004; Eaves et al., 2006).

Charman et al. (2004) afirmam que é possível coletar informações úteis do progresso de crianças do espectro autístico utilizando os pais como informantes. Dados obtidos por meio de questionários aplicados com pais tornam-se úteis no processo de avaliação e no planejamento terapêutico individual.

Moes e Frea (2002), com o objetivo de investigar o uso da informação do contexto familiar para direcionar a avaliação e o processo terapêutico, relataram o uso dessas informações em processos de avaliação e terapia não geram problemas, podendo contribuir para a estabilidade e durabilidade da redução de comportamentos desafiantes alcançados por meio de uma abordagem funcional da comunicação.

Sousa (2004) afirma que o uso de provas e testes específicos para avaliar crianças do espectro autístico, bem como considerar a perspectiva dos pais destas crianças são instrumentos de grande valia, pois permitem o acompanhamento da trajetória percorrida entre a aquisição, a realização e aprendizagem dos aspectos avaliados em relação a cada paciente, bem como a mudança de ótica dos pais em relação ao comportamento e desempenho de seus filhos. 
De acordo com Fernandes (2002), não há um padrão específico para se avaliar as alterações encontradas nos distúrbios do espectro autístico. A escolha dos procedimentos a serem utilizados, sejam eles instrumentos de avaliação específicos, como provas, testes e questionários, ou a observação dos aspectos lingüísticos, sociais e cognitivos em situação espontânea, traz de forma intrínseca suas vantagens e desvantagens. Mas por outro lado, garante a possibilidade desta escolha de procedimentos tornar-se um processo experimental, sempre baseado na tríade central de sintomas - linguagem, cognição e socialização - que caracteriza os distúrbios do espectro autístico.

Em relação à intervenção clínico-terapêutica, pode-se dizer que a análise subjetiva tem seu papel de destaque, mas deve-se considerar a possibilidade de análise de diferentes pontos de vista. Sendo assim, a busca de uma análise baseada em evidências, torna-se cada vez mais necessária, no sentido de padronizar e avaliar procedimentos válidos, no que diz respeito à detecção precoce, ao diagnóstico e às intervenções terapêuticas (Lima et al., 2000; Gray, 2004). 


\section{0-Estudol}

Adaptação sócío-comunicativa e Perfil Funcional da Comunicação de crianças do espectro autístico: dados obtidos com pais e terapeutas

\section{1- Hipótese:}

Os resultados referentes à adaptação sócio-comunicativa obtidos a partir das entrevistas com as terapeutas apresentarão maiores correlações com o perfil funcional da comunicação do que aqueles obtidos a partir de entrevistas com os familiares.

\section{2- Objetivos Específicos:}

- Verificar a efetividade da aplicação do protocolo de adaptação sóciocomunicativa a diferentes fontes de informação, neste caso; pais e terapeutas, na identificação de diferenças individuais em crianças com Distúrbios do Espectro Autístico (DEA).

- Verificar se há diferenças significativas entre os dados referentes ao perfil funcional da comunicação e os dados da adaptação sóciocomunicativa obtidos por meio de entrevistas individuais com os pais e com as terapeutas de crianças com Distúrbios do Espectro Autístico (DEA). 


\section{3- Método:}

Esta pesquisa foi encaminhada à comissão de ética da instituição e recebeu aprovação sob o protocolo no- 420/04, apresentado no anexo 1.

Foi solicitada a autorização para a utilização dos dados, para fins de pesquisa, ao adulto responsável e às terapeutas responsáveis pelo cuidado de um cada dos sujeitos (anexo 2) sendo critério de inclusão que todos os participantes desta pesquisa estivessem em atendimento semanal, no período mínimo de um ano, no Laboratório de Investigação Fonoaudiológica nos Distúrbios do Espectro Autístico do curso de Fonoaudiologia da Faculdade de Medicina da Universidade de São Paulo.

\subsection{1- Sujeitos:}

Participaram deste estudo 48 crianças, entre 3 anos e 0 meses e 11 anos e 10 meses de idade, com diagnóstico clínico incluído no espectro autístico, atribuído por médicos neurologistas e/ou psiquiatras segundo critérios específicos do DSM-IV (1995) ou da CID-10 (1993).

Foram também sujeitos deste trabalho, 46 mães e dois pais, responsáveis pelas 48 crianças acima citadas. Eles foram convidados a participar deste estudo respondendo a um questionário sobre o relacionamento social de seu (a) filho (a) que se encontra em atendimento fonoaudiológico no Laboratório de Investigação Fonoaudiológica nos Distúrbios do Espectro Autístico - FMUSP. 
Faz-se necessário lembrar, que não há critério de inclusão dos pais nesta pesquisa e que o nível sócio-econômico e educacional dos mesmos não foi uma variável considerada.

Participaram ainda deste estudo, 15 terapeutas, responsáveis pelo atendimento fonoaudiológico das 48 crianças, sujeitos deste estudo, por um período mínimo de aproximadamente doze meses. Neste período foram realizadas filmagens semestrais de sessões de terapia, para fins de avaliação da evolução terapêutica. Para este estudo as terapeutas também foram convidadas a responder ao mesmo questionário aplicado aos pais, quanto ao relacionamento social de seus pacientes. Apresenta-se no Quadro I.1 o número de pacientes designados a cada uma das 15 terapeutas participantes deste estudo, bem como sua situação acadêmica.

QUADRO I.1- CARACTERIZAÇÃO DA AMOSTRA DE TERAPEUTAS:

\begin{tabular}{|r|c|c|c|c|c|}
\hline Terapeutas & $\begin{array}{c}\text { Número de } \\
\text { pacientes }\end{array}$ & $\begin{array}{c}\text { Titulação } \\
\text { acadêmica }\end{array}$ & Terapeutas & $\begin{array}{c}\text { Número de } \\
\text { pacientes }\end{array}$ & $\begin{array}{c}\text { Titulação } \\
\text { acadêmica }\end{array}$ \\
\hline Terapeuta 1 & 2 & Mestranda & Terapeuta 9 & 3 & Especializanda \\
\hline Terapeuta 2 & 2 & Mestranda & Terapeuta 10 & 5 & Especializanda \\
\hline Terapeuta 3 & 1 & Mestranda & Terapeuta 11 & 2 & Graduanda \\
\hline Terapeuta 4 & 1 & Graduanda & Terapeuta 12 & 1 & Aprimoranda \\
\hline Terapeuta 5 & 11 & Aprimoranda & Terapeuta 13 & 1 & Doutoranda \\
\hline Terapeuta 6 & 13 & Aprimoranda & Terapeuta 14 & 1 & Graduanda \\
\hline Terapeuta 7 & 3 & Mestranda & Terapeuta 15 & 1 & Doutoranda \\
\hline Terapeuta 8 & 1 & Graduanda & & & \\
\hline
\end{tabular}


ESQUEMA I.1- DIVISÃO METODOLÓGICA DOS SUJEITOS DO ESTUDO I:

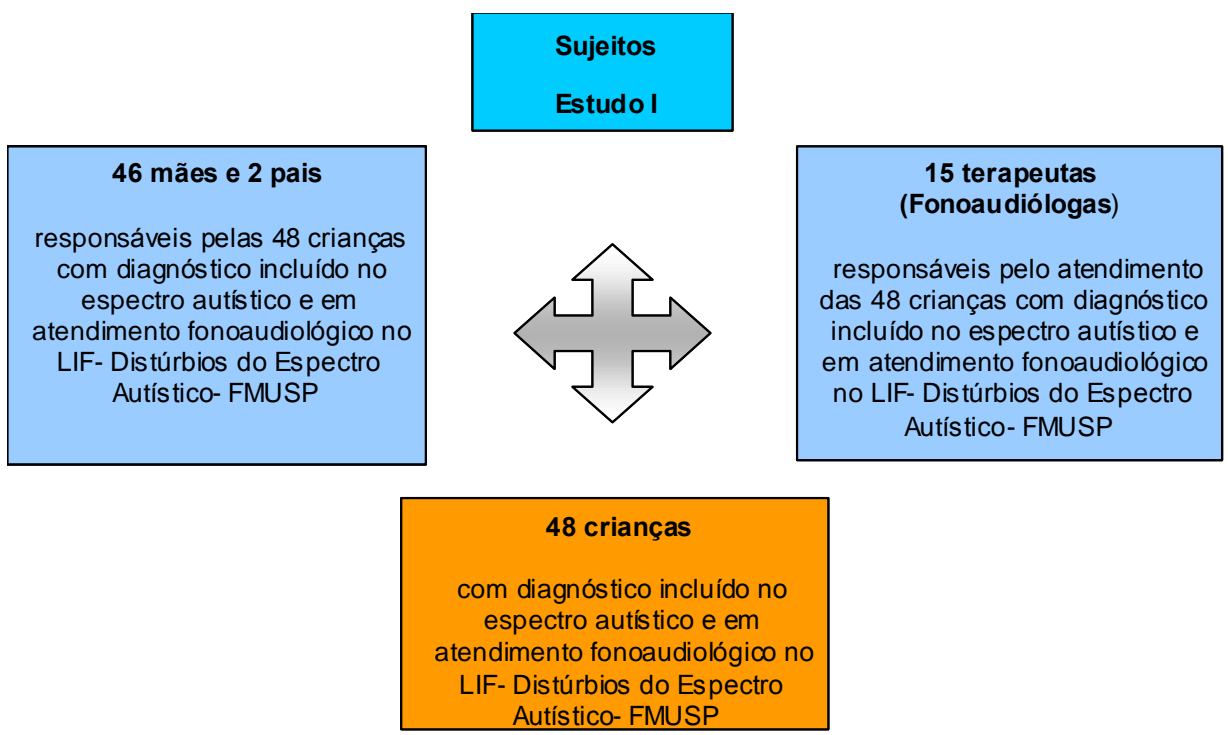

Quanto às 48 crianças, observa-se que houve variações quanto à idade média e ao tempo médio de intervenção terapêutica fonoaudiológica realizada no Laboratório de Investigação Fonoaudiológica nos Distúrbios do Espectro Autístico (LIF-DEA), em que estas crianças estão inseridas. Estão apresentados na Tabela I.1 os valores médios e o desvio padrão das referidas variáveis.

TABELA I.1- VALORES DE MÉDIA E DESVIO-PADRÃO DA IDADE E TEMPO DE INTERVENÇÃO FONOAUDIOLÓGICA NO LIF-DEA DOS SUJEITOS DO ESTUDO 1:

\begin{tabular}{lcc}
\hline Estatística & Idade & Tempo de terapia em anos no momento da coleta \\
\hline Média & $8 \mathrm{a}$ e $2 \mathrm{~m}$ & 2,58 \\
Desvio-padrão & 2,30 & 1,70 \\
\hline
\end{tabular}


O Quadro I.2 caracteriza de forma sintética os dados referentes à idade e ao tempo até o momento da coleta de dados, em que cada sujeito deste estudo freqüenta o atendimento terapêutico de linguagem no Laboratório de Investigação Fonoaudiológica nos Distúrbios do Espectro Autístico (LIF-DEA).

QUADRO I.2- CARACTERIZAÇÃO DA AMOSTRA DAS 48 CRIANÇAS PERTENCENTES AO ESPECTRO AUTÍSTICO:

\begin{tabular}{|c|c|c|c|c|c|}
\hline sujeito & T_terap & idade_coleta & sujeito & T_terap & idade_coleta \\
\hline$\overline{1}$ & 1 & $9 a \mathrm{e} 7 \mathrm{~m}$ & 25 & 2 & $8 a$ e $0 m$ \\
\hline 2 & 3 & $8 a$ e $11 \mathrm{~m}$ & 26 & 1 & $9 a$ e $5 m$ \\
\hline 3 & 1 & $11 a$ e $2 m$ & 27 & 1 & $5 a \mathrm{e} 1 \mathrm{~m}$ \\
\hline 4 & 1 & $3 a$ e $11 m$ & 28 & 1 & $6 a$ e $0 m$ \\
\hline 5 & 3 & $7 a$ e $6 m$ & 29 & 2 & $6 a$ e $10 \mathrm{~m}$ \\
\hline 6 & 3 & 7a e7m & 30 & 6 & 10a e 9m \\
\hline 7 & 5 & $9 a$ e $9 m$ & 31 & 2 & $7 a$ e $11 \mathrm{~m}$ \\
\hline 8 & 1 & $4 a$ e $11 m$ & 32 & 1 & $6 a$ e $9 m$ \\
\hline 9 & 6 & $11 a$ e $4 m$ & 33 & 1 & $6 a$ e $0 m$ \\
\hline 10 & 5 & $8 a$ e $11 m$ & 34 & 1 & $7 a$ e $8 m$ \\
\hline 11 & 6 & $11 a$ e $7 m$ & 35 & 1 & $3 a$ e $0 m$ \\
\hline 12 & 1 & $5 a$ e $4 m$ & 36 & 2 & $8 a$ e $9 m$ \\
\hline 13 & 5 & $7 a$ e $6 m$ & 37 & 2 & $6 a$ e $0 m$ \\
\hline 14 & 1 & $7 a$ e $8 m$ & 38 & 5 & $9 a$ e $9 m$ \\
\hline 15 & 3 & $8 a$ e $1 m$ & 39 & 3 & $8 a$ e $3 m$ \\
\hline 16 & 3 & $8 a$ e $8 m$ & 40 & 1 & $8 a$ e $11 m$ \\
\hline 17 & 1 & $4 a$ e $4 m$ & 41 & 3 & $8 a$ e $1 m$ \\
\hline 18 & 1 & $4 a$ e $7 m$ & 42 & 1 & $6 a$ e $2 m$ \\
\hline 19 & 4 & $11 a$ e $10 m$ & 43 & 1 & $10 a$ e $11 m$ \\
\hline 20 & 3 & $7 a$ e $7 m$ & 44 & 6 & $11 \mathrm{a}$ e $10 \mathrm{~m}$ \\
\hline 21 & 4 & $11 \mathrm{a}$ e $7 \mathrm{~m}$ & 45 & 2 & $10 \mathrm{a}$ e $10 \mathrm{~m}$ \\
\hline 22 & 2 & $8 a$ e $3 m$ & 46 & 1 & $6 a$ e $0 m$ \\
\hline 23 & 4 & $11 \mathrm{a}$ e $10 \mathrm{~m}$ & 47 & 2 & $8 a$ e $9 m$ \\
\hline 24 & 5 & $9 a$ e $0 \mathrm{~m}$ & 48 & 4 & $10 a$ e $2 m$ \\
\hline
\end{tabular}

Legenda:

T terapia: anos em terapia no referido LIF até o ano de 2005

İade_coleta: idade em anos e meses apresentada no momento da coleta de dados 


\subsection{2- Material:}

\section{Perfil Funcional da Comunicação:}

Para a coleta de dados do perfil funcional da comunicação foi utilizado o protocolo de registro, proposto por Fernandes (2004), em que os dados são analisados considerando a perspectiva pragmática da linguagem.

Foram selecionados brinquedos de acordo com a vontade e/ou solicitação das crianças para estimular a comunicação espontânea durante a situação de brincadeira, visando melhores situações comunicativas para registro em vídeo.

Os protocolos específicos para transcrição das fitas VHS e/ou Dvds e análise do perfil comunicativo encontram-se nos anexos 3a e3b.

\section{Adaptação Sócio-comunicativa:}

Para a coleta dos dados da adaptação sócio-comunicativa foram utilizados o questionário e o protocolo específico propostos pela pesquisadora em 2004, estando estes apresentados nos anexos $4 \mathrm{a}$ e $4 \mathrm{~b}$.

\section{Outros materiais utilizados:}

- Filmadoras VHS e Digital;

- Fitas VHS e DVDs;

- Brinquedos em geral; 


\subsection{3- Procedimentos:}

\section{Procedimentos para coleta de dados do Perfil Funcional da Comunicação:}

A coleta de dados foi realizada entre os meses de abril e maio de 2005 , sendo que a terapeuta de cada sujeito procurou fornecer um contexto comunicativo amplo, buscando a espontaneidade comunicativa.

Foram fornecidos às crianças diversos materiais lúdicos a fim de propiciar situações de interação espontânea, atenção conjunta, uso da representação simbólica, além de incentivar a iniciativa comunicativa e o uso de respostas no discurso, sem a exigência de regras e procedimentos rígidos.

Desta forma, foram realizadas filmagens de um período de 30 minutos de brincadeira espontânea em situação clínica, sendo que o desempenho comunicativo foi analisado e registrado em protocolos específicos, propostos por Fernandes (2004).

Dos 30 minutos de filmagem foram selecionados os 15 minutos contínuos de comunicação mais simétrica, apresentados por cada sujeito, sendo que o número de atos comunicativos expressos pela criança foi registrado, o número de atos comunicativos expressos por minuto pela criança foi calculado dividindo-se o número total de atos comunicativos expressos pelo tempo de gravação, neste caso 15 minutos. 
Calculou-se também o percentual do espaço comunicativo ocupado pelos sujeitos em relação ao número total de atos comunicativos registrados. Obteve-se o registro do número total de vezes e a porcentagem representada no total de cada função comunicativa expressa por um determinado meio comunicativo, além do percentual do uso de cada meio comunicativo (gestual, vocal e verbal). Foi realizada ainda a classificação das funções comunicativas quanto ao seu caráter mais ou menos interpessoal, segundo Fernandes e Galinari (1999).

\section{Procedimentos para a investigação da adaptação sócio-comunicativa:}

Os protocolos da adaptação sócio-comunicativa foram aplicados individualmente com os pais e terapeutas dos sujeitos, em entrevistas realizadas pela pesquisadora, sendo que os entrevistados deveriam responder sim ou não a questões relacionadas ao desempenho sócio-comunicativo de seus filhos e pacientes, respectivamente. A cada resposta sim, era marcado o número um (1) e a cada resposta negativa marcado o número zero (0) para possibilitar o estudo estatístico dos dados.

Informante (p): As entrevistas com os pais ou responsáveis de cada sujeito foram realizadas pela pesquisadora, enquanto estes aguardavam o início ou término do atendimento fonoaudiológico de seus filhos, sendo todas as respostas registradas em protocolo específico. 
Os pais de cada criança foram apresentados pelas terapeutas de seus filhos à pesquisadora, sendo que esta realizava uma explanação aos mesmos sobre o procedimento da pesquisa e solicitava a autorização para participação neste trabalho científico e assinatura do termo de consentimento.

Informante (t): A pesquisadora realizou as entrevistas com as terapeutas de cada criança, registrando todas as respostas em protocolo específico.

O mesmo procedimento foi realizado, em ambas as situações, após um mês do início do processo terapêutico fonoaudiológico no ano de 2005 , entre os meses de abril e maio.

Apresenta-se no anexo 5 a escala de adaptação sócio-comunicativa (Sousa, 2004) que é composta por quatro níveis, sendo cada um composto de quatro estágios.

Manteve-se neste trabalho as mesmas classificações propostas em estudos anteriores (Sousa, 2004; Sousa-Morato e Fernandes, 2006a e 2006b), entretanto na aplicação do questionário foram realizadas algumas modificações nas exemplificações como forma de proporcionar uma maior compreensão das perguntas por parte dos entrevistados.

Para uma maior compreensão das idéias e classificações propostas pela escala de adaptação sócio-comunicativa, o questionário dirigido aos pais e às terapeutas está apresentado no anexo 4a. 
Para a aplicação deste questionário, o pesquisador perguntava ao entrevistado a respeito da primeira exemplificação fornecida, caso este não compreendesse ou não conseguisse responder, e apresentava-se o segundo exemplo, sendo as respostas obtidas anotadas no protocolo de registro específico.

\subsection{4- Análise Estatística:}

O programa SPSS (Statistical Package for Social Sciences), em sua versão 14.0 foi utilizado como instrumento para análise estatística dos dados. Para a aplicação dos testes estatísticos deste estudo foi adotado o nível de significância de $5 \%(\alpha=0,050-$ significância adotada). Ou seja, quando a significância calculada ( $p$ ) for menor do que $5 \%(0,050)$, encontra-se uma diferença (ou relação) estatisticamente significante; quando a significância calculada (p) for igual ou maior do que $5 \%(0,050)$, dá-se uma diferença (ou relação) estatisticamente não-significante, ou seja, uma semelhança. 
Para este estudo foram realizados o teste de Wilcoxon, para identificar possíveis diferenças entre as informações obtidas pelo questionário de adaptação sócio-comunicativa colhidas com dois diferentes informantes, bem como a Análise de Correlação de Spearman (Rosner, 1986) para identificar possíveis relações entre os dados das variáveis de interesse. O coeficiente de correlação varia de -1 até +1 , sendo que valores positivos indicam comportamentos paralelos dos dados observados, e valores negativos indicam comportamentos opostos. Quanto mais próximos de 1, tanto mais próximos os comportamentos entre as variáveis contrapostas (Rosner, 1986).

Foi realizada, ainda, uma análise estatística descritiva, CrossTabs, pela aplicação do Teste de McNemar, a aplicação dos testes de Kruskal-Wallis e ManWhitney, além da análise de aglomerados (Clusters), para identificar subgrupos específicos (quais os mais semelhantes e quais os mais diferentes entre si), aglomerando os sujeitos de cada nível da escala de adaptação sóciocomunicativa quanto à proximidade nas diferentes áreas do perfil funcional da comunicação. Para a análise dos Dendogramas foi considerado que aglomerados entre os valores de referência 25 e15 apresentariam grandes diferenças entre os sujeitos, entre 15 e10 diferença média, entre os valores de 10 e 5 pouca diferença e aglomerados de sujeitos menores que 5 representariam muito pouca diferença entre os mesmos. 


\section{4- Resultados:}

Os resultados serão apresentados, primeiramente, a partir de uma análise estatística global dos 48 sujeitos deste estudo em relação ao desempenho sóciocomunicativo obtido com pais e terapeutas, a sua relação com as diferentes áreas do perfil funcional da comunicação, bem como o comportamento da idade e do tempo em terapia fonoaudiológica dos referidos sujeitos no Laboratório de Investigação Fonoaudiológica nos Distúrbios do Espectro Autístico - FMUSP, em função dos níveis e estágios da escala de adaptação sócio-comunicativa obtidos em diferentes situações.

Vale ressaltar que os resultados que serão apresentados neste capítulo são somente os resultados estatisticamente significativos. Os resultados completos estão apresentados no CD, anexo 6.

Realizando a comparação entre o número de respostas positivas obtidas com pais e terapeutas dos sujeitos em cada estágio de cada nível da escala de adaptação sócio-comunicativa, podemos observar, na Figura I.1, que o desempenho geral dos sujeitos em ambas as situações aparenta estar genericamente semelhante, apresentando somente três diferenças significativas, estando estas destacadas em amarelo. 
FIGURA I.1- NÚMERO DE SUJEITOS COM RESPOSTAS POSITIVAS EM CADA NÍVEL/ESTÁGIO DA ESCALA DE ADAPTAÇÃO SÓCIO-COMUNICATIVA, OBTIDAS EM ENTREVISTAS COM OS PAIS E COM AS TERAPEUTAS:

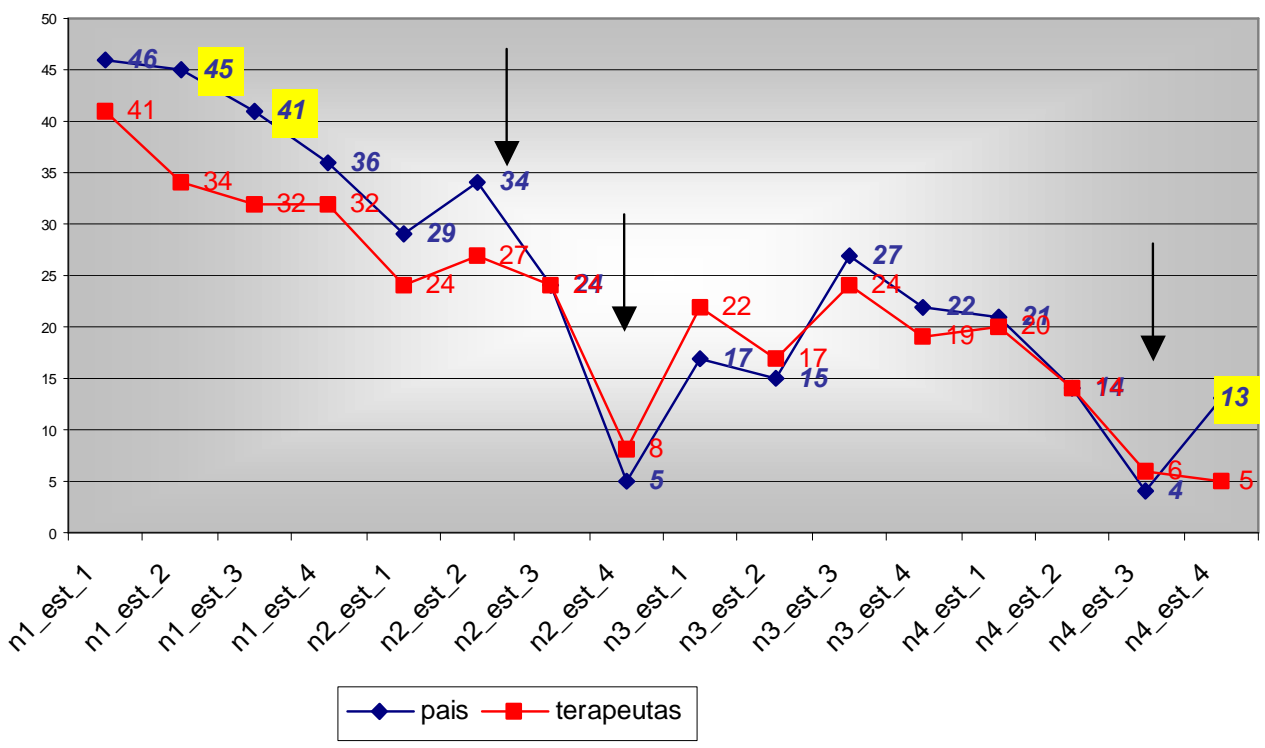

De forma geral, pode-se dizer que as respostas quanto à adaptação sócio-comunicativa, obtidas por meio de diferentes fontes de informação, ou seja, pais e terapeutas, foram genericamente semelhantes. Entretanto, analisando os dados brutos observa-se que os pais apresentaram consistentemente um número maior de respostas positivas do que as terapeutas, para as questões relativas ao desempenho social de seus filhos.

Nas duas situações de coleta de dados pode-se notar uma diminuição mais acentuada no número de respostas positivas por parte dos dois informantes, pais e terapeutas dos sujeitos, como nos mostram as setas pretas na Figura I.1. Esse resultado ocorre a partir do estágio dois do nível 2, que significa que a criança é capaz de se adaptar a mudanças e variações e a queda é acentuada no 
estágio 4 do nível 2 e no estágio 3 do nível 4, que se referem, respectivamente, à preocupação com os outros e capacidade de compreendê-los e à capacidade de compartilhar idéias, combinando e integrando idéias como uma unidade.

Apresentam-se na Tabela I.2 os valores de significância obtidos na comparação dos dados de adaptação sócio-comunicativa relatados por diferentes fontes de informação, ou seja pais e terapeutas, por meio da aplicação do Teste de Wilcoxon (Rosner, 1986). É possível notar uma diferença significativa quanto aos estágios 2 e 3 do nível 1, que se referem respectivamente, aos aspectos de referência social -em que a criança deve ser capaz de passar pelas etapas de referência social, utilizando expressões não-verbais do parceiro como referência crítica para suas ações- e à habilidade de ser um aprendiz por meio de um guia a criança consegue aprender e realizar ações ensinadas pelos pais (guias), seguindo modelos e/ou por meio de imitações. Em ambos os estágios o maior número de respostas positivas foram fornecidas pelos pais.

Observa-se também uma diferença significativa quanto ao estágio 4 do nível 4 em que a criança torna-se capaz de experenciar amigos que dividem os mesmos interesses e experiências em comum, sendo mais uma vez maior o número de respostas positivas dadas pelos pais. 
TABELA I.2- VALORES DE SIGNIFICÂNCIA NA COMPARAÇÃO DOS DADOS DE ADAPTAÇÃO SÓCIOCOMUNICATIVA OBTIDOS COM PAIS E TERAPEUTAS:

\begin{tabular}{cc}
\hline Pares de variáveis & Valores de significância \\
\hline $\begin{array}{c}\text { Nível 1estágio2 (colhido com os pais) X Nível 1 estágio } \\
2 \text { (colhido com as terapeutas) }\end{array}$ & 0,001 \\
Nível 1 estágio 3 (colhido com os pais) X Nível 1 & 0,029 \\
estágio 3 colhido com as terapeutas) & \\
Nível 4 estágio 4(colhido com os pais) X Nível 4 & 0,033 \\
estágio 4 (colhido com as terapeutas) & \\
\hline
\end{tabular}

Foi realizada a análise estatística descritiva -CrossTabs- pela aplicação do Teste de McNemar, buscando comparar as semelhanças e diferenças entre as respostas dadas por diferentes grupos de pessoas, neste caso, pais e terapeutas que avaliaram a adaptação sócio-comunicativa de seus filhos (as) e pacientes, respectivamente. Estão apresentadas na Tabela I.3 os valores de significância encontrados na aplicação do referido teste.

TABELA I.3- VALORES DE SIGNIFICÂNCIA OBTIDOS NA COMPARAÇÃO DE RESPOSTAS DADAS POR PAIS E TERAPEUTAS, A CADA ESTÁGIO E NÍVEL DA ESCALA DE ADAPTAÇÃO SÓCIOCOMUNICATIVA:

\begin{tabular}{|c|c|c|c|c|c|c|c|c|}
\hline Pares de & N1e1 (pais) & N1e2 (pais) & N1e3 (pais) & N1e4 (pais) & N2e1 (pais) & N2e2 (pais) & N2e3 (pais) & N2e4 (pais) \\
\hline \multirow[t]{2}{*}{ comparação } & $x$ & $x$ & $x$ & $x$ & $x$ & $x$ & $x$ & $x$ \\
\hline & $\begin{array}{c}\text { N1e1 } \\
\text { (terapeutas) }\end{array}$ & $\begin{array}{c}\text { N1e2 } \\
\text { (terapeutas) }\end{array}$ & $\begin{array}{c}\text { N1e3 } \\
\text { (terapeutas) }\end{array}$ & $\begin{array}{c}\text { N1e4 } \\
\text { (terapeutas) }\end{array}$ & $\begin{array}{c}\mathrm{N2e1} \\
\text { (terapeutas) }\end{array}$ & $\begin{array}{c}\mathrm{N} 2 \mathrm{e} 2 \\
\text { (terapeutas) }\end{array}$ & $\begin{array}{c}\mathrm{N} 2 \mathrm{e} 3 \\
\text { (terapeutas) }\end{array}$ & $\begin{array}{c}\text { N4e4 } \\
\text { (terapeutas) }\end{array}$ \\
\hline significância & 0,125 & 0,001 & 0,049 & 0,454 & 0,383 & 0,189 & 1,000 & 0,453 \\
\hline Pares de & N3e1 (pais) & N3e2 (pais) & N3e3 (pais) & N3e4 (pais) & N4e1 (pais) & N4e2 (pais) & N4e3 (pais) & N4e4 (pais) \\
\hline \multirow[t]{3}{*}{ comparação } & $x$ & $x$ & $x$ & $x$ & $x$ & $x$ & $x$ & $x$ \\
\hline & $N 3 e 1$ & $N 3 e 2$ & N3e3 & N3e4 & $N 4 \mathrm{e} 1$ & $\mathrm{~N} 4 \mathrm{e} 2$ & N4e3 & N4e4 \\
\hline & (terapeutas) & (terapeutas) & (terapeutas) & (terapeutas) & (terapeutas) & (terapeutas) & (terapeutas) & (terapeutas) \\
\hline significância & 0,383 & 0,774 & 0,648 & 0,607 & 1,000 & 1,000 & 0,688 & 0,057 \\
\hline
\end{tabular}


Os resultados do teste, apresentados na Tabela I.3 indicam apenas duas diferenças estatisticamente significativas, e uma forte tendência à diferença significativa em relação ao estágio 4 do nível 4 , uma vez que o valor de significância encontrado foi de 0,057 . Os dados apresentados pela aplicação do Teste de McNemar corroboram os dados apresentados na Figura I.1, uma vez que as diferenças estatisticamente significativas encontradas na aplicação do Teste de Wilcoxon, também são referentes aos estágios 2 e 3 do nível 1 e ao estágio 4 do nível 4.

Quanto às diferenças estatisticamente significativas encontradas, observa-se mais especificamente, uma em relação ao estágio 2 do nível 1, com valor de 0,001 e outra, em relação ao estágio 3 do nível 1, com valor de 0,049, estando demonstradas abaixo na Tabela I.4, a comparação de respostas atribuídas pelos diferentes informantes aos referidos níveis e estágios da escala de adaptação sócio-comunicativa. 
TABELA I.4- VALORES OBTIDOS NA COMPARAÇÃO DAS REPOSTAS SIM OU NÃO DADAS POR DIFERENTES INFORMANTES PARA OS NÍVEIS E ESTÁGIOS DA ESCALA DE ADAPTAÇÃO SÓCIOCOMUNICATIVA QUE APRESENTARAM DIFERENÇA ESTATISTICAMENTE SIGNIFICATIVA:

\begin{tabular}{|c|c|c|c|c|}
\hline Níveis /estágios & & Não-Terapeutas & Sim-Terapeutas & Total \\
\hline & Nã o- Pais & 3 & 0 & 3 \\
\hline \multirow{4}{*}{ Nível 1 estágio 2} & $\%$ do total & & & \\
\hline & & $6,3 \%$ &, $0 \%$ & $6,3 \%$ \\
\hline & Sim-Pais & 11 & 34 & 45 \\
\hline & $\%$ do total & $22,9 \%$ & $70,8 \%$ & $93,6 \%$ \\
\hline \multirow[t]{2}{*}{ Total } & $\%$ do total & 14 & 34 & 48 \\
\hline & & $29,2 \%$ & $70,8 \%$ & $100,0 \%$ \\
\hline \multirow[t]{2}{*}{ Níveis /estágios } & & Não-Terapeutas & Sim-Terapeutas & Total \\
\hline & Nã o- Pais & 3 & 4 & 7 \\
\hline \multirow[t]{4}{*}{ Nível 1 estágio 3} & $\%$ do total & & & \\
\hline & & $6,3 \%$ & $8,3 \%$ & $14,6 \%$ \\
\hline & Sim-Pais & 13 & 28 & 41 \\
\hline & $\%$ do total & $27,1 \%$ & $58,3 \%$ & $85,4 \%$ \\
\hline \multirow[t]{2}{*}{ Total } & $\%$ do total & 16 & 32 & 48 \\
\hline & & $33,3 \%$ & $66,7 \%$ & $100,0 \%$ \\
\hline
\end{tabular}

De acordo com a análise dos resultados estabelecidos pela análise estatística descritiva, pelo teste de McNemar, pode-se dizer que ocorre uma tendência de semelhança entre as respostas obtidas com pais e terapeutas em relação ao questionário da escala de adaptação sócio-comunicativa. Observa-se que o teste foi bastante homogêneo, demonstrando que as informações podem ser colhidas com diferentes fontes de informantes. 
Foi também estabelecida a correlação entre os dados de adaptação sócio-comunicativa obtidos com os pais e o perfil funcional da comunicação em suas áreas específicas (número de atos comunicativos utilizados e expressos por minuto, percentual do espaço comunicativo ocupado, número de funções comunicativas utilizadas, e percentual dos meios comunicativos -gestual, vocal e verbal-, bem como o percentual de funções comunicativas mais ou menos interpessoais). Na Tabela I.5 apresentam-se os valores de significância e as explanações das referidas correlações.

Das 144 correlações possíveis pode-se observar apenas cinco correlações positivas estatisticamente significativas. Nota-se uma correlação significativa entre o número de funções comunicativas e o estágio 4 do nível 2, e quatro correlações entre o percentual de uso do meio comunicativo verbal e os estágios 2 do nível 1, estágio 1 do nível 2 e estágios 2 e 4 do nível 3.

É necessário considerar que quanto maior a amostra, menores serão os coeficientes de correlação, ou seja, mais próximos de zero serão os coeficientes de correlação, sendo isto esperado e previsto pelo teste, o que não invalida a conclusão a ser tirada em função dos resultados obtidos pelo mesmo. 
TABELA I.5- VALORES DE SIGNIFICÂNCIA ENCONTRADOS NA CORRELAÇÃO ENTRE PERFIL FUNCIONAL DA COMUNICAÇÃO E OS DADOS DE ADAPTAÇÃO SÓCIO-COMUNICATIVA OBTIDOS COM OS PAIS:

\begin{tabular}{|c|c|c|c|}
\hline Pares de variáveis & $\begin{array}{l}\text { Coeficiente de } \\
\text { correlação }\end{array}$ & Significância & Explicações das correlações significativas \\
\hline $\begin{array}{l}\text { Nível } 2 \text { estágio } 4 X \\
\text { No- funções } \\
\text { comunicativas }\end{array}$ & $+0,311$ & 0,031 & $\begin{array}{l}\text { Quanto mais presente está a habilidade de perceber e identificar } \\
\text { comportamentos e emoções, modificando seu comportamento para } \\
\text { um maior aproveitamento das experiências compartilhadas, tanto } \\
\text { maior o número de funções comunicativas expressadas. }\end{array}$ \\
\hline $\begin{array}{l}\text { Nível } 1 \text { estágio } 2 X \\
\text { \% meio verbal }\end{array}$ & $+0,295$ & 0,041 & $\begin{array}{l}\text { Quanto mais presente está a habilidade de utilizar expressões não- } \\
\text { verbais do parceiro como referência crítica para suas ações, tanto } \\
\text { maior o percentual de uso do meio verbal. }\end{array}$ \\
\hline $\begin{array}{l}\text { Nível } 2 \text { estágio } 1 X \\
\quad \% \text { meio verbal }\end{array}$ & $+0,296$ & 0,043 & $\begin{array}{l}\text { Quanto mais presente está a habilidade da criança de gostar e } \\
\text { reagir bem ou não às novidades introduzidas, tanto maior o } \\
\text { percentual de uso do meio verbal. }\end{array}$ \\
\hline $\begin{array}{l}\text { Nível } 3 \text { estágio } 2 X \\
\text { \% meio verbal }\end{array}$ & $+0,300$ & 0,038 & $\begin{array}{l}\text { Quanto mais presente está a habilidade da criança de descobrir } \\
\text { sua criatividade e imaginação, aprendendo a se divertir como um } \\
\text { parceiro igual na co-criação, tanto maior o percentual de uso do } \\
\text { meio verbal. }\end{array}$ \\
\hline $\begin{array}{l}\text { Nível } 3 \text { estágio } 4 X \\
\text { \% meio verbal }\end{array}$ & $+0,302$ & 0,037 & $\begin{array}{l}\text { Quanto mais presente está a capacidade da criança de } \\
\text { experenciar a alegria de dividir percepções com amigos, tanto } \\
\text { maior o percentual de uso do meio verbal. }\end{array}$ \\
\hline
\end{tabular}

No estudo da correlação do perfil funcional da comunicação e dos dados de adaptação sócio-comunicativa obtidos com as terapeutas, das 144 correlações possíveis foram encontradas 43 correlações estatisticamente significativas, sendo neste total 11 correlações negativas e 32 correlações positivas. Todas as correlações estatisticamente significativas estão enumeradas e explanadas na Tabela I.6. 
Quanto à correlação do número de atos comunicativos expressos pelas crianças com os dados de adaptação sócio comunicativa, foram encontradas oito correlações positivas, com os estágios 2 e 4 do nível 1, estágios 1, 2 e 3 do nível 2, estágios 2 e 4 do nível 3 e estágio 2 do nível 4 .

$\mathrm{Na}$ relação entre o percentual do espaço comunicativo ocupado pelos sujeitos e os níveis e estágios de adaptação sócio-comunicativa, só foi observada uma correlação estatisticamente significativa, sendo esta negativa e referente ao estágio 3 do nível 4.

Em relação ao número de atos comunicativos expressos por minuto pelos sujeitos e os dados de adaptação sócio-comunicativa, os resultados demonstraram oito correlações estatisticamente significativas, destes com os níveis e estágios apresentados a seguir, respectivamente, 1 e 2, 1 e 3, 2 e 1, 2 e 2,2 e 3,3 e 2,3 e 4,4 e 3.

Obtiveram-se duas correlações estatisticamente significativas positivas e duas negativas quanto à relação do percentual de funções comunicativas, mais interpessoais e menos interpessoais, respectivamente, expressadas e o estágio 2 e 4 do nível 1.

Observam-se três correlações significativas e positivas entre o número de funções comunicativas utilizadas pelos sujeitos e os estágios 1 e 2 do nível 1 e estágio 4 do nível 3. 
Quanto à relação entre o percentual de uso dos meios comunicativos e os níveis e estágios da escala de adaptação sócio-comunicativa obtidos com os terapeutas, foram encontradas 11 correlações significativas e positivas entre o uso do meio verbal e os estágios 2, 3 e 4 do nível 1, estágios 1 e 4 do nível 2, estágios 1, 2 e 4 do nível 3 e estágios 2, 3 e 4 do nível 4. Na relação com o uso do meio vocal, apenas uma correlação significativa estatisticamente foi encontrada, sendo esta negativa quanto ao estágio 3 do nível 4 . Entretanto, sete correlações, também negativas, foram observadas quanto ao meio gestual e os estágios 4 do nível 2, estágios 1, 2 e 4 do nível 3, estágio 4 do nível 3 e estágios 2, 3 e 4 do nível 4 da escala.

TABELA I.6- VALORES DE SIGNIFICÂNCIA ENCONTRADOS NA CORRELAÇÃO ENTRE O PERFIL FUNCIONAL DA COMUNICAÇÃO E OS DADOS DE ADAPTAÇÃO SÓCIO-COMUNICATIVA OBTIDOS COM AS TERAPEUTAS:

\begin{tabular}{|c|c|c|c|}
\hline Pares de variáveis & $\begin{array}{c}\text { Coeficiente de } \\
\text { correlação }\end{array}$ & Significância & Explicações das correlações significativas \\
\hline $\begin{array}{c}\text { Nível 1estágio1 } x \\
n^{\circ-} \text { funções comunicativas }\end{array}$ & $+0,330$ & 0,022 & $\begin{array}{l}\text { Quanto mais presente está a habilidade da criança em realizar } \\
\text { contato visual significativo com os terapeutas, tanto maior é o } \\
\text { número de funções comunicativas expressadas. }\end{array}$ \\
\hline $\begin{array}{c}\text { Nível 1estágio } 2 x \\
n^{\circ-} \text { atos comunicativos }\end{array}$ & $+0,344$ & 0,017 & $\begin{array}{l}\text { Quanto mais presente está a habilidade da criança utilizar } \\
\text { expressões não-verbais do parceiro como referência crítica para } \\
\text { suas ações, tanto maior é o número de atos comunicativos } \\
\text { expressos por ela. }\end{array}$ \\
\hline $\begin{array}{l}\text { Nível } 1 \text { estágio } 2 x \\
n^{0-} \text { atos } \\
\text { comunicativos/minuto }\end{array}$ & $+0,342$ & 0,017 & $\begin{array}{l}\text { Quanto mais presente está a habilidade da criança utilizar } \\
\text { expressões não-verbais do parceiro como referência crítica para } \\
\text { suas ações, tanto maior é o número de atos comunicativos } \\
\text { expressos por minuto. }\end{array}$ \\
\hline $\begin{array}{l}\text { Nível } 1 \text { estágio } 2 x \\
\text { \% funções com. }(+) \\
\text { interpessoais }\end{array}$ & $+0,352$ & 0,014 & $\begin{array}{l}\text { Quanto mais presente está a habilidade da criança utilizar } \\
\text { expressões não-verbais do parceiro como referência crítica para } \\
\text { suas ações, tanto maior é o percentual de funções comunicativas } \\
\text { mais interpessoais utilizadas. }\end{array}$ \\
\hline $\begin{array}{l}\text { Nível } 1 \text { estágio } 2 \text { x } \\
\text { \% funções com. (-) } \\
\text { interpessoais }\end{array}$ & $-0,351$ & 0,014 & $\begin{array}{l}\text { Quanto mais presente está a habilidade da criança utilizar } \\
\text { expressões não-verbais do parceiro como referência crítica para } \\
\text { suas ações, tanto menor é o percentual de funções comunicativas } \\
\text { menos interpessoais utilizadas. }\end{array}$ \\
\hline $\begin{array}{c}\text { Nível } 1 \text { estágio } 2 x \\
n^{\circ-} \text { funções comunicativas }\end{array}$ & $+0,300$ & 0,038 & $\begin{array}{l}\text { Quanto mais presente está a habilidade da criança utilizar } \\
\text { expressões não-verbais do parceiro como referência crítica para } \\
\text { suas ações, tanto maior é o número de funções comunicativas } \\
\text { utilizadas. }\end{array}$ \\
\hline
\end{tabular}




\section{Nível 1estágio $2 x$ $\%$ meio verbal}

\section{Nível 1estágio $3 x$ \\ $n^{0-}$ atos comunicativos/minuto} Nível 1estágio $3 x$
$\%$ meio verbal

Nível 1 estágio $4 \mathrm{x}$ $n^{\circ-}$ atos comunicativos

\section{Nível 1 estágio $4 x$ \\ $\%$ funções com. ${ }^{+}$ interpessoais}

\section{Nível 1estágio $4 x$ \\ $\%$ funções com. (-) interpessoais}

\section{Nível 1estágio $4 \mathrm{x}$ $\%$ meio verbal}

Nível 2estágio $1 \mathrm{x}$ $n^{0-}$ atos comunicativos

$$
n^{0-} \text {. atos }
$$

comunicativos/minuto

Nível 2 estágio $1 \mathrm{x}$

$\%$ meio verbal

Nível 2 estágio $2 x$ $n^{0}$. atos comunicativos

Nível 2 estágio $2 x$ $n^{0-}$ atos comunicativos/minuto

Nível 2 estágio $3 x$ $n^{0-}$ atos comunicativos
$+0,456$

0,001
Quanto mais presente está a habilidade da criança utilizar expressões não-verbais do parceiro como referência crítica para suas ações, tanto maior é o percentual de uso do meio comunicativo verbal.

Quanto mais presente está a habilidade da criança conseguir aprender e realizar ações ensinadas pelos pais (guias), seguindo modelos e/ou por meio de imitações, tanto maior o número de atos comunicativos expressos por minuto.

Quanto mais presente está a habilidade da criança conseguir aprender e realizar ações ensinadas pelos pais (guias), seguindo modelos e/ou por meio de imitações, tanto maior o percentual de uso do meio comunicativo verbal.

Quanto mais presente está a habilidade da criança coordenar com o parceiro, ações simples, em que os dois desfrutam-nas mutuamente, tanto maior é o número de atos comunicativos expressos por ela.

Quanto mais presente está a habilidade da criança coordenar com o parceiro, ações simples, das quais os dois possam desfrutar mutuamente, tanto maior é o percentual de uso de funções comunicativas mais interpessoais.

Quanto mais presente a habilidade da criança em coordenar com o parceiro, ações simples, das quais os dois possam desfrutar mutuamente, tanto menor 0 percentual de uso de funções comunicativas menos interpessoais.

Quanto maior a presença da habilidade da criança em coordenar com o parceiro, ações simples, das quais os dois possam desfrutar mutuamente, tanto maior o percentual de uso do meio comunicativo verbal.

Quanto mais presente a habilidade da criança de gostar e reagir bem às novidades introduzidas, tanto maior é o número de atos comunicativos expressos por ela.

Quanto maior a presença da habilidade da criança de gostar e reagir bem às novidades introduzidas, tanto maior é o número de atos comunicativos expressos por minuto.

Quanto mais presente a habilidade da criança de gostar e reagir bem às novidades introduzidas, tanto maior é o percentual de uso do meio comunicativo verbal.

Quanto maior a presença da habilidade da criança em adaptar-se bem a introdução de alguma novidade e brincar com a mesma, tanto maior é o número de atos comunicativos expressos.

Quanto mais presente está a habilidade da criança em adaptar-se bem a introdução de alguma novidade e brincar com a mesma, tanto maior é 0 número de atos comunicativos expressos por minuto.

Quanto mais presente está a habilidade da criança em conseguir usar o outro como referência e regulação para coordenar suas ações, tanto maior é o número de atos comunicativos expressos. 


\section{Nível 2 estágio $3 x$ \\ $n^{0-}$ atos \\ comunicativos/minuto}

$+0,430$

\begin{abstract}
Nível 2 estágio $4 x$
$\%$ meio verbal
\end{abstract}

Nível 2 estágio $4 x$

$\%$ meio gestual

Nível 3 estágio $1 x$ $\%$ meio verbal

Nível 3 estágio $1 \mathrm{x}$ $\%$ meio gestual

Nível 3 estágio $2 x$ $n^{0-}$ atos comunicativos

\author{
Nível 3 estágio $2 x$ \\ $n^{0-}$ atos
}

comunicativos/minuto

\section{Nível 3 estágio $2 x$ \\ $\%$ meio verbal}

Nível 3 estágio $2 x$

$\%$ meio gestual

Nível 3 estágio $4 x$

$n^{0-}$ atos comunicativos

$+0,464$

0,001

Nível 3 estágio $4 x$

$n^{0-}$ atos

comunicativos/minuto
Quanto mais presente está a habilidade da criança de descobrir sua criatividade e imaginação, aprendendo a se divertir como um parceiro igual na co-criação maior é o percentual de uso do meio comunicativo verbal.

Quanto maior a presença da habilidade da criança de descobrir sua criatividade e imaginação, aprendendo a se divertir como um parceiro igual na co-criação, tanto menor é o percentual de uso do meio comunicativo gestual.

Quanto mais presente está a habilidade da criança experenciar a alegria de dividir percepções com amigos, ou seja, se ela realiza comentários a respeito de ações e fatos ocorridos, tanto maior o número de atos comunicativos expressos.

Quanto maior a presença da habilidade de experenciar a alegria de dividir concepções com amigos, ou seja, realizar comentários a respeito de ações e fatos ocorridos, tanto maior o número de atos comunicativos expressos por minuto. 
Nível 3 estágio $4 x$

$n^{\circ}$-funções comunicativas

$+0,333$

0,02

Nível 3 estágio $4 x$
$\%$ meio verbal

$+0,484$

0,000

Nível 3 estágio $4 x$

$\%$ meio gestual

$-0,431$

0,002

Nível 4 estágio $2 \times n^{\circ-}$ atos comunicativos

Nível 4 estágio $2 \times \%$ meio verbal gestual

Nível 4 estágio $3 \times \%$ espaço comunicativo ocupado

\section{Nível 4 estágio $3 x$} $n^{\circ}$ - atos comunicativos/minuto

Nível 4 estágio $3 x$ $\%$ meio verbal

Nível 4 estágio $3 x$ $\%$ meio vocal

Nível 4 estágio $3 \times \%$ meio gestual

Nível 4 estágio $4 \times \%$ meio verbal gestual
Quanto mais presente está a habilidade da criança de experenciar a alegria de dividir percepções com amigos, ou seja, se ela realiza comentários a respeito de ações e fatos ocorridos, tanto maior o número de funções comunicativas utilizadas.

Quanto maior a presença da habilidade da criança experenciar a alegria de dividir percepções com amigos, ou seja, se ela realiza comentários a respeito de ações e fatos ocorridos, tanto maior é o percentual de uso do meio comunicativo verbal.

Quanto mais presente está a habilidade da criança experenciar a alegria de dividir percepções com amigos, ou seja, se ela realiza comentários a respeito de ações e fatos ocorridos, tanto menor é o percentual de uso do meio comunicativo gestual.

Quanto mais presente está a habilidade da criança de aproveitar e combinar as imaginações compartilhadas entre si e o parceiro, tanto maior o número de atos comunicativos expressos.

Quanto maior a habilidade da criança de aproveitar e combinar as imaginações compartilhadas entre si e o parceiro, tanto maior é o percentual de uso do meio comunicativo verbal.

Quanto mais presente está a habilidade da criança de aproveitar e combinar as imaginações compartilhadas entre si e o parceiro, tanto menor é o percentual de uso do meio comunicativo gestual.

Quanto menos presente está habilidade da criança de combinar e integrar idéias como uma unidade, tanto maior é o percentual de espaço comunicativo ocupado.

Quanto mais presente está a habilidade da criança de conseguir combinar e integrar idéias como uma unidade, tanto maior 0 número de atos comunicativos expressos por minuto.

Quanto maior a presença da habilidade da criança de conseguir combinar e integrar idéias como uma unidade, tanto maior 0 percentual de uso do meio comunicativo verbal.

Quanto menos presente está a habilidade da criança de conseguir combinar e integrar idéias como uma unidade, tanto maior é o percentual de uso do meio comunicativo vocal.

Quanto menos presente está a habilidade da criança em conseguir combinar e integrar idéias como uma unidade, tanto maior é o percentual de uso do meio comunicativo gestual.

Quanto mais presente está a habilidade da criança de experenciar amigos que dividem os mesmos interesses e experiências em comum, tanto maior é o percentual de uso do meio comunicativo verbal.

Quanto mais presente está a habilidade da criança de experenciar amigos que dividem os mesmos interesses e experiências em comum, tanto menor é o percentual de uso do meio comunicativo gestual. 
Para verificar se os resultados obtidos no estudo não estão relacionados a variáveis como a idade e o tempo em terapia no Laboratório de Investigação Fonoaudiológica nos Distúrbios do Espectro Autístico-FMUSP (LIF-DEA), foi proposta a análise do comportamento da idade e do tempo em terapia fonoaudiológica, frente aos níveis e estágios da adaptação sócio-comunicativa obtidos por diferentes informantes por meio da Análise de Correlação de Spearman.

Na correlação da idade com os dados de adaptação sócio-comunicativa obtidos com os pais, das dezesseis correlações possíveis, somente três apresentaram significância estatística, sendo todas positivas, uma em relação ao estágio 3 do nível 1 (saber se a criança consegue aprender e realizar ações ensinadas pelos pais (guias), seguindo modelos elou por meio de imitações), uma quanto estágio 4 do nível 1 (saber se a criança é capaz de coordenar com o parceiro, ações simples, das quais os dois possam desfrutar mutuamente, portanto, saber se a criança consegue realizar trocas de turno) e outra quanto ao estágio 4 do nível 2 (saber se a criança é capaz de perceber e identificar comportamentos e emoções, modificando seu comportamento para um maior aproveitamento das experiências compartilhadas).

Quanto à correlação da idade com os dados de adaptação sóciocomunicativa obtidos com as terapeutas, sendo também possíveis dezesseis correlações, foi encontrada somente uma correlação positiva estatisticamente significativa no estágio 4 do nível 4 , em que a criança é capaz de experenciar amigos que dividem os mesmos interesses. 
Segundo a análise estatística de todos os dados, pode-se sugerir que a idade comporta-se independentemente nesta população, não influenciando na complexidade das habilidades observadas.

Os dados a respeito das relações significativas das correlações da idade e dos dados de adaptação sócio-comunicativa obtidos com pais e terapeutas, estão expostos na Tabela I.7.

TABELA I.7 - CORRELAÇÕES SIGNIFICATIVAS DO COMPORTAMENTO DA IDADE FRENTE AOS DADOS DE ADAPTAÇÃO SÓCIO-COMUNICATIVA OBTIDOS COM OS PAIS E TERAPEUTAS:

\begin{tabular}{lcc}
\hline \multicolumn{1}{c}{ Pares de variáveis } & Coeficiente de correlação & Significância \\
\hline Idade x Nível 1estágio3 (pais) & $+0,386$ & 0,007 \\
Idade x Nível 1 estágio 4 (pais) & $+0,288$ & 0,047 \\
Idade x Nível 2 estágio 4 (pais) & $+0,386$ & 0,007 \\
Idade x Nível4 estágio 4 (terapeuta) & $+0,372$ & 0,009 \\
\hline
\end{tabular}

O estudo da correlação do tempo de terapia fonoaudiológica em anos no LIF_DEA com os dados de adaptação sócio-comunicativa obtidos com os pais e com as terapeutas, pela aplicação da Análise de Correlação de Spearman (Rosner, 1986), indica que, com as terapeutas e com os pais, das dezesseis correlações possíveis para cada fonte de informação de dados de adaptação sócio-comunicativa, foram encontradas, respectivamente, zero e quatro correlações estatisticamente significativas, sendo todos os coeficientes de correlação positivos. Apresentam-se na Tabela I.8 os valores das correlações significativas e suas explanações. 
TABELA I.8 - CORRELAÇÕES SIGNIFICATIVAS DO COMPORTAMENTO DO TEMPO DE TERAPIA (EM ANOS) FONOAUDIOLÓGICA NO LIF-DEA FRENTE AOS DADOS DE ADAPTAÇÃO SÓCIOCOMUNICATIVA OBTIDOS COM OS PAIS COMO INFORMANTES:

\begin{tabular}{|c|c|c|c|}
\hline Pares de variáveis & Coeficiente de correlação & Significância & Explicações das correlações positivas \\
\hline $\begin{array}{c}\text { Tempo de terapia (anos) } x \\
\text { Nível } 1 \text { estágio3 (pais) }\end{array}$ & $+0,308$ & 0,033 & $\begin{array}{l}\text { Quanto maior o tempo de terapia, maior a } \\
\text { presença da habilidade da criança em } \\
\text { conseguir aprender e realizar ações } \\
\text { ensinadas pelos pais (guias), seguindo } \\
\text { modelos e/ou por meio de imitações. }\end{array}$ \\
\hline $\begin{array}{l}\text { Tempo de terapia (anos) } x \\
\text { Nível } 1 \text { estágio4 (pais) }\end{array}$ & $+0,298$ & 0,040 & $\begin{array}{l}\text { Quanto maior o tempo de terapia, maior a } \\
\text { presença da habilidade da criança em } \\
\text { coordenar com o parceiro, ações simples, das } \\
\text { quais os dois possam desfrutar mutuamente. }\end{array}$ \\
\hline $\begin{array}{l}\text { Tempo de terapia (anos) } x \\
\text { Nível } 2 \text { estágio1 (pais) }\end{array}$ & $+0,402$ & 0,005 & $\begin{array}{l}\text { Quanto maior o tempo de terapia, maior a } \\
\text { presença da habilidade da criança de gostar e } \\
\text { reagir bem ou não às novidades introduzidas. }\end{array}$ \\
\hline $\begin{array}{l}\text { Tempo de terapia (anos) } x \\
\text { Nível } 3 \text { estágio3 (pais) }\end{array}$ & $+0,294$ & 0,042 & $\begin{array}{l}\text { Quanto maior o tempo de terapia, maior a } \\
\text { presença da habilidade da criança de lidar em } \\
\text { situações imprevistas, conseguindo manter o } \\
\text { contato social. }\end{array}$ \\
\hline
\end{tabular}

De forma geral, pode-se observar que o número de anos em terapia fonoaudiológica não influencia diretamente o desempenho na escala de adaptação sócio-comunicativa obtida em diferentes situações, embora, notem-se algumas interferências pontuais.

Para realizar diferentes análises estatísticas em relação ao perfil funcional da comunicação em função dos níveis da escala de adaptação sóciocomunicativa, os 48 sujeitos deste estudo foram classificados segundo esses níveis. Para essa classificação foi considerado o nível mais alto no qual cada sujeito foi descrito como apresentando pelo menos três estágios completos da escala de adaptação sócio-comunicativa. Caso não tivessem sido atribuídas ao sujeito respostas que completassem três estágios em nenhum dos níveis, este passou a ser considerado como instável. 
Desta forma, a casuística ficou dividida da forma exposta no Quadro I.3.

QUADRO I.3- DIVISÃO DOS SUJEITOS EM FUNÇÃO DO NÍVEL DE ADAPTAÇÃO SÓCIOCOMUNICATIVA DADO PELOS PAIS E TERAPEUTAS:

\begin{tabular}{|c|c|c|}
\hline $\begin{array}{c}\text { Nível de Adaptação Sócio- } \\
\text { comunicativa }\end{array}$ & $\begin{array}{c}\text { Número de sujeitos } \\
\text { classificados pelos pais }\end{array}$ & $\begin{array}{c}\text { Número de sujeitos classificados pelas } \\
\text { terapeutas }\end{array}$ \\
\hline Nível 1 & 18 & 13 \\
\hline Nível 2 & 9 & 5 \\
\hline Nível 3 & 9 & 8 \\
\hline Nível 4 & 9 & 6 \\
\hline Instáveis & 3 & 16 \\
\hline
\end{tabular}

Estando todos os sujeitos classificados pelos pais e terapeutas nos níveis da escala de adaptação sócio-comunicativa, foram utilizados os testes de KruskalWallis e Mann-Whitney (quando detectada alguma diferença estatisticamente significativa), para estabelecer diferenças quanto ao perfil funcional da comunicação entre todos níveis de adaptação sócio-comunicativa, incluindo o grupo dos considerados instáveis.

$\mathrm{Na}$ aplicação do teste de Kruskal-Wallis, em relação aos grupos classificados pelos pais, somente foi encontrada uma diferença estatisticamente significativa sendo esta em relação ao percentual de uso do meio comunicativo verbal, com valor de significância de 0,017.

Sendo assim, foi realizada a análise do percentual de uso do meio verbal na comparação entre os níveis da escala de adaptação sócio-comunicativa por meio do teste de Mann-Whitney, sendo encontradas cinco diferenças estatisticamente significativas, como demonstra a Tabela I.9 . 
TABELA I.9- VALORES DE SIGNIFICÂNCIA OBTIDOS NA COMPARAÇÃO DO PERCENTUAL DE USO DO MEIO VERBAL ENTRE OS NÍVEIS CLASSIFICADOS PELOS PAIS DA ESCALA DE ADAPTAÇÃO SÓCIOCOMUNICATIVA:

\begin{tabular}{cccccc}
\hline \multicolumn{3}{c}{ Pares de Níveis sócio-comunicativos } \\
\hline \% Uso do Meio Verbal & Instáveis $\times 1$ & Instáveis $\times 2$ & Instáveis $\times 3$ & Instáveis $\times 4$ & Nível $1 \times 3$ \\
significância & 0,027 & 0,010 & 0,006 & 0,034 & 0,033 \\
\hline
\end{tabular}

Pode-se concluir que o percentual de uso do meio verbal é o aspecto diferenciador da classificação em níveis de adaptação sócio-comunicativa, sendo o grupo dos instáveis o mais diferente entre todos os outros níveis na classificação dada pelos pais, uma vez que a média de uso do meio verbal foi de $0 \%$.

$\mathrm{Na}$ aplicação do mesmo teste, com o intuito de verificar possíveis diferenças entre as áreas do perfil funcional da comunicação entre os níveis de adaptação sócio-comunicativa atribuídos pelas terapeutas, concomitantemente, foram encontradas as diferenças estatisticamente significativas, demonstradas na Tabela I.10. 
TABELA I.10- VALORES DE SIGNIFICÂNCIA OBTIDOS NA COMPARAÇÃO DAS ÁREAS DO PERFIL FUNCIONAL DA COMUNICAÇÃO ENTRE OS NÍVEIS DA ESCALA DE ADAPTAÇÃO SÓCIOCOMUNICATIVA ATRIBUÍDOS PELAS TERAPEUTAS:

\begin{tabular}{|c|c|c|c|c|c|c|c|}
\hline Variável & $\begin{array}{l}\text { Níveis sócio- } \\
\text { comunicativos }\end{array}$ & $n$ & Média & $\begin{array}{l}\text { Desvio- } \\
\text { padrão }\end{array}$ & Mínimo & Máximo & $\begin{array}{l}\text { Significância } \\
\text { (p) }\end{array}$ \\
\hline \multirow{6}{*}{$\begin{array}{l}\text { Número de atos } \\
\text { comunicativos utilizados }\end{array}$} & 0 & 16 & 47,81 & 13,39 & 30,00 & 73,00 & \multirow{6}{*}{0,008} \\
\hline & 1 & 13 & 86,62 & 51,17 & 26,00 & 228,00 & \\
\hline & 2 & 5 & 61,40 & 8,02 & 48,00 & 69,00 & \\
\hline & 3 & 8 & 66,25 & 14,05 & 43,00 & 86,00 & \\
\hline & 4 & 6 & 90,83 & 52,67 & 34,00 & 189,00 & \\
\hline & Total & 48 & 68,19 & 36,90 & 26,00 & 228,00 & \\
\hline \multirow{6}{*}{$\begin{array}{l}\text { Número de funções } \\
\text { comunicativas utilizadas }\end{array}$} & 0 & 16 & 9,63 & 1,86 & 5,00 & 12,00 & \multirow{6}{*}{0,049} \\
\hline & 1 & 13 & 11,54 & 2,26 & 8,00 & 16,00 & \\
\hline & 2 & 5 & 12,20 & 2,39 & 10,00 & 16,00 & \\
\hline & 3 & 8 & 10,38 & 1,30 & 9,00 & 13,00 & \\
\hline & 4 & 6 & 12,00 & 2,19 & 9,00 & 15,00 & \\
\hline & Total & 48 & 10,83 & 2,17 & 5,00 & 16,00 & \\
\hline \multirow{6}{*}{$\%$ de uso do meio verbal } & 0 & 16 & 9,27 & 23,79 & 0,00 & 94,00 & \multirow{6}{*}{$<0,001$} \\
\hline & 1 & 13 & 30,45 & 28,28 & 0,00 & 76,00 & \\
\hline & 2 & 5 & 15,76 & 29,00 & 0,00 & 67,00 & \\
\hline & 3 & 8 & 50,00 & 32,95 & 2,00 & 97,00 & \\
\hline & 4 & 6 & 77,17 & 12,70 & 53,00 & 89,00 & \\
\hline & Total & 48 & 30,96 & 33,98 & 0,00 & 97,00 & \\
\hline \multirow{6}{*}{$\%$ de uso do meio gestual } & 0 & 16 & 81,77 & 20,46 & 33,00 & 100,00 & \multirow{6}{*}{0,006} \\
\hline & 1 & 13 & 85,42 & 12,40 & 54,00 & 98,50 & \\
\hline & 2 & 5 & 92,10 & 5,30 & 85,00 & 98,50 & \\
\hline & 3 & 8 & 78,25 & 8,84 & 61,00 & 92,00 & \\
\hline & 4 & 6 & 51,83 & 19,05 & 31,00 & 76,00 & \\
\hline & Total & 48 & 79,51 & 18,76 & 31,00 & 100,00 & \\
\hline
\end{tabular}

Como, para algumas variáveis, foram observadas diferenças estatisticamente significativas, foi aplicado o Teste de Mann-Whitney, com o intuito de identificar quais níveis sócio-comunicativos diferenciam-se entre si quanto ao número de atos comunicativos expressos, número de funções comunicativas utilizadas, percentual de uso do meio verbal e gestual, estando essas diferenças apresentadas na Tabela I.11. 
TABELA 1.11 - VALORES DE SIGNIFICÂNCIA NA COMPARAÇÃO DE ÁREAS DO PERFIL COMUNICATIVO QUE SE DIFERENCIAM ENTRE OS NÍVEIS SÓCIO-COMUNICATIVOS ATRIBUÍDOS PELAS TERAPEUTAS:

\begin{tabular}{|c|c|c|c|c|}
\hline \multirow[t]{2}{*}{ Variável } & \multicolumn{4}{|c|}{ Pares de comparação } \\
\hline & Instáveis $\times 1$ & Instáveis x 2 & Instáveis $\times 3$ & Instáveis $\times 4$ \\
\hline No- atos comunicativos & 0,008 & 0,034 & 0,011 & 0,010 \\
\hline No- funções comunicativas & 0,033 & 0,036 & 0,381 & 0,037 \\
\hline$\%$ de uso do meio verbal & 0,009 & 0,279 & 0,001 & 0,001 \\
\hline \%de uso do meio gestual & 0,895 & 0,508 & 0,257 & 0,009 \\
\hline \multirow[t]{2}{*}{ Variável } & \multicolumn{4}{|c|}{ Pares de comparação } \\
\hline & $1 \times 3$ & $1 \times 4$ & $2 \times 3$ & $2 \times 4$ \\
\hline No- atos comunicativos & 0,404 & 0,930 & 0,464 & 0,067 \\
\hline No- funções comunicativas & 0,210 & 0,626 & 0,097 & $>0,999$ \\
\hline$\%$ de uso do meio verbal & 0,128 & 0,002 & 0,040 & 0,010 \\
\hline \%de uso do meio gestual & 0,069 & 0,003 & 0,013 & 0,006 \\
\hline
\end{tabular}

Analisando a Tabela I.11, pode-se notar que os aspectos de número de atos comunicativos expressados e número de funções utilizadas apresentam-se como fatores diferenciais entre o grupo considerado instável e os demais níveis da escala de adaptação sócio-comunicativa. O grupo instável apresenta, em média, menor número de atos comunicativos expressos, bem como menor número de funções comunicativas utilizadas.

Pode-se notar, na Figura I.2, com os valores de percentual de uso do meio gestual e do meio verbal, que quanto maior o nível sócio-comunicativo, maior o uso do meio verbal e menor o uso do meio gestual. Sendo assim, observa-se que o percentual de uso dos meios comunicativos verbal e gestual foram os fatores determinantes na diferenciação e classificação dos 48 sujeitos em cada nível da escala de adaptação sócio-comunicativa para os terapeutas. 
FIGURA I.2- MÉDIAS DOS PERCENTUAIS DE USO DO MEIO VERBAL E GESTUAL PARA CADA NÍVEL DA ESCALA DE ADAPTAÇÃO SÓCIO-COMUNICATIVA:

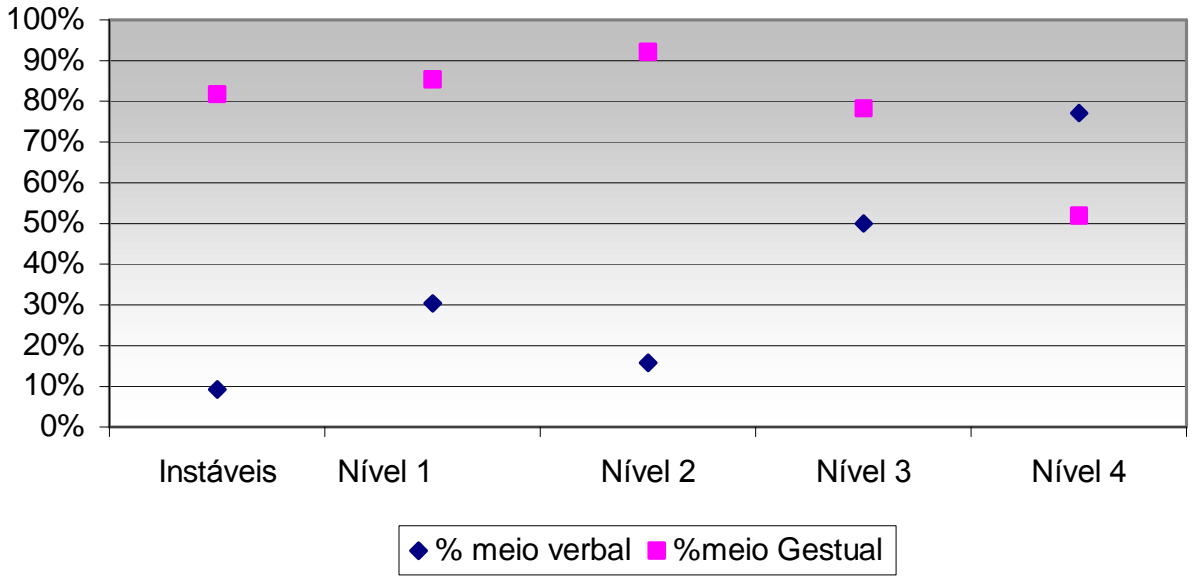

Além disso, também foi realizada a análise de aglomerados (Clusters), sendo este estudo estatístico foi realizado primeiramente com as classificações em níveis dos dados da escala de adaptação sócio-comunicativa obtida com os pais e logo em seguida, com os dados obtidos com as terapeutas. 
DENDOGRAMAS I.1 E I.2- AGLOMERADOS DETERMINADOS PELAS VARIÁVEIS DO PERFIL FUNCIONAL DA COMUNICAÇÃO DOS SUJEITOS DO NÍVEL 1 DA ESCALA DE ADAPTAÇÃO SÓCIOCOMUNICATIVA CLASSIFICADOS PELOS PAIS E TERAPEUTAS:
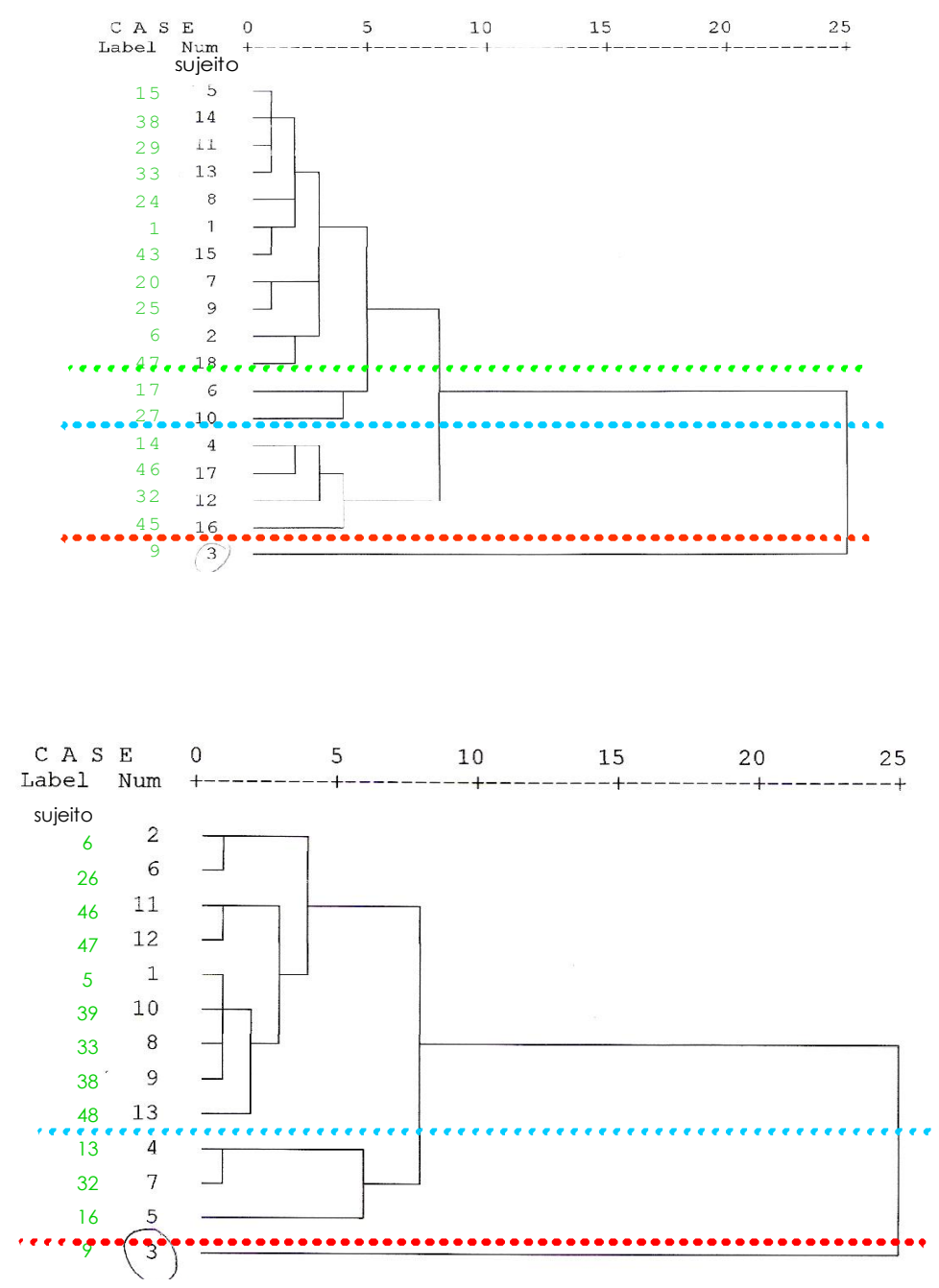

DENDOGRAMA I.1- CLASSIFICAÇÃO ATRIBUÍDA PELOS PAIS:

3- muito pouca diferença: Baixo número de atos comunicativos totais e expressos por minuto.

2- pouca diferença: Uso predominante de funções comunicativas mais interpessoais e dos meios verbais e gestuais

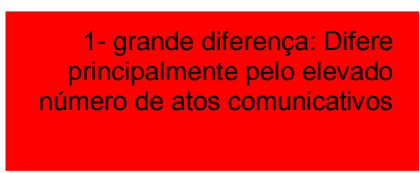

DENDOGRAMA I.2- CLASSIFICAÇÃO ATRIBUÍDA PELAS TERAPEUTAS:

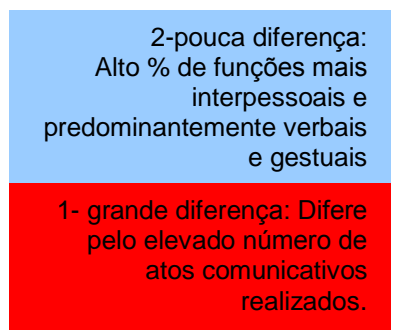

Segundo os Dendogramas 1.1 e 1.2 pode-se dizer que os sujeitos classificados no nível 1 da escala de adaptação sócio-comunicativa, de forma geral apresentam perfis comunicativos semelhantes, tanto na situação com os pais quanto na com as terapeutas. Os dados colhidos com as terapeutas revelaram perfis comunicativos ainda mais semelhantes entre si do que os observados a partir dos dados obtidos com os pais. 
DENDOGRAMAS I.3 E I.4- AGLOMERADOS DETERMINADOS PELAS VARIÁVEIS DO PERFIL FUNCIONAL DA COMUNICAÇÃO DOS SUJEITOS DO NÍVEL 2 DA ESCALA DE ADAPTAÇÃO SÓCIOCOMUNICATIVA CLASSIFICADOS PELOS PAIS E TERAPEUTAS :

DENDOGRAMA I.3- CLASSIFICAÇÃO ATRIBUIDDA PELOS PAIS:

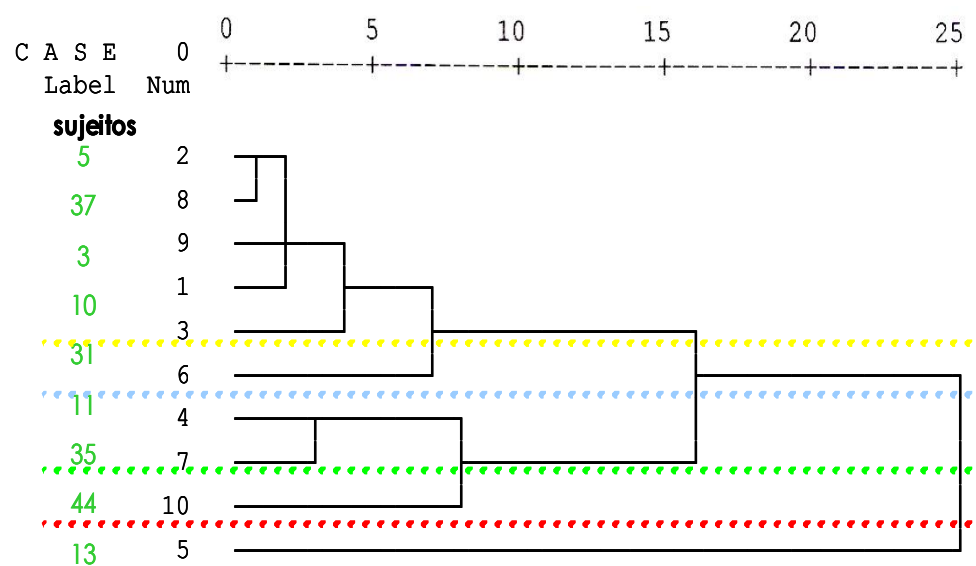

4-muito pouca diferença: Predomínio dos meios vocais e gestuais e simetria no uso de funções mais e menos interpessoais.

3- pouca diferença: Baixo número de atos comunicativos.

2- diferença média: Alto \% de funções mais interpessoais e predominantemente verbais e gestuais.

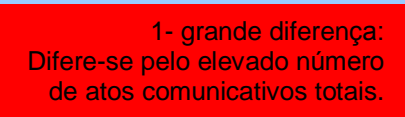

DENDOGRAMA I.4- CLASSIFICAÇÃO

C A S E 0

5
5 10 15 20 25 Label sujeitos

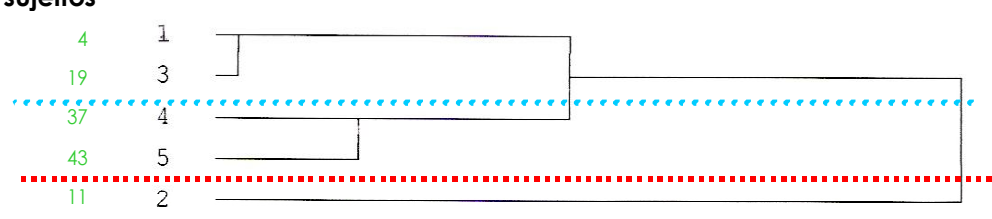

ATRIBUÍDA PELAS TERAPEUTAS:

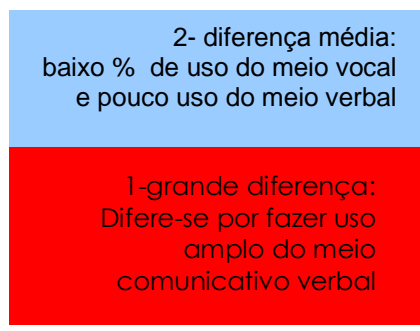

A partir dos Dendogramas 1.3 e I.4 nota-se uma grande heterogeneidade quanto ao perfil comunicativo dos sujeitos classificados no nível 2 da escala de adaptação sócio-comunicativa por parte dos pais em relação às terapeutas, sendo que nos dados obtidos com as terapeutas existe uma maior semelhança entre os sujeitos. 
DENDOGRAMAS I.5 E I.6- AGLOMERADOS DETERMINADOS PELAS VARIÁVEIS DO PERFIL FUNCIONAL DA COMUNICAÇÃO DOS SUJEITOS DO NÍVEL 3 DA ESCALA DE ADAPTAÇÃO SÓCIOCOMUNICATIVA CLASSIFICADOS PELOS PAIS E TERAPEUTAS:

DENDOGRAMA I.5- CLASSIFICAÇÃO

ATRIBUÍDA PELOS PAIS

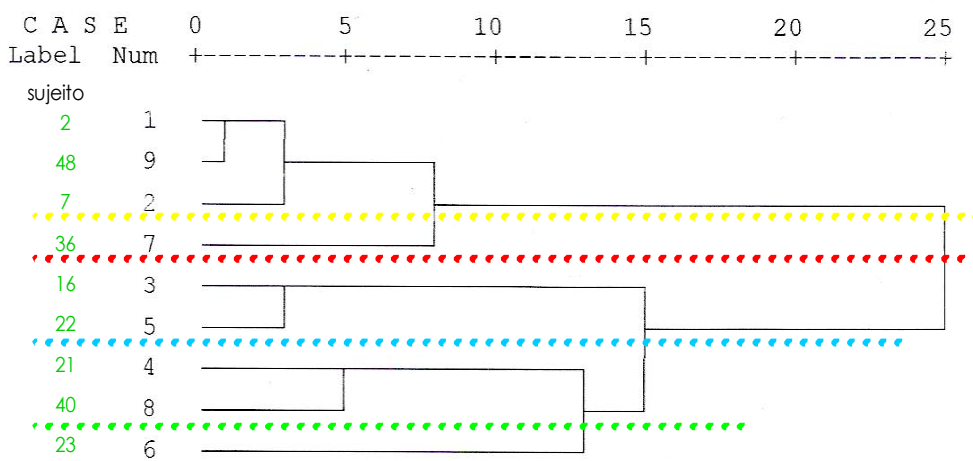

4-muito pouca diferença: Predominantemente gestual e uso simétrico das funções mais e menos interpessoais.

3- pouca diferença: \% elevado no uso dos meios comunicativos verbais, gestuais e vocais.

2- média diferença Predominantemente verbais e gestuais.

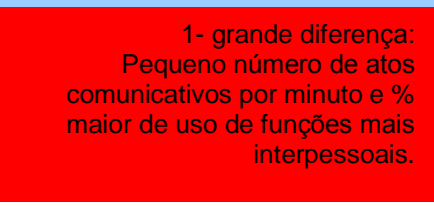

DENDOGRAMA I.6- CLASSIFICAÇÃO

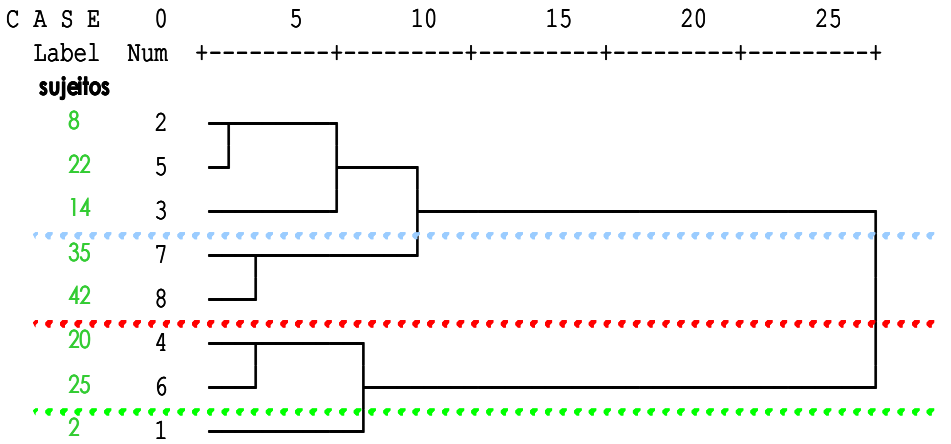

ATRIBUÍDA PELAS TERAPEUTAS:

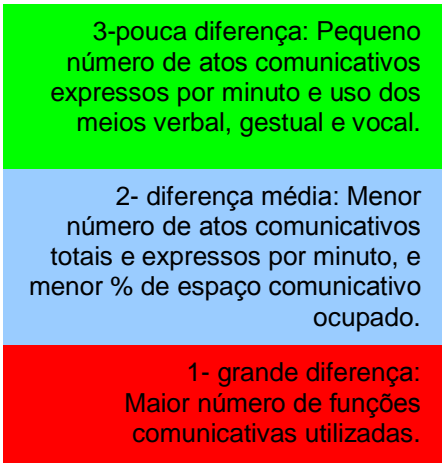

Como já observado anteriormente, nos Dendogramas I.5 e I.6 os sujeitos classificados no nível 3 da escala de adaptação sócio-comunicativa, de forma geral apresentam perfis comunicativos semelhantes, tanto quando os pais foram os informantes quanto quando as terapeutas foram. Entretanto, os sujeitos que compõem a classificação do nível 2 atribuída pelas terapeutas, apresentam perfis comunicativos mais semelhantes. 
DENDOGRAMAS 1.7 e I.8- AGLOMERADOS DETERMINADOS PELAS VARIÁVEIS DO PERFIL FUNCIONAL DA COMUNICAÇÃO DOS SUJEITOS DO NÍVEL 4 DA ESCALA DE ADAPTAÇÃO SÓCIOCOMUNICATIVA CLASSIFICADOS PELOS PAIS E TERAPEUTAS :

DENDOGRAMA I.7- CLASSIFICAÇÃO ATRIBUÍDA PELOS PAIS:
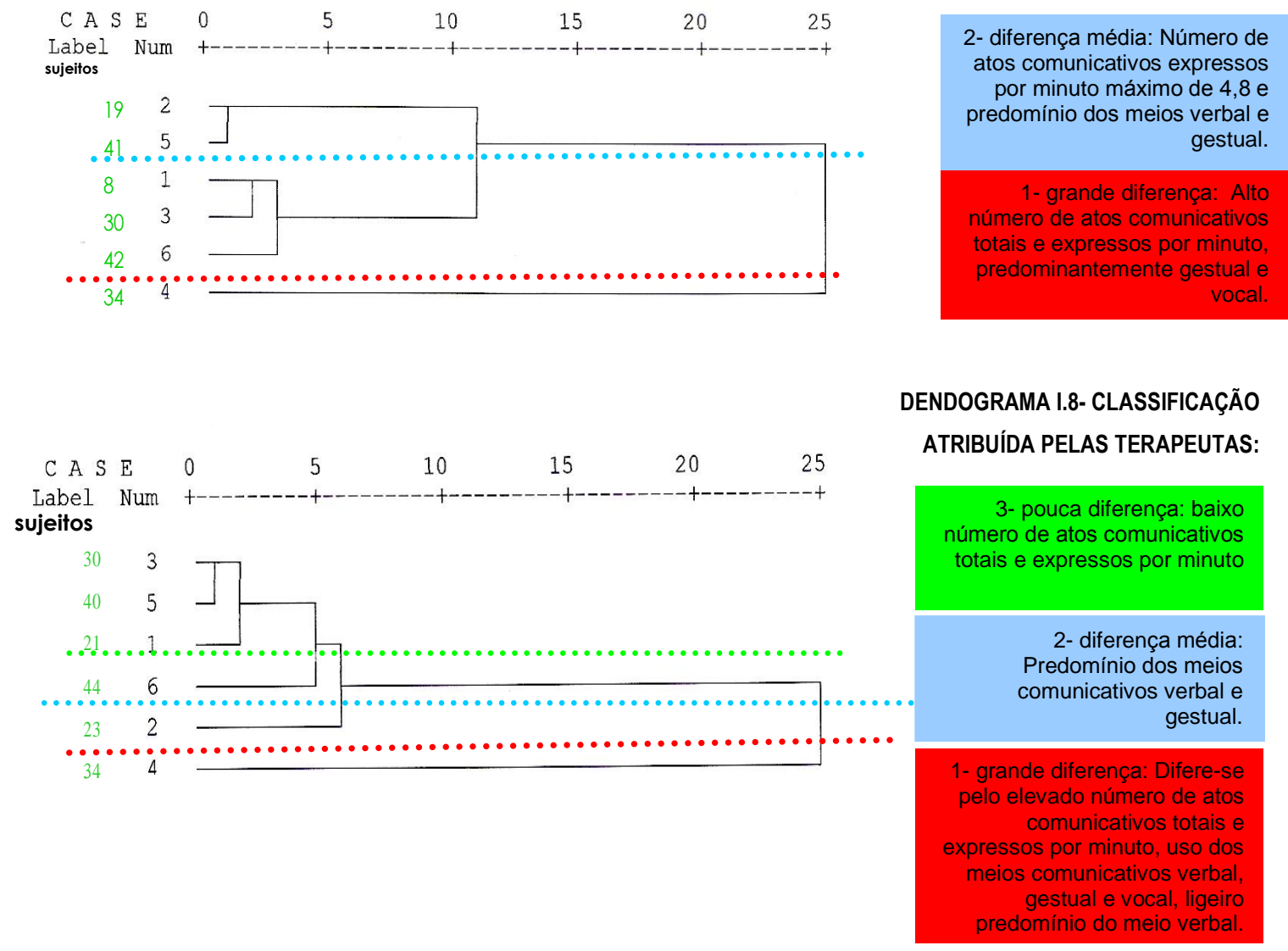

De acordo com os Dendogramas I.7 e I.8, pode-se observar uma maior semelhança entre o perfil funcional da comunicação dos sujeitos classificados pelas terapeutas quanto os aspectos do perfil funcional da comunicação, uma vez que o perfil comunicativo do grupo classificado pelos pais apresenta-se um pouco mais heterogêneo. 


\section{5- Discussão:}

Os dados obtidos neste estudo indicam que houve semelhança no número de respostas quanto à adaptação sócio-comunicativa obtidas por meio de diferentes fontes de informação; ou seja, pais e terapeutas. Isso deixa claro que a aplicação do questionário e protocolo de adaptação sócio-comunicativa com diferentes informantes pode fornecer um resultado bastante homogêneo, sendo possível realizar de forma fidedigna a caracterização das habilidades de relacionamento social dessas crianças. Esses dados são compatíveis com as idéias de diversos autores (p.ex: Luiselli et al., 2001; Charman et. al, 2004, Siperstein e Volkmark, 2004; Eaves et al., 2006; Charman et al., 2004; Moes e Frea, 2002) no sentido de que a consideração da perspectiva dos pais de crianças do espectro autístico quanto ao comportamento lingüístico, cognitivo e social de seus filhos merece destaque, possibilitando que estes tornem-se parceiros dos profissionais envolvidos no processo de intervenção, ajudando no monitoramento do nível de desenvolvimento destas crianças.

A análise dos dados revela que os pais apresentaram consistentemente um número maior de respostas positivas do que as terapeutas, para as questões relativas ao desempenho social de seus filhos. Isso pode estar associado ao descrito por Tager-Flusberg (1999) no sentido de que, um dos fatores importantes na interpretação do comportamento social é o papel da familiaridade, rotinas e estruturação da participação desta criança em atividades sociais. 
Rotinas e atividades estruturadas reduzem a complexidade e a imprevisibilidade do mundo social, o que pode ter sido o fator diferenciador no reconhecimento das habilidades sócio-comunicativas por parte dos pais e das terapeutas, uma vez que a familiaridade com as terapeutas era menor no momento da coleta dos dados. Esses dados corroboram também a afirmação da mesma autora de que, em contextos familiares, crianças autistas são mais interessadas e responsivas à aproximação das pessoas, apresentando iniciativas comunicativas e ações de cooperação.

Pode-se observar que o comportamento sócio-comunicativo das crianças do espectro autístico é extremamente variável, sendo que este passa a ser cada vez mais diferenciado a partir do momento em que a criança necessita perceber, compreender e aceitar a intervenção do outro como agente de participação, colaboração e de co-criação, o que corrobora a afirmação de Turner et al. (2006) de que em crianças autistas também ocorre um desenvolvimento significativo das habilidades lingüísticas relacionado a melhoras significativas nas habilidades cognitivas e sócio-comunicativas, sendo que este desenvolvimento ocorre em diferentes formas e ritmos, considerando sempre as variações individuais que são aparentes.

Este comportamento pode ser notado a partir dos estágios 2 e 3 do nível 2 da escala de adaptação sócio-comunicativa, em que a criança necessita adaptarse bem a novidades, bem como usar a referência e regulação para funcionar como um parceiro em ações coordenadas, sendo encontradas diversas diferenças estatisticamente significantes em relação a esses estágios e níveis sócio-comunicativos em todo o estudo, e correlações sempre positivas com o 
número de atos comunicativos totais e expressos por minuto, e percentual de uso do meio verbal, o que pode estar ligado às variações do contexto comunicativo em que estas crianças se desenvolvem, pois este é sensível a dimensões como formalidade da situação, objetivo da interação e relação entre interlocutores (Yont et al, 2003).

Um aspecto interessante a ser observado é que correlações importantes entre as áreas de linguagem e adaptação sócio-comunicativa foram encontradas na situação em que os pais foram os informantes. Principalmente em relação ao percentual de uso do meio verbal, que foi o aspecto mais correlacionado com as habilidades de relacionamento social. Os resultados indicam que quanto maior o percentual de uso do meio verbal tanto mais presente está a habilidade de utilizar expressões não-verbais do parceiro como referência crítica para suas ações, a habilidade de gostar e reagir bem ou não às novidades introduzidas, de descobrir sua criatividade e imaginação, aprendendo a se divertir como um parceiro igual na co-criação; e a habilidade de experenciar a alegria de dividir percepções com amigos, o que parece confirmar a idéia de que existem diferenças individuais no uso das habilidades de adaptação sócio-comunicativas que são associadas com os resultados de linguagem. O desenvolvimento nas habilidades sociais é associado a mudanças na linguagem receptiva e expressiva, bem como a apresentação de níveis de linguagem mais elaborados; sendo que crianças que respondem com maior freqüência a oportunidades de atenção compartilhada apresentam maiores ganhos nas habilidades de linguagem (Bono et al., 2004). 
Foram também observadas várias correlações entre as demais áreas do perfil funcional da comunicação e da adaptação sócio-comunicativa segundo dados obtidos com as terapeutas, como o número de funções comunicativas utilizadas, números de atos comunicativos totais e expressos por minuto, percentual de espaço comunicativo ocupado, percentual de uso dos meio verbais e gestuais, percentual de uso das funções mais e menos interpessoais. Esses dados demonstram que, de uma forma geral, esses informantes consideram a possibilidade dessas crianças adquirir e desenvolver habilidades comunicativas as quais podem influenciar diretamente nas demais áreas do desenvolvimento lingüístico e sócio-comunicativo. Esses dados corroboram as idéias de Cardoso (2001) e Cardoso e Fernandes (2003) de que esse desenvolvimento social e lingüístico de crianças do espectro autístico pode acontecer de diferentes maneiras, sendo necessário levar em consideração todos os meios comunicativos utilizados e as diferenças contextuais e individuais, que podem influenciar diretamente na efetividade da comunicação.

Neste mesmo estudo de correlações, na situação em que as terapeutas foram as informantes, observa-se a relação entre:

1- quanto mais presente está a habilidade de referência social (estágio 2 do nível 1) maior é o número de funções comunicativas utilizadas, o número de atos comunicativos expressos, e o percentual de uso de funções mais interpessoais; corroborando assim as conclusões de Palermo et al. (2006), de que a socialização requer habilidades de comunicação efetivas, incluindo comunicação não-verbal e que a compreensão das expressões faciais é um ingrediente fundamental no comportamento social. Mas os dados discordam dos autores 
quando eles afirmam que crianças com distúrbios do espectro autístico são inábeis em compreender e usar apropriadamente informações sociais relevantes obtidas das faces dos outros;

2- quanto mais presente a habilidade de aprender e realizar ações por meio de imitações (estágio 3 do nível 1), maior o número de atos comunicativos expressos por minuto e o percentual de uso do meio verbal, o que corrobora os estudos de Ingersoll e Schreibman (2006), que observaram que crianças do espectro autístico desenvolveram suas habilidades de imitação, sendo capazes de generalizá-las para novas situações, além de apresentarem ganhos em comportamentos sócio-comunicativos, incluindo linguagem, jogo simbólico e atenção compartilhada. Entretanto esses dados discordam em parte dos achados de Hwang e Hughes (2000) e Tager-Flusberg (1999), no sentido de que crianças com autismo freqüentemente apresentam profundos déficits nas habilidades de troca social, como a atenção conjunta ou o jogo social imitativo, além de déficits na imitação simples de atos motores, sendo que estas falhas nas habilidades sociais não somente impedem uma interação recíproca, mas também podem retardar o desenvolvimento do comportamento sócio-comunicativo e ampliar o desnível entre estas.

3- as habilidades de dividir percepções (nível 3 estágio 4) e imaginações (nível 4 estágio 2), compartilhar idéias e ser capaz de combiná-las (nível 4 estágio 3), ter amigos (nível 4 estágio 4) e outras áreas do perfil funcional da comunicação - o aumento no percentual de uso do meio verbal e o decréscimo no uso do meio gestual - como o aumento no número de funções utilizadas e de atos comunicativos expressos, e a diminuição do percentual de uso do espaço 
comunicativo. Isso corrobora as idéias de Prinz (1982), Ochs Keenan (1983) e Wetherby et al (1998) de que a habilidade de orientação para o ponto de vista do outro é a chave para o desenvolvimento sócio-lingüístico. Sendo assim, a criança é capaz de usar e compreender comportamentos não-verbais apropriados, respeitar regras conversacionais, seqüenciar e integrar as informações baseadas em experiências passadas, adaptando-se ao contexto social.

Em relação à possibilidade de correlações entre os dados da adaptação sócio-comunicativa e a idade cronológica, bem como o tempo de permanência das 48 crianças em terapia fonoaudiológica no Laboratório de Investigação Fonoaudiológica nos Distúrbios da Espectro Autística-FMUSP, pode-se observar que estes aspectos não apresentam uma interdependência proporcional, apesar de ser encontradas diferenças pontuais, principalmente quando os pais foram os informantes. Van Berckelaer-Onnes (2003) afirma que programas de intervenção de modo geral, apresentam resultado positivo permitindo a essas crianças compreender melhor o mundo e os objetos, de forma geral. Entretanto, deve-se levar em consideração aspectos de intervenção precoce e os diferentes níveis de linguagem e jogo, as experiências terapêuticas anteriores, planos terapêuticos específicos (Bernard-Optiz et al., 2004; Turner et al., 2006), uma vez que esta análise foi realizada em grupo e que o presente estudo refere-se a um recorte transversal. De forma geral os resultados parecem indicar a ausência de interferência sistemática e linear entre fatores como idade e tempo de terapia e os resultados referentes à adaptação sócio-comunicativa. 
$\mathrm{Na}$ aplicação dos Testes de Kruskal-Wallis e de Mann-Whitney, em relação aos níveis sócio-comunicativos classificados pelos pais e pelas terapeutas, podese observar mais uma vez que o fator determinante é o percentual de uso do meio verbal, apesar de que na classificação dada pelas terapeutas foram encontradas diferenças significativas para as áreas de número de atos comunicativos expressos, número de funções comunicativas utilizadas e percentual de uso do meio gestual. Observa-se na Figura I.2 que quanto maior o nível de adaptação sócio-comunicativa maior o percentual de uso do meio verbal e menor o percentual de uso do meio gestual, o que pode estar relacionado com as questões de atenção e intenção comunicativa, levando a uma melhora no desenvolvimento social e lingüístico (Carpenter e Tomasello, 2001).

A classificação das 48 crianças segundo seu nível na escala de adaptação sócio-comunicativa possibilita a identificação de correlações importantes entre este aspecto e as demais áreas do desenvolvimento, como observado no estudo dos aglomerados sendo possível notar que os sujeitos que fizeram parte de cada nível da escala de adaptação sócio-comunicativa, tanto por parte dos pais como das terapeutas, apresentaram, de certa forma, perfis comunicativos muito semelhantes entre si. Algumas diferenças foram encontradas, aparentemente, por tratar-se de um grupo de crianças que apesar de apresentarem um mesmo diagnóstico psiquiátrico, não apresentam as mesmas características, mas foi possível observar que quanto maior o nível sócio-comunicativo, maior a habilidade em utilizar o meio verbal, maior o número de atos comunicativos expressos e funções comunicativas utilizadas e menor a necessidade de uso do meio gestual. 
O percentual de uso do meio verbal parece ter sido o maior responsável pela classificação de cada sujeito em cada nível da escala de adaptação sóciocomunicativa. Este mesmo aspecto aparece em diversos momentos cruciais na apresentação dos resultados deste estudo. Torna-se necessário levar em consideração o papel de destaque da linguagem oral no desenvolvimento infantil, uma vez que no decorrer do trabalho fica clara a evolução dos níveis sóciocomunicativos sempre associados ao processo de evolução dos meios comunicativos gestual, vocal e verbal.

O desenvolvimento da comunicação ocorre de maneiras distintas em crianças do espectro autístico. Aparentemente, a presença ou a ausência da verbalização interfere na forma em que essas crianças são observadas pelos pais e terapeutas quanto ao seu desempenho sócio-comunicativo. A fala é um dos maiores instrumentos para a comunicação interpessoal, e quando este instrumento não está presente, muitas vezes a troca comunicativa se torna ineficiente, podendo ser confundida com a falta de competência comunicativa, podendo levar à diminuição do interesse em relações sociais.

Neste estudo, pode-se observar de forma geral que, os pais e terapeutas percebem que o maior uso do meio verbal estaria relacionado a indivíduos mais participativos e integrados aos contextos comunicativos, mais interessado em trocas interpessoais, e que apresentariam melhores habilidades para resolver problemas, realizar projetos e desenvolver-se sócio-comunicativamente. 


\section{6- Conclusão:}

A hipótese proposta para este estudo de que os resultados referentes à adaptação sócio-comunicativa obtida a partir de entrevistas com terapeutas apresentariam maiores correlações com o perfil funcional da comunicação do que aqueles obtidos a partir de entrevistas com familiares foi confirmada.

De forma geral, o estudo das correlações entre os aspectos do perfil funcional da comunicação e da adaptação sócio-comunicativa não apresentaram um grande número de correlações, sendo este número ainda menor quando os pais foram os informantes. Este estudo determinou um número maior de correlações significativas entre o perfil funcional da comunicação e a adaptação sócio-comunicativa quando as terapeutas foram as informantes. 


$$
\begin{aligned}
& 4.0 \text { - Estudo ll: } \\
& \text { Adaptação sócio-comunicativa e Perfil Funcional da Comunicação } \\
& \text { no espectro autístico: estudo longitudinal }
\end{aligned}
$$

\section{1- Hipóteses:}

Hipótese 1- Ao final de um período de aproximadamente um ano de atendimento fonoaudiológico haverá maior convergência entre os dados obtidos com os pais e aqueles obtidos com as terapeutas, no que diz respeito à adaptação sócio-comunicativa.

Hipótese 2- Ao final de um período de aproximadamente um ano de atendimento fonoaudiológico haverá maior convergência entre os resultados do perfil funcional da comunicação e da adaptação sócio-comunicativa.

\section{2- Objetivos Específicos:}

- Verificar se existem correlações entre os dados de adaptação sóciocomunicativa obtidos com os pais ou responsáveis e com as terapeutas, após um período de aproximadamente 12 meses de terapia fonoaudiológica com crianças com Distúrbios do Espectro Autístico (DEA).

- Verificar se há aumento nas relações entre os níveis de adaptação sóciocomunicativa e o perfil funcional da comunicação observado após um período de 12 meses de terapia fonoaudiológica com crianças com Distúrbios do Espectro Autístico (DEA). 


\section{3- Método:}

Esta pesquisa foi encaminhada à comissão de ética da instituição e recebeu aprovação sob o protocolo no- 420/04, apresentado no anexo 1.

Foi solicitada a autorização para a utilização dos dados para fins de pesquisa ao adulto responsável pelo cuidado de um cada dos sujeitos (anexo 2) sendo critério de inclusão que todos os participantes desta pesquisa estivessem em atendimento semanal, no período mínimo de um ano, no Laboratório de Investigação Fonoaudiológica nos Distúrbios do Espectro Autístico do curso de Fonoaudiologia da Faculdade de Medicina da Universidade de São Paulo.

\subsection{1-Sujeitos:}

Participaram deste estudo 37 crianças, entre 3 anos e 0 meses e 12 anos e 11 meses de idade, com diagnóstico clínico incluído no espectro autístico, atribuído por médicos neurologistas e/ou psiquiatras segundo critérios específicos do DSM-IV (1995) e da CID-10 (1993), sendo elas, sorteadas, aleatoriamente, entre aqueles que tenham feito parte do Estudo I e que tenham permanecido em atendimento fonoaudiológico no Laboratório de Investigação Fonoaudiológica nos

Distúrbios do Espectro Autístico- FMUSP, por aproximadamente 1 ano, sem interrupções maiores do que 4 semanas, e que tenham freqüentado pelo menos 45 sessões. 
Quanto aos sujeitos, observa-se que estes variaram quanto à idade média e ao tempo médio de intervenção terapêutica fonoaudiológica realizada no Laboratório de Investigação Fonoaudiológica nos Distúrbios do Espectro Autístico (LIF-DEA), em que estas crianças estão inseridas.

TABELA II.1- VALORES DE MÉDIA E DESVIO-PADRÃO DA IDADE E TEMPO DE INTERVENÇÃO FONOAUDIOLÓGICA EM ANOS DOS SUJEITOS NOS DIFERENTES MOMENTOS DE COLETA:

\begin{tabular}{|c|c|c|c|c|c|}
\hline $\begin{array}{l}\text { Estatístical } \\
\text { Variáveis }\end{array}$ & $\begin{array}{c}\text { Idade_PFC1 e SOC- } \\
\text { COM1 }\end{array}$ & Idade_PFC2 & Idade_SOC_COM_2 & T_terapia_1 & T_terapia_2 \\
\hline Média & 8 anos e 0 meses & 9 anos e 0 meses & 8 anos e 10 meses & 3,62 & 4,38 \\
\hline Desvio-padrão & 2,43 & 2,43 & 2,42 & 1,80 & 1,83 \\
\hline
\end{tabular}

Legenda:

Idade_pfc_1e soc-com_1: idade apresentada no primeiro momento da coleta do perfil funcional da comunicação e da adaptação sócio-comunicativa.

Idade_pfc_2: idade apres entada no segundo momento da coleta do perfil funcional da comunic ação.

Idade_soc-com_2: idade apresentada no segundo momento da coleta da adaptação sócio-comunicativa.

T_terapia_1: anos em terapia no referido LIF até o primeiro momento de coleta dos dados

T_terapia_2: anos em terapia no referido LIF até o segundo momento de coleta dos dados

O Quadro II.1 caracteriza de forma sintética os dados referentes à idade, bem como ao tempo em que cada sujeito deste estudo freqüenta a intervenção terapêutica fonoaudiológica no Laboratório de Investigação Fonoaudiológica nos Distúrbios do Espectro Autístico (LIF-DEA) nos dois diferentes momentos de coleta dos dados. 
QUADRO II.1- CARACTERIZAÇÃO DA AMOSTRA:

\begin{tabular}{|c|c|c|c|c|c|c|c|c|c|}
\hline RP & Suj. & T_terapia_1 & Id_pfc_1 & Id_soc-com 1 & $\mathrm{RP}$ & Suj. & T_terap_2 & Id_pfc_2 & Id_soc-com_2 \\
\hline 1 & 3 & 2 & $11 a$ e $2 m$ & $11 a$ e $2 m$ & 1 & 3 & 3 & $12 a$ e $2 m$ & $12 a$ e $0 m$ \\
\hline 2 & 4 & 2 & $3 a$ e $11 \mathrm{~m}$ & $3 a$ e $11 \mathrm{~m}$ & 2 & 4 & 4 & $4 a$ e $11 \mathrm{~m}$ & 4 a e $9 m$ \\
\hline 3 & 5 & 4 & $7 a$ e $6 m$ & $7 a$ e $6 m$ & 3 & 5 & 5 & $8 a$ e $6 m$ & $8 a$ e $4 m$ \\
\hline 4 & 6 & 4 & $7 \mathrm{a}$ e $7 \mathrm{~m}$ & $7 a$ e $7 m$ & 4 & 6 & 5 & $8 a$ e $6 m$ & $8 a$ e $4 m$ \\
\hline 5 & 7 & 6 & $9 a$ e $7 m$ & $9 a$ e $7 m$ & 5 & 7 & 7 & $10 a$ e $9 m$ & $10 a$ e $9 m$ \\
\hline 6 & 8 & 1 & $4 a$ e $11 \mathrm{~m}$ & $4 a$ e $11 m$ & 6 & 8 & 2 & $5 \mathrm{a}$ e $11 \mathrm{~m}$ & $5 a$ e $9 m$ \\
\hline 7 & 10 & 6 & $8 a$ e $11 m$ & $8 a$ e $11 \mathrm{~m}$ & 7 & 10 & 7 & $10 a$ e $0 m$ & $9 a$ e $10 m$ \\
\hline 8 & 11 & 7 & $11 \mathrm{a}$ e $6 \mathrm{~m}$ & $11 a$ e $6 m$ & 8 & 11 & 8 & $12 \mathrm{a}$ e $7 \mathrm{~m}$ & $12 a$ e $5 m$ \\
\hline 9 & 12 & 1 & $5 a$ e $4 m$ & $5 a$ e $4 m$ & 9 & 12 & 2 & $6 a$ e $4 m$ & $6 a$ e $4 m$ \\
\hline 10 & 13 & 5 & $7 a$ e $5 m$ & $7 a$ e $5 m$ & 10 & 13 & 6 & $8 a$ e $7 m$ & $8 a$ e $5 m$ \\
\hline 11 & 15 & 3 & $8 a$ e $1 \mathrm{~m}$ & $8 a$ e $1 \mathrm{~m}$ & 11 & 15 & 4 & $9 a$ e $2 m$ & $9 a$ e $0 m$ \\
\hline 12 & 16 & 4 & $8 a$ e $8 m$ & $8 a$ e $8 m$ & 12 & 16 & 5 & $9 a$ e $8 m$ & $9 a$ e $6 m$ \\
\hline 13 & 17 & 2 & $4 a$ e $4 m$ & $4 a$ e $4 m$ & 13 & 17 & 3 & $5 a$ e $4 m$ & $5 a$ e $1 m$ \\
\hline 14 & 18 & 2 & $4 a$ e $7 m$ & $4 a$ e $7 m$ & 14 & 18 & 3 & $5 a$ e $7 m$ & $5 a$ e $5 m$ \\
\hline 15 & 19 & 5 & $11 \mathrm{a}$ e $10 \mathrm{~m}$ & $11 \mathrm{a}$ e $10 \mathrm{~m}$ & 15 & 19 & 6 & $12 a$ e $10 m$ & $12 a$ e $8 m$ \\
\hline 16 & 20 & 4 & $7 a$ e $7 m$ & $7 a$ e $7 m$ & 16 & 20 & 5 & $8 a$ e $7 m$ & $8 a$ e $5 m$ \\
\hline 17 & 21 & 5 & $11 \mathrm{a}$ e $7 \mathrm{~m}$ & $11 \mathrm{a}$ e $7 \mathrm{~m}$ & 17 & 21 & 6 & $12 \mathrm{a}$ e $7 \mathrm{~m}$ & $12 a$ e $5 \mathrm{~m}$ \\
\hline 18 & 22 & 3 & $8 a$ e $3 m$ & $8 a$ e $3 m$ & 18 & 22 & 4 & $9 a$ e $3 m$ & $9 \mathrm{a}$ e $1 \mathrm{~m}$ \\
\hline 19 & 23 & 5 & $11 \mathrm{a}$ e $10 \mathrm{~m}$ & $11 \mathrm{a}$ e $10 \mathrm{~m}$ & 19 & 23 & 6 & $12 \mathrm{a}$ e $10 \mathrm{~m}$ & $12 \mathrm{a}$ e $8 \mathrm{~m}$ \\
\hline 20 & 24 & 6 & $9 a$ e $0 m$ & $9 a$ e $0 m$ & 20 & 24 & 7 & $10 a$ e $0 m$ & $9 a$ e $10 m$ \\
\hline 21 & 25 & 3 & $8 a$ e $0 m$ & $8 a$ e $0 m$ & 21 & 25 & 4 & $9 a$ e $0 m$ & $8 a$ e $11 m$ \\
\hline 22 & 27 & 1 & $5 \mathrm{a}$ e $1 \mathrm{~m}$ & $5 a$ e $1 \mathrm{~m}$ & 22 & 27 & 2 & $6 a$ e $1 \mathrm{~m}$ & $5 a$ e $11 m$ \\
\hline 23 & 28 & 2 & $6 a$ e $0 \mathrm{~m}$ & $6 a$ e $0 m$ & 23 & 28 & 3 & $7 \mathrm{a}$ e $1 \mathrm{~m}$ & $6 a$ e $11 m$ \\
\hline 24 & 29 & 3 & $6 a$ e $10 m$ & $6 a$ e $10 m$ & 24 & 29 & 4 & $7 a$ e $10 m$ & $7 a$ e $8 m$ \\
\hline 25 & 30 & 7 & $10 a$ e $9 m$ & $10 a$ e $9 m$ & 25 & 30 & 8 & $11 \mathrm{a}$ e $9 \mathrm{~m}$ & $11 \mathrm{a}$ e $6 \mathrm{~m}$ \\
\hline 26 & 33 & 2 & 6 a e $0 m$ & 6 a e $0 \mathrm{~m}$ & 26 & 33 & 3 & $7 a$ e $1 m$ & $6 a$ e $10 m$ \\
\hline 27 & 34 & 2 & $7 a$ e $7 m$ & $7 \mathrm{a}$ e $7 \mathrm{~m}$ & 27 & 34 & 3 & $8 a$ e $9 m$ & $8 a$ e $6 m$ \\
\hline 28 & 35 & 2 & $3 a$ e $0 \mathrm{~m}$ & $3 a$ e $0 \mathrm{~m}$ & 28 & 35 & 2 & $4 a$ e $0 m$ & $3 a$ e $10 m$ \\
\hline 29 & 36 & 3 & 8 a e $9 m$ & 8 a e $9 m$ & 29 & 36 & 3 & $9 a$ e $9 m$ & $9 a$ e $7 m$ \\
\hline 30 & 37 & 3 & 6 a e $0 m$ & 6 a e $0 m$ & 30 & 37 & 3 & $7 a$ e $0 m$ & $6 a$ e $10 m$ \\
\hline 31 & 38 & 6 & 9 a e $9 m$ & 9 a e $9 m$ & 31 & 38 & 6 & $10 a$ e $8 m$ & $10 a$ e $6 m$ \\
\hline 32 & 40 & 2 & $8 a$ e $11 m$ & $8 a$ e $11 m$ & 32 & 40 & 2 & $9 a$ e $10 m$ & $9 a$ e $8 m$ \\
\hline 33 & 41 & 4 & $8 a$ e $1 \mathrm{~m}$ & $8 a$ e $1 m$ & 33 & 41 & 4 & $9 a$ e $0 m$ & $8 a$ e $10 m$ \\
\hline 34 & 44 & 7 & 11 a e $10 \mathrm{~m}$ & 11 a e $10 \mathrm{~m}$ & 34 & 44 & 7 & $12 \mathrm{a}$ e $11 \mathrm{~m}$ & $12 a$ e $8 m$ \\
\hline 35 & 46 & 2 & 6 a e $0 m$ & 6 a e $0 m$ & 35 & 46 & 2 & $7 \mathrm{a}$ e $0 \mathrm{~m}$ & $6 a$ e $10 m$ \\
\hline 36 & 47 & 3 & 8 a e $9 m$ & 8 a e $9 m$ & 36 & 47 & 3 & $9 a$ e $9 m$ & $9 a$ e $7 m$ \\
\hline 37 & 48 & 5 & 10 a e $2 m$ & 10 a e $2 \mathrm{~m}$ & 37 & 48 & 5 & $11 \mathrm{a}$ e $2 \mathrm{~m}$ & $11 \mathrm{a}$ e $0 \mathrm{~m}$ \\
\hline
\end{tabular}

Legenda:

RP: registro de pesquisa

Suj: sujeitos (número de registro de cada sujeito no banco de dados

T_terapia_1: anos em terapia no referido LIF até o primeiro momento de coleta dos dados.

Id_pfc_1: idade em anos e meses apresentada no primeiro momento de coleta do perfil funcional da comunicação.

Id_soc-com_1: idade em anos e meses apresentada no primeiro momento da coleta da adaptação sócio-comunicativa

T_terapia_2: anos em terapia no referido LIF até o segundo momento de coleta dos dados

Id_pfc_2: idade em anos e meses apresentada no segundo momento da coleta do perfil funcional da

Id_soc-com_2: idade em anos e meses apresentada no segundo momento da coleta da adaptação sócio-comunicativa 
Foram também sujeitos deste trabalho, 35 mães e dois pais responsáveis pelas 37 crianças acima citadas, sendo que eles foram convidados a participar deste estudo respondendo a um questionário sobre o relacionamento social de seu (a) filho (a) que se encontra em atendimento fonoaudiológico no Laboratório de Investigação nos Distúrbios do Espectro Autístico - FMUSP. Não houve o estabelecimento de critérios de inclusão e/ou exclusão dos pais para a participação desta pesquisa, sendo importante relatar que o nível sócioeconômico e educacional não foi uma variável considerada.

Participaram ainda 15 terapeutas, responsáveis pelo atendimento fonoaudiológico das 37 crianças pertencentes ao espectro autístico durante um período de aproximadamente 12 meses. Neste período as terapeutas realizaram o atendimento fonoaudiológico de seus (as) pacientes normalmente, sendo realizadas, como sempre, filmagens semestrais de sessões de terapia, para fins de avaliação da evolução terapêutica.

Para este estudo as terapeutas também foram convidadas a responder ao mesmo questionário aplicado aos pais quanto, ao relacionamento social de seus pacientes e filhos, respectivamente. Apresenta-se no Quadro I.2 o número de pacientes designados para cada uma das 15 terapeutas participantes deste estudo, bem como sua situação acadêmica. 
QUADRO II.2- CARACTERIZAÇÃO DA AMOSTRA DE TERAPEUTAS:

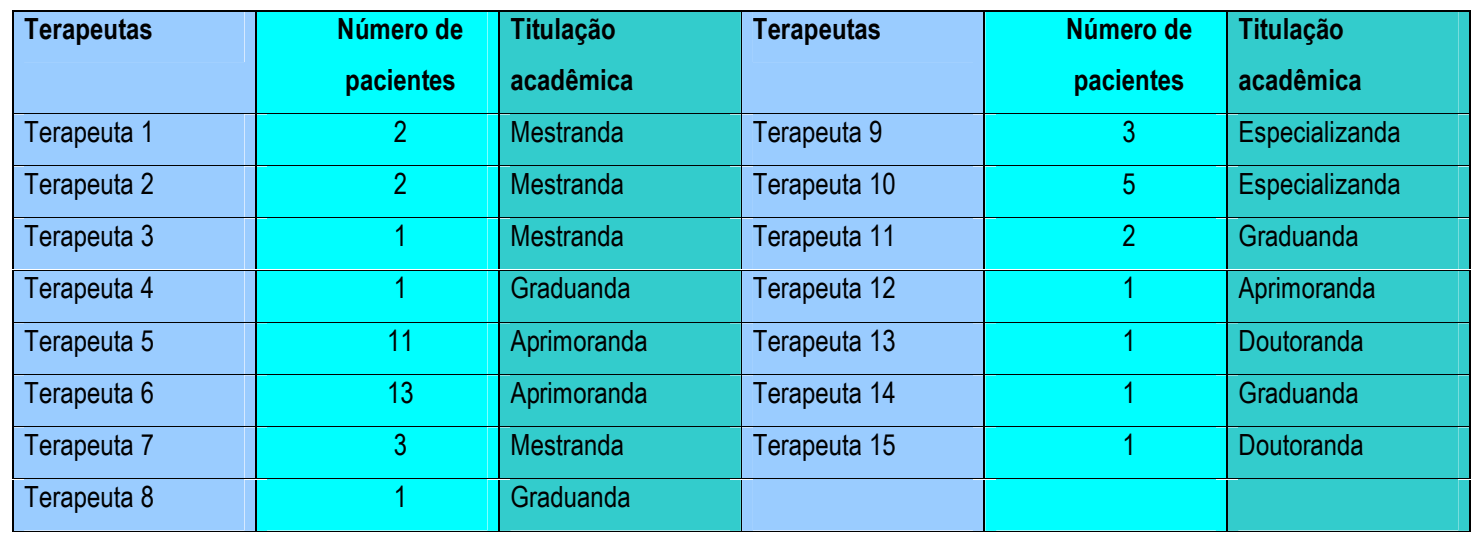

\subsection{2-Material:}

\section{Perfil Funcional da Comunicação:}

Para a coleta de dados do perfil funcional da comunicação foi utilizado o protocolo de registro, proposto por Fernandes (2004), em que os dados são analisados considerando as teorias pragmáticas.

Foram selecionados brinquedos de acordo com a vontade e/ou solicitação das crianças para estimular a comunicação espontânea durante a situação de brincadeira, visando melhores situações comunicativas para registro em vídeo.

Os protocolos específicos para transcrição das fitas VHS e/ou DVDs e análise do perfil comunicativo encontram-se nos anexos 3 a e 3b. 


\section{Adaptação Sócio-comunicativa:}

Para a coleta dos dados da adaptação sócio-comunicativa foram utilizados o questionário e o protocolo específico proposto pela pesquisadora em 2004, estando este material apresentado nos anexos 4a e 4b.

\section{Outros materiais utilizados:}

- Filmadoras VHS e Digital;

- Fitas VHS e DVDs;

- Brinquedos em geral;

\subsection{3- Procedimentos:}

\section{Procedimentos para coleta de dados do Perfil Funcional da}

\section{Comunicação:}

A coleta de dados foi realizada em dois diferentes momentos, com um intervalo de aproximadamente 12 meses entre os mesmos, sendo que a terapeuta de cada sujeito procurou fornecer um contexto comunicativo amplo, buscando a espontaneidade comunicativa.

O primeiro momento de coleta de dados foi realizado entre os meses de abril e maio de 2005, sendo que o segundo momento de coleta ocorreu nos mesmos meses, ou seja, abril e maio, do ano de 2006. 
Foram fornecidos às crianças diversos materiais lúdicos a fim de propiciar situações de interação espontânea, atenção conjunta, uso da representação simbólica, além de incentivar a iniciativa comunicativa e o uso de respostas no discurso, sem a exigência de regras e procedimentos rígidos.

Desta forma, foram realizadas filmagens de um período de 30 minutos de brincadeira espontânea em situação clínica, sendo que o desempenho comunicativo foi analisado e registrado em protocolos específicos, propostos por Fernandes (2004)

Dos 30 minutos de filmagem foram selecionados os 15 minutos contínuos de comunicação mais simétrica apresentados por cada sujeito, sendo analisados os aspectos de atos comunicativos produzidos, espaço comunicativo ocupado, meios comunicativos e funções comunicativas apresentadas.

O número de atos comunicativos expressos pela criança foi registrado, e o número total de atos comunicativos expressos por minuto pela criança foi calculado dividindo-se o número total de atos comunicativos expressos pela criança pelo tempo de gravação, neste caso 15 minutos.

Calculou-se também o percentual do espaço comunicativo utilizado em relação ao número total de atos comunicativos registrados. Realizou-se a classificação das funções comunicativas quanto ao seu caráter mais ou menos interpessoal, segundo Fernandes e Galinari (1999), bem como, o registro do número total de vezes e a porcentagem representada no total de cada função expressa por um determinado meio comunicativo, além do percentual do uso de cada meio comunicativo (gestual, vocal e verbal). 


\section{Procedimentos para a investigação da adaptação sócio-comunicativa:}

O questionário da avaliação da adaptação sócio-comunicativa foi aplicado individualmente com os pais e terapeutas dos sujeitos, em entrevistas realizadas pela pesquisadora, sendo que os entrevistados deveriam responder sim ou não a questões relacionadas ao desempenho sócio-comunicativo de seus filhos e pacientes, respectivamente. A cada resposta sim, era marcado o número um (1) e a cada resposta não, era marcado o número zero (0) para possibilitar o estudo estatístico dos dados.

Estas entrevistas foram realizadas com as terapeutas em horários de supervisão clínica do referido laboratório e com os pais ou responsáveis de cada sujeito, enquanto estes aguardavam o início ou término do atendimento fonoaudiológico de seus filhos.

Na situação de coleta de dados com os pais, a terapeuta de cada criança apresentava-os à pesquisadora, sendo que esta realizava uma explanação aos mesmos sobre o procedimento da pesquisa, solicitava a autorização dos mesmos para participar neste trabalho científico e registrava todas as respostas obtidas em protocolo específico.

A coleta dos dados da adaptação sócio-comunicativa ocorreu em dois diferentes momentos e em ambos foi realizada a entrevista com as terapeutas e com os pais de todos os sujeitos. 
Para uma melhor compreensão foram classificados como, T1 e T2, os informantes e os momentos de entrevistas com as terapeutas, assim como P1 e P2 para os pais.

O primeiro momento da coleta dos dados foi realizado após um mês do início do processo terapêutico fonoaudiológico no ano de 2005 , entre os meses de abril e maio, e o segundo momento da coleta de dados aconteceu em um mês prévio ao final de um ano do processo terapêutico, -entre fevereiro e março de 2006-, uma vez que, anualmente ocorre a troca de terapeutas como procedimento de rotina do Laboratório de Investigação Fonoaudiológica dos Distúrbios do Espectro Autístico-FMUSP.

Manteve-se neste trabalho as mesmas classificações propostas em estudos anteriores (Sousa, 2004; Sousa-Morato e Fernandes, 2006a e 2006b), apresentadas no anexo 5.

$\mathrm{Na}$ aplicação do questionário foram realizadas algumas modificações nas exemplificações como forma de proporcionar um maior entendimento para os entrevistados. Para uma maior compreensão das idéias e classificações propostas pela escala de adaptação sócio-comunicativa estão apresentados nos anexos 4a e 4b, o questionário e o protocolo específico da investigação da adaptação sócio-comunicativa. 
No procedimento de aplicação do questionário, o pesquisador perguntava ao entrevistado a respeito da primeira exemplificação fornecida, caso este não compreendesse ou não conseguisse responder, apresentava-se o segundo exemplo, sendo as respostas obtidas anotadas no protocolo de registro específico.

\subsection{4- Análise Estatística:}

Foi utilizado como instrumento o programa SPSS (Statistical Package for Social Sciences), em sua versão 14.0, para a análise estatística dos dados sendo adotado o nível de significância de 5\% ( $\alpha=0,050$ — significância adotada), para a aplicação dos testes estatísticos deste estudo, ou seja, quando a significância calculada $(p)$ for menor do que $5 \%(0,050)$, considera-se uma diferença (ou relação) estatisticamente significativa; quando a significância calculada (p) for igual ou maior do que $5 \%(0,050)$, é considerada uma diferença (ou relação) estatisticamente não-significativa, ou seja, uma semelhança.

Para identificar possíveis diferenças entre duas médias aritméticas simples, de dados obtidos em dois diferentes momentos, ou seja, os dados de adaptação sócio-comunicativa, foi aplicado o Teste de Wilcoxon (Rosner, 1986). 
Para estudar a correlação entre o perfil funcional da comunicação e os dados de adaptação sócio-comunicativa foi utilizada a Análise de Correlação de Spearman para identificar possíveis relações entre os dados das variáveis de interesse. Neste caso o coeficiente de correlação varia de -1 até +1 , sendo que valores positivos indicam comportamentos paralelos dos dados observados, e valores negativos indicam comportamentos opostos. Quanto mais próximos de 1, tanto mais próximos os comportamentos entre as variáveis contrapostas (Rosner, 1986).

$\mathrm{Na}$ análise do estudo das correlações é importante considerar que quanto maior a amostra; menores serão os coeficientes de correlação, ou seja, mais próximos de zero serão os coeficientes de correlação, sendo isto esperado e previsto pelo teste, o que não invalida a conclusão a ser tirada em função dos resultados obtidos pelo mesmo.

Foi realizada ainda, uma análise estatística descritiva, CrossTabs, pela aplicação do Teste de McNemar, a aplicação dos testes de Kruskal-Wallis e ManWhitney, além da análise de aglomerados (Clusters), para identificar subgrupos específicos (quais os mais semelhantes e quais os mais diferentes entre si), aglomerando os sujeitos de cada nível da escala de adaptação sóciocomunicativa quanto à proximidade nas diferentes áreas do perfil funcional da comunicação. 


\section{4- Resultados:}

Os resultados serão apresentados, a partir de uma análise estatística global dos 37 sujeitos que permaneceram em atendimento fonoaudiológico no Laboratório de Investigação Fonoaudiológica nos Distúrbios do Espectro Autístico-FMUSP por um período de aproximadamente 12 meses, sem interrupções maiores do que 4 semanas, e que tenham freqüentado pelo menos 45 sessões. Foi objeto de análise deste estudo, a relação dos dados de adaptação sócio-comunicativa obtidos com pais e terapeutas com as diferentes áreas do perfil funcional da comunicação, ambos obtidos em dois momentos de coleta.

Vale ressaltar que serão apresentados neste capítulo somente os resultados estatisticamente significativos. Os resultados completos estão apresentados no CD, anexo 6.

Por este estudo compreender um acompanhamento longitudinal e se tratar de um transtorno do desenvolvimento tão abrangente, em que as inúmeras diferenças individuais dos sujeitos são marcantes, optou-se por considerar cada sujeito como seu próprio controle, determinando dados mais fidedignos.

A apresentação dos resultados será iniciada pela comparação do número de respostas positivas obtidas na aplicação do questionário de adaptação sóciocomunicativa com os pais e terapeutas em diferentes momentos, e logo em seguida, na comparação entre os dados obtidos com os pais e terapeutas no primeiro momento e no segundo momento de coleta, sendo também realizada a análise estatística dos referidos dados. 
Na comparação do número de respostas positivas da escala de adaptação sócio-comunicativa obtidas com os pais nos dois momentos de coleta, pode-se observar, na Figura II.1, um perfil de adaptação sócio-comunicativa muito semelhante nos dois momentos de coleta. Observa-se apenas um aumento relevante no número de respostas positivas, sendo este no estágio 1 do nível 2 (se a criança é capaz de gostar e reagir bem ou não às novidades introduzidas), determinando uma diferença estatisticamente significativa, na aplicação do teste de Wilcoxon, com valor de 0,008 , indicada pela seta preta .

FIGURA II.1- COMPARAÇÃO DO NÚMERO DE RESPOSTAS POSITIVAS NA ESCALA DE ADAPTAÇÃO SÓCIO-COMUNICATIVA, OBTIDAS COM OS PAIS NOS DOIS DIFERENTES MOMENTOS DE COLETA:

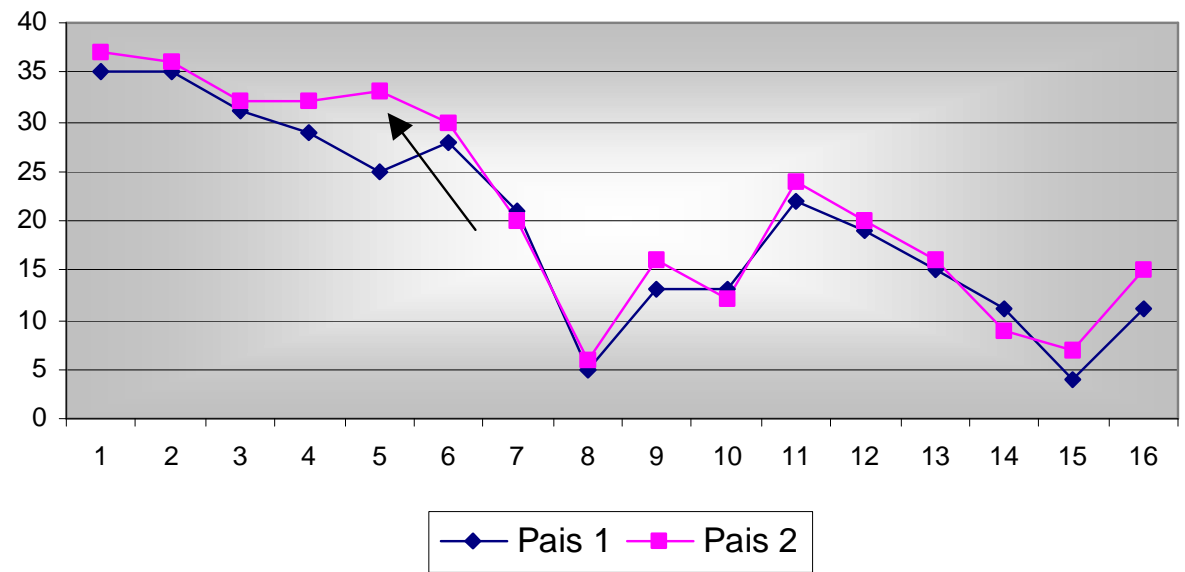

\begin{tabular}{|c|c|}
\hline \multicolumn{2}{|c|}{ Legenda } \\
\hline 1- estágio 1 do nível 1 & 9- estágio 1 do nível 3 \\
\hline 2-estágio 2 do nível1 & 10-estágio 2 do nível 3 \\
\hline 3-estágio 3 do nível 1 & 11-estágio 3 do nível 3 \\
\hline 4-estágio 4 do nível1 & 12-estágio 4 do nível 3 \\
\hline 5-estágio 1 do nível 2 & 13-estágio 1 do nível 4 \\
\hline 6-estágio 2 do nível 2 & 14-estágio 2 do nível 4 \\
\hline 7-estágio 3 do nível 2 & 15-estágio 3 do nível 4 \\
\hline 8-estágio 4 do nível 2 & 16-estágio 4 do nível 4 \\
\hline
\end{tabular}


A partir dos dados de adaptação sócio-comunicativa obtidos com as terapeutas, observa-se a comparação do número de respostas positivas na Figura II.2. Ocorre um perfil semelhante no desenho das curvas, mas que se difere de forma quantitativa, ou seja, o número de respostas obtidas no segundo momento da coleta mostrou-se, genericamente maior em todos os estágios da escala de adaptação sócio-comunicativa, apesar de manter o mesmo traçado gráfico.

FIGURA II.2- COMPARAÇÃO DO NÚMERO DE RESPOSTAS POSITIVAS NA ESCALA DE ADAPTAÇÃO SÓCIOCOMUNICATIVA, OBTIDAS COM AS TERAPEUTAS NOS DOIS DIFERENTES MOMENTOS DE COLETA:

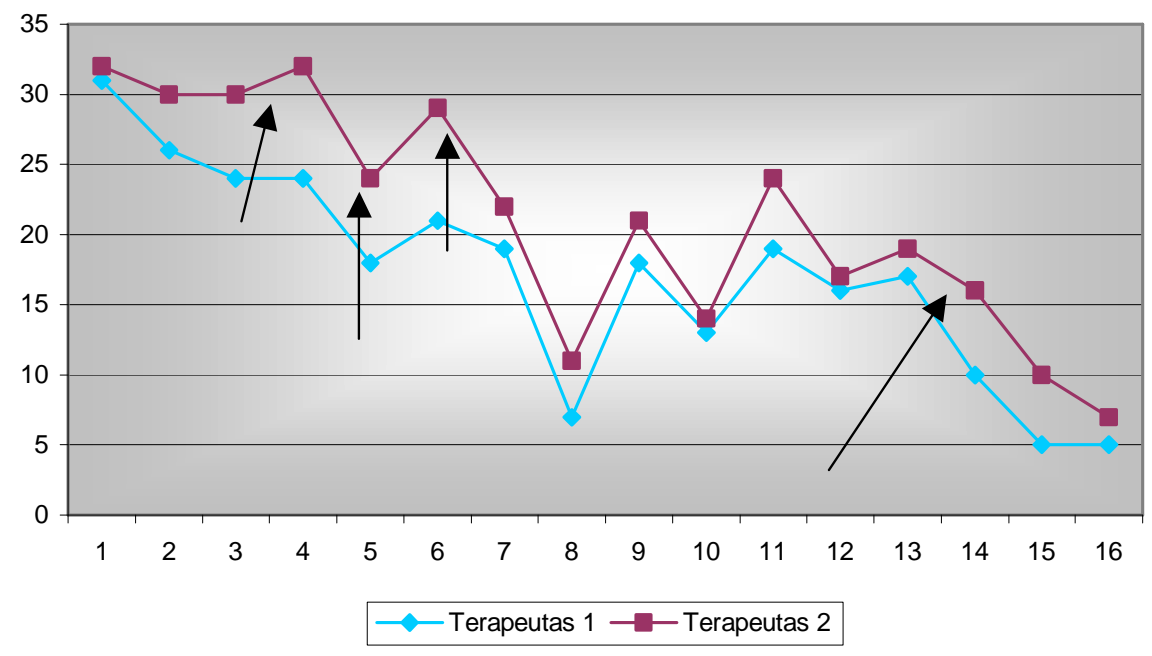

\begin{tabular}{|l|l|}
\hline & Legenda \\
1- estágio 1 do nível1 & 9- estágio 1 do nível 3 \\
2-estágio 2 do nível1 & 10-estágio 2 do nível 3 \\
3-estágio 3 do nível 1 & 11-estágio 3 do nível 3 \\
4-estágio 4 do nível1 & 12-estágio 4 do nível 3 \\
5-estágio 1 do nível 2 & 13-estágio 1 do nível 4 \\
6-estágio 2 do nível 2 & 14-estágio 2 do nível 4 \\
7-estágio 3 do nível 2 & 15-estágio 3 do nível 4 \\
8-estágio 4 do nível 2 & 16-estágio 4 do nível 4 \\
\hline
\end{tabular}


Na análise do Teste de Wilcoxon, na comparação dos dados de adaptação sócio-comunicativa obtidos com as terapeutas em diferentes momentos foram encontradas quatro diferenças estatisticamente significativas, estando os resultados expostos na Tabela II.2 e indicados pelas setas pretas da Figura II.2.

TABELA II.2- VALORES DE SIGNIFICÂNCIA NA COMPARAÇÃO ENTRE OS DADOS DE ADAPTAÇÃO SÓCIO-COMUNICATIVA OBTIDOS COM AS TERAPEUTAS NOS DOIS DIFERENTES MOMENTOS DE COLETA:

\begin{tabular}{ccccc}
\hline $\begin{array}{c}\text { Pares de } \\
\text { variáveis }\end{array}$ & $\begin{array}{c}\text { Estágio } 4 \text { do nivel 1 } \\
(11 \times \text { t2) }\end{array}$ & $\begin{array}{c}\text { Estágio } 1 \text { do nivel } 2 \\
(t 1 \times \text { t2) }\end{array}$ & $\begin{array}{r}\text { Estágio } 2 \text { do nivel } 2 \\
(11 \times t 2)\end{array}$ & $\begin{array}{c}\text { Estágio } 2 \text { do nivel } 4 \\
(t 1 \times \text { t2 })\end{array}$ \\
\hline Significância & 0,005 & 0,014 & 0,021 & 0,014 \\
\hline
\end{tabular}

A partir das Figuras II.1 e II.2, observam-se quedas acentuadas no número de respostas positivas praticamente nos mesmos estágios da escala de adaptação sócio-comunicativa, sendo estas quedas mais acentuadas no primeiro momento da coleta para ambas as situações.

A queda no número de respostas positivas torna-se mais marcante a partir do estágio 2 do nível 2, que significa que a criança é capaz de se adaptar a mudanças e variações, sendo esta queda acentuada no estágio 4 do nível 2 e no estágio 3 do nível 4, que se referem, respectivamente, à preocupação com os outros e capacidade de compreendê-los e à capacidade de compartilhar idéias, combinando e integrando idéias como uma unidade.

Ao observar o estágio 4 do nível 4 , nota-se uma diferença em relação ao número de respostas positivas dadas pelos pais e pelas terapeutas nos dois momentos de coleta, sendo que, quando os pais foram os informantes apresenta- 
se um aumento neste número na segunda coleta, diferente do que acontece com as terapeutas, onde este número permanece de certa forma baixo.

Ao comparar entre si o número de respostas positivas obtidas na escala de adaptação sócio-comunicativa pelos pais e terapeutas em diferentes momentos, obteve-se os resultados apresentados nas Figuras II.3 e II.4.

FIGURA II. 3- NÚMERO DE RESPOSTAS POSITIVAS NA ESCALA DE ADAPTAÇÃO SÓCIOCOMUNICATIVA, OBTIDAS PELOS PAIS E TERAPEUTAS NO PRIMEIRO MOMENTO DE COLETA:

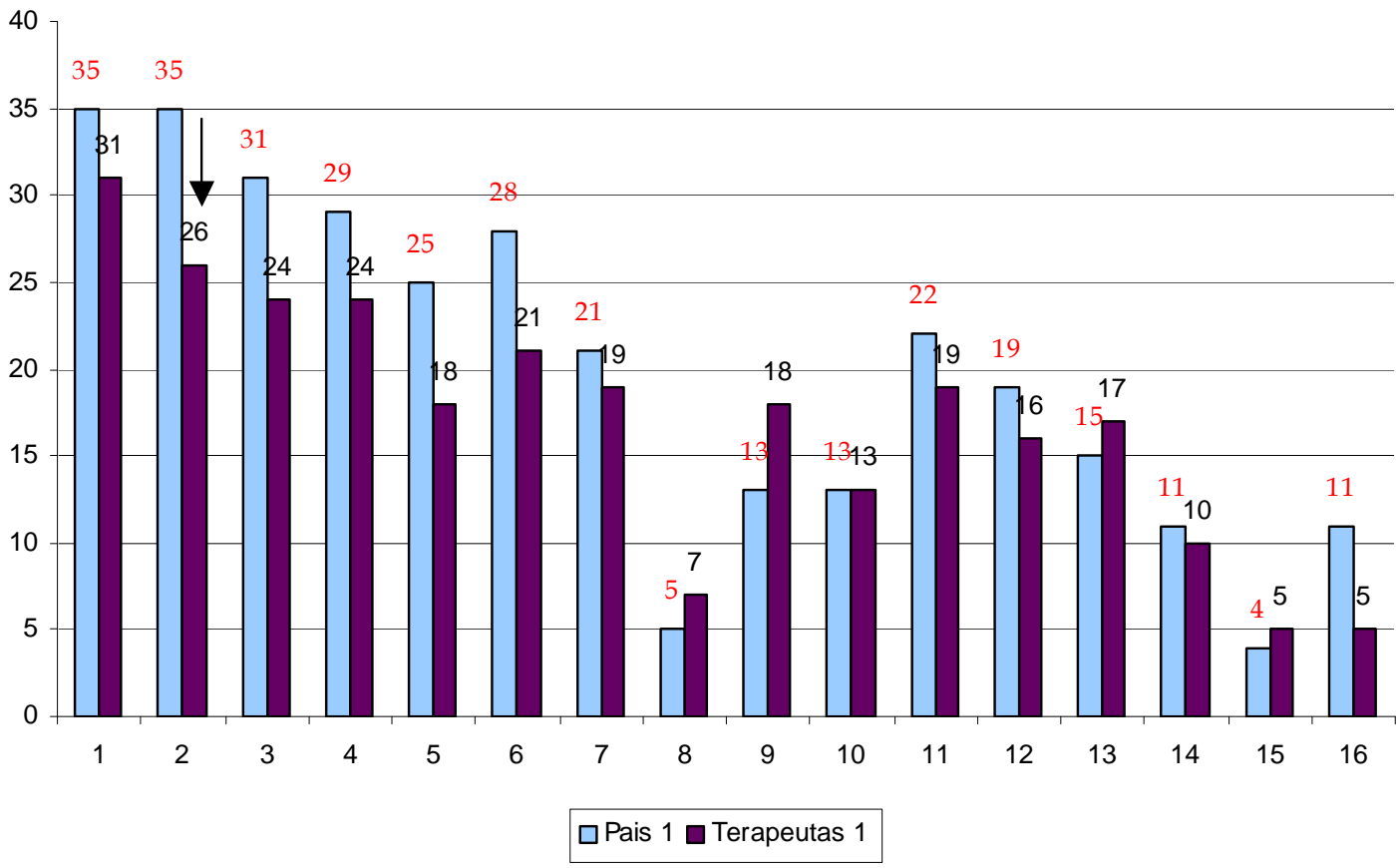

\begin{tabular}{|l|l|}
\hline \multicolumn{2}{|c|}{ Legenda } \\
1- estágio 1 do nível1 & 9- estágio 1 do nível 3 \\
2-estágio 2 do nível1 & 10-estágio 2 do nível 3 \\
3-estágio 3 do nível 1 & 11-estágio 3 do nível 3 \\
4-estágio 4 do nível1 & 12-estágio 4 do nível 3 \\
5-estágio 1 do nível 2 & 13-estágio 1 do nível 4 \\
6-estágio 2 do nível 2 & 14-estágio 2 do nível 4 \\
7-estágio 3 do nível 2 & 15-estágio 3 do nível 4 \\
8-estágio 4 do nível 2 & 16-estágio 4 do nível 4 \\
\hline
\end{tabular}


Observando os resultados da Figura II.3, na comparação do número de respostas positivas obtidas por meio de pais e terapeutas no primeiro momento de coleta dos dados de adaptação sócio-comunicativa, observa-se, de forma genérica, a semelhança entre os resultados obtidos. Na aplicação no Teste de Wilcoxon, foi encontrada apenas uma diferença estatisticamente significativa, em relação ao estágio 2 do nível 1 com valor de 0,003, marcada com a seta preta na Figura II.3.

Pode-se ainda dizer que no primeiro momento de coleta, dos dezesseis estágios que compõem a escala de adaptação sócio-comunicativa, somente em quatro estágios o número de respostas positivas dos pais foi menor que o das terapeutas, sendo estes referentes ao estágio 4 do nível 2 (se a criança é capaz de perceber e identificar comportamentos e emoções, modificando seu comportamento para um maior aproveitamento das experiências compartilhadas), estágio 1 do nível 3 (se a criança consegue balancear ações de co-regulação regular seu comportamento em base de um referencial social- e ações de covariação -estabelecer relações de variações mutuamente com o parceiro em uma determinada atividade- em atividades de cooperação entre os parceiros), ao estágio 1 do nível 4 (se a criança é capaz de aprender a valorizar o ponto de vista do outro) e ao estágio 3 do nível 4 (se a criança consegue combinar e integrar idéias como uma unidade). 
Na comparação dos dados de adaptação sócio-comunicativa, obtidos com pais e terapeutas no segundo momento de coleta, foram identificadas cinco diferenças estatisticamente significativas pela aplicação do Teste de Wilcoxon, estando estas apresentadas na Tabela II.3 e indicadas pelas setas pretas na Figura II.4 .

TABELA II.3- VALORES DE SIGNIFICÂNCIA NA COMPARAÇÃO ENTRE OS DADOS DE ADAPTAÇÃO SÓCIO-COMUNICATIVA OBTIDOS COM PAIS E TERAPEUTAS NO SEGUNDO MOMENTO DE COLETA:

\begin{tabular}{|c|c|c|c|c|c|}
\hline $\begin{array}{l}\text { Pares de } \\
\text { variáveis }\end{array}$ & $\begin{array}{l}\text { Estágio } 1 \text { do nível } \\
\qquad 1 \text { (p2 } x \text { t2) }\end{array}$ & $\begin{array}{c}\text { Estágio } 2 \text { do nível } 1 \\
\text { (p2 } \times \text { t2) }\end{array}$ & $\begin{array}{l}\text { Estágio } 1 \text { do nível } 2 \\
\text { (p2x t2) }\end{array}$ & $\begin{array}{l}\text { Estágio } 2 \text { do nível } 4 \\
\text { (p2 } x \text { t2) }\end{array}$ & $\begin{array}{c}\text { Estágio } 4 \text { do nível } 4 \\
\text { (p2 xt2) }\end{array}$ \\
\hline Significância & 0,025 & 0,014 & 0,020 & 0,035 & 0,021 \\
\hline
\end{tabular}

As diferenças estatisticamente significativas encontradas referem-se aos estágios 1 e 2 do nível 1 (se a criança realiza contato visual significativo com os pais, terapeutas ou cuidadores e/ou ri de expressões faciais apresentadas pelos mesmos e se a criança percebe as expressões faciais e preocupa-se com a compreensão e reação); ao estágio 1 do nível 2, em que a criança é capaz de gostar e reagir bem ou não às novidades introduzidas; e aos estágios 2 e 4 do nível 4, que significam, respectivamente, se a criança é capaz de aproveitar e combinar as imaginações compartilhadas entre si e o parceiro; e se a criança é capaz de experenciar amigos que dividem os mesmos interesses e experiências em comum. 
FIGURA II.4- COMPARAÇÃO DO NÚMERO DE RESPOSTAS POSITIVAS NA ESCALA DE ADAPTAÇÃO SÓCIOCOMUNICATIVA, OBTIDAS COM PAIS E TERAPEUTAS NO SEGUNDO MOMENTO DE COLETA:

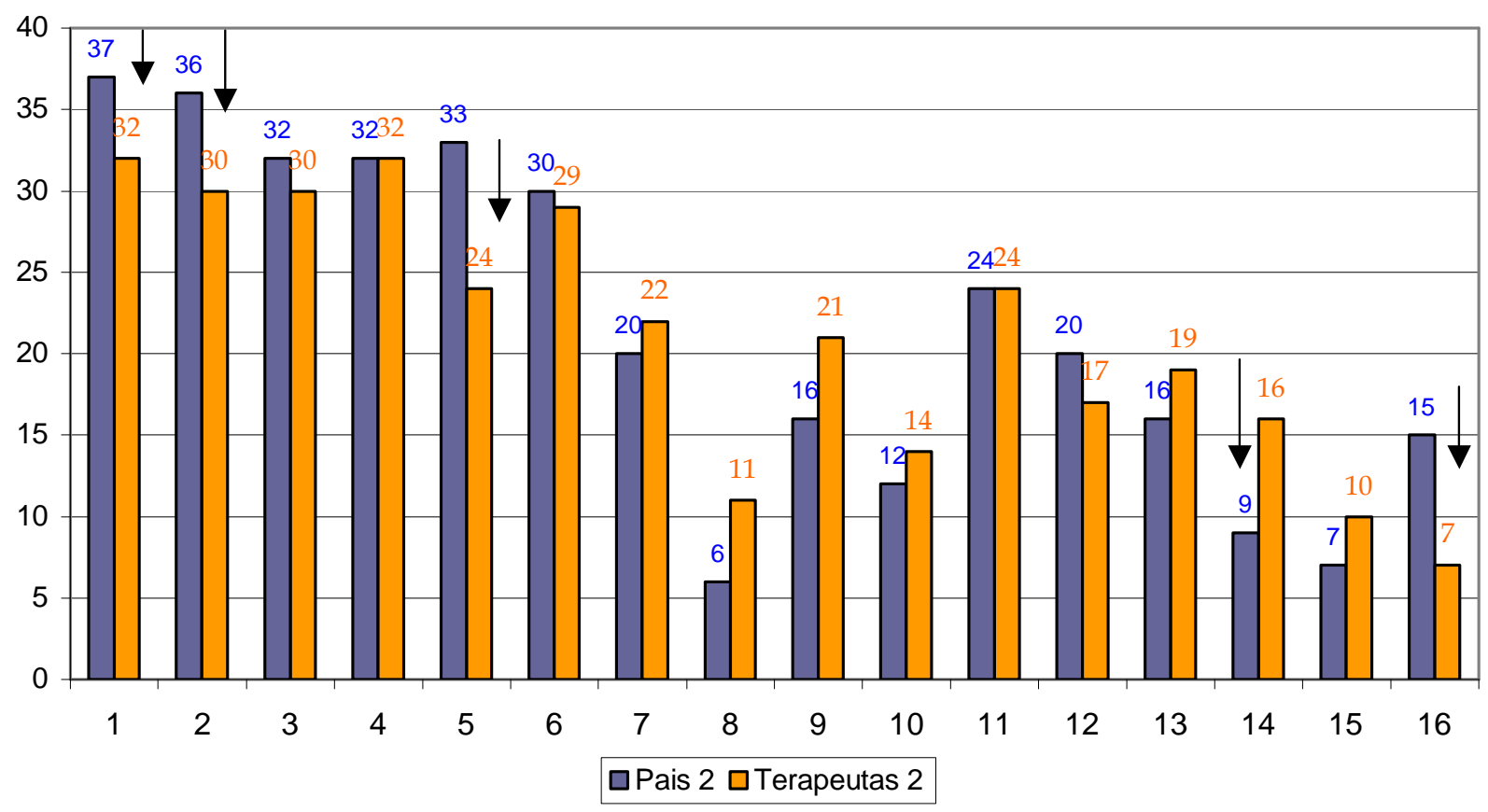

Legenda

1- estágio 1 do nív el 1

2-estágio 2 do nivel1

3-estágio 3 do nível 1

4-estágio 4 do nível1

5-estágio 1 do nível 2

6 -estágio 2 do nível 2

7-estágio 3 do nível 2

8-estágio 4 do nível 2
9- es tágio 1 do nível 3

10-estágio 2 do nivel 3

11-estágio 3 do nivel 3

12-estágio 4 do nivel 3

13-estágio 1 do nível 4

14-estágio 2 do nivel 4

15-estágio 3 do nível 4

16-estágio 4 do nível 4

Observa-se que, do estágio 1 do nível 1 ao estágio 2 do nível 2, o número de respostas positivas obtidas com os pais é quase sempre maior que o das terapeutas. Entretanto, do estágio 3 do nível 2 ao estágio 2 do nível 3, o número de respostas positivas das terapeutas é freqüentemente maior que o dos pais. Nos demais estágios o predomínio de respostas positivas oscila entre pais e terapeutas, mas observa-se mais uma vez que no estágio 4 do nível 4 , o número de respostas dos pais é maior do que o atribuído pelas terapeutas. 
Na comparação das semelhanças e diferenças entre as respostas dadas por pais e terapeutas ao questionário que avalia a adaptação sócio-comunicativa de seus filhos (as) e pacientes, respectivamente, no primeiro momento de coleta dos dados foi encontrada, pela aplicação do Teste de McNemar e CrosTabs, somente uma diferença estatisticamente significativa, sendo esta mais uma vez em relação ao estágio 2 do nível 1, com valor de 0,004.

Estão demonstrados na Tabela II.4, todos os valores de significância obtidos nessa comparação e na Tabela II.5, a comparação de respostas atribuídas pelos diferentes informantes ao referido nível e estágio da escala de adaptação sócio-comunicativa que apresentou diferença estatisticamente significativa.

TABELA II.4- VALORES DE SIGNIFICÂNCIA OBTIDOS NA COMPARAÇÃO DE RESPOSTAS DADAS POR PAIS E TERAPEUTAS A CADA ESTÁGIO E NIIVEL DA ESCALA DE ADAPTAÇÃO SÓCIO-COMUNICATIVA, NO PRIMEIRO MOMENTO DE COLETA:

\begin{tabular}{|c|c|c|c|c|c|c|c|c|}
\hline Pares de & N1e1 (pais) & N1e2 (pais) & N1e3 (pais) & N1e4 (pais) & N2e1 (pais) & N2e2 (pais) & N2e3 (pais) & N2e4 (pais) \\
\hline \multirow[t]{3}{*}{ comparação } & $x$ & $x$ & $x$ & $x$ & $x$ & $x$ & $x$ & $x$ \\
\hline & N1e1 & N1e2 & N1e3 & N1e4 & $N 2 e 1$ & $\mathrm{~N} 2 \mathrm{e} 2$ & N2e3 & N4e4 \\
\hline & (terapeutas) & (terapeutas) & (terapeutas) & (terapeutas) & (terapeutas) & (terapeutas) & (terapeutas) & (terapeutas) \\
\hline significância & 0,219 & 0,004 & 0,092 & 0,180 & 0,092 & 0,118 & 1,000 & 0,688 \\
\hline Pares de & N3e1 (pais) & N3e2 (pais) & N3e3 (pais) & N3e4 (pais) & N4e1 (pais) & N4e2 (pais) & N4e3 (pais) & N4e4 (pais) \\
\hline \multirow[t]{3}{*}{ comparação } & $x$ & $x$ & $x$ & $x$ & $x$ & $x$ & $x$ & $x$ \\
\hline & N3e1 & $N 3 e 2$ & N3e3 & N3e4 & N4e1 & $N 4 \mathrm{e} 2$ & N4e3 & N4e4 \\
\hline & (terapeutas) & (terapeutas) & (terapeutas) & (terapeutas) & (terapeutas) & (terapeutas) & (terapeutas) & (terapeutas) \\
\hline significância & 0,332 & 1,000 & 0,581 & 0,581 & 0,774 & 1,000 & 1,000 & 0,146 \\
\hline
\end{tabular}


TABELA II.5- VALORES OBTIDOS NA COMPARAÇÃO DAS REPOSTAS SIM OU NÃO DADAS POR DIFERENTES INFORMANTES PARA O NÍVEL E ESTÁGIO DA ESCALA DE ADAPTAÇÃO SÓCIOCOMUNICATIVA QUE APRESENTOU DIFERENÇA ESTATISTICAMENTE SIGNIFICATIVA, NO PRIMEIRO MOMENTO DE COLETA:

\begin{tabular}{ccccc}
\hline Níveis /estágios & Não-Terapeutas & Sim-Terapeutas & Total \\
\hline Nível 1 estágio 2 & \%ão- Pais & 2 & 0 & 2 \\
& & $5,4 \%$ &, $0 \%$ & $5,4 \%$ \\
& Sim-Pais & 9 & 26 & 35 \\
\% dotal total & $24,3 \%$ & $70,3 \%$ & $94,6 \%$ \\
& \% do total & 11 & 26 & 37 \\
& & $29,7 \%$ & $70,3 \%$ & $100,0 \%$ \\
\hline
\end{tabular}

Ao comparar as respostas dadas por todos os informantes a cada estágio da escala de adaptação sócio-comunicativa no segundo momento de coleta, foram encontradas três diferenças estatisticamente significativas em relação aos estágios 2 do nível $1(p=0,031)$, ao estágio 1 do nível $2(p=0,035)$ e ao estágio 4 do nível $4(p=0,039)$ na aplicação do teste de McNemar. Estão apresentados na Tabela II.6 todos os valores de significância obtidos nessa comparação e na Tabela II.7, a comparação de respostas dadas concomitantemente pelos diferentes informantes aos níveis e estágios da escala de adaptação sóciocomunicativa que determinaram diferença estatisticamente significativa. 
TABELA II.6- VALORES DE SIGNIFICÂNCIA OBTIDOS NA COMPARAÇÃO DE RESPOSTAS DADAS POR PAIS E TERAPEUTAS A CADA ESTÁGIO E NIIVEL DA ESCALA DE ADAPTAÇÃO SÓCIO-COMUNICATIVA, NO SEGUNDO MOMENTO DE COLETA:

\begin{tabular}{|c|c|c|c|c|c|c|c|c|}
\hline Pares de & N1e1 (pais) & N1e2 (pais) & N1e3 (pais) & N1e4 (pais) & N2e1 (pais) & N2e2 (pais) & N2e3 (pais) & N2e4 (pais) \\
\hline \multirow[t]{2}{*}{ comparação } & $x$ & $x$ & $x$ & $x$ & $x$ & $x$ & $x$ & $x$ \\
\hline & $\begin{array}{c}\text { N1e1 } \\
\text { (terapeutas) }\end{array}$ & $\begin{array}{c}\text { N1e2 } \\
\text { (terapeutas) }\end{array}$ & $\begin{array}{c}\mathrm{N1e3} \\
\text { (terapeutas) }\end{array}$ & $\begin{array}{c}\text { N1e4 } \\
\text { (terapeutas) }\end{array}$ & $\begin{array}{c}\text { N2e1 } \\
\text { (terapeutas) }\end{array}$ & $\begin{array}{c}\mathrm{N} 2 \mathrm{e} 2 \\
\text { (terapeutas) }\end{array}$ & $\begin{array}{c}\text { N2e3 } \\
\text { (terapeutas) }\end{array}$ & $\begin{array}{c}\mathrm{N} 4 \mathrm{e} 4 \\
\text { (terapeutas) }\end{array}$ \\
\hline significância & $>0,999$ & 0,031 & 0,688 & 1,000 & 0,035 & 1,000 & 0,774 & 0,125 \\
\hline Pares de & N3e1 (pais) & N3e2 (pais) & N3e3 (pais) & N3e4 (pais) & N4e1 (pais) & N4e2 (pais) & N4e3 (pais) & N4e4 (pais) \\
\hline \multirow[t]{3}{*}{ comparação } & $x$ & $x$ & $x$ & $x$ & $x$ & $x$ & $x$ & $x$ \\
\hline & $N 3 e 1$ & $N 3 e 2$ & N3e3 & N3e4 & $N 4 e 1$ & $N 4 \mathrm{e} 2$ & N4e3 & N4e4 \\
\hline & (terapeutas) & (terapeutas) & (terapeutas) & (terapeutas) & (terapeutas) & (terapeutas) & (terapeutas) & (terapeutas) \\
\hline significância & 0,302 & 0,774 & 1,000 & 0,549 & 0,581 & 0,065 & 0,688 & 0,039 \\
\hline
\end{tabular}

De forma geral, pode-se dizer que a aplicação do questionário e protocolo de adaptação sócio-comunicativa com diferentes informantes nos dá resultados semelhantes e de certa forma homogêneos e condizentes com os dados encontrados na aplicação do Teste de Wilcoxon. Todos esses achados demonstram que este pode ser um material passível de aplicação em diferentes fontes de informação, levando a uma objetivação da avaliação do desenvolvimento social de crianças do espectro autístico, possibilitando a identificação e diferenciação dos progressos obtidos quantitativa e qualitativamente de uma forma fidedigna. 
TABELA II.7- VALORES OBTIDOS NA COMPARAÇÃO DAS REPOSTAS SIM OU NÃO DADAS POR DIFERENTES INFORMANTES PARA OS NÍVEIS E ESTÁGIOS DA ESCALA DE ADAPTAÇÃO SÓCIOCOMUNICATIVA QUE APRESENTARAM DIFERENÇA ESTATISTICAMENTE SIGNIFICATIVA, NO SEGUNDO MOMENTO DE COLETA:

\begin{tabular}{|c|c|c|c|c|}
\hline Níveis /estágios & & Não-Terapeutas & Sim-Terapeutas & Total \\
\hline \multirow{4}{*}{ Nível 1 estágio 2} & & 1 & 0 & 1 \\
\hline & $\%$ do total & $2,7 \%$ &, $0 \%$ & $2,7 \%$ \\
\hline & Sim-Pais & 6 & 30 & 36 \\
\hline & $\%$ do total & $16,2 \%$ & $81,1 \%$ & $97,3 \%$ \\
\hline \multirow[t]{2}{*}{ Total } & $\%$ do total & 7 & 30 & 37 \\
\hline & & $18,9 \%$ & $81,1 \%$ & $100,0 \%$ \\
\hline \multirow{4}{*}{ Nível 2 estágio 2} & & 1 & 3 & 1 \\
\hline & $\%$ do total & $2,7 \%$ & $8,1 \%$ & $10,8 \%$ \\
\hline & Sim-Pais & 12 & 21 & 36 \\
\hline & $\%$ do total & $32,4 \%$ & $56,8 \%$ & $89,2 \%$ \\
\hline \multirow[t]{2}{*}{ Total } & $\%$ do total & 13 & 24 & 37 \\
\hline & & $35,1 \%$ & $64,9 \%$ & $100,0 \%$ \\
\hline \multirow{4}{*}{ Nível 4 estágio 4} & -10 & 20 & 2 & 22 \\
\hline & $\%$ do total & $54,1 \%$ & $5,4 \%$ & $59,5 \%$ \\
\hline & Sim-Pais & 10 & 5 & 15 \\
\hline & $\%$ do total & $27,0 \%$ & $13,5 \%$ & $40,5 \%$ \\
\hline \multirow[t]{2}{*}{ Total } & $\%$ do total & 30 & 7 & 37 \\
\hline & & $81,1 \%$ & $18,9 \%$ & $100,0 \%$ \\
\hline
\end{tabular}


No estudo das correlações do perfil funcional da comunicação e os dados de adaptação sócio-comunicativa colhidos com os pais, ambos obtidos no primeiro momento de coleta, das 144 correlações possíveis somente 10 correlações estatisticamente significativas foram encontradas, sugerindo que o perfil funcional da comunicação atua independente da adaptação sóciocomunicativa.

Entretanto, não se pode negar a interferência em alguns pontos desta relação, principalmente a grande relação dos meios comunicativos verbal e gestual com os dados da adaptação sócio-comunicativa, como mostra a Tabela II.8.

TABELA II.8- CORRELAÇÕES SIGNIFICATIVAS ENTRE OS DADOS DA ADAPTAÇÃO SÓCIOCOMUNICATIVA OBTIDOS COM OS PAIS E O PERFIL FUNCIONAL DA COMUNICAÇÃO NO PRIMEIRO MOMENTO DE COLETA:

\begin{tabular}{|c|c|c|c|}
\hline Pares de variáveis & $\begin{array}{c}\text { Coeficiente de } \\
\text { correlação }\end{array}$ & Significância & Explanações \\
\hline $\begin{array}{l}\text { estágio } 4 \text { do nível } 1 \mathrm{x} \\
\% \text { uso do Meio verbal }\end{array}$ & $+0,325$ & 0,050 & $\begin{array}{l}\text { Quanto maior a presença da habilidade de coordenar com o } \\
\text { parceiro, ações simples, das quais os dois possam desfrutar } \\
\text { mutuamente, portanto, saber se a criança consegue realizar } \\
\text { trocas de turno, tanto maior o percentual de uso do meio verbal. }\end{array}$ \\
\hline $\begin{array}{l}\text { estágio } 1 \text { do nível } 2 \text { x \% } \\
\text { uso do Meio verbal }\end{array}$ & $+0,419$ & 0,011 & $\begin{array}{l}\text { Quanto maior a presença da habilidade da criança gostar e } \\
\text { reagir bem ou não às novidades introduzidas, tanto maior o } \\
\text { percentual de uso do meio verbal. }\end{array}$ \\
\hline $\begin{array}{l}\text { estágio } 2 \text { do nível } 2 \text { x \% } \\
\text { uso do Meio vocal }\end{array}$ & $-0,463$ & 0,004 & $\begin{array}{l}\text { Quanto maior a presença da habilidade da criança de adaptar- } \\
\text { se bem a introdução de alguma novidade, tanto menor } 0 \\
\text { percentual de uso do meio vocal. }\end{array}$ \\
\hline $\begin{array}{l}\text { estágio } 3 \text { do nível } 2 \mathrm{x} \\
\% \text { uso do Meio verbal }\end{array}$ & $+0,428$ & 0,008 & $\begin{array}{l}\text { Quanto maior a presença da habilidade da criança conseguir } \\
\text { usar o outro como referência e regulação para coordenar suas } \\
\text { ações, tanto maior o percentual de uso do meio verbal. }\end{array}$ \\
\hline $\begin{array}{l}\text { estágio } 3 \text { do nível } 2 \text { x \% } \\
\text { uso do Meio vocal }\end{array}$ & $-0,360$ & 0,028 & $\begin{array}{l}\text { Quanto maior a presença da habilidade da criança conseguir } \\
\text { usar o outro como referência e regulação para coordenar suas } \\
\text { ações, tanto menor o percentual de uso do meio vocal. }\end{array}$ \\
\hline $\begin{array}{l}\text { estágio } 4 \text { do nível } 2 x \\
\text { No- de funções } \\
\text { comunicativas } \\
\text { utilizadas }\end{array}$ & $+0,334$ & 0,044 & $\begin{array}{l}\text { Quanto mais presente está a habilidade da criança perceber e } \\
\text { identificar comportamentos e emoções, modificando seu } \\
\text { comportamento para um maior aproveitamento das experiências } \\
\text { compartilhadas, tanto maior o número de funções comunicativas } \\
\text { utilizadas. }\end{array}$ \\
\hline
\end{tabular}




\begin{tabular}{|c|c|c|c|}
\hline $\begin{array}{l}\text { estágio } 2 \text { do nível } 3 \text { x \% } \\
\text { ocupação do espaço } \\
\text { comunicativo }\end{array}$ & $-0,356$ & 0,030 & $\begin{array}{l}\text { Quanto maior a presença da habilidade da criança descobrir sua } \\
\text { criatividade e imaginação, aprender a se divertir como um } \\
\text { parceiro igual na co-criação, tanto menor o percentual de } \\
\text { ocupação do espaço comunicativo. }\end{array}$ \\
\hline $\begin{array}{l}\text { estágio } 2 \text { do nível } 3 \text { x \% } \\
\text { uso do Meio verbal }\end{array}$ & $+0,428$ & 0,008 & $\begin{array}{l}\text { Quanto maior a presença da habilidade da criança descobrir sua } \\
\text { criatividade e imaginação, aprender a se divertir como um } \\
\text { parceiro igual na co-criação, tanto maior o percentual de uso do } \\
\text { meio verbal. }\end{array}$ \\
\hline $\begin{array}{l}\text { estágio } 4 \text { do nível } 3 \times \% \\
\text { uso do Meio verbal }\end{array}$ & $+0,398$ & 0,015 & $\begin{array}{l}\text { Quanto maior a presença da habilidade de experenciar a alegria } \\
\text { de dividir percepções com amigos, ou seja, realizar comentários } \\
\text { a respeito de ações e fatos ocorridos, tanto maior o percentual } \\
\text { de uso do meio verbal. }\end{array}$ \\
\hline $\begin{array}{l}\text { estágio } 4 \text { do nível } 4 \text { x \% } \\
\text { ocupação do espaço } \\
\text { comunicativo }\end{array}$ & $-0,394$ & 0,016 & $\begin{array}{l}\text { Quanto maior a presença da habilidade de experenciar amigos } \\
\text { que dividem os mesmos interesses e experiências em comum, } \\
\text { tanto menor o percentual de ocupação do espaço comunicativo. }\end{array}$ \\
\hline
\end{tabular}

Também foi realizado o estudo das correlações entre os dados do perfil funcional da comunicação e de adaptação sócio-comunicativa colhidos com os pais, após um período de aproximadamente um ano, em que seus filhos permaneceram em atendimento fonoaudiológico no Laboratório de Investigação Fonoaudiológica nos Distúrbios do Espectro Autístico- FMUSP (LIF-DEA).

$\mathrm{Na}$ correlação dos dados de adaptação sócio-comunicativa tendo os pais como informantes com o perfil funcional da comunicação, no segundo momento de coleta, foram encontradas 6 correlações estatisticamente significativas, das 144 correlações possíveis, como pode-se observar a seguir na Tabela II.9. 
TABELA II.9- CORRELAÇÕES SIGNIFICATIVAS ENTRE OS DADOS DA ADAPTAÇÃO SÓCIOCOMUNICATIVA OBTIDOS COM OS PAIS E O PERFIL FUNCIONAL DA COMUNICAÇÃO NO SEGUNDO MOMENTO DE COLETA:

\begin{tabular}{|c|c|c|c|}
\hline Pares de variáveis & $\begin{array}{l}\text { Coeficiente de } \\
\text { correlação }\end{array}$ & Significância & Explanações \\
\hline $\begin{array}{l}\text { estágio } 3 \text { do nível } 1 \mathrm{x} \\
\% \text { uso do Meio verbal }\end{array}$ & $+0,411$ & 0,012 & $\begin{array}{l}\text { Quanto maior a presença da habilidade da criança de aprender } \\
\text { e realizar ações ensinadas pelos pais (guias), seguindo modelos } \\
\text { e/ou por meio de imitações, tanto maior o percentual de uso do } \\
\text { meio verbal. }\end{array}$ \\
\hline $\begin{array}{l}\text { estágio } 3 \text { do nível } 2 \text { x \% } \\
\text { uso do Meio verbal }\end{array}$ & $+0,419$ & 0,010 & $\begin{array}{l}\text { Quanto maior a presença da habilidade da criança conseguir } \\
\text { usar o outro como referência e regulação para coordenar suas } \\
\text { ações, tanto maior o percentual de uso do meio verbal. }\end{array}$ \\
\hline $\begin{array}{l}\text { estágio } 3 \text { do nível } 2 \text { x \% } \\
\text { uso do Meio vocal }\end{array}$ & $-0,364$ & 0,027 & $\begin{array}{l}\text { Quanto maior a presença da habilidade da criança em usar o } \\
\text { outro como referência e regulação para coordenar suas ações, } \\
\text { tanto menor o percentual de uso do meio vocal. }\end{array}$ \\
\hline $\begin{array}{l}\text { estágio } 2 \text { do nível } 3 \text { x } \\
\% \text { uso do Meio vocal }\end{array}$ & $-0,425$ & 0,009 & $\begin{array}{l}\text { Quanto maior a presença da habilidade da criança de descobrir } \\
\text { sua criatividade e imaginação, aprendendo a se divertir como } \\
\text { um parceiro igual na co-criação, tanto menor o percentual de } \\
\text { uso do meio vocal. }\end{array}$ \\
\hline $\begin{array}{l}\text { estágio } 2 \text { do nível } 4 \text { x \% } \\
\text { ocupação do espaço } \\
\text { comunicativo }\end{array}$ & $-0,519$ & 0,001 & $\begin{array}{l}\text { Quanto maior a presença da habilidade da criança de aproveitar } \\
\text { e combinar as imaginações compartilhadas entre si e o parceiro, } \\
\text { tanto menor o percentual de ocupação do espaço comunicativo. }\end{array}$ \\
\hline $\begin{array}{l}\text { estágio } 4 \text { do nível } 4 \text { x \% } \\
\text { ocupação do espaço } \\
\text { comunicativo }\end{array}$ & $-0,415$ & 0,011 & $\begin{array}{l}\text { Quanto maior a presença da habilidade de experenciar amigos } \\
\text { que dividem os mesmos interesses e experiências em comum, } \\
\text { tanto menor o percentual de ocupação do espaço comunicativo. }\end{array}$ \\
\hline
\end{tabular}

Nota-se que as correlações pontuais existentes entre os dados de adaptação sócio-comunicativa obtidos com os pais e o perfil funcional da comunicação, baseiam-se mais uma vez na relação dos meios comunicativos verbal e vocal com as habilidades de relacionamento social. 
Ao correlacionar os dados de adaptação sócio-comunicativa relatados pelas terapeutas e os dados do perfil funcional da comunicação no primeiro momento de coleta, das 144 correlações possíveis foram encontradas 48 correlações estatisticamente significativas, demonstrando uma maior inter-relação entre as referidas variáveis.

Estão apresentadas em azul e amarelo, na Tabela II.10, as correlações estatisticamente significativas e seus coeficientes de correlação, sendo possível notar um grande número destas correlações em relação ao número de atos comunicativos expressos por minuto e o percentual de uso do meio verbal por parte da criança. Observam-se interferências pontuais na correlação das referidas variáveis.

Legenda da Tabela II.10:

$\mathrm{N}$-ac_1: número de atos comunicativos

P_ec_1: \% espaço comunicativo ocupado

N_acm_1: número de atos comunicativos expressos por minuto

Pf_mai_1:\% funções comunicativas mais interpessoais

Pf_mei_1:\% funções comunicativas menos interpessoais
$\mathrm{N} \_$f1: número de funções comunicativas utilizadas

M_ve1:\% de uso do meio verbal

M_v01: \% de uso do meio vocal

M_g1: \%uso do meio gestual 
TABELA II.10- CORRELAÇÕES SIGNIFICATIVAS ENTRE A ADAPTAÇÃO SÓCIO-COMUNICATIVA OBTIDA PELAS TERAPEUTAS E O PERFIL FUNCIONAL DA COMUNICAÇÃO NO PRIMEIRO MOMENTO DE COLETA:

\begin{tabular}{|c|c|c|c|c|c|c|c|c|c|}
\hline & & n1_est_1t1 & n1_est_2t1 & n1_est_3t1 & n1_est_4t1 & n2_est_1t1 & n2_est_2t1 & n2_est_3t1 & n2_est_4t1 \\
\hline \multirow[t]{2}{*}{$\overline{\text { n_ac_1 }}$} & Correlation Coefficient & 0,189 & 0,452 & 0,433 & 0,289 & 0,375 & 0,458 & 0,480 & 0,194 \\
\hline & Sig. (2-tailed) & 0,262 & 0,005 & 0,007 & 0,082 & 0,022 & 0,004 & 0,003 & 0,250 \\
\hline \multirow[t]{2}{*}{ p_ec_1 } & Correlation Coefficient & $-0,014$ & 0,111 & $-0,040$ & 0,040 & $-0,117$ & $-0,097$ & $-0,215$ & $-0,356$ \\
\hline & Sig. (2-tailed) & 0,936 & 0,513 & 0,815 & 0,815 & 0,491 & 0,567 & 0,208 & 0,030 \\
\hline \multirow[t]{2}{*}{ n_acm_1 } & Correlation Coefficient & 0,330 & 0,427 & 0,395 & 0,252 & 0,436 & 0,412 & 0,432 & 0,213 \\
\hline & Sig. (2-tailed) & 0,046 & 0,008 & 0,015 & 0,132 & 0,007 & 0,011 & 0,009 & 0,205 \\
\hline \multirow[t]{2}{*}{ pf_mai_1 } & Correlation Coefficient & 0,003 & 0,524 & $-0,112$ & 0,223 & $-0,071$ & 0,210 & 0,177 & 0,126 \\
\hline & Sig. (2-tailed) & 0,984 & 0,001 & 0,511 & 0,185 & 0,676 & 0,213 & 0,302 & 0,457 \\
\hline \multirow[t]{2}{*}{ pf_mei_1 } & Correlation Coefficient & 0,024 & $-0,519$ & 0,106 & $-0,223$ & 0,086 & $-0,215$ & $-0,185$ & $-0,113$ \\
\hline & Sig. (2-tailed) & 0,888 & 0,001 & 0,531 & 0,184 & 0,612 & 0,201 & 0,280 & 0,504 \\
\hline \multirow[t]{2}{*}{ n_f_l } & Correlation Coefficient & 0,337 & 0,322 & 0,276 & $-0,051$ & 0,282 & 0,274 & 0,339 & 0,167 \\
\hline & Sig. (2-tailed) & 0,041 & 0,052 & 0,098 & 0,764 & 0,091 & 0,101 & 0,043 & 0,324 \\
\hline \multirow[t]{2}{*}{ m_vel } & Correlation Coefficient & 0,299 & 0,493 & 0,516 & 0,510 & 0,514 & 0,661 & 0,676 & 0,592 \\
\hline & Sig. (2-tailed) & 0,073 & 0,002 & 0,001 & 0,001 & 0,001 & 0,000 & 0,000 & 0,000 \\
\hline \multirow[t]{2}{*}{ m_vol } & Correlation Coefficient & 0,041 & $-0,019$ & $-0,085$ & $-0,167$ & 0,167 & $-0,087$ & $-0,013$ & $-0,230$ \\
\hline & Sig. (2-tailed) & 0,809 & 0,909 & 0,617 & 0,323 & 0,322 & 0,609 & 0,938 & 0,172 \\
\hline \multirow[t]{3}{*}{ m_gl } & Correlation Coefficient & 0,062 & $-0,294$ & $-0,133$ & $-0,196$ & $-0,155$ & $-0,251$ & $-0,324$ & $-0,437$ \\
\hline & Sig. (2-tailed) & 0,716 & 0,077 & 0,434 & 0,244 & 0,361 & 0,135 & 0,054 & 0,007 \\
\hline & & n3_est_1t1 & n3_est_2t1 & n3_est_3t1 & n3_est_4t1 & n4_est_1t1 & n4_est_2t1 & n4_est_3t1 & n4_est_4t1 \\
\hline \multirow[t]{2}{*}{$\overline{\text { n_ac_1 }}$} & Correlation Coefficient & $\overline{0,395}$ & $\overline{0,433}$ & $\overline{0,160}$ & $\overline{0,529}$ & $\overline{0,097}$ & $\overline{0,337}$ & $\overline{0,315}$ & $\overline{0,289}$ \\
\hline & Sig. (2-tailed) & 0,015 & 0,007 & 0,345 & 0,001 & 0,569 & 0,042 & 0,058 & 0,083 \\
\hline \multirow[t]{2}{*}{ p_ec_1 } & Correlation Coefficient & $-0,079$ & $-0,330$ & 0,178 & $-0,020$ & $-0,283$ & $-0,340$ & $-0,316$ & $-0,219$ \\
\hline & Sig. (2-tailed) & 0,643 & 0,046 & 0,293 & 0,904 & 0,090 & 0,039 & 0,057 & 0,193 \\
\hline \multirow[t]{2}{*}{ n_acm_1 } & Correlation Coefficient & 0,345 & 0,486 & 0,104 & 0,596 & 0,147 & 0,377 & 0,330 & 0,304 \\
\hline & Sig. (2-tailed) & 0,037 & 0,002 & 0,540 & 0,000 & 0,384 & 0,022 & 0,046 & 0,067 \\
\hline \multirow[t]{2}{*}{ pf_mai_1 } & Correlation Coefficient & 0,099 & 0,154 & $-0,003$ & 0,082 & 0,176 & 0,211 & 0,041 & 0,085 \\
\hline & Sig. (2-tailed) & 0,560 & 0,363 & 0,988 & 0,630 & 0,299 & 0,209 & 0,811 & 0,616 \\
\hline \multirow[t]{2}{*}{ pf_mei_1 } & Correlation Coefficient & $-0,101$ & $-0,141$ & $-0,010$ & $-0,067$ & $-0,163$ & $-0,200$ & $-0,033$ & $-0,070$ \\
\hline & Sig. (2-tailed) & 0,550 & 0,406 & 0,952 & 0,696 & 0,336 & 0,236 & 0,845 & 0,679 \\
\hline \multirow[t]{2}{*}{ n_f_1 } & Correlation Coefficient & 0,226 & 0,153 & 0,195 & 0,323 & 0,139 & 0,058 & 0,169 & 0,217 \\
\hline & Sig. (2-tailed) & 0,180 & 0,366 & 0,248 & 0,051 & 0,413 & 0,734 & 0,318 & 0,196 \\
\hline \multirow[t]{2}{*}{ m_ve1 } & Correlation Coefficient & 0,409 & 0,774 & 0,134 & 0,640 & 0,410 & 0,708 & 0,483 & 0,517 \\
\hline & Sig. (2-tailed) & 0,012 & 0,000 & 0,430 & 0,000 & 0,012 & 0,000 & 0,002 & 0,001 \\
\hline \multirow[t]{2}{*}{ m_vo1 } & Correlation Coefficient & $-0,071$ & $-0,207$ & 0,132 & $-0,097$ & $-0,089$ & $-0,319$ & $-0,404$ & $-0,211$ \\
\hline & Sig. (2-tailed) & 0,676 & 0,219 & 0,437 & 0,567 & 0,601 & 0,054 & 0,013 & 0,210 \\
\hline \multirow[t]{2}{*}{ m_g1 } & Correlation Coefficient & $-0,294$ & $-0,369$ & 0,096 & $-0,499$ & $-0,264$ & $-0,428$ & $-0,537$ & $-0,500$ \\
\hline & Sig. (2-tailed) & 0,077 & 0,025 & 0,571 & 0,002 & 0,114 & 0,008 & 0,001 & 0,002 \\
\hline
\end{tabular}


Da mesma maneira, foi realizada a análise das correlações dos dados do perfil funcional da comunicação e da adaptação sócio-comunicativa, obtidos com as terapeutas no segundo momento de coleta, observando 34 correlações estatisticamente significativas das 144 correlações possíveis, sendo que 10 destas correlações já eram significativas no primeiro momento, estando todas as correlações apresentadas na Tabela II.11.

Observando as correlações estatisticamente significativas obtidas quando as terapeutas foram os informantes nos dois momentos de coleta, fica claro que estas também são de certa forma pontuais. Existe, entretanto, maior relação entre as diversas áreas dos dois objetos de estudo, ou seja, o perfil funcional da comunicação e a adaptação sócio-comunicativa. Fica evidente também que o maior número de correlações dá-se com a habilidade de utilizar o meio verbal, como se pode notar na situação em que os pais foram os informantes.

Tendo as terapeutas como os informantes, foram observadas correlações significativas em quase todos os estágios da escala de adaptação sóciocomunicativa, exceto nos estágios 2 e 1 dos níveis 1 e 2, respectivamente, no segundo momento de coleta. Pode-se notar, ainda, um grande número de correlações relativas aos meios comunicativos verbal e gestual, também no segundo momento de coleta.

Legenda da Tabela II.11:

$\mathrm{N}$-ac_2: número de atos comunicativos

P_ec_2: \% espaço comunicativo ocupado N_acm_2: número de atos comunicativos expressos por minuto

Pf_mai_2:\% funções comunicativas mais interpessoais

Pf_mei_2:\% funções comunicativas menos interpessoais
$\mathrm{N} \_$f2: número de funções comunicativas utilizadas

M_ve2:\% de uso do meio verbal

M_vo2: \% de uso do meio vocal

M_g2:\% de uso do meio gestual 
TABELA II.11- CORRELAÇÕES SIGNIFICATIVAS ENTRE A ADAPTAÇÃO SÓCIO-COMUNICATIVA OBTIDA COM AS TERAPEUTAS E O PERFIL FUNCIONAL DA COMUNICAÇÃO NO SEGUNDO MOMENTO DE COLETA:

\begin{tabular}{|c|c|c|c|c|c|c|c|c|c|}
\hline & & n1_est_1t2 & n1_est_2t2 & n1_est_3t2 & n1_est_4t2 & n2_est_1t2 & n2_est_2t2 & n2_est_3t2 & n2_est_4t2 \\
\hline \multirow[t]{2}{*}{ n_ac_2 } & Correlation Coefficient & 0,307 & 0,229 & 0,052 & 0,137 & 0,233 & $-0,025$ & 0,338 & 0,355 \\
\hline & Sig. (2-tailed) & 0,064 & 0,172 & 0,761 & 0,419 & 0,165 & 0,885 & 0,041 & 0,031 \\
\hline \multirow[t]{2}{*}{ p_ec_2 } & Correlation Coefficient & $-0,037$ & 0,156 & $-0,198$ & 0,041 & $-0,136$ & $-0,229$ & $-0,127$ & 0,047 \\
\hline & Sig. (2-tailed) & 0,827 & 0,357 & 0,240 & 0,810 & 0,422 & 0,173 & 0,454 & 0,781 \\
\hline \multirow[t]{2}{*}{ n_acm_2 } & Correlation Coefficient & 0,307 & 0,229 & 0,052 & 0,137 & 0,233 & $-0,025$ & 0,338 & 0,355 \\
\hline & Sig. (2-tailed) & 0,064 & 0,172 & 0,761 & 0,419 & 0,165 & 0,885 & 0,041 & 0,031 \\
\hline \multirow[t]{2}{*}{ pf_mai_2 } & Correlation Coefficient & $-0,097$ & 0,010 & 0,107 & 0,249 & 0,247 & 0,185 & 0,292 & 0,319 \\
\hline & Sig. (2-tailed) & 0,570 & 0,954 & 0,529 & 0,138 & 0,140 & 0,273 & 0,079 & 0,054 \\
\hline pf_mei_2 & Correlation Coefficient & 0,097 & $-0,010$ & $-0,107$ & $-0,249$ & $-0,247$ & $-0,185$ & $-0,292$ & $-0,319$ \\
\hline \multirow[t]{2}{*}{ n_f_2 } & Correlation Coefficient & 0,217 & 0,254 & 0,179 & 0,108 & 0,324 & 0,341 & 0,447 & 0,335 \\
\hline & Sig. (2-tailed) & 0,198 & 0,129 & 0,288 & 0,524 & 0,051 & 0,039 & 0,006 & 0,043 \\
\hline \multirow[t]{2}{*}{ m_ve2 } & Correlation Coefficient & 0,294 & 0,421 & 0,322 & 0,294 & 0,545 & 0,203 & 0,583 & 0,499 \\
\hline & Sig. (2-tailed) & 0,077 & 0,009 & 0,052 & 0,077 & 0,000 & 0,227 & 0,000 & 0,002 \\
\hline \multirow[t]{2}{*}{ m_vo2 } & Correlation Coefficient & 0,011 & $-0,146$ & $-0,003$ & $-0,241$ & $-0,058$ & 0,025 & $-0,062$ & $-0,161$ \\
\hline & Sig. (2-tailed) & 0,948 & 0,390 & 0,985 & 0,151 & 0,731 & 0,885 & 0,716 & 0,342 \\
\hline \multirow[t]{3}{*}{ m_g2 } & Correlation Coefficient & $-0,230$ & $-0,317$ & $-0,363$ & $-0,111$ & $-0,475$ & $-0,222$ & $-0,439$ & $-0,494$ \\
\hline & Sig. (2-tailed) & 0,171 & 0,056 & 0,027 & 0,512 & 0,003 & 0,187 & 0,007 & 0,002 \\
\hline & & n3_est_1t2 & n3_est_2t2 & n3_est_3t2 & n3_est_4t2 & n4_est_1t2 & n4_est_2t2 & n4_est_3t2 & n4_est_4t2 \\
\hline n_ac_2 & Sig. (2-tailed) & 0,249 & 0,126 & 0,563 & 0,014 & 0,052 & 0,123 & 0,098 & 0,423 \\
\hline \multirow[t]{2}{*}{ p_ec_2 } & Correlation Coefficient & 0,044 & $-0,155$ & $-0,051$ & $-0,158$ & $-0,191$ & $-0,190$ & $-0,054$ & $-0,260$ \\
\hline & Sig. (2-tailed) & 0,797 & 0,360 & 0,766 & 0,349 & 0,258 & 0,260 & 0,749 & 0,120 \\
\hline \multirow[t]{2}{*}{ n_acm_2 } & Correlation Coefficient & 0,194 & 0,256 & 0,098 & 0,401 & 0,322 & 0,258 & 0,277 & 0,136 \\
\hline & Sig. (2-tailed) & 0,249 & 0,126 & 0,563 & 0,014 & 0,052 & 0,123 & 0,098 & 0,423 \\
\hline \multirow[t]{2}{*}{ pf_mai_2 } & Correlation Coefficient & 0,128 & 0,317 & 0,072 & 0,173 & 0,241 & 0,284 & 0,371 & 0,178 \\
\hline & Sig. (2-tailed) & 0,450 & 0,056 & 0,673 & 0,305 & 0,150 & 0,088 & 0,024 & 0,291 \\
\hline \multirow[t]{2}{*}{ pf_mei_2 } & Correlation Coefficient & $-0,128$ & $-0,317$ & $-0,072$ & $-0,173$ & $-0,241$ & $-0,284$ & $-0,371$ & $-0,178$ \\
\hline & Sig. (2-tailed) & 0,450 & 0,056 & 0,673 & 0,305 & 0,150 & 0,088 & 0,024 & 0,291 \\
\hline \multirow[t]{2}{*}{ n_f_2 } & Correlation Coefficient & 0,234 & 0,232 & 0,356 & 0,289 & 0,110 & 0,265 & 0,224 & 0,062 \\
\hline & Sig. (2-tailed) & 0,162 & 0,168 & 0,031 & 0,082 & 0,518 & 0,112 & 0,182 & 0,716 \\
\hline \multirow[t]{2}{*}{ m_ve2 } & Correlation Coefficient & 0,382 & 0,632 & 0,232 & 0,631 & 0,433 & 0,622 & 0,537 & 0,447 \\
\hline & Sig. (2-tailed) & 0,020 & 0,000 & 0,167 & 0,000 & 0,007 & 0,000 & 0,001 & 0,005 \\
\hline \multirow[t]{2}{*}{ m_vo2 } & Correlation Coefficient & $-0,049$ & $-0,144$ & 0,096 & $-0,376$ & $-0,302$ & $-0,151$ & $-0,114$ & $-0,311$ \\
\hline & Sig. (2-tailed) & 0,775 & 0,396 & 0,574 & 0,022 & 0,070 & 0,373 & 0,501 & 0,610 \\
\hline \multirow[t]{2}{*}{ m_g2 } & Correlation Coefficient & $-0,468$ & $-0,526$ & $-0,308$ & $-0,448$ & $-0,213$ & $-0,555$ & $-0,662$ & $-0,327$ \\
\hline & Sig. (2-tailed) & 0,003 & 0,001 & 0,064 & 0,005 & 0,205 & 0,000 & 0,000 & 0,048 \\
\hline
\end{tabular}


Para realizar diferentes análises estatísticas em relação ao perfil funcional da comunicação em função dos níveis da escala de adaptação sóciocomunicativa, os 37 sujeitos deste estudo foram classificados segundo esses níveis. Para essa classificação, foi considerado o nível mais alto no qual cada sujeito foi descrito como apresentando pelo menos três estágios completos da escala de adaptação sócio-comunicativa. Caso não tivessem sido atribuídas ao sujeito respostas que completassem os três estágios em nenhum dos níveis, este passa a ser considerado como instável.

Desta forma, a casuística ficou dividida da forma exposta no Quadro II.3.

QUADRO II.3- DIVISÃO DOS SUJEITOS EM FUNÇÃO DO NÍVEL DE ADAPTAÇÃO SÓCIOCOMUNICATIVA CLASSIFICADOS POR PAIS E TERAPEUTAS NOS DOIS DIFERENTES MOMENTOS DE COLETA:

\begin{tabular}{|c|c|c|c|c|c|}
\hline Nível de Adaptação Sócio-comunicativa & Nível 1 & Nível 2 & Nível 3 & Nível 4 & Instáveis \\
\hline $\begin{array}{l}\text { Número de sujeitos classificados pelos pais no primeiro momento } \\
\text { de coleta }\end{array}$ & 12 & 8 & 8 & 5 & 4 \\
\hline $\begin{array}{l}\text { Número de sujeitos classificados pelos pais no segundo momento } \\
\text { de coleta }\end{array}$ & 14 & 7 & 6 & 7 & 3 \\
\hline $\begin{array}{l}\text { Número de sujeitos classificados pelas terapeutas no primeiro } \\
\text { momento de coleta }\end{array}$ & 8 & 5 & 5 & 6 & 13 \\
\hline $\begin{array}{l}\text { Número de sujeitos classificados pelas terapeutas no segundo } \\
\text { momento de coleta }\end{array}$ & 12 & 4 & 6 & 9 & 6 \\
\hline
\end{tabular}


As 37 crianças do espectro autístico foram divididas de acordo com os níveis da escala de adaptação sócio-comunicativa segundo informações obtidas com os pais, no primeiro momento de coleta. Foi, então, proposto um estudo estatístico com o objetivo de verificar possíveis diferenças entre áreas do perfil funcional da comunicação, concomitantemente, incluindo o grupo das crianças consideradas instáveis.

Em um primeiro momento foi realizado o Teste de Kruskal-Wallis a fim de verificar possíveis diferenças entre o perfil funcional da comunicação apresentado por cada grupo de crianças classificadas em níveis da escala de adaptação sóciocomunicativa. $\mathrm{O}$ teste detectou somente uma diferença estatisticamente significativa com valor de 0,014 , em relação ao percentual de uso do meio verbal.

Ao excluir o grupo dos instáveis e realizar o mesmo teste somente com os níveis sócio-comunicativos $1,2,3$ e 4 , os resultados obtidos mantiveram-se mesmos já apresentados.

Sendo assim, foi realizado o teste de Mann-Whitney, com o intuito de identificar quais níveis sócio-comunicativos diferenciam-se entre si em relação ao percentual de uso do meio verbal, estando demonstrados na Tabela II.12 os valores de significância encontrados e em azul os valores que demonstraram diferença estatisticamente significativa. 
TABELA II.12 - VALORES DE SIGNIFICÂNCIA ENCONTRADOS NA IDENTIFICAÇÃO DE DIFERENÇAS DO PERFIL FUNCIONAL DA COMUNICAÇÃO ENTRE OS NIVEIS SÓCIO-COMUNICATIVOS , TENDO OS PAIS COMO INFORMANTES NO PRIMEIRO MOMENTO DE COLETA, INCLUINDO O GRUPO INSTÁVEL:

\begin{tabular}{|c|c|c|c|c|c|c|c|c|c|c|}
\hline \multirow{2}{*}{ Variável } & \multicolumn{10}{|c|}{ Pares de Níveis sócio-comunicativos } \\
\hline & Instáveis & táveis & stáveis & stáveis & $1 \times 2$ & $1 \times 3$ & $1 \times 4$ & $2 \times 3$ & $2 \times 4$ & $3 \times 4$ \\
\hline \multicolumn{11}{|c|}{$\begin{array}{l}\% \text { de uso do meio } \\
\text { verbal }\end{array}$} \\
\hline & 0,094 & 0,030 & 0,014 & 0,081 & 0,130 & 0,005 & 0,221 & 0,144 & 0,656 & 0,606 \\
\hline
\end{tabular}

As áreas do perfil funcional da comunicação como número de atos comunicativos, número de atos comunicativos expressos por minuto e número de funções comunicativas utilizadas, apresentaram-se semelhantes nos quatro níveis da escala de adaptação sócio-comunicativa, tendo os pais como informantes no primeiro momento de coleta.

As demais áreas do perfil funcional da comunicação como percentual de ocupação do espaço comunicativo, percentual de funções mais e menos interpessoais e percentual de uso dos meios vocal, gestual também se apresentaram semelhantes entre os quatro níveis sócio-comunicativos, como mostra a Figura II.5, que apresenta as médias encontradas em áreas do perfil funcional da comunicação em cada nível da escala de adaptação sóciocomunicativa, demonstrando que o percentual de uso do meio verbal foi o aspecto que mais variou entre os níveis de adaptação sócio-comunicativa. 
FIGURA II.5- MÉDIAS DO PERFIL FUNCIONAL DA COMUNICAÇÃO ENTRE OS NIVEIS DA ESCALA DE ADAPTAÇÃO SÓCIO-COMUNICATIVA, COM OS PAIS COMO INFORMANTES NO PRIMEIRO MOMENTO DE COLETA:

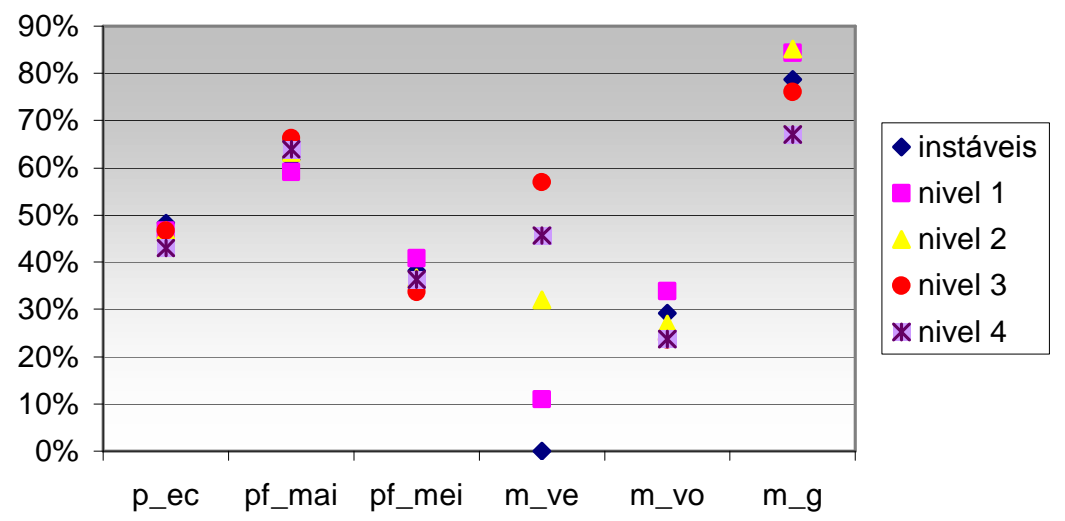

$\begin{array}{ll}\text { P_ec: \% espaço comunicativo ocupado } & \text { M_ve:\% de uso do meio verbal } \\ \begin{array}{l}\text { Pf_mai:\% funções comunicativas } \\ \text { mais interpessoais }\end{array} & \text { M_vo: \% de uso do meio vocal } \\ \text { Pf_mei:\% funções comunicativas } & \text { M_g:\% de uso do meio gestual } \\ \text { menos interpessoais } & \end{array}$

O mesmo estudo estatístico foi realizado com os grupos classificados em níveis segundo as informações das terapeutas, também no primeiro momento de coleta dos dados. Foram encontradas três diferenças estatisticamente significativas, sendo elas quanto ao número de atos comunicativos expressos $(0,002)$, número de atos comunicativos expressos por minuto $(0,002)$ e percentual de uso do meio verbal $(<0,001)$, neste caso incluindo o grupo de instáveis, estando os valores de significância apresentados na Tabela II.13. 
TABELA II.13 - VALORES DE SIGNIFICÂNCIA ENCONTRADOS NA IDENTIFICAÇÃO DE DIFERENÇAS DO PERFIL FUNCIONAL DA COMUNICAÇÃO ENTRE OS NÍVEIS SÓCIO-COMUNICATIVOS, INCLUINDO O GRUPO INSTÁVEL, ATRIBUÍDOS PELAS TERAPEUTAS NO PRIMEIRO MOMENTO DE COLETA:

\begin{tabular}{ccccccccccc}
\hline Variável & \multicolumn{10}{c}{ Pares de Níveis sócio-comunicativos } \\
\cline { 2 - 11 } & $0 \times 1$ & $0 \times 2$ & $0 \times 3$ & $0 \times 4$ & $1 \times 2$ & $1 \times 3$ & $1 \times 4$ & $2 \times 3$ & $2 \times 4$ & $3 \times 4$ \\
$\begin{array}{c}\text { No- atos } \\
\text { comunicativos } \\
\text { expressos }\end{array}$ & 0,050 & 0,136 & 0,009 & 0,001 & 0,380 & 0,826 & 0,366 & 0,173 & 0,006 & 0,042 \\
$\begin{array}{c}\text { No- atos } \\
\text { comunicativos } \\
\text { expressos/ } \\
\text { minuto }\end{array}$ & 0,095 & 0,165 & 0,009 & 0,001 & 0,661 & 0,607 & 0,155 & 0,173 & 0,006 & 0,042 \\
$\begin{array}{c}\% \text { de uso do } \\
\text { meio verbal }\end{array}$ & 0,006 & 0,053 & 0,001 & $<0,001$ & 0,882 & 0,187 & 0,004 & 0,249 & 0,099 & 0,360 \\
\hline
\end{tabular}

Neste estudo observa-se uma forte tendência para que o percentual de ocupação do espaço comunicativo apresente diferença estatisticamente significativa, uma vez que esta área apresenta valor de 0,054. Esta tendência se confirma ao se retirar o grupo dos instáveis e realizar o teste novamente, agora só com os níveis sócio-comunicativos de 1 a 4, sendo possível notar uma diferença significativa, com valor de 0,020, mantendo ainda uma diferença de 0,046 para o percentual de uso do meio verbal, como apresentam as Tabelas II.13 e II.14 .

TABELA II.14 - VALORES DE SIGNIFICÂNCIA ENCONTRADOS NA IDENTIFICAÇÃO DE DIFERENÇAS DO PERFIL FUNCIONAL DA COMUNICAÇÃO ENTRE OS NÍVEIS SÓCIO-COMUNICATIVO, EXCLUINDO O GRUPO INSTÁVEL, ATRIBUÍDOS PELAS TERAPEUTAS NO PRIMEIRO MOMENTO DE COLETA:

\begin{tabular}{|c|c|c|c|c|c|c|}
\hline \multirow{2}{*}{ Variável } & \multicolumn{6}{|c|}{ Pares de níveis sócio-comunicativos } \\
\hline & $1 \times 2$ & $1 \times 3$ & $1 \times 4$ & $2 \times 3$ & $2 \times 4$ & $3 \times 4$ \\
\hline \multicolumn{7}{|l|}{ \% ocupação do } \\
\hline $\begin{array}{c}\text { espaço } \\
\text { comunicativo }\end{array}$ & 0,018 & 0,045 & 0,009 & 0,753 & 0,357 & 0,521 \\
\hline $\begin{array}{l}\% \text { de uso do } \\
\text { meio verbal }\end{array}$ & 0,882 & 0,187 & 0,004 & 0,249 & 0,099 & 0,360 \\
\hline
\end{tabular}


Observando os dados descritos e a Figura II.6, nota-se uma maior interrelação entre o perfil funcional da comunicação e os dados de adaptação sóciocomunicativa tendo como informantes as terapeutas, sugerindo que desde 0 primeiro momento de coleta, elas parecem considerar aspectos globais da comunicação e não só a utilização dos meios comunicativos como parâmetro para a classificação dos sujeitos em níveis sócio-comunicativos.

FIGURA II.6- MÉDIAS DO PERFIL FUNCIONAL DA COMUNICAÇÃO ENTRE OS NIVEIS DA ESCALA DE ADAPTAÇÃO SÓCIO-COMUNICATIVA, TENDO AS TERAPEUTAS COMO INFORMANTES NO PRIMEIRO MOMENTO DE COLETA:

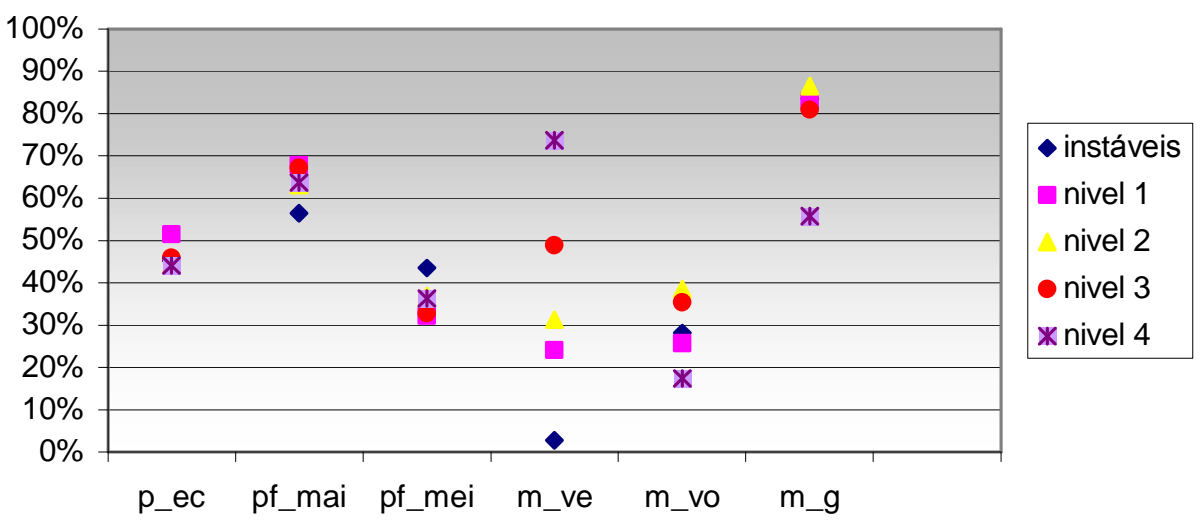

\begin{tabular}{|c|c|}
\hline \multicolumn{2}{|c|}{ Legenda: } \\
\hline P_ec: \% espaço comunicativo ocupado & M_ve:\% de uso do meio verbal \\
\hline $\begin{array}{l}\text { Pf_mai:\% funções comunicativas } \\
\text { mais interpessoais }\end{array}$ & M_vo: \% de uso do meio vocal \\
\hline $\begin{array}{l}\text { Pf_mei:\% funções comunicativas } \\
\text { menos interpessoais }\end{array}$ & M_g:\% de uso do meio gestual \\
\hline
\end{tabular}


Utilizando os dados de adaptação sócio-comunicativa, colhidos com os pais no segundo momento de coleta, a partir da classificação em níveis incluindo o grupo instável, foi realizado novamente o Teste de Kruskal-Wallis que detectou somente uma diferença estatisticamente significativa com valor de 0,006 em relação ao percentual de uso do meio vocal.

Posteriormente, foi realizado o teste de Mann-Whitney para estabelecer quais níveis sócio-comunicativos diferenciam-se entre si em relação ao percentual de uso do meio vocal, estando demonstrados na Tabela II.15 os valores que demonstraram diferença estatisticamente significativa.

TABELA II.15 - VALORES DE SIGNIFICÂNCIA ENCONTRADOS NA IDENTIFICAÇÃO DE DIFERENÇAS DO PERFIL FUNCIONAL DA COMUNICAÇÃO ENTRE OS NÍVEIS SÓCIOCOMUNICATIVOS CLASSIFICADOS PELOS PAIS NO SEGUNDO MOMENTO DE COLETA, INCLUINDO O GRUPO INSTÁVEL:

\begin{tabular}{|c|c|c|c|}
\hline \multirow[t]{2}{*}{ Variável } & \multicolumn{3}{|c|}{ Pares de Níveis sócio-comunicativos } \\
\hline & $1 \times 2$ & $1 \times 3$ & $2 \times 3$ \\
\hline$\%$ de uso do meio vocal & 0,019 & 0,001 & 0,025 \\
\hline
\end{tabular}

Entretanto, ao excluir o grupo classificado como instável pelos pais no segundo momento de coleta e realizarmos o estudo estatístico considerando apenas os níveis $1,2,3$ e 4, foram encontradas diferenças estatisticamente significativas em relação ao percentual de espaço comunicativo ocupado $(0,044)$ e ao percentual de uso do meio vocal $(0,003)$. Na aplicação do Teste de MannWhiteny foram encontrados os seguintes resultados apresentados na Tabela II.16 e em amarelo os valores de diferença estatisticamente significativa. 
TABELA II.16 - VALORES DE SIGNIFICÂNCIA ENCONTRADOS NA IDENTIFICAÇÃO DE DIFERENÇAS DO PERFIL FUNCIONAL DA COMUNICAÇÃO ENTRE OS NÍVEIS SÓCIO-COMUNICATIVOS, EXCLUINDO O GRUPO INSTÁVEL, ATRIBUÍDOS PELOS PAIS NO SEGUNDO MOMENTO DE COLETA:

\begin{tabular}{ccccccc}
\hline \multicolumn{6}{c}{ Pares de Niveis sócio-comunicativos } \\
\hline \multicolumn{1}{c}{ Variáveis } & $1 \times 2$ & $1 \times 3$ & $1 \times 4$ & $2 \times 3$ & $2 \times 4$ & $3 \times 4$ \\
$\begin{array}{l}\text { \% ocupação } \\
\text { do espaço } \\
\text { comunicativo }\end{array}$ & 0,821 & 0,507 & 0,014 & 0,829 & 0,034 & 0,021 \\
$\begin{array}{c}\text { \% de uso do } \\
\text { meio vocal }\end{array}$ & 0,019 & 0,001 & 0,108 & 0,025 & 0,749 & 0,114 \\
\hline
\end{tabular}

Analisando as Figuras II. 5 e II.7, pode-se dizer que, em um primeiro momento, o perfil funcional da comunicação dos sujeitos classificados nos quatro níveis da escala de adaptação sócio-comunicativa segundo informações dos pais, apresenta-se genericamente semelhante, sendo o meio verbal o único ponto diferenciador destes grupos. No segundo momento de coleta, apesar de ainda manter um perfil muito semelhante, observa-se uma maior consideração de outros aspectos comunicativos, como o uso do meio vocal, verbal e percentual de ocupação do espaço comunicativo. 
FIGURA II.7- MÉDIAS DAS ÁREAS DO PERFIL FUNCIONAL DA COMUNICAÇÃO ENTRE OS NÍVEIS DA ESCALA DE ADAPTAÇÃO SÓCIO-COMUNICATIVA, TENDO OS PAIS COMO INFORMANTES NO SEGUNDO MOMENTO DE COLETA:

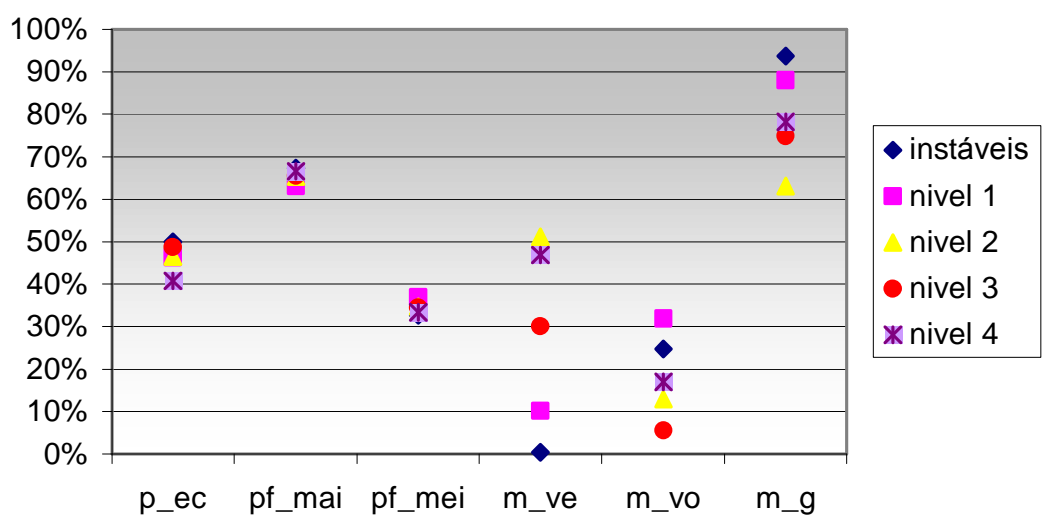

\begin{tabular}{|c|c|}
\hline \multicolumn{2}{|c|}{ Legenda: } \\
\hline P_ec: \% espaço comunicativo ocupado & M_ve:\% de uso do meio verbal \\
\hline $\begin{array}{l}\text { Pf_mai:\% funções comunicativas } \\
\text { mais interpessoais }\end{array}$ & M_vo: \% de uso do meio vocal \\
\hline $\begin{array}{l}\text { Pf_mei:\% funções comunicativas } \\
\text { menos interpessoais }\end{array}$ & M_g:\% de uso do meio gestual \\
\hline
\end{tabular}

Foi realizado mais uma vez o Teste de Kruskal-Wallis, agora com os dados obtidos com as terapeutas no segundo momento de coleta, incluindo o grupo instável de classificação em níveis sócio-comunicativos, sendo encontradas diferenças estatisticamente significativas em relação ao percentual de uso do meio verbal $(0,003)$ e percentual de uso do meio gestual $(0,016)$.

Como para algumas variáveis foram observadas diferenças estatisticamente significativas foi aplicado o Teste de Mann-Whitney, estando os resultados obtidos apresentados na Tabela II.17. 
TABELA II.17 - VALORES DE SIGNIFICÂNCIA ENCONTRADOS NA IDENTIFICAÇÃO DE DIFERENÇAS DO PERFIL FUNCIONAL DA COMUNICAÇÃO ENTRE OS NÍVEIS SÓCIO-COMUNICATIVOS, INCLUINDO O GRUPO INSTÁVEL, ATRIBUÍDOS PELAS TERAPEUTAS NO SEGUNDO MOMENTO DE COLETA:

\begin{tabular}{|c|c|c|c|c|c|c|c|c|c|c|}
\hline \multirow{2}{*}{ Variável } & \multicolumn{10}{|c|}{ Pares de Níveis sócio-comunicativos } \\
\hline & $\begin{array}{c}\text { Instáveis } \\
\times 1\end{array}$ & $\begin{array}{c}\text { Instáveis } \\
\times 2\end{array}$ & $\begin{array}{c}\text { Instáveis } \\
\times 3\end{array}$ & $\begin{array}{c}\text { Instáveis } \\
\times 4\end{array}$ & $1 \times 2$ & $1 \times 3$ & $1 \times 4$ & $2 \times 3$ & $2 \times 4$ & $3 \times 4$ \\
\hline $\begin{array}{c}\% \text { de uso } \\
\text { do meio } \\
\text { verbal }\end{array}$ & 0,237 & 0,186 & 0,020 & 0,013 & 0,708 & 0,005 & 0,006 & 0,033 & 0,063 & 0,479 \\
\hline $\begin{array}{c}\text { \% de uso } \\
\text { do meio } \\
\text { gestual }\end{array}$ & 0,888 & $>0,999$ & 0,065 & 0,025 & 0,625 & 0,054 & 0,009 & 0,055 & 0,031 & 0,288 \\
\hline
\end{tabular}

Realizando uma nova análise dos dados obtidos com as terapeutas no segundo momento de coleta, mas excluindo o grupo classificado como instável pelas terapeutas e considerando apenas os níveis $1,2,3$ e 4 , os resultados obtidos confirmam as variáveis já apresentadas como significativas no estudo incluindo o grupo instável - percentual de uso do meio verbal $(0,005)$ e meio gestual $(0,014)$.

Porém, neste caso pode-se observar uma tendência muito forte em encontrar diferença estatisticamente significativa em relação ao percentual de uso de funções mais e menos interpessoais, com valor de 0,054 , o que torna efetiva a comparação entre os níveis para essas duas variáveis,estando os valores médios mais distantes entre os níveis 1 e 4 para as duas variáveis, como demonstra a Figura II.8. 
FIGURA II.8- MÉDIAS DO PERFIL FUNCIONAL DA COMUNICAÇÃO ENTRE OS 4 NÍVEIS DA ESCALA DE ADAPTAÇÃO SÓCIO-COMUNICATIVA, TENDO AS TERAPEUTAS COMO INFORMANTES NO SEGUNDO MOMENTO DE COLETA:

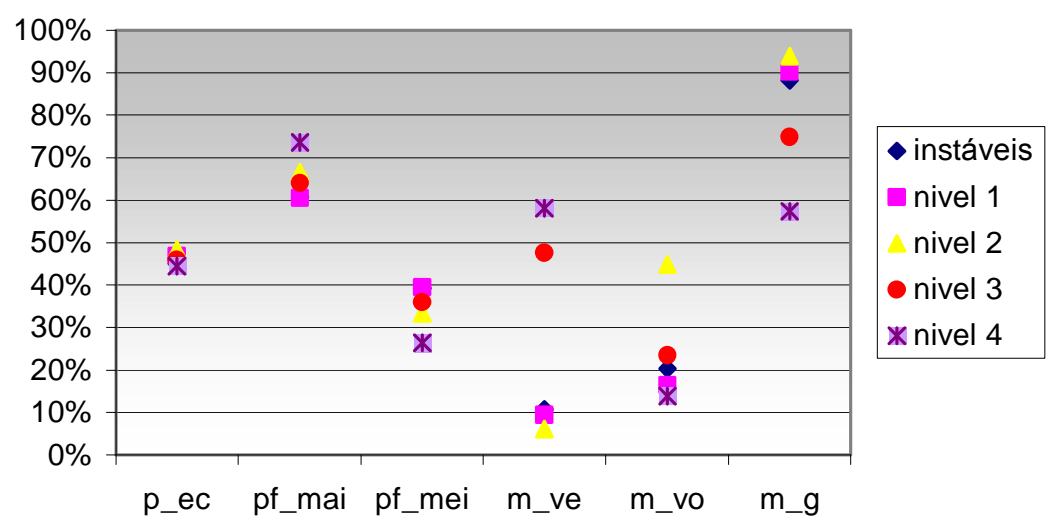

P_ec: \% espaço comunicativo ocupado
$\begin{aligned} & \text { Pf_mai:\% funções comunicativas } \\ & \text { mais interpessoais }\end{aligned}$
$\begin{aligned} & \text { Pf_mei:\% funções comunicativas } \\ & \text { menos interpessoais }\end{aligned}$

Além disso, foi possível designar novos pares de níveis de comparação com diferenças estatisticamente significativas como apresenta a Tabela II.18.

TABELA II.18 - VALORES DE SIGNIFICÂNCIA ENCONTRADOS NA IDENTIFICAÇÃO DE DIFERENÇAS DO PERFIL FUNCIONAL DA COMUNICAÇÃO ENTRE OS NIVEIS SÓCIO-COMUNICATIVOS, EXCLUINDO O GRUPO INSTÁVEL, ATRIBUÍDOS PELAS TERAPEUTAS NO SEGUNDO MOMENTO DE COLETA:

\begin{tabular}{ccccccc}
\hline \multirow{2}{*}{ Variável } & \multicolumn{5}{c}{ Pares de Níveis sócio-comunicativos } \\
\cline { 2 - 7 } & $1 \times 2$ & $1 \times 3$ & $1 \times 4$ & $2 \times 3$ & $2 \times 4$ & $3 \times 4$ \\
\% de uso do meio verbal & 0,708 & 0,005 & 0,006 & 0,033 & 0,063 & 0,479 \\
\% de uso do meio gestual & 0,625 & 0,054 & 0,009 & 0,055 & 0,031 & 0,288 \\
\hline
\end{tabular}


No segundo momento de coleta de dados com as terapeutas, observa-se que estes informantes também utilizaram um fator muito importante como a habilidade de interagir socialmente, demonstrada pelo percentual de uso das funções mais interpessoais, na classificação destes sujeitos em níveis. Os dados evidenciam que crianças no nível 4 da escala de adaptação sócio-comunicativa apresentam um perfil comunicativo mais interativo.

Os dados dos 37 sujeitos, classificados em níveis da escala de adaptação sócio-comunicativa foram submetidos à análise de aglomerados (Clusters), para identificar subgrupos específicos. Este estudo estatístico será apresentado comparando as classificações em níveis dos dados da escala de adaptação sócio-comunicativa obtida com os pais e as terapeutas nos dois diferentes momentos da coleta. 
DENDOGRAMAS II.1 E II.2- AGLOMERADOS DETERMINADOS PELAS VARIÁVEIS DO PERFIL FUNCIONAL DA COMUNICAÇÃO DOS SUJEITOS DO NÍVEL 1 DA ESCALA DE AD APTAÇÃO SÓCIOCOMUNICATIVA CLASSIFICADOS PELOS PAIS E TERAPEUTAS NO PRIMEIRO MOMENTO DE COLETA:

DENDOGRAMA II.1- CLASSIFICAÇÃO ATRIBUÍDA PELOS PAS:

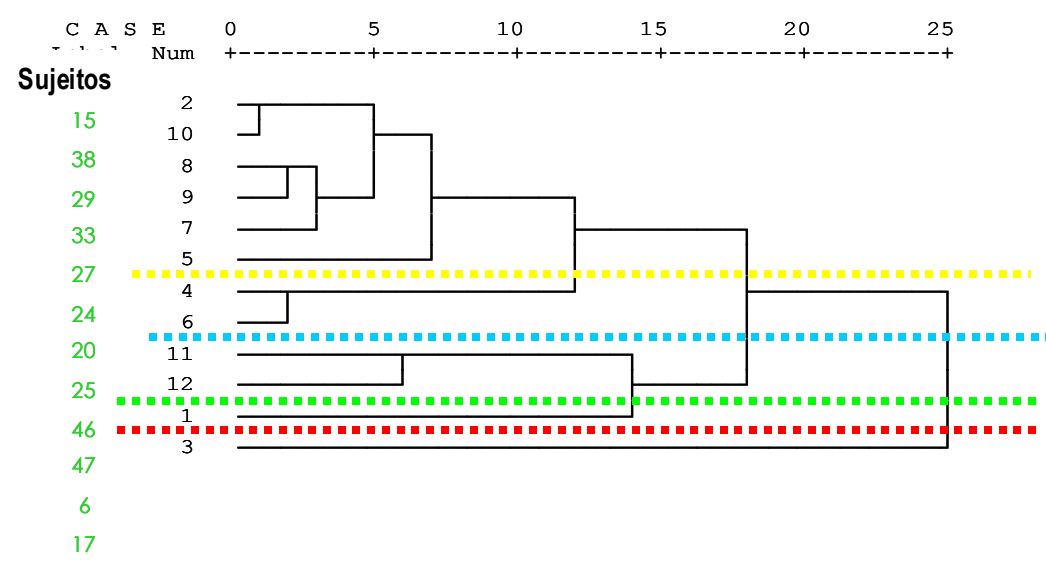

4- diferença muito pequena: simetria no uso das funções mais e menos interpess oais, predominantemente vocais e ges tuais.

3-diferença pequena: difere-se pelo elevado número de atos comunicativos expressos

2-diferença média: semelhança no \% de ocupação do espaço comunicativo e utilizam os meios comunicativos verbal, vocal e ges tual

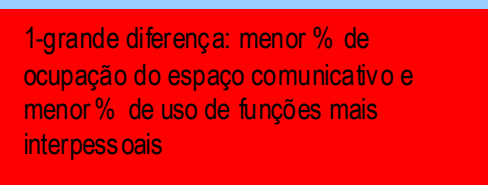

$\begin{array}{lllllll}\text { C A S E } & 0 & 5 & 10 & 15 & 20 & 25\end{array}$

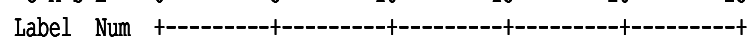

sujeltos

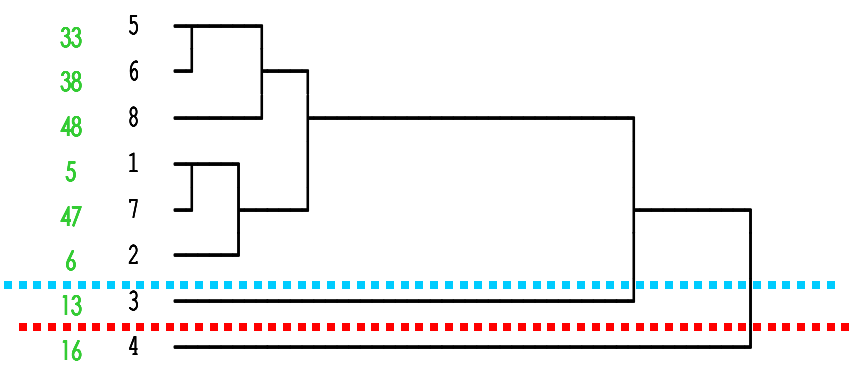

PELAS TERAPEUTAS:

Nos Dendogramas II.1 e II.2, em relação aos sujeitos classificados por pais e terapeutas como integrantes do nível 1 da escala de adaptação sóciocomunicativa no primeiro momento de coleta, pode-se observar perfis comunicativos muito heterogêneos na situação em que os pais foram os informantes e perfis comunicativos mais semelhantes entre si nos dados colhidos com as terapeutas, situação que persiste no segundo momento de coleta, como demonstra os Dendogramas II.3 e II.4. 
DENDOGRAMAS II.3 E II.4- AGLOMERADOS DETERMINADOS PELAS VARIÁVEIS DO PERFIL FUNCIONAL DA COMUNICAÇÃO DOS SUJEITOS DO NÍVEL 1 DA ESCALA DE AD APTAÇÃO SÓCIOCOMUNICATIVA CLASSIFICADOS PELOS PAIS E TERAPEUTAS NO SEGUNDO MOMENTO DE COLETA:

DENDOGRAMA II.3- CLASSIFICAÇÃO ATRIBUÍDA

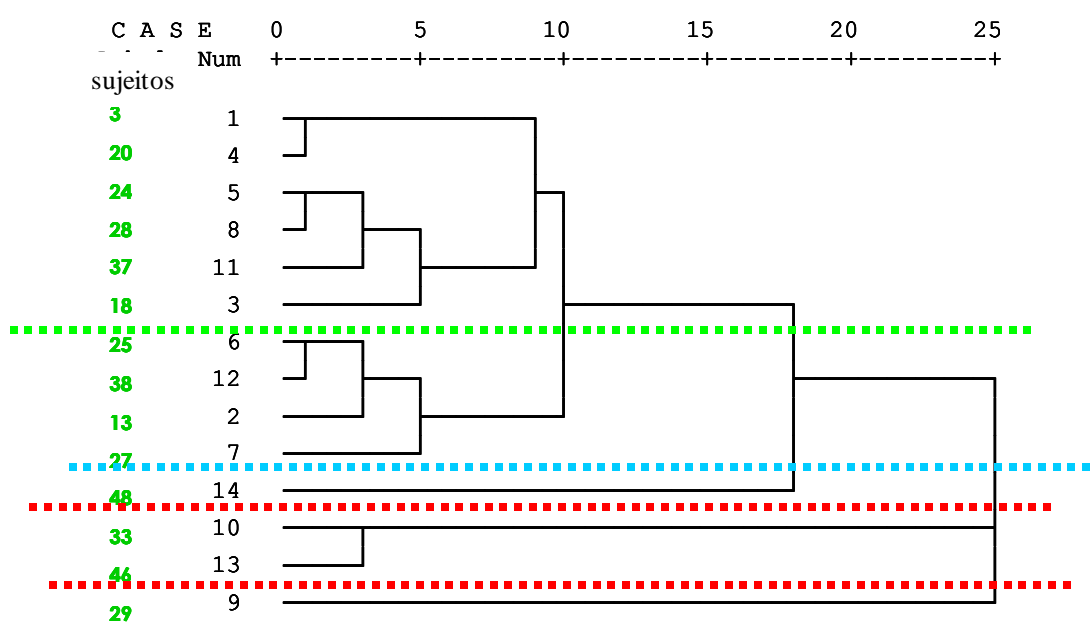

PELOS PAS:

4- diferença muito pequena: assemelham-se pelo número de atos comunicativos totais e expressos por minuto, \% de ocupação do espaço comunicativo e pouco uso do meio verbal.

3-diferença pequena: elevados número de atos comunicativos totais e expressos por minuto. Predominantemente vocais e gestuais.

2-diferença média: menor número de atos comunicativos totais e expressos por minuto

1-grande diferença: elevado \% de uso do meio comunicativo verba

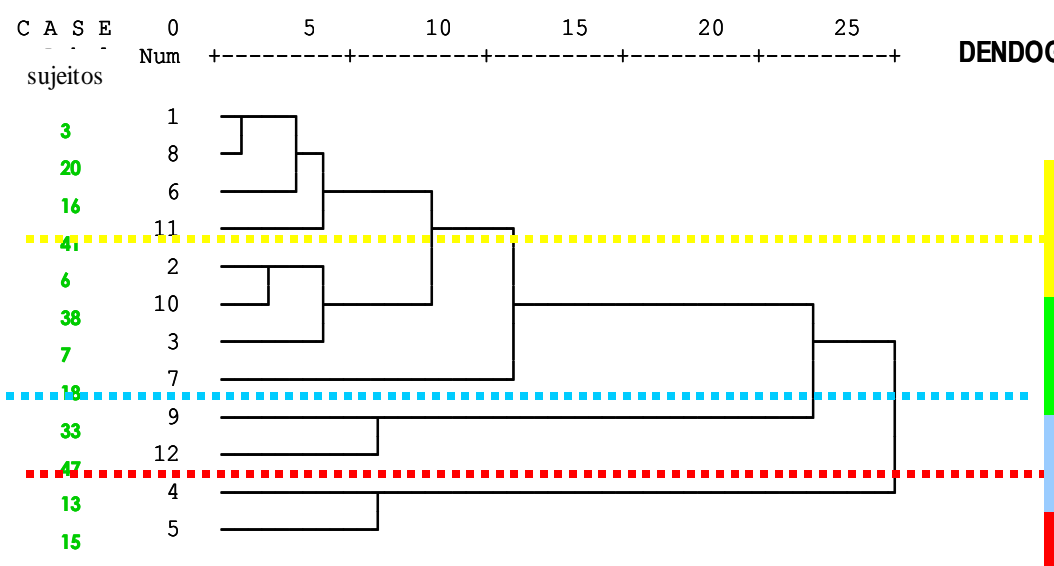

4- diferença muito pequena: \% grande de uso dos meios comunicativ os verbal, vocal e gestual.

3-diferença pequena: difere-se pelo maior $\%$ de uso funções menos interpess oais.

2-diferença média: predominantemente verbais e gestuais.

1- grande diferença: elevados número de atos comunic ativos totais e expressos por minuto. Predominantemente vocais $\epsilon$ gestuais. 
DENDOGRAMAS II.5 E II.6- AGLOMERADOS DETERMINADOS PELAS VARIÁVEIS DO PERFIL FUNCIONAL DA COMUNICAÇÃO DOS SUJEITOS DO NÍVEL 2 DA ESCALA DE ADAPTAÇÃO SÓCIO-COMUNICATIVA CLASSIFICADOS PELOS PAIS E TERAPEUTAS NO PRIMEIRO MOMENTO DE COLETA:

DENDOGRAMA II.5- CLASSIFICAÇÃO ATRIBUÍDA PELOS PAS:

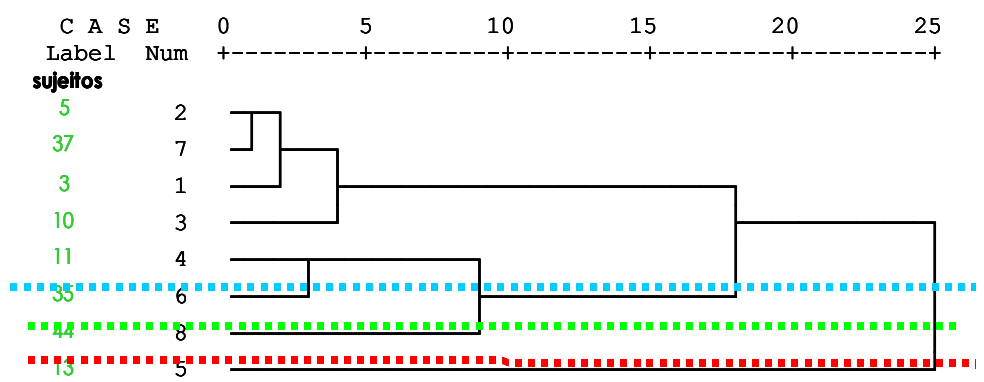

\section{3-diferença pequena: Menor número de} atos comunicativos totais e expressos por minuto. Menor no- de funções comunicativas utilizadas.

2- diferença média: simetria no \% de uso do es paço comunicativo e no uso de funções mais e menos interpessoais.

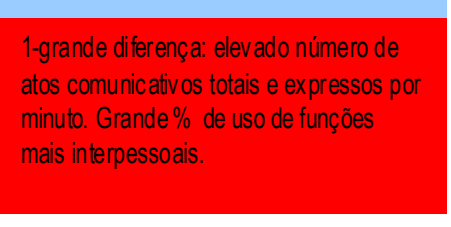

DENDOGRAMA II.6- CLASSIFICAÇÃO ATRIBUÍDA PELAS TERAPEUTAS

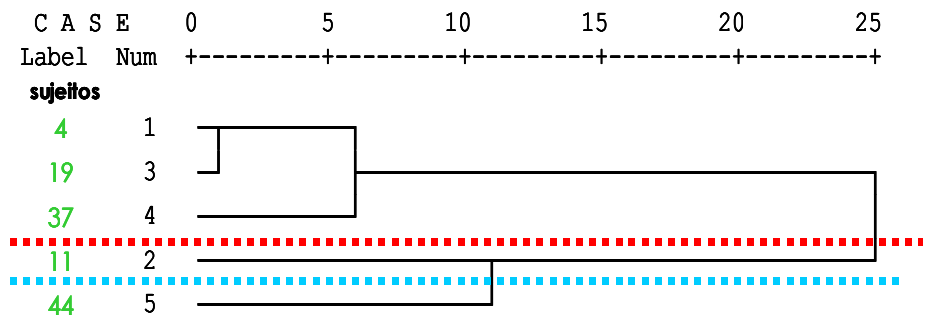

2-diferença média: menor número de atos comunicativos totais e expressos por minuto, menor \% de ocupação do espaço comunicativo

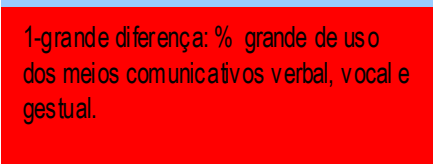

De acordo com os Dendogramas II.5 e II.6 pode-se notar que os sujeitos classificados no nível 2 da escala de adaptação sócio-comunicativa no primeiro momento de coleta, apresentam perfis comunicativos muito semelhantes, principalmente na situação em que as terapeutas foram as informantes.

De forma geral, a diferença entre os perfis comunicativos dos grupos de sujeitos atribuídos ao nível 2 pelos dois informantes foi mínima, sendo possível dizer que os informantes identificaram perfis comunicativos muito semelhantes, embora os sujeitos em cada grupo sejam diferentes. 
DENDOGRAMAS 11.7 E $\quad$ II.8- AGLOMERADOS DETERMINADOS PELAS VARIÁVEIS DO PERFIL FUNCIONAL DA COMUNICAÇÃO DOS SUJEITOS DO NÍVEL 2 DA ESCALA DE ADAPTAÇÃO SÓCIOCOMUNICATIVA CLASSIFICADOS PELOS PAIS E TERAPEUTAS NO SEGUNDO MOMENTO DE COLETA:

DENDOGRAMA II.7- CLASSIFICAÇÃO ATRIBUÍDA

PELOS PAS:

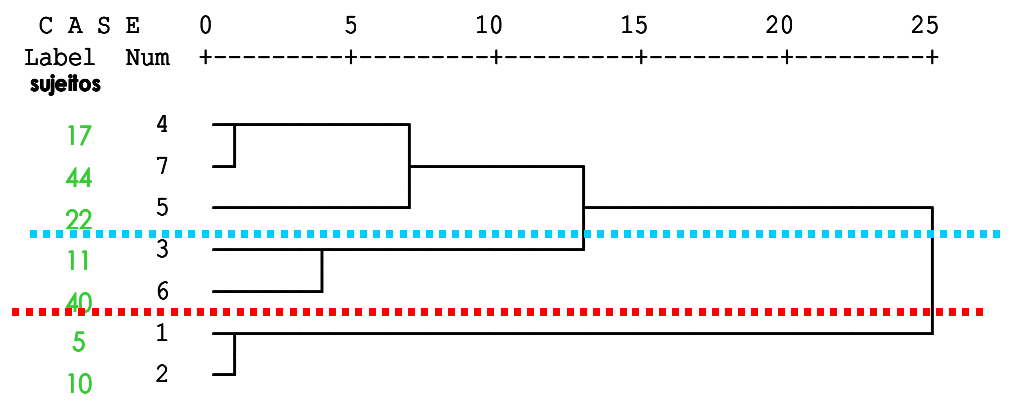

2-diferença média: diferem-se pelo elevado número de atos comunicativos totais e expressos por minuto.

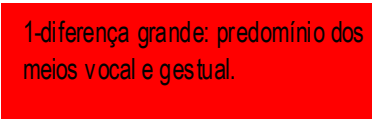

DENDOGRAMA II.8- CLASSIFICAÇÃO ATRIBUÍDA PELAS TERAPEUTAS:

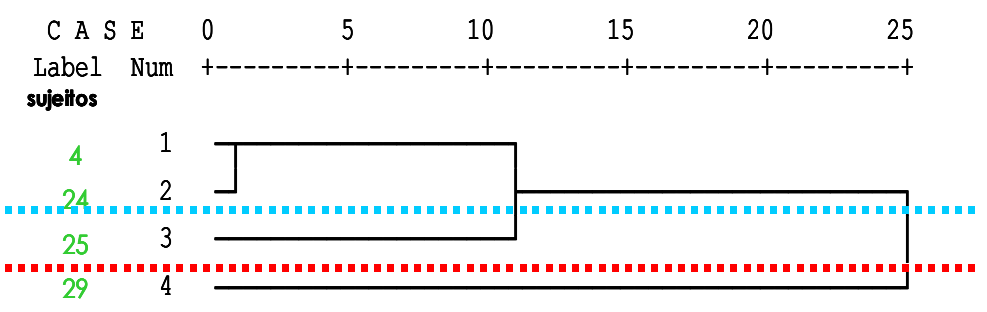

2-diferença média: difere-se pelo maior $\%$ de uso funções menos interpessoais.

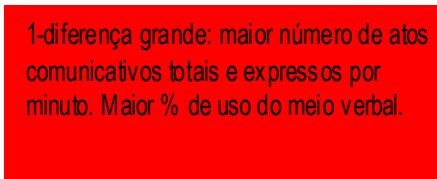

Os Dendogramas II.7 e II.8, abordam o perfil funcional da comunicação das crianças que foram classificadas pelos pais e terapeutas como integrantes do nível 2 da escala de adaptação sócio-comunicativa, no segundo momento de coleta.

É interessante notar, que no segundo momento de coleta é possível formar grupos em que os perfis comunicativos apresentaram-se ainda mais semelhantes, tanto quando os pais foram os informantes quanto quando as terapeutas os foram. 
DENDOGRAMAS II.9 E II.10- AGLOMERADOS DETERMINADOS PELAS VARIÁVEIS DO PERFIL FUNCIONAL DA COMUNICAÇÃO DOS SUJEITOS DO NÍVEL 3 DA ESCALA DE ADAPTAÇÃO SÓCIO-COMUNICATIVA CLASSIFIC ADOS PELOS PAIS E TERAPEUTAS NO PRIMEIRO MOMENTO DE COLETA:

\section{DENDOGRAMA II.9- CLASSIFICAÇÃO ATRIBUÍDA} PELOS PAS:

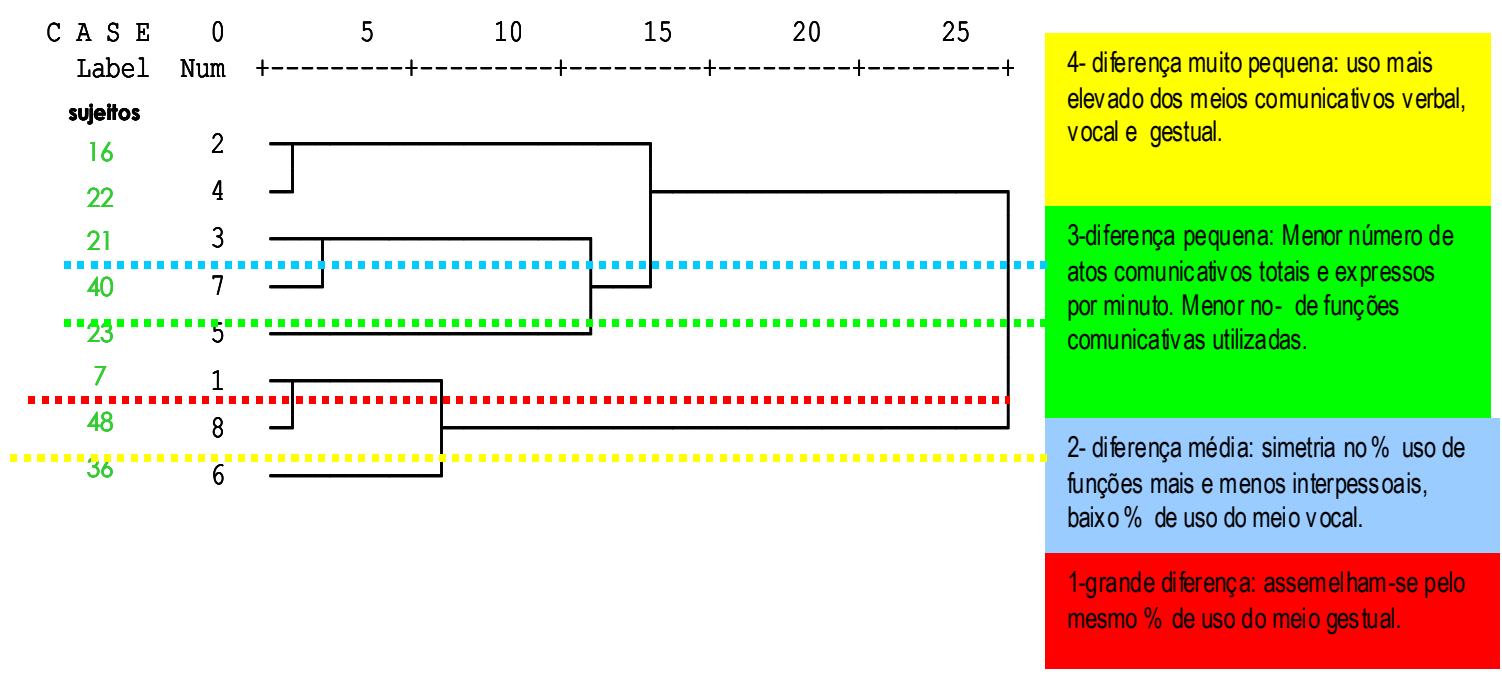

DENDOGRAMA II.10- CLASSIFICAÇÃO ATRIBUIDA PELAS TERAPEUTAS:

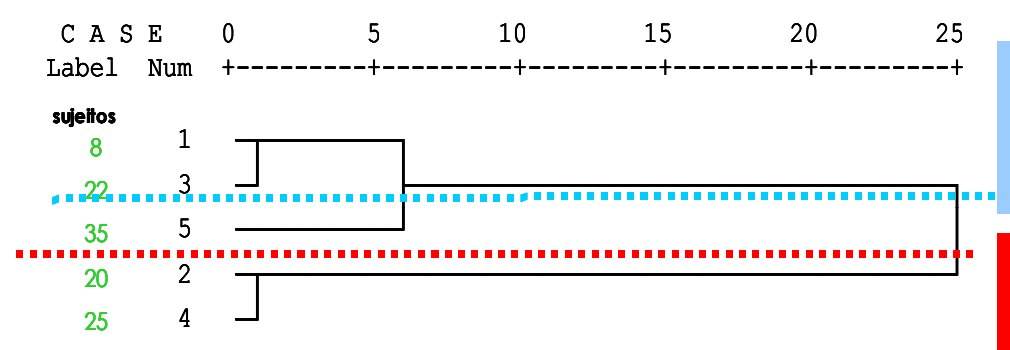

2- diferença média: difere-se pelo elevado \% uso dos meios comunicativos verbal, vocal e gestual.

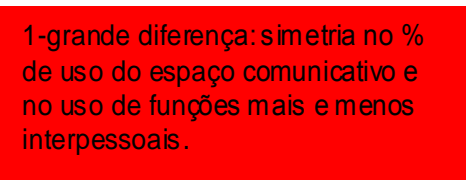

No Dendograma II.9 observa-se uma grande heterogeneidade quanto ao perfil comunicativo dos sujeitos classificados no nível 3 pelos pais no primeiro momento de coleta.

Diferente do que ocorre com as crianças classificadas neste mesmo nível sócio-comunicativo pelas terapeutas, como apresenta 0 Dendograma Il.10, uma vez que os dados obtidos com estas demonstram uma maior semelhança entre os sujeitos. 
DENDOGRAMAS II.11 E II.12- AGLOMERADOS DETERMINADOS PELAS VARIÁVEIS DO PERFIL FUNCIONAL DA COMUNICAÇÃO DOS SUJEITOS DO NIVVEL 3 DA ESCALA DE ADAPTAÇÃO SÓCIO-COMUNICATVVA CLASSIFICADOS PELOS PAISE TERAPEUTAS NO SEGUNDO MOMENTO DECOLETA:

DENDOGRAMA II.11- CLASSIFICAÇÃO ATRIBUÍDA PELOS PAS:

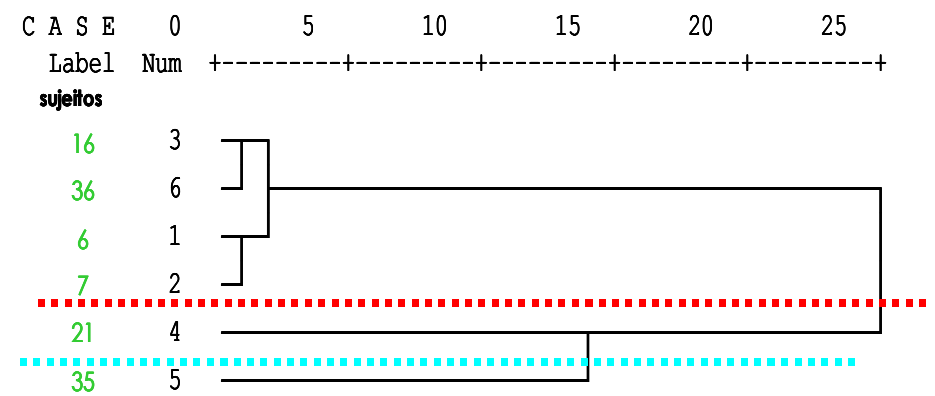

2- diferença média: maior número de atos comunicativos totais e expressos por minuto, número de funções comunicativas utilizadas.

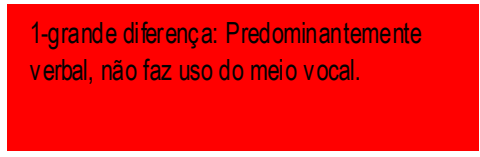

DENDOGRAMA II.12- CLASSIFICAÇÃO ATRIBUÍDA PELAS TERAPEUTAS:

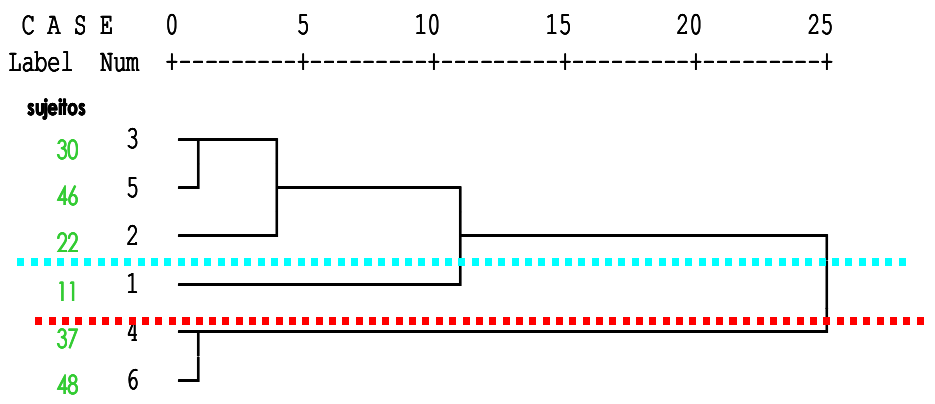

2- diferença média: maior número de atos comunicativos totais e express os por minuto e \% de ocupação do espaço comunicativo.

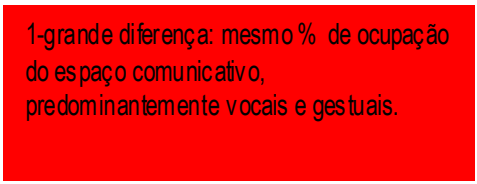

Os Dendogramas II.11 e II.12, demonstram o funcionamento do perfil funcional da comunicação das crianças que foram classificadas segundo informações fornecidas pelos pais e terapeutas como integrantes do nível 3 da escala de adaptação sócio-comunicativa no segundo momento de coleta. Mais uma vez, como já observado anteriormente, no segundo momento de coleta os perfis comunicativos apresentaram-se ainda mais semelhantes, tanto quando os pais foram os informantes quanto quando as terapeutas os foram. 
DENDOGRAMAS II.13 E II.14- AGLOMERADOS DETERMINADOS PELAS VARIÁVEIS DO PERFIL FUNCIONAL DA COMUNICAÇÃO DOS SUJEITOS DO NÍVEL 4 DA ESCALA DE ADAPTAÇÃO SÓCIOCOMUNICATIVA CLASSIFICADOS PELOS PAIS E TERAPEUTAS NO PRIMEIRO MOMENTO DE COLETA:

DENDOGRAMA II.13- CLASSIFICAÇÃO ATRIBUÍDA

PELOS PAS:

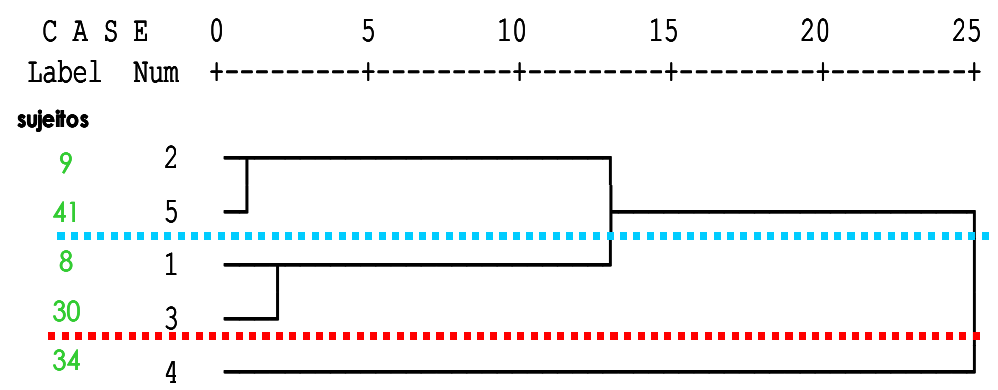

2- diferença média: assemelham-se pelo

$\%$ espaço comunicativo ocupado e número de atos comunicativos/minuto. Predominantemente verbais e gestuais.

DENDOGRAMA II.14- CLASSIFICAÇÃO ATRIBUÍDA PELAS TERAPEUTAS:

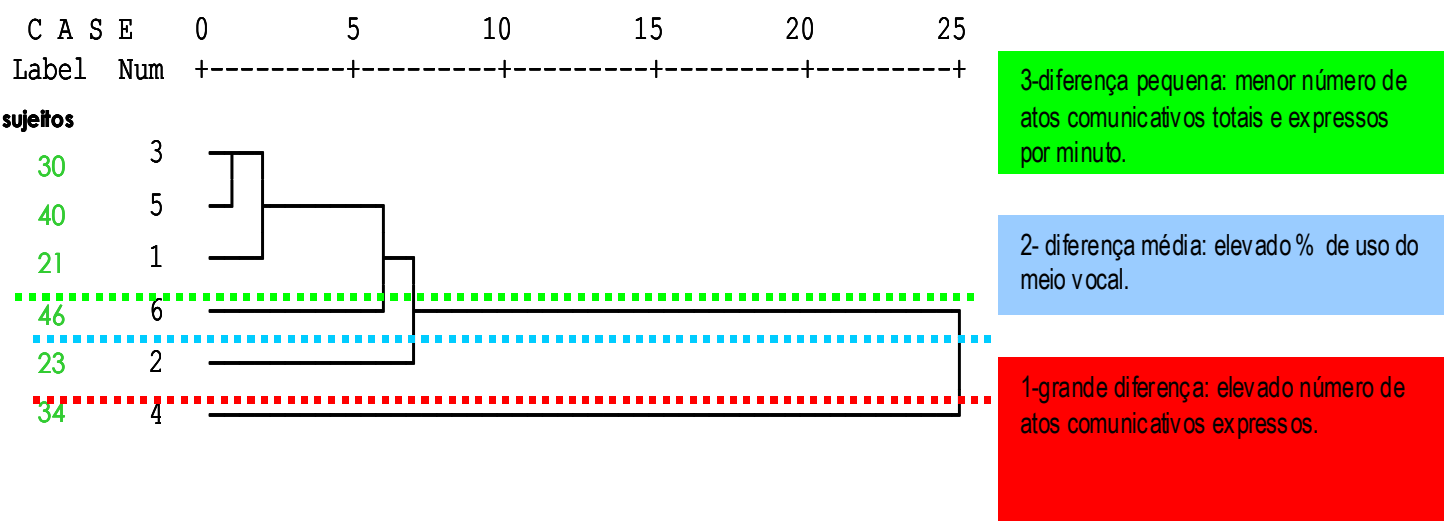

Observando os Dendogramas II.13 e II.14, nota-se a semelhança entre o perfil funcional da comunicação dos sujeitos classificados no nível 4 da escala de adaptação sócio-comunicativa no primeiro momento de coleta pelos pais e terapeutas. 
DENDOGRAMAS II.15 E II.16- AGLOMERADOS DETERMINADOS PELAS VARIÁVEIS DO PERFIL FUNCIONAL DA COMUNICAÇÃO DOS SUJEITOS DO NÍVEL 4 DA ESCALA DE ADAPTAÇÃO SÓCIO-COMUNICATIVA CLASSIFIC ADOS PELOS PAIS E TERAPEUTAS NO SEGUNDO MOMENTO DE COLETA:

DENDOGRAMA II.15- CLASSIFICAÇÃO ATRIBUÍDA

PELOS PAS:

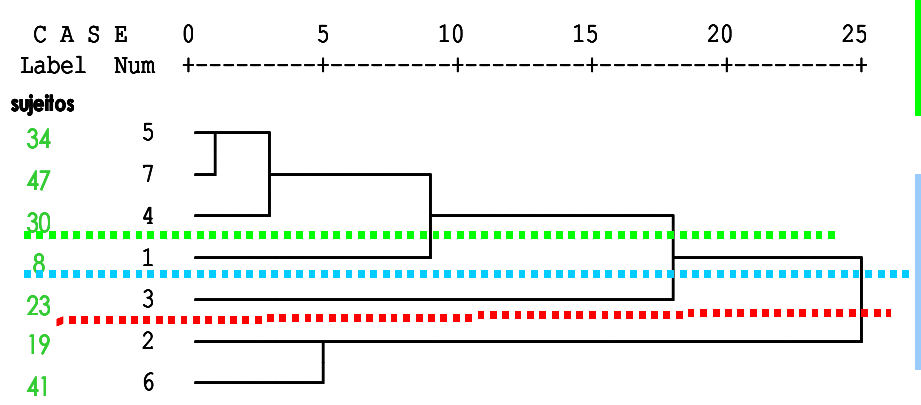

3-diferença pequena: menor número de funções comunicativas ex pres

2- diferença média: elevado número de atos comunicativos totais e expressos por minuto. Grande \% de uso de funções mais interpessoais.

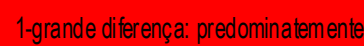
gestuais e vocais, não fazem uso do meio verbal.

DENDOGRAMA II.16- CLASSIFICAÇÃO ATRIBUÍDA PELAS TERAPEUTAS:

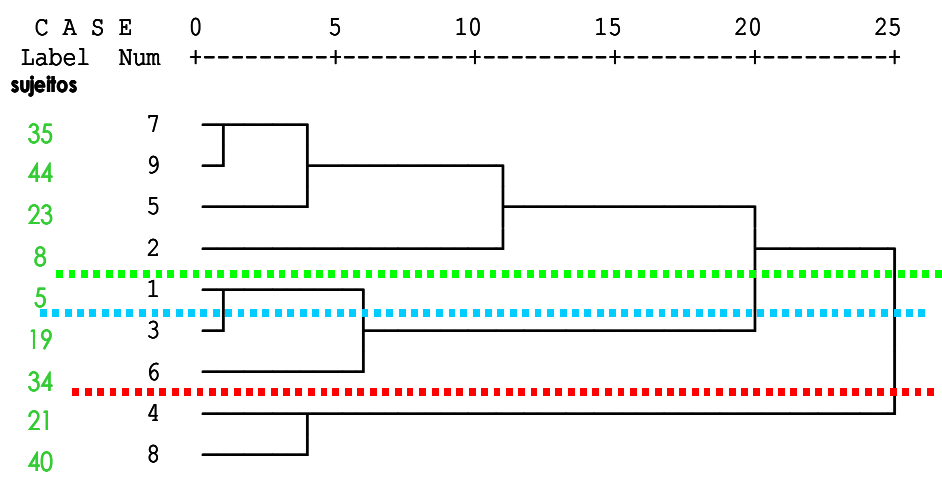
pelo \% espaço comunicativo oc upado e número de atos comunicativos expressos. Predominantemente verbais e gestuais

Mais uma vez, pode-se observar nos Dendogramas II.15 e II.6, apesar de existirem grandes variações individuais, os perfis comunicativos apresentados pelos grupos classificados pelos pais e pelas terapeutas apresentam-se bastante semelhantes no segundo momento de coleta. 


\section{5- Discussão:}

Os dados serão discutidos na mesma ordem de apresentação dos resultados, sendo assim, a pesquisadora abordará os dados relacionados à adaptação sócio-comunicativa relatada por pais e terapeutas em diferentes momentos de coleta; à adaptação sócio-comunicativa e seus correlatos com o perfil funcional da comunicação; aos níveis de adaptação sócio-comunicativos e suas relações com as variáveis do perfil funcional da comunicação.

Quanto aos dados de adaptação sócio-comunicativa obtidos com os pais nos dois momentos de coleta, observou-se uma grande semelhança nas respostas dadas. Apesar de haver um aumento em quase todos os estágios sócio-comunicativos no segundo momento de coleta, somente uma diferença estatisticamente significativa foi encontrada. Esta diferença refere-se à habilidade da criança ser capaz de gostar e reagir bem ou não às novidades introduzidas, o que poderia estar ligado a questões que relacionam o desenvolvimento cognitivo e social, pois as habilidades de engajamento social, variação, solicitação de objetos e ações são o resultado da relação íntima entre as habilidades de comunicação e as de cognição social (Rutter, 1981, 1983, 1987; Tager-Flusberg, 2000). Pode-se também, considerar as questões do contexto, uma vez que ao aprender níveis básicos de competência sócio-lingüística, usar e compreender comportamentos não-verbais apropriados, a criança começa a se adaptar ao contexto social (Prinz, 1982). 
Em relação aos dados de adaptação sócio-comunicativa, obtidos com as terapeutas nos dois momentos de coleta, observou-se um aumento significativo em quase todos os estágios sócio-comunicativos que pode estar relacionado a questões de aumento de familiaridade e contextos mais estruturados (TagerFlusberg, 1999; Yont, 2003), bem como, ao tipo de situação interativa proposta e o tipo de linguagem utilizada (Carter,1979 e Yont et al., 2003).

As diferenças estatisticamente significativas encontradas na comparação dos dados sócio-comunicativos obtidos com as terapeutas nos dois momentos de coleta referem-se à habilidade de coordenar com o parceiro ações simples (trocas de turno), corroborando as idéias de Tager-Flusberg (1999) de que algumas habilidades sociais, como a troca de turno, tornam-se presentes no contexto de jogos ou outras atividades estruturadas. Mas esses mesmos resultados discordam das idéias de Hwang e Hughes (2000), de que crianças com autismo freqüentemente apresentam profundos déficits nas habilidades de troca social, sendo que estas falhas nas habilidades sociais não somente impedem uma interação recíproca, mas também podem retardar o desenvolvimento do comportamento sócio-comunicativo e ampliar o desnível entre estas crianças e seus pares. 
Como na situação com os pais, na situação em as terapeutas foram os informantes também aparece a diferença significativa em relação ao estágio 1 do nível 2, ou seja, a habilidade de gostar de variações, novidades introduzidas. Observam-se ainda, diferenças quanto à habilidade de se adaptar bem a introdução de novidades e ser capaz de aproveitar e combinar imaginações compartilhadas entre si e o parceiro; reforçando mais uma vez a teoria de que rotinas e familiaridades reduzem a imprevisibilidade do mundo; e que habilidades de troca social, como o compartilhamento de experiências, ações e objetos são resultado da relação íntima entre as habilidades de linguagem, cognição e socialização (Tager-Flusberg, 1999, 2000).

Na comparação dos dados de adaptação sócio-comunicativa, obtidos com os pais e as terapeutas no primeiro momento de coleta foi encontrada somente uma diferença estatisticamente significativa em relação à habilidade de referência social, utilizar expressões não-verbais do parceiro como referência crítica para suas ações, o que corrobora em parte os achados de Palermo et al. (2006), de que a socialização requer habilidades de comunicação efetivas, incluindo comunicação não-verbal e a compreensão das expressões faciais, que é um ingrediente fundamental no comportamento social. Por outro lado os dados deste estudo contrariam a idéia de que crianças com distúrbios do espectro autístico são inábeis em compreender e usar apropriadamente, informações sociais relevantes obtidas das faces dos outros (Bieberich e Morgan, 2004; Palermo et al., 2006). 
Comparando os dados de adaptação sócio-comunicativa colhidos com pais e terapeutas, no segundo momento de coleta, foram encontradas 5 diferenças estatisticamente significativas, sendo que três delas foram em relação às habilidades de referência social, adaptação e imaginação compartilhada, já discutidas anteriormente, e as outras duas em relação à habilidade de sintonia (realizar contato visual significativo) o que contraria a afirmação de alguns autores (p.ex: Buitelaar , 1991 e Bosa, 2002) de que estariam presentes déficits comunicativos, sociais e pragmáticos, como alterações na reciprocidade visual, na atenção compartilhada, na coordenação funcional, na integração do olhar e mecanismos gestuais.

A homogeneidade encontrada na análise das semelhanças e diferenças entre as respostas dadas por pais e terapeutas ao questionário e protocolo de adaptação sócio-comunicativa, sugere que este pode ser considerado um instrumento viável e confiável para a avaliação do relacionamento social de crianças do espectro autístico. Ele permite a objetivação dessa análise, corroborando os achados de vários autores (p.ex: Gutstein, 2000; Sousa, 2004; Sousa et al., 2005; Gerbelli et al., 2006). Segundo esses estudos, este protocolo mostrou-se como um instrumento sensível e útil na identificação de variações individuais relativas às habilidades sociais, possibilitando a caracterização do desenvolvimento social dessas crianças, bem como a adequação de procedimentos clínico-terapêuticos e de orientação aos pais. 
No estudo das correlações entre as áreas do perfil funcional da comunicação e a adaptação sócio-comunicativa colhida com os pais nos dois momentos de coleta foi encontrado um número muito pequeno de correlações estatisticamente significativas, o que não deve conduzir à desvalorização dos dados obtidos, e que pode estar associado ao fato deste estudo ser realizado com diferentes instrumentos de análise voltados para habilidades específicas de linguagem e socialização e às características e variações individuais da população incluída no espectro autístico.

Dentre as correlações estabelecidas identificou-se a presença de correlações positivas entre o percentual de uso do meio verbal e os níveis e estágios sócio-comunicativos, bem como a presença de correlações negativas da adaptação sócio-comunicativa e do percentual de uso do meio vocal, principalmente em níveis sócio-comunicativos mais altos, o que nos leva a pensar que quanto mais elaborada a habilidade sócio-comunicativa menor o uso meio vocal por crianças do espectro autístico. Isto poderia estar associado a um aumento na competência comunicativa que está especificamente relacionada à habilidade verbal, e por estas crianças fazerem parte de um grupo que apresentam um transtorno do desenvolvimento abrangente em que as inúmeras diferenças individuais dos sujeitos são marcantes, determinando assim um importante fator na expressão dos déficits comunicativos (Joseph et al., 2002). 
Um outro aspecto interessante que foi apresentado neste estudo de correlações com os dados colhidos com os pais foram as correlações negativas entre o percentual de ocupação do espaço comunicativo e os níveis e estágios sócio-comunicativos, o que corrobora os achados de Cardoso (2006) de que diferenças na ocupação do espaço comunicativo podem sugerir um maior equilíbrio entre os agentes comunicativos, bem como o início da formação do papel de interlocutor, o que torna essas crianças cada vez mais capazes de exercer a reciprocidade comunicativa, levando a padrões cada vez mais simétricos de comunicação. Esses achados confirmam também as idéias de Prinz (1982) de que com o desenvolvimento da criança, esta começa a orientar-se para o ponto de vista do ouvinte na conversação e a afirmação de Wollner e Geller (1982) que a perspectiva pragmática influencia nas habilidades de expressar atos comunicativos; iniciar e estender seqüências conversacionais, responder a quebras comunicativas, bem como na utilização dos meios comunicativos, observando a habilidade da criança em funcionar tanto como falante quanto como ouvinte.

Em relação às correlações entre o perfil funcional da comunicação e os dados de adaptação sócio-comunicativa colhidos com as terapeutas foi encontrado um número significante de diferenças estatisticamente significativas nos dois momentos de coleta, sendo encontradas 48 e 34 correlações significativas no momento 1 e no momento 2, respectivamente. Ao observar as Tabelas II.10 e II.11 fica clara a inter-relação entre as diversas áreas do perfil 
funcional da comunicação e as questões de relacionamento social, possivelmente por esses informantes, apesar dos diferentes estágios de formação, compartilham uma base em comum de conhecimentos teóricos do processo de heterocronia, em que áreas específicas e independentes como a cognição e a socialização desenvolvem-se em função de habilidades não-lingüísticas, gerando diferentes e novas interações entre os elementos destas áreas, criando uma nova capacidade simbólica (Bates, 1979).

A grande presença de correlações negativas significativas entre 0 percentual de uso do meio gestual e a adaptação sócio-comunicativa, bem como a de correlações positivas do meio verbal com os níveis e estágios sóciocomunicativos, condiz com a idéia de que as crianças utilizam as vocalizações e os gestos como instrumentos nos processos iniciais de aquisição da linguagem, efetivando assim sua troca comunicativa. Entretanto, com o desenvolvimento sócio-comunicativo elas passam a utilizar atos que envolvem a atenção conjunta e requerem a compressão da intencionalidade, principalmente pelo meio verbal (Hale e Tager-Flusberg, 2005 a). Esses achados podem ter desempenhado um papel muito importante sobre a análise do relacionamento sócio-comunicativo, atribuída pelos pais e terapeutas, às crianças do espectro autístico que compõem este trabalho. 
$\mathrm{Na}$ classificação das 37 crianças deste estudo em níveis sóciocomunicativos por pais e terapeutas, no primeiro momento de coleta, apresentase novamente que o aspecto do perfil funcional da comunicação que mais se diferenciou entre os níveis sócio-comunicativos foi o percentual de uso do meio verbal. Especialmente, na situação em que os pais foram os informantes, fica claro que os níveis sócio-comunicativos mais altos apresentam um maior uso deste meio comunicativo, sendo possível observar esses dados pela análise da Figura II. 5. O grupo classificado como instável, ou seja, aqueles a quem não foram atribuídas respostas que completassem os três estágios em nenhum dos níveis sócio-comunicativos, não apresentaram uso do meio verbal, embora não seja possível dizer que este seja o pior grupo.

Também no primeiro momento de coleta, quando as terapeutas foram as informantes, foi observado, mais uma vez, diferenças em relação aos níveis sócio-comunicativos quanto ao percentual de uso do meio verbal, e ao percentual de ocupação do espaço comunicativo. Esses resultados exigem a reflexão do papel da verbalização no desenvolvimento comunicativo e na maneira como o indivíduo é visto como um agente de trocas sociais. Tudo isso torna perceptível o reflexo que a ausência da comunicação verbal produz na adaptação sóciocomunicativa. 
Em relação ao mesmo tipo de análise realizada anteriormente com a classificação em níveis dada pelos pais, no segundo momento de coleta, apresentou-se o percentual de uso do meio vocal como o aspecto do perfil funcional da comunicação que mais se diferenciou entre os níveis sóciocomunicativos, uma vez que o percentual de uso desta área vai diminuindo progressivamente em relação ao desenvolvimento dos níveis da escala de adaptação sócio-comunicativos, sendo cada vez mais usado o meio verbal, concomitantemente com o meio gestual, corroborando com o fato de que quanto maior o uso do meio comunicativo verbal menor a necessidade de uso de outros meios comunicativos (Tager-Flusberg, 1999; Hale e Tager-Flusberg, 2005a; Rubin e Laurent , 2002).

Quanto à análise dos dados obtidos com as terapeutas no segundo momento de coleta, observam-se diferenças entre os níveis sócio-comunicativos em relação ao percentual de uso dos meios verbal e gestual, além de uma forte tendência para o percentual de uso de funções mais interpessoais como mostra a Figura II.8. Os resultados expostos na comparação entre os sujeitos dos níveis sócio-comunicativos demonstram claramente que os sujeitos classificados no nível 4 apresentam maior proporção de uso de funções mais interpessoais e diminuem no uso de funções menos interpessoais, além de evidenciarem o aumento no uso do meio verbal e a diminuição o uso dos meios gestual e vocal. 
A partir desses resultados, os achados corroboram as afirmações de Gutstein (2000), de que no nível 4 da escala de adaptação sócio-comunicativa essas crianças seriam capazes de estabelecer relações de amizade, começando a valorizar o ponto de vista do outro, a compartilhar imaginações, a misturar e integrar idéias e ter amigos que dividem interesses e experiências em comum, em síntese, as crianças começam a compreender a importância do grupo e de ser parte do grupo.

Apesar de existir um número pequeno de crianças no nível 4 da escala de adaptação sócio-comunicativa, os achados nos permitem também discordar em parte de Konstantareas e Stewart (2006) que afirmam que crianças com desordens do espectro autístico apresentariam uma particular desvantagem devido às suas dificuldades de interação social, pois elas falhariam na regulação do afeto, bem como com os achados de McDonald e Hemmes (2003) de que essas crianças com déficits na iniciativa e na interação social, não receberiam a quantidade ou a qualidade da atenção dos outros indivíduos sem o distúrbio.

Esses dados podem ajudar no direcionamento de estudos mais aprofundados e criteriosos das habilidades de relacionamento social de crianças do espectro autístico, no sentido de descobrir as variáveis envolvidas na possibilidade deste pequeno grupo ser capaz de atingir as habilidades sóciocomunicativas mais elaboradas. 
O estudo dos dendogramas nos fornece dados bastante interessantes no sentido de que, genericamente, no primeiro momento da coleta as crianças classificadas em níveis sócio-comunicativos a partir dos dados obtidos com os pais apresentaram perfis comunicativos mais heterogêneos, em comparação com os grupos definidos a partir das informações fornecidas pelas terapeutas. Entretanto, no segundo momento de coleta observa-se uma tendência à similaridade do perfil funcional da comunicação das crianças classificadas em cada nível sócio-comunicativo, demonstrando que ao final de um período de aproximadamente um ano de atendimento fonoaudiológico houve uma maior convergência entre os dados obtidos com os pais e aqueles obtidos com as terapeutas, no que diz respeito à adaptação sócio-comunicativa.

Esses achados reiteram a importância do papel dos pais e terapeutas na reabilitação dessas crianças, e de que é possível coletar informações úteis do progresso de crianças do espectro autístico utilizando os pais como informantes. A riqueza da toca de informações entre pais e terapeutas reflete de forma direta na clínica, tornando estes, parceiros no processo de intervenção e no monitoramento do nível de desenvolvimento destas crianças (Luiselli et al., 2001; Charman et. al, 2004, Siperstein e Volkmark, 2004; Eaves et al., 2006). 
Dados obtidos por meio de questionários aplicados com pais e terapeutas tornam-se úteis no processo de avaliação e no planejamento terapêutico individual, bem como, considerar a perspectiva dos mesmos são instrumentos de grande valia, pois permitem o acompanhamento da trajetória percorrida entre a aquisição e a realização, aprendizagem, dos aspectos avaliados em relação a cada criança, bem como a mudança de ótica dos pais e terapeutas em relação ao comportamento e desempenho de seus filhos e pacientes (Moes e Frea, 2002; Charman et al., 2004; Sousa, 2004).

É importante considerar que não há um padrão específico para se avaliar as alterações encontradas nos distúrbios do espectro autístico e de acordo com Fernandes (2002), a escolha dos procedimentos a serem utilizados, sejam eles instrumentos de avaliação específicos, como provas, testes e questionários, ou a observação dos aspectos lingüísticos, sociais e cognitivos em situação espontânea, traz de forma intrínseca suas vantagens e desvantagens. 


\section{6- Conclusão:}

Foi confirmada a primeira hipótese deste estudo, de que ao final de um período de aproximadamente um ano de atendimento fonoaudiológico haveria maior convergência entre os dados obtidos com os pais e aqueles obtidos com as terapeutas, no que diz respeito à adaptação sócio-comunicativa. De acordo com os resultados encontrados no segundo momento de coleta observa-se uma tendência maior à similaridade dos perfis comunicativos.

Quanto à segunda hipótese de que ao final de um período de aproximadamente um ano de atendimento fonoaudiológico haveria maior convergência entre os resultados do perfil funcional da comunicação e da adaptação sócio-comunicativa também foi confirmada. Observa-se o desenvolvimento do uso dos meios comunicativos, com ênfase no aumento do uso do meio verbal em níveis sócio-comunicativos mais elaborados, além de ser possível observar o aumento do uso de funções comunicativas, atos comunicativos totais e expressos por minuto, e o aumento da interatividade no perfil funcional da comunicação de crianças com melhores resultados na escala de adaptação sócio-comunicativa. 


\subsection{Conclusão Geral:}

O objetivo deste trabalho envolveu a verificação das relações entre a adaptação sócio-comunicativa e o perfil funcional da comunicação de crianças com distúrbios do desenvolvimento incluídos no espectro autístico e em atendimento fonoaudiológico especializado, por um período de aproximadamente um ano. Fica claro que o maior ganho foi a possibilidade de correlacionar duas áreas tão importantes do desenvolvimento infantil, por meio de dois estudos que incluíram aspectos de avaliação do perfil funcional da comunicação e o estabelecimento de dados do relacionamento social de crianças do espectro autístico, a partir de informações fornecidas por pais e terapeutas.

A hipótese de que os resultados referentes à adaptação sócio-comunicativa obtida a partir de entrevistas com terapeutas apresentariam maiores correlações com o perfil funcional da comunicação do que aqueles obtidos a partir de entrevistas com familiares foi confirmada no Estudo I.

A análise dos aspectos do perfil funcional da comunicação e da adaptação sócio-comunicativa determinou um número maior de correlações significativas quando as terapeutas foram as informantes. 
Esses dados podem demonstrar que as terapeutas, apesar de estarem em diferentes estágios da formação acadêmica, apresentam um conhecimento básico dos fundamentos lingüísticos, baseando a intervenção clínica em fundamentos pragmáticos, que propõe a análise conjunta dos aspectos do desenvolvimento lingüístico, cognitivo e social, o que pode fornecer grandes informações e diferentes tipos de análise global para o planejamento do processo diagnóstico e terapêutico.

O estudo II confirmou ambas as hipóteses propostas. A primeira afirmava que ao final de um período de aproximadamente um ano de atendimento fonoaudiológico haveria maior convergência entre os dados obtidos com os pais e aqueles obtidos com os terapeutas, no que diz respeito à adaptação sóciocomunicativa. A segunda sugeria que ao final de um período de aproximadamente um ano de atendimento fonoaudiológico haveria maior convergência entre os resultados do perfil funcional da comunicação e da adaptação sócio-comunicativa.

Os resultados do Estudo II revelaram que no primeiro momento da coleta as crianças classificadas em níveis sócio-comunicativos a partir dos dados obtidos com os pais apresentaram perfis comunicativos mais heterogêneos, em comparação com os grupos definidos a partir das informações fornecidas pelas terapeutas, mas no segundo momento de coleta observa-se uma tendência maior à similaridade dos perfis comunicativos. Indicaram também que crianças com melhores resultados na escala de adaptação sócio-comunicativa apresentaram maior interatividade no perfil funcional da comunicação, aumento no uso do meio verbal de comunicação e das iniciativas de comunicação. 
De forma geral, saber como o perfil funcional da comunicação funciona dentro de cada nível sócio-comunicativo sugere como essas crianças funcionam individualmente, sendo clara a grande variação entre elas e a idéia de que crianças em níveis iniciais da escala de adaptação sócio-comunicativa apresentam perfis comunicativos diferentes das crianças em níveis mais elevados, apresentando em graus variados comprometimentos nas áreas abordadas, estando associado à evolução dos meios comunicativos.

O estabelecimento de dados de adaptação sócio-comunicativa pôde caracterizar esta população, demonstrando que este instrumento pode ser aplicado com diferentes informantes, e que as respostas dadas pelos mesmos foram de certa forma homogêneas, confirmando que os dados foram fidedignos, apesar de existiram diferenças significativas na comparação dos níveis e estágios sócio-comunicativos.

A utilização dos pais e também das terapeutas na coleta dos dados de adaptação sócio-comunicativa mostrou-se de grande valia, possibilitando uma produtiva troca de informações e a formação de parcerias que agem na detecção de possíveis falhas no processo de reabilitação, acompanhando de forma sistemática e objetiva o trabalho terapêutico. 
Em relação aos objetivos específicos dos dois estudos propostos, a análise do relacionamento entre as áreas do perfil funcional da comunicação e os níveis e estágios sócio-comunicativos, confirmou-se mais uma vez a interdependência das áreas estudas. Esses dados podem estar associados às grandes variações individuais de crianças com distúrbios globais do desenvolvimento que podem envolver um grande número de variáveis não controláveis e influenciar na dispersão dos resultados.

A verbalização é um ponto muito importante no desenvolvimento infantil, e neste estudo observou-se que este fato também contribui para marcar o desenvolvimento sócio-comunicativo de crianças do espectro autístico, evidenciando que este pode ser o aspecto que mais influenciaria a determinação da competência sócio-comunicativa de crianças do espectro autístico por parte das terapeutas e principalmente, dos pais.

Uma das maiores evidências deste trabalho é que mesmo que as crianças do espectro autístico apresentem um desenvolvimento deficitário das habilidades de linguagem, cognição e socialização, ainda sim elas são capazes de extrair pistas lingüísticas e não-lingüísticas do meio comunicativo, e utilizá-las de forma contextual em sua vida social, associando-as com os ganhos na linguagem e no desempenho sócio-cognitivo. 
Um outro ganho que este trabalho fornece é a realização de um estudo com um grande número de sujeitos, apesar de que em alguns estudos estatísticos ser este o fator responsável pelo estabelecimento de coeficientes de correlação baixos, o que não invalida os resultados obtidos, mas pode possibilitar a identificação de variações muitos sutis nos perfis comunicativos e sóciocomunicativos de cada criança.

Essas variações também permitem ao terapeuta verificar os ganhos de cada criança neste período de aproximadamente 12 meses de terapia fonoaudiológica especializada, possibilitando assim fornecer processos terapêuticos mais adequados e específicos às dificuldades e necessidades de cada criança, embasados em habilidades direcionadas a cada nível sóciocomunicativo, associados às habilidades lingüísticas e sócio-cognitivas.

Pode-se dizer que, para crianças do espectro autístico a correlação entre as áreas de perfil funcional da comunicação e adaptação sócio-comunicativa não é inteiramente proporcional, e que a diversidade dos sintomas e características destas crianças incluídas no espectro autístico exigem também uma gama de abordagens para a real valorização das habilidades de cada uma.

A partir dos resultados obtidos na realização deste trabalho, pode-se sugerir uma nova proposta de análise do relacionamento social, não só de crianças incluídas no espectro autístico, mas de crianças em desenvolvimento típico e com outros distúrbios do desenvolvimento, uma vez que a competência social é claramente um importante aspecto no desenvolvimento infantil. 
Este trabalho contribui no sentido de fornecer uma forma de analisar e acompanhar o desenvolvimento de habilidades sociais necessárias para as crianças se adaptarem e funcionarem como parceiros, além de incentivar a proposta de programas de intervenção para crianças com distúrbios do desenvolvimento, voltados para as alterações das habilidades sóciocomunicativas, a fim de que estas melhorem suas interações sociais com seus pares, desenvolvendo conjuntamente as habilidades de linguagem, cognição e socialização.

Um outro aspecto relevante neste trabalho é a necessidade de estudos quanto à adaptação sócio-comunicativa de crianças em desenvolvimento típico, utilizando pais, familiares e cuidadores como informantes. Crianças em desenvolvimento típico apresentam formas de comunicação e socialização progressivamente mais elaboradas. Nesse processo, áreas específicas e independentes como a cognição, a linguagem e a socialização desenvolvem-se gerando diferentes interações entre seus elementos. A investigação deste processo e de suas relações com as diferentes áreas do desenvolvimento é fundamental para que dados de normalidade sejam estabelecidos e possam ajudar como possíveis parâmetros de comparação da evolução clínica e diagnóstica de crianças com distúrbios do desenvolvimento. 


\section{0- Referências Bibliográficas}

Adams C. Practitioner Review: the assessment of language pragmatics. J Child Psychol Psychiatry 2002; 43(8): 973-987.

American Psychiatry Association. DSM-IV. Manual diagnóstico estatístico de transtornos mentais. Trad: Dayse Batista; 4⿳⺈-ed. Porto Alegre- RS, Artes Médicas,1994.

American Psychiatry Association. DSM-IV-TR. Diagnostic and statistical Manual of Mental disorders. Fourth edition, Text Revised, Washington,. DC: American Psychiatry Publishing Inc: 2001.

Amato $\mathrm{CAH}$. Questões funcionais e sócio-cognitivas no desenvolvimento da linguagem em crianças normais e autistas. [tese]: São Paulo- Faculdade de Filosofia, Letras e Ciências Humanas, Universidade de São Paulo; 2006.

Bailey A, Luther $\mathrm{P}$, Dean A, Harding B, Janota I, Montgomery $\mathrm{M}$, et al. $A$ clinicopathological study of autism. Brain 1998;121:889-905.

Baird G, Hilary C, Slonims V. Diagnosis of Autism. BMJ 2003; 327(30):488493.

Bara BG, Tirassa M, Zettin M. Neuropragmatics: neuropsychological constraints on formal theories of dialogue. Brain and Language, 59. p.4-49, 1997. 
Baron-Cohen S, Wheelwright S, Cox A, Baird G, Charman T Swettenham J, Drew A, Doehring P. Early identification of autism by the Checklist for Autism in Toddlers (CHAT). J R Soc Med 2000;93: 521-525.

Bates E. Why pragmatics? In: Bates, E. Language and context: The acquisition of pragmatics. New York Academic Press, cap1: 1-41, 1976.

Bates E. On the evolution and developmental of symbols. In: Bates, Benigni, Bretherton, Camaioni, Volterra, eds. The emergence of symbols: cognition and communication in infancy. New York: New York Academic Press; 1979.

Bauman M, Kemper T. Neuroanatomic observations of the brain in autism. In M.L. Bauman, TL Kemper (eds), The neurologyn of autism .Baltimore, MD: Johns Hopkins University Press. 1994; p.119-145.

Bauminger N, Shulman C. The development and maintenance of friendship in high-functioning children with autism. Autism 2002; 7(1):81-97.

Bernard-Optiz V. Pragmatic analysis of the communicative behavior of an autistic child. J Speech Hear Disord. 1982; 47(1):99-109.

Bernard-Optiz V, Ing S, Kong TY. Comparison of behavioural and natural play interventions for young children with autism. Autism 2004; 8(3):319-333.

Beyer j, Gammeltoft L. Autism and Play. London: Jessica Kingsley 2000. 
Bieberich AA, Morgan SB. Self-Regulation and Affective Expression During Play in Children with Autism or Down Syndrome: A Short-Term Longitudinal Study. J Autism Dev Disord 2004; 34(4):439-448.

Bishop DVM. Autism, Asperger's syndrome and semantic-pragmatic disorder: Where are the boundaries? British Journal of Communication, v.24, p.107-121, 1989

Blanc R, Adien J-L, Roux S, Barthélémy C. Dysregulation of pretend play and communications development in children with autism. Autism 2005; 9(3):229245.

Bono MA, Daley T, Sigman M. Relations Among Joint attention, Amount of Intervention and Language Gain in Autism. J Autism Dev Disord 2004; 34(5) 495:510.

Bosa C. Sinais precoces de comprometimento social no autismo: evidências e controvérsias. In: CAMARGOS JR., W e colaboradores. TID: $3^{\circ}-$ Milênio. $1^{\mathrm{a}}-$ ed. Brasília: Ministério da Justiça, Coordenadoria Nacional para Integração da Pessoa Portadora de Deficiência, AMES, ABRA, 2002.

Buitelaar JK. Differences in the structure of social behavior of autistic children and non-autistic retarded controls. J Child Psychol Psychiatry 1991; 32(6):9951015. 
Cardoso C. A atuação fonoaudiológica em uma instituição psiquiátrica com crianças do espectro autístico. [dissertação]: São Paulo.Faculdade de Medicina; Universidade de São Paulo, 2001.

Cardoso C. Funções comunicativas em diferentes situações com crianças do espectro autístico. Rev Soc Bras Fonoaudiol 2006; 11(1):22-7.

Cardoso C, Fernandes FDM. Uso de funções comunicativas interpessoais e não interpessoais em crianças do espectro autístico. Barueri (SP), Pró-Fono Revista de Atualização Científica 2003; 15(3):279-286.

Carpenter M, Tomasello M. Joint attention, cultural learning and language acquisition. In: Wetherby, Prizant, edit. Autism spectrum disorders - a transactional developmental perspective. Baltimore: Paul Brooks; 2001.

Carter AL. Prespeech meaning relations: an outline of one infant's sensoriomotor morphem developmental. In: Fletcher P, Garman M. Language acquisition. Cambrigde, Cambrigde University Press, p. 71-91, 1979.

Cervone LM, Fernandes FDM. Análise do perfil comunicativo de crianças de 4 a 5 anos na interação com o adulto. Rev Soc Bras Fonoaudiol. 2005; 10(2): 97-105.

Charman T, Howlin P, Berry B, Prince E. Measuring developmental progress of children with autism spectrum disorder on school entry using parent report. Autism 2004; 8(1) 89-100. 
Chugani DC. Role of altered brain serotonin mechanisms in autism. Molecular Psychiatry 2002; 7(supl 2): S16-S17.

Creghead N. Children with disorders of pragmatics. In: Irwin JV. Pragmatics: the role in language development. La Verne, Fox Point Publ., 6, p.105-134, 1982.

Dawson G, Toth K, Abbott R, Osterling J, Munson J, Estes A, Liaw J. Early Social Attention Impairments in Autism: Social Orienting, Joint attention, and Attention to Distress. Dev Psychol 2004; 40(2): 271-283.

Dominguez A, Ziviani J, Rodger S. Play behaviours and play object preferences of young children with autistic disorder in a clinical play environment. Autism 2006; 10(1): 53-69.

Downs A, Smith T. Emotional Understanding, Cooperation, and Social Behavior in High-Functioning Children with Autism? J Autism Dev Disord 2004;34(6):625-635 .

Eaves LC, Wingert HD, Ho HH, Mickelson ECR. Screening for Autism Spectrum Disorders with the Social Communication Questionnaire. J Dev Behav Pediatr 2006; 27(2):95-103.

Fernandes FDM. Autismo infantil - repensando o enfoque fonoaudiológico. São Paulo, Lovise, 1996a. 
Fernandes FDM. Autismo infantil. In: Fernandes FDM, Pastorello L, Scheur Cl. (orgs.). A Fonoaudiologia em Distúrbios Psiquiátricos da Infância, São Paulo, Lovise, 1996b; p.17-29.

Fernandes FDM, Galinari HS. Oficina de linguagem em hospital-dia infantilprimeiros relatos. Barueri (SP), Pró-Fono Revista de Atualização Científica 1999;11(2):85-91.

Fernandes FDM. Atuação fonoaudiológica com crianças com transtornos do espectro autístico [tese]. São Paulo: Faculdade de Medicina, Universidade de São Paulo; 2002.

Fernandes FDM. Sugestões de procedimentos terapêuticos de linguagem em distúrbios de espectro autístico. In: Limongi SCO, organizadora. Fonoaudiologia - informação para a formação. Rio de Janeiro: Guanabara Koogan; 2003. p.55-65.

Fernandes FDM. Pragmática. In: Andrade CRF, Béfi-Lopes DM, Fernandes FDM, Wertzner HF. ABFW- teste de Linguagem Infantil nas áreas de Fonologia, Vocabulário, Fluência e Pragmática. Carapicuíba (SP), Pró-Fono, 2004.

Fernandes FDM, Teles P. Linguagem nos transtornos do espectro autístico. Rev Soc Bras Fonoaudiol. 2005; 10(4):207-10. 
Fernandes FDM, Molini-Avejonas DR, Sousa-Morato PF. Perfil Funcional da Comunicação nos Distúrbios do Espectro Autístico. Rev CEFAC; 2006: 8(1), 20-6.

Folstein SE, Rosen-Sheidley B. Gentics of autism: complex aetiology for a heterogeneous disorder. Genetics 2001; 2:943:955.

Gerbelli AE, Sousa-Morato PF, Fernandes FDM. Adaptação sóciocomunicativa em crianças de um ano de idade. XIV Congresso Brasileiro de Fonoaudiologia- Suplemento Especial Rev Soc Bras Fonoaudiol. Outubro 4-7, 2006; Salvador-BA, Brasil.

Gilmour J, Hill B, Place M, Skuse DH. Social communication deficits in condut disorder: a clinical and community survey . J Child Psychol Psychiatry 2004; 45(5):967-678.

Goldstein H. Communication Intervention for Children with Autism: A Review of Treatment Efficacy. J Autism Dev Disord 2002; 32(5):373-396.

Golsen B. Autismo Infantil: despiste e prevenção. Rev Latinoam Psicopat Fund 2005; 8(3): 428-442.

Gray GE. Psiquiatria baseada em evidências. Trad: Magda França Lopes; $4^{a}{ }_{-}$ ed. Porto Alegre- RS, Art Med, 2004.

Gutstein S. Solving The Relationship Puzzle. Arlington, Texas; Future Horyons, 2000. 
Gutstein S, Whitney T. Asperger Syndrome and the Development of social competence. Focus on Autism and Developmental Disorders 2002; 17:161-71.

Gutstein S. Solving the relationship puzzle for autism and Asperger syndrome [apostilado]. Tallahasse: Institute on Autism at FSU; 2002.29p.

Hale CM, Tager-Flusberg $\mathrm{H}$. Social communication in children with autism- The relationship between theory of mind and discourse development. Autism 2005a; 9(2):157-178.

Hale CM, Tager-Flusberg H. Brief report: The relationship between Discourse deficits and Autism symptomatology. J Autism Dev Disord 2005b; 35(4):519524.

Howlin P. An overview of Social Behaviour in autism. In: E Schopler, GB Melsibov 9eds) Social Behaviour in Autism. New York: Plenum 1986.

Hwang B, Hughes C. The effects of social interactive training on early social communicative skills of children with autism. Journal of Autism and Developmental Disorders 2000; 30(4):331-343.

Ingersoll B, Schreibman L. Teaching Reciprocal Imitation Skills to Young Children with Autism Using a Naturalistic Behavioral Approach: Effects on Language, Pretend Play, and Joint Attention. J Autism Dev Disord 2006; 36(4):487-505.

Jordan R. Social play and autistic spectrum disorders- A perspective on theory, implications and educational approaches. Autism 2003; 7(4):347-360. 
Joseph RM, Tager-Flusberg H, Lord C. Cognitive profiles and socialcommunicative functioning in children with autism spectrum disorder. J Child Psychol Psychiatry 2002; 43(6): 807-821.

Joseph RM, McGrath LM, Tager-Flusberg H. Executive Dysfunction and Its relation to Language Ability in Verbal School-Age Children with Autism. Dev Neuropsychol 2005; 27(3):361-378.

Kecskés I. A cognitive-pragmatic approach to situation-bound utterances. Journal of pragmatics $2000 ; 32: 605-625$.

Kent RD. Pragmatics. In: The MIT Encyclopedia of Communication Disorders. Cambridge, Massachusetts, London, England, MIT Press, p. 2004.

Kjelgaard MM, Tager-Flusberg H. An Investigation of Language Impairment in Autism: implications for genetic Subgroups. Lang Cogn Process 2001; 16(23):287-308.

Klin A. Autismo e síndrome de Asperger. Rev Bras Psiquitr. 2006; 28(supl I):S3-11.

Kok JA, Kong TY, Bernard-Optiz V. A comparison of the effects of structured play and facilitated play approaches on preschoolers with autism. Autism 2002; $6(2): 181-196$.

Konstantareas MM, Stewart K. Affect Regulation and Temperament in Children with autism Spectrum Disorder. J Autism Dev Disord 2006; 36(2):143-154. 
Kylliäinen A, Hietanen JK. Skin Conductance Responses to Another Person's Gaze in Children with Autism. J Autism Dev Disord 2006; 36(4):517-525.

Landa RJ, Garrett-Mayer M. Language, social, and executive functions in High Functioning Autism: A Continuum of Performance. J Autism Dev Disord 2005; 35(5):557-573.

Leekam SR, Ramsden CAH. Dyadic Orienting and Joint Attention in Preschool Children with Autism. J Autism Dev Disord 2006; 36(2):185-197.

Legof DB, Sherman M. Long-term outcome of social skills based on interactive LEGO play. Autism 2006,10(4):317-329.

Lima MS, Soares BGO, Bacaltchuk J. Psiquiatria baseada em evidências. Rev Bras Psiquiatr 2000; 22(3):142-6.

Lord C, Risi S. Diagnosis of autism spectrum disorders in young children. In: Wetherby AM, Prizant BM, ED. Autism spectrum disorders- a transacional developmental perspective. Baltimore: Paul Brooks, p.11-30, 2001.

Lord C. The Development of Peer Relations in Children with Autism. In: FJ Morrison, C Lord, DP Keating (eds). Advances in Applied Developmental Psychology . New York: Academic.1984. p. 75-97.

Lord C, Magill J. Methodological and Theoretical Issues in Stuyding PeerDirected Behaviour and Autism. In: G Dawson (ed). Autism: New Directions in Diagnosis and Treatment. New York: Guilford, 1989. 
Loveland KA, Pearson DA, Tunali-Kotoski B, Ortegon J, Gibbs MC. Judgments of social appropriateness by children and adolescents with autism. J Autism Dev Disord 2001; 31:367-76.

Luiselli JK, Campbell S, Cannon B, DiPietro, Ellis JT, Taras M, Lifter K. Assessment instruments used in the education and treatment of pearsons with autism: brief report of a survey of national service centers. Res Dev Disabil $2001 ; 22: 389-398$

Macintosh K, Dissanayake C. A comparative study of the spontaneous social interactions of children with high-functioning autism and children with Asperger's disorder. Autism 2006; 10(2) 199-220.

McDonald M, Hemmes NS. Increases in social initiation toward an adolescent with autism: reciprocity effects. Res Dev Disabil 2003; 24: 453-465.

Mcduffie AS, Yoder PJ, Stone WL. Labels increase attention to novel objects in children with autism and comprehension-matched children with typical development. Autism 2006; 10(3):288-301.

Meyer JA, Mundy PC, Hecke AVV, Durocher JS. Social attribution processes and comorbid psychiatric symptoms in children with Asperger syndrome. Autism 2006; 10(4):383-402.

Moes DR, Frea WD. Contextualized Behavioral Support in Early Intervention for Children with Autism and Their Families. J Autism Dev Disord 2002; 32(6): 519-533. 
Molini DR. Aspectos sócio - cognitivos observáveis na terapia fonoaudiológica de crianças com distúrbios psiquiátricos [relatório de iniciação científica FAPESP]. São Paulo: Faculdade de Medicina, Universidade de São Paulo; 1997.

Molini DR. Verificação de diferentes modelos de coleta de dados dos aspectos sócio-cognitivos na terapia fonoaudiológica de crianças com distúrbios psiquiátricos. [dissertação]. São Paulo: Faculdade de Medicina, Universidade de São Paulo; 2001.

Molini DR, Fernandes FDM. Intenção comunicativa e uso de instrumento em crianças com distúrbios psiquiátricos. Barueri (SP), Pró-Fono Revista de Atualização Científica 2003; 15(2):149-158.

Molini-Avejonas DR. Perfil comunicativo de crianças normais, com síndrome de Down e autismo pareados pelo desempenho sócio-cognitivo. [tese] São Paulo: Faculdade de Medicina, Universidade de São Paulo, 2004.

Mundy P, Stella J. Joint attention, social orienting, and nonverbal communication in autism. In: Wetherby AM, Prizant BM, editores Autism Spectrum Disorders- a Transactional Developmental Perspective. Baltimore: Paul Brooks; 2001. p.55-77.

Ochs Keenan E. Conversational competence in children. In: Ochs E; Schieffelin B. Acquiring conversational competence. London, Routledge 7 Kegan Paul,1983. p.3-25. 
Organização Mundial de Saúde. Classificação de Transtornos Mentais de Comportamento- CID-10- Critérios Diagnósticos para Pesquisa. Trad. Maria Lúcia Domingues. 10ª- ed. Porto Alegre- RS, Artes Médicas, 1983.

Palermo MT, Pasqualetti P, Basbati G, Inteligente F, Rossini PM. Recognition of Schematic facial displays of emotion in parents of children with autism. Autism 2006; 10(4): 353-364.

Pastorello LM. Contribuições da abordagem funcionalista do desenvolvimento da linguagem: análise clínica de dois casos. In: Fernandes FDM, Pastorello L, Scheuer C, organizadoras. A fonoaudiologia em distúrbios psiquiátricos da infância. São Paulo: Lovise; 1996. p.81-200.

Prinz P. Development of pragmatics: multi-word level. In: IRWIN, J. Pragmatics: The role in Language Development. La Verne, Fox Publish. 1982. p.49-81

Prizant BM. Language acquisition and communicative behavior in autism: toward an understanding of the "whole"of it. Journal of Speech and Hearing Disorders, 1983;48: 296-307.

Prutting CA . Pragmatic as social competence. Journal of Speech, Hearing Disorders, 1982;47:123-143.

Pry R, Petersen A, Baghdadli A. The relationship between expressive language leval and psychological development in children with autism 5 years of age. Autism 2005; 9(2):179-189. 
Receuver C, Lenoir P, Desombre H, Roux S, Barthelemy C, Malvy J. Interaction and imitation deficits from infancy to 4 years of age in children with autism. Autism 2005; 9(1):69-82.

Rice ML. Specific language impairments: in search of diagnostic markers and genetic contributions. Ment Retard Dev Disabil Res 1997; 3:350-357.

Rollins PR, Snow CE. Shared attention and grammatical development in typical children and children with autism. Journal of child language. Cambridge, Cambridge University Press, 1998; 25:653-673.

Rosner B. Fundaments of Biostatistics, $2^{\text {nd }}$ edition, Boston, Duxburry Press, 1986

Rutter M. Diagnosis and definition. In: Rutter M, Schopler E. Autism- a reappraisal of concepts and treatment. New York and London, Plenum Press; 1981.p.1-25.

Rutter M. Cognitive deficits in the pathogenesis of autism. Journal Child Psychol Psychiatric. 1983; 24(4):513-531.

Rutter M, Shopler E. Autism and developmental disorders: concepts and diagnostic issues. J Autism Dev Disord. 1987;17(2):159-86.

Rutter M. Diagnosis and definition, In: M Rutter e E Schopler( eds). Autism: A reappraisal of concepts and treatment. New York: Plenum Press.1978.p.1-25. 
Schieffelin BB. Looking and talking: the functions of gaze direction in the conversations of a young child and her mother. In: Ochs-Keenan E, Schieffelin B. Acquiring Conversational Competence, London, Routledge 7 Kegan Paul, $1983 ; 4$, p.50-65.

Sinclair H. El papel de las estructuras cognitivas en la adquisicion del lenguaje. In: Lennenberg, H; Lennenberg, E. Fundamentos del desarrolo del lenguaje, Madrid, Aza Universidad,1975.

Siperstein R, Volkmark F. Brief Report: Parental Reporting of Regression in Children with Pervasive Developmental Disorders. J Autism Dev Disord 2004; $34(6): 731-734$.

Sousa PFG, Matsumoto AK, Mimura C, Fernandes FDM. Relações da adaptação sócio-comunicativa da criança como parâmetro de normalidade. In: Congresso Brasileiro de Fonoaudiologia, Fortaleza (CE), 2003.

Sousa PFG, Fernandes FDM, Gibo HM, Pifaia LR, Santos IG. Adaptação sócio-comunicativa de crianças entre 3.0 e 3.11 anos como parâmetro de normalidade. Rev Soc Bras Fonoaudiol Suplemento especial- XIII Congresso Brasileiro de Fonoaudiologia- Santos-SP, 2005. [CD-ROM].

Sousa PFG. Relações entre o perfil comunicativo, desempenho sócio-cognitivo e adaptação sócio-comunicativa em crianças com transtornos do espectro autístico. [dissertação]: São Paulo-Faculdade de Filosofia, Letras e Ciências Humanas, Universidade de São Paulo; 2004. 
Sousa-Morato PF, Fernandes FDM; Moreira CR; Barbosa MP; Faustino KAKS. Déficits de Atenção Social em crianças com distúrbios do espectro autístico. XIV Congresso Brasileiro de Fonoaudiologia- Suplemento Especial Rev Soc Bras de Fonoaudiol. Outubro 4-7, 2006; Salvador-BA, Brasil.

Sousa-Morato PF, Fernandes FDM. Análise do perfil sócio-comunicativo quanto à adaptação sócio-comunicativa em crianças do espectro autístico. Rev Soc Bras de Fonoaudiol; 2006a: 11(2) 70-74.

Sousa-Morato PF, Fernandes FDM. Relações entre o desempenho sóciocognitivo e a adaptação sócio-comunicativa em crianças do espectro autístico. Rev Soc Bras Fonoaudiol; 2006b: 11(4) 243-249.

Sperry LA, Mesibov GB. Perceptions of social challenges of adults with autism spectrum disorder. Autism 2005; 9(4):362-376.

Stone WL, Caro-Martinez LM. Naturalistic observations of spontaneous communication in autistic children. J Autism Dev Disord. 1990; 20(4):437-53.

Tafuri MI. A capacidade do bebê para estar só e o isolamento autista. Rev Latinoam Psicopat Fund 2002; 5(3):124-137.

Tager-Flusbeg H. Brief Report: current theory and research on language and communication in autism. J Autism Dev Disord 1996; 26(2).

Tager-Flusberg H. A Psychological approach to Understanding the Social and language Impairments in Autism. Int Rer Psychiatry 1999; 11(4):325-334. 
Tager-Flusberg H. Language and understanding minds: connection in autism. In: Baroh-Cohen S; Tager Fluesbger H; Cohen ED; Understanding others minds. 2.ed.Great Britain:Oxford University Press, 2000. p.124-149.

Tanguay PE, Robertson J, Derrick A. A dimensional classification of autism spectrum disorder by social communication domains. J Am Acad Child Adoles Psychiatr.1998;37:271-7.

Turner LM, Stone WL, Pozdol SL, Coonrod EE. Follow-up of children with autism spectrum disorders from age 2 to age 9. Autism 2006; 10(3):243-265.

Van Berckelaer-Onnes IA. Promoting early play. Autism 2003; 7(4):415-423.

Verté ES, Geurts HM, Roeyers H, Rosseel Y, Oosterlaan J, Sergeantt JA. Can the Children's Communication Checklist differentiate autism spectrum subtypes? Autism 2006; 10(3):266-287.

Volkmar FR, Pauls D. Autism. Lancet 2003;362:1133-41.

Wetherby AM, Gaines RM. Cognition and language development in autism. Journal of Speech, Hearing and Disorders, 47 (1), p.63-70. 1982.

Wetherby AM, Prutting C. Profiles of communicative and cognitive-social abilities in autistic children. Journal of Speech and Hearing Research, v.27, p.364-377, 1984. 
Wetherby AM, Cain DH, Yonclas DC, Walker VC. Analysis of intentional communication of normal children from the prelinguistic to the multiword stage. Journal of Speech and Hearing Research, 31, p.240-252, 1998.

White C. The social play record: The Development and Evaluation of a new instrument for assessing and guiding the social interaction of children with autistic spectrum disorders. Good Autism practice 2002; 3:63-78.

Wing L. The autistic continuum. In: Wing, editor. Aspects of autism: biological research. London: Royal College of Psychiatrists \& The National Autistic Society; 1988. p.5-8.

Wolfberg P. Play and Imagination in Children with Autism. New York: Teachers College Press;1999

Wollner S, Geller E. Methods of assessing pragmatic abilities. In: Irwin J. Pragmatics: the role in language development. La Verne, Fox Publishing; 1982. p.135-159.

Yont KM, Snow CE, Vernon-Fegans L. The role of context in mother-child interactions: an analysis of communicative intents expressed during toy play and book reading with 12-month-olds. Journal of Pragmatics 2003; 35:435-454. 
Departamento de Fisioterapia, Fonoaudiologia e Terapia Ocupacional

\section{Comissão de Pesquisa do Departamento}

Após análise, a Comissão de Pesquisa do Departamento de Fisioterapia, Fonoaudiologia e Terapia Ocupacional aprovou o Projeto protocolado sob № 420/04: "Correlatos de Desempenho e Uso Funcional da Linguagem na Adaptacão Sócio-Comunicativa de Criancas do Espectro Autista.",

Pesquisador Responsável : :Prof. Dra. Fernanda Dreux M Fernandes Pesquisador Executante :Fga. Priscilla Faria Gomes de Souza

São Paulo, 26 setembro de 2006.

Dra Renata Mota Mamede Carvallo

Comissão de Pesquisa do Departamento de Fisioterapia, Fonoaudiologia e Terapia Ocupacional 


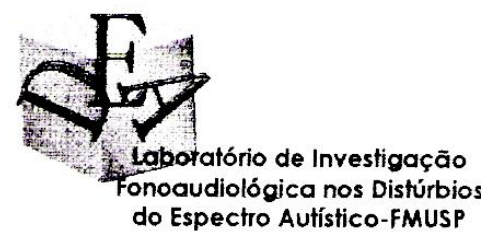

\section{COMPROMISSO}

Estou ciente de que $\circ$ atendimento fonoaudiológico de

será realizado no Laboratório de Investigação Fonoaudiológica nos Distúrbios do Espectro Autístico do Curso de Fonoaudiologia da Faculdade de Medicina da Universidade de São Paulo, uma vez por semana em sessões de $\mathbf{4 5}$ minutos e que a ausência não justificada em três sessões consecutivas ou em $\mathbf{5 0 \%}$ das sessões previstas para o mês, implicará no reencaminhamento do paciente. Estou ciente, também, da necessidade de pontualidade no comparecimento para o atendimento, sendo que os atrasos não serão compensados.

(nome do responsável e grau de parentesco)

\section{AUTORIZAÇÃO}

Autorizo que

seja submetido à avaliação e/ou terapia fonoaudiológica e que os dados colhidos, filmagens e gravações sejam utilizados exclusivamente para fins de pesquisa mantendo-se o sigilo de sua identidade.

Nome do responsável:

RG:

CPF:

TEL:

TEL $p /$ recado:

End:

No. LIF:

Data:
1

(nome do responsável e grau de parentesco) 
Anexo 3a

$2 k$

ALIFW' - TESTE DE LINGLIAGEM INFANTIL

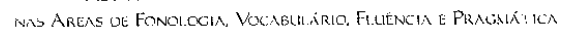

$\sum+3$

Capítulo 4 - Pragmática

FLRNANDA DRELIX MiRANDA FERNANDES

\section{ANEXO 1}

Pragmálilla. Protocolo para transcricão de fita

Nome:

Idade: Data:

\begin{tabular}{|c|c|c|c|c|}
\hline \multicolumn{5}{|c|}{ Atos Comunicativos } \\
\hline $\mathbf{N}$ & $\begin{array}{c}\text { Meio } \\
\text { (VE - VO - G) }\end{array}$ & $\begin{array}{l}\text { Iniciativa } \\
\text { Criança (C) } \\
\text { Adulto (A) }\end{array}$ & Função & $\begin{array}{l}\text { Observaçōes/ } \\
\text { Comentários }\end{array}$ \\
\hline & & & & \\
\hline & & & & \\
\hline & & & & \\
\hline & & & & \\
\hline & & & & \\
\hline & & & & \\
\hline & & & & \\
\hline & & & & \\
\hline & & & & \\
\hline & & & & \\
\hline & & & & \\
\hline & & & & \\
\hline & & & & \\
\hline & & & & \\
\hline & & & & \\
\hline & & & & \\
\hline & & & & \\
\hline & & & & \\
\hline & & & & \\
\hline & & & & \\
\hline & & & & \\
\hline
\end{tabular}

Referenciar este material como:

FERNANDES, FD.M.- Hagmaduca. III. ANDRADE, C. R.F; BEFI-LOPES, D.M.; FERNANDES, F.D.M.; WERTZNER, H.F.- ABFW; teste de linguagem

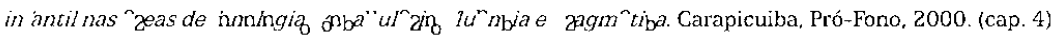




\section{Anexo 3b}

统

ABHW - TESTE DE LINGLIAGEM INFANT"IL

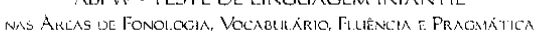

$\sum \hat{B}$

Capítulo 4 - Pragmática

FERNANDA DREUX MIRANOA FERNANDES

ANEXO 2

Pragmática. Ficha - Síntese

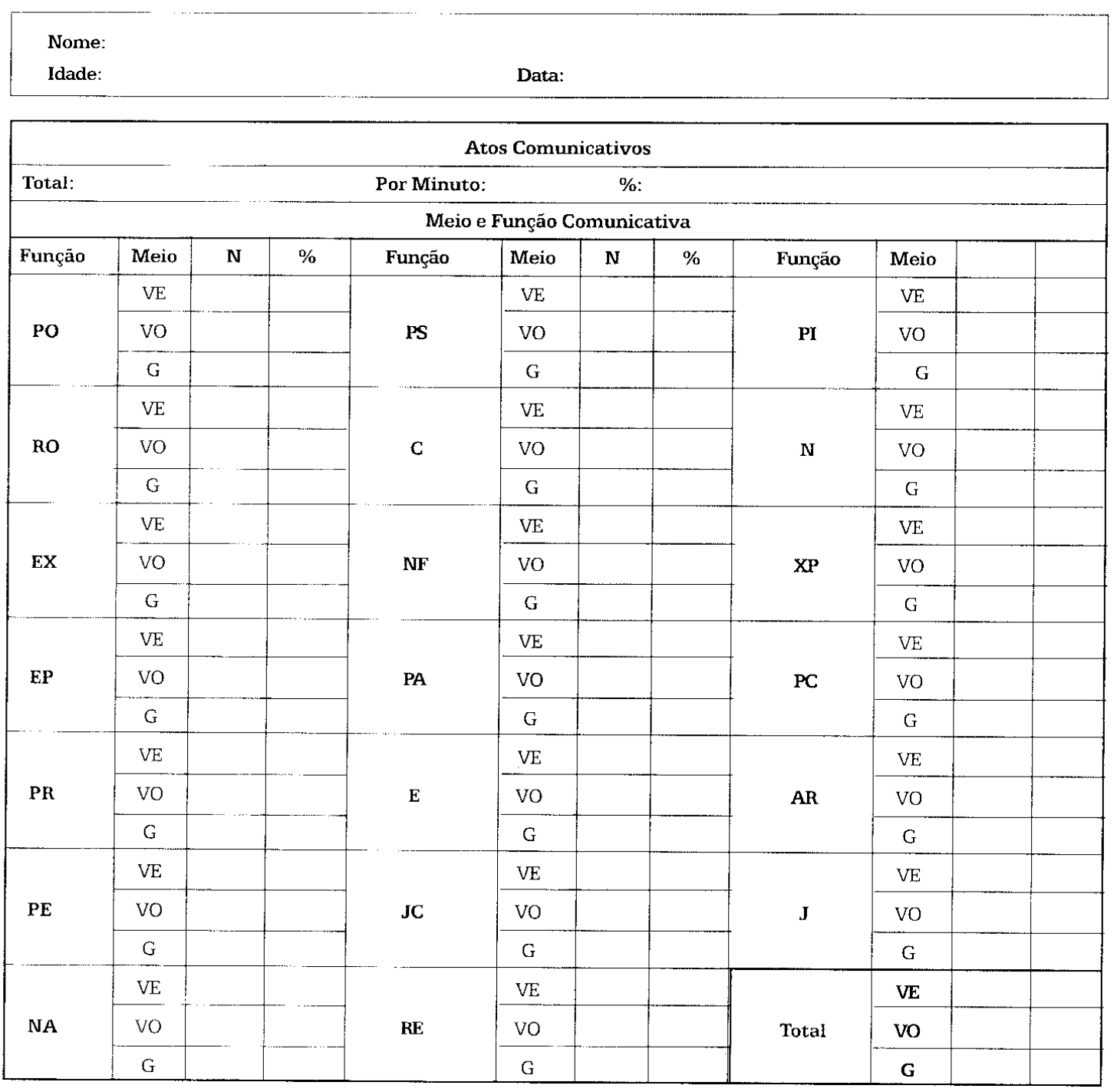

Referenciak este material como:

FERNANDLS, F.D M - Pragnaatica. Iri, ANDRADE, C.R.F.; BEFI-LOPES, D.M.; FERNANDES, F.D.M.; WERTZNER, H.F.- ABFW; teste de linguagem

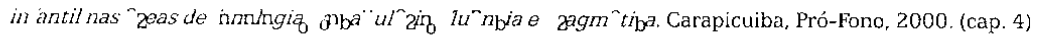




\section{Anexo $4 a$}

\section{Escala de Adaptação Sócio-comunicativa}

\section{- Nível 1: Principiante}

- Estágio 1: Sintonia

Objetivo: saber se a criança realiza contato visual significativo com os pais, terapeutas ou cuidadores e/ou ri de expressões faciais apresentadas pelos mesmos.

Exemplos:

1. Quando algum familiar se esconde e aparece repentinamente como em brincadeiras de "achou", a criança ri?

2. Dá risadas quando alguma novidade é introduzida, alguma brincadeira diferente é realizada?

- Estágio 2: Referência Social

Objetivo: passar pelas etapas de referência social, utilizando expressões não-verbais do parceiro como referência crítica para suas ações. Saber se a criança consegue perceber as expressões faciais e preocupa-se com a compreensão e reação.

Exemplos:

1. Se os pais, terapeutas fazem cara de bravos, ou de ansiosos e preocupados com alguma ação da criança que possa ser perigosa, como cair de uma escada, esta consegue perceber e adequar seu comportamento?

2. A criança apresenta curiosidade pelos outros oferecendo objetos, brinquedos aos mesmos para observar suas reações?

- Estágio 3: Aprendiz/ Guia

Objetivo: saber se a criança consegue aprender e realizar ações ensinadas pelos pais (guias), seguindo modelos e/ou por meio de imitações.

Exemplos:

1. Quando os pais ou terapeutas propõem-se em ensinam alguma ação, como montar um brinquedo, a criança consegue aprender imitando-os?

2. Enquanto os pais ou terapeutas guiam as crianças para aprender alguma ação, estas se mostram interessadas pela novidade e mantêm essa experiência de troca em foco, ou mudam o foco de sua atenção?

- Estágio 4: Coordenação Social

Objetivo: saber se a criança é capaz de coordenar com o parceiro, ações simples, das quais os dois possam desfrutar mutuamente, portanto, saber se a criança consegue realizar trocas de turno.

Exemplos:

1. Se jogar um brinquedo, como uma bola, a criança é capaz de jogar novamente?

2. Em uma montagem de uma torre com blocos de encaixe a criança consegue alternar com o parceiro a colocação das peças, para depois os dois juntos derrubarem-nas? 


\section{- $\quad$ Nível 2: Aprendiz}

- Estágio 1: Variação

Objetivo: saber se a criança é capaz de gostar e reagir bem ou não às novidades introduzidas

Exemplos:

1. Na brincadeira de basquete, a criança aceita variar o uso da cesta de basquete, pela cesta de lixo, aceitando bem a pequena mudança e até propondo novas possibilidades?

2. Na brincadeira de boliche, no lugar da bola, ela aceita que se jogue outro objeto?

- Estágio 2: Adaptação

Objetivo: saber se a criança é capaz de adaptar-se bem a introdução de alguma novidade, ou melhor, depois que se insere uma novidade, a criança também é capaz de brincar com a mesma.

Exemplos:

1. Se os pais, terapeutas chegam com um novo brinquedo, a criança pega e brinca com o mesmo ou somente explora-o e volta a brincar com o brinquedo antigo?

2. Se a criança come sempre com um mesmo prato, ou bebe sempre no mesmo copo a criança é capaz de aceitar a novidade ou não se adapta a esta?

- Estágio 3: Sincronização

Objetivo: saber se a criança consegue usar o outro como referência e regulação para coordenar suas ações.

Exemplos:

1) A criança consegue seguir um referencial social como na brincadeira de siga o líder co-regulando seu comportamento?

2) A criança realiza brincadeiras de esconde-esconde, e quando é encontrada demonstra grande alegria como resposta à reação do parceiro?

- Estágio 4: Preocupação com os outros

Objetivo: saber se a criança é capaz de perceber e identificar comportamentos e emoções, modificando seu comportamento para um maior aproveitamento das experiências compartilhadas.

Exemplos:

1. A criança ao brincar seu jogo favorito com um parceiro é capaz de perceber que este está distraído e entediado, e perguntar ao mesmo se está aborrecido e sugerir um novo jogo?

2. Em uma situação de brincadeira com uma bola, a criança é capaz de perceber que seu parceiro não está conseguindo pegar a bola, porque ela está jogando a bola muito forte, modificando assim o seu comportamento? 


\section{- Nível 3: Desafiante}

- Estágio 1: Colaboração

Objetivo: se a criança consegue balancear ações de co-regulação (regular seu comportamento em base de um referencial social) e ações de co-variação (estabelecer relações de variações mutuamente com o parceiro em uma determinada atividade) em atividades de cooperação entre os parceiros.

Exemplos:

1. Quando em uma brincadeira o parceiro fala que o seu carrinho ficará em um determinado lugar, e a criança diz que não, que ali ficará o carrinho dela. A criança consegue negociar com o outro qual carrinho ficará no lugar determinado?

2. Quando a criança quer realizar uma determinada brincadeira e o parceiro diz que agora eles vão fazer uma brincadeira diferente, a criança aceita e brinca normalmente negociando quando poderão realizar a outra brincadeira?

- Estágio 2: Co-criação

Objetivo: se a criança é capaz de descobrir sua criatividade e imaginação, aprendendo a se divertir como um parceiro igual na co-criação.

Exemplos:

1. A criança e o parceiro estão montando um carro com peças de Lego, eles conseguem pensar juntos em outra forma de brincar com as peças?

2. Nesta mesma situação, a criança dá e aceita sugestões de como poderia ser montado o brinquedo?

\section{- Estágio 3: Improvisação}

Objetivo: saber se a criança consegue lidar em situações imprevistas, conseguindo manter o contato social.

Exemplos:

1. Em uma situação em que chegam pessoas estranhas na casa, ou na sala de terapia sem avisar, a criança consegue chegar perto e realizar contato com as mesmas?

2. Quando acontece alguma situação ou fato que não era esperado a criança apresenta-se agitada, confusa ou consegue utilizar a linguagem para regular a situação?

Estágio 4: Percepções compartilhadas

Objetivo: saber se a criança é capaz de experenciar a alegria de dividir percepções com amigos, ou seja, se ela realiza comentários a respeito de ações e fatos ocorridos. Pode ocorrer em todos os meios comunicativos.

Exemplos:

1. Quando passa algum avião, ambulância ou faz algum barulho forte a criança realiza comentários, chama para ver o que está acontecendo a fim de buscar sua atenção conjunta para o fato?

2. A criança realiza comentários de fatos que ocorreram na escola ou em outros lugares, buscando sua atenção? 


\section{- Nível 4: Desbravador}

- Estágio 1: Perspectivas compartilhadas

Objetivo: se a criança é capaz de aprender a valorizar o ponto de vista do outro.

Exemplos:

1. A criança é capaz de aceitar a opinião dos outros como uma possibilidade?

2. A criança demonstra curiosidade pela opinião dos outros e aceita-a com o mesmo valor como as suas próprias perspectivas?

- Estágio 2: Imaginação compartilhada

Objetivo: se a criança é capaz de aproveitar e combinar as imaginações compartilhadas entre si e o parceiro.

Exemplos:

1. A criança dá opiniões e gosta de compartilhar suas idéias?

2. A criança é capaz de aproveitar uma idéia dada pelos pais ou terapeutas e combinar com suas próprias idéias, como em uma brincadeira com uma boneca, o parceiro coloca um biquíni na boneca e a criança propõe que a boneca vai para a praia?

- Estágio 3: Compartilhando idéias

Objetivo: se a criança consegue combinar e integrar idéias como uma unidade.

Exemplos:

1. A criança é capaz de juntar uma idéia que teve com a idéia de um amigo, e formar uma só idéia?

2. A criança fala que eles poderiam criar um animal diferente, o parceiro pensa em um elefante e a criança em uma zebra, os dois juntos são capazes de combinar estes dois animais e criar um só, ou seja, uma "elezebra"?

- Estágio 4: Amigos

Objetivo: se a criança é capaz de experenciar amigos que dividem os mesmos interesses e experiências em comum.

Exemplos:

1. A criança tem relações de amizade verdadeiras, sente saudades, pede para ver?

2. A criança é sempre capaz de estabelecer relações de jogos com estes parceiros? 


\section{Anexo $4 b$}

UNIVERSIDADE DE SÃO PAULO- USP

Laboratório de Investigação Fonoaudiológica nos Distúrbios do Espectro Autístico-FMUSP

Escala de Adaptação Sócio-Comunicativa

Identificação:

Nome:-

- Idade:

Nome do responsável:-

- Nível 1: Principiante

\begin{tabular}{|l|l|l|l|l|}
\hline Estágios & Classificação & Ações Realizadas & Sim & Não \\
\hline Estágio 1 & Sintonia & $\begin{array}{l}\text { Compartilhando as experiências e } \\
\text { emoções, com ações face a face. }\end{array}$ & & \\
\hline Estágio 2 & Referência Social & $\begin{array}{l}\text { Usando expressões não- verbais do } \\
\text { parceiro como ponto de referência } \\
\text { crítica para suas ações. }\end{array}$ & & \\
\hline Estágio 3 & Aprendiz/ Guia & $\begin{array}{l}\text { Tornando-se um bom aprendiz } \\
\text { através de um adulto como guia. }\end{array}$ & & \\
\hline Estágio 4 & $\begin{array}{l}\text { Coordenação } \\
\text { Social }\end{array}$ & $\begin{array}{l}\text { Sincronizando ações simples para } \\
\text { aproveitamento mútuo. }\end{array}$ & & \\
\hline
\end{tabular}

- Nível 2: Aprendiz

\begin{tabular}{|l|l|l|l|l|}
\hline Estágios & Classificação & Ações Realizadas & Sim & Não \\
\hline Estágio 1 & Variação & $\begin{array}{l}\text { Aprendendo a gostar de variações e } \\
\text { novidades quando cuidadosamente } \\
\text { introduzidas. }\end{array}$ & $\begin{array}{l}\text { Conseguindo a se adaptar a } \\
\text { mudanças e variações. }\end{array}$ & \\
\hline Estágio 2 & Adaptação & $\begin{array}{l}\text { Usando referência e regulação para } \\
\text { funcionar como um parceiro em } \\
\text { ações coordenadas. }\end{array}$ & & \\
\hline Estágio 3 & Sincronização & $\begin{array}{l}\text { Aprendendo a identificar, fazer } \\
\text { referências na mudança do } \\
\text { aproveitamento e compreensão do } \\
\text { parceiro tornando-os guias críticos } \\
\text { para suas ações. }\end{array}$ & \\
\hline Estágio 4 & $\begin{array}{l}\text { Preocupação os outros } \\
\text { com }\end{array}$ & & & \\
\hline
\end{tabular}

- Nível 3: Desafiante

\begin{tabular}{|c|c|c|c|c|}
\hline Estágios & Classificação & Ações Realizadas & Sim & Não \\
\hline Estágio 1 & Colaboração & $\begin{array}{l}\text { Equilibrando co-regulação com co- } \\
\text { variação em atividades de } \\
\text { cooperação com parceiro da } \\
\text { mesma idade. }\end{array}$ & & \\
\hline Estágio 2 & Co- criação & $\begin{array}{l}\text { Descobrindo sua criatividade e } \\
\text { imaginação. Aprendendo a desfrutar } \\
\text { como um igual ao parceiro na co- } \\
\text { criação. }\end{array}$ & & \\
\hline Estágio 3 & Improvisação & Praticando encontros improvisados & & \\
\hline Estágio 4 & $\begin{array}{l}\text { Percepções } \\
\text { Compartilhadas }\end{array}$ & $\begin{array}{l}\text { Experenciando entusiasmo em dividir } \\
\text { percepções com amigos }\end{array}$ & & \\
\hline
\end{tabular}

- Nível 4 : Desbravador

\begin{tabular}{|c|c|c|c|c|}
\hline Estágios & Classificação & Ações Realizadas & Sim & Não \\
\hline Estágio 1 & Perspectivas & $\begin{array}{l}\text { Aprendendo o valor do ponto de } \\
\text { vista do outro. }\end{array}$ & & \\
\hline Estágio 2 & $\begin{array}{l}\text { Imaginação } \\
\text { Compartilhada }\end{array}$ & $\begin{array}{l}\text { Demonstra a alegria de compartilhar } \\
\text { imaginações. }\end{array}$ & & \\
\hline Estágio 3 & $\begin{array}{l}\text { Compartilhando } \\
\text { Idéias }\end{array}$ & $\begin{array}{l}\text { Combinando e integrando idéias } \\
\text { como uma unidade. }\end{array}$ & & \\
\hline Estágio 4 & Amigos & $\begin{array}{l}\text { Experenciando amigos que dividem } \\
\text { experiências em comum }\end{array}$ & & \\
\hline
\end{tabular}




\section{Anexo 5}

\section{ESCALA DE ADAPTAÇÃO SÓCIO-COMUNICATIVA}

\begin{tabular}{|c|c|c|c|c|}
\hline $\begin{array}{c}\text { Estágios/ } \\
\text { Níveis }\end{array}$ & Nível 1: Principiante & $\begin{array}{c}\text { Nível 2: } \\
\text { Aprendiz }\end{array}$ & $\begin{array}{c}\text { Nível 3: } \\
\text { Desafiante }\end{array}$ & $\begin{array}{c}\text { Nível 4: } \\
\text { Desbravador }\end{array}$ \\
\hline Estágio 1 & Sintonia & Variação & Perspectivas \\
\hline Estágio 2 & Referênçãa Social & Adaptação & Co-criação & $\begin{array}{c}\text { Imaginação } \\
\text { compartilhada }\end{array}$ \\
\hline Estágio 3 & Aprendiz/ Guia & Sincronização & Improvisação & Compartilhando idéias \\
\hline Estágio 4 & Coordenação Social & $\begin{array}{c}\text { Preocupação com os } \\
\text { outros }\end{array}$ & $\begin{array}{c}\text { Percepções } \\
\text { compartilhadas }\end{array}$ & Amigos \\
\hline
\end{tabular}


Anexo 6 


\section{Contato:}

PRISCILLA FARIA SOUSA MORATO

NOME EM CITAÇÕES: SOUSA-MORATO, PF

E-MAIL: priscillafsmorato@yahoo.com.br 